\title{
Global distribution of sediment-hosted metals controlled by craton edge stability
}

\author{
Mark J. Hoggard, ${ }^{*, a, b}$ Karol Czarnota, ${ }^{*, c, d}$ Fred D. Richards, ${ }^{a, e}$ David L. Huston, ${ }^{c}$ \\ A. Lynton Jaques, ${ }^{d} \&$ Sia Ghelichkhan ${ }^{d}$
}

\author{
${ }^{a}$ Department of Earth and Planetary Sciences, Harvard University, USA. \\ ${ }^{b}$ Lamont-Doherty Earth Observatory, Columbia University, USA. \\ ${ }^{c}$ Geoscience Australia, Canberra, Australia. \\ ${ }^{d}$ Research School of Earth Sciences, Australian National University, Canberra, Australia. \\ ${ }^{e}$ Department of Earth Science and Engineering, Imperial College London, UK. \\ *www.mjhoggard.com; mark_hoggard@fas.harvard.edu; karol.czarnota@ga.gov.au \\ Cite as: Hoggard, M.J., K. Czarnota, F.D. Richards, D.L. Huston, A.L. Jaques, \& S. Ghelichkhan (2020). Global distribution \\ of sediment-hosted metals controlled by craton edge stability, Nature Geoscience, 13(7), 504-510. \\ https://doi.org/10.1038/s41561-020-0593-2
}

\begin{abstract}
Sustainable development and the transition to a clean-energy economy drives ever-increasing demand for base metals, substantially outstripping the discovery rate of new deposits and necessitating dramatic improvements in exploration success. Rifting of the continents has formed widespread sedimentary basins, some of which contain large quantities of copper, lead and zinc. Despite over a century of research, the geological structure responsible for the spatial distribution of such fertile regions remains enigmatic. Here, we use statistical tests to compare deposit locations with new maps of lithospheric thickness, which outline the base of tectonic plates. We find that $85 \%$ of sediment-hosted base metals, including all giant deposits (>10 megatonnes of metal), occur within $200 \mathrm{~km}$ of the transition between thick and thin lithosphere. Rifting in this setting produces greater subsidence and lower basal heat flow, enlarging the depth extent of hydrothermal circulation available for forming giant deposits. Given that mineralisation ages span the last 2 billion years, this observation implies long-term lithospheric edge stability and a genetic link between deep Earth processes and near-surface hydrothermal mineral systems. This discovery provides an unprecedented global framework for identifying fertile regions for targeted mineral exploration, reducing the search-space for new deposits by two-thirds on this lithospheric thickness criterion alone.
\end{abstract}

Consumption of base metals (copper, lead, zinc and nickel) over the next $\sim 25$ years is set to exceed the total produced in human history to date (Ali et al., 2017; Schodde, 2017). Moreover, critical minerals (e.g. cobalt, indium and germanium) are often produced as by-products of base metal mining and are essential in many high-tech applications (Nassar et al., 2015; Mudd et al., 2018; IRENA, 2019; Dominish et al., 2019; Sovacool et al., 2020). A growing concern is that the rate of exploitation of existing reserves is outstripping discovery of new deposits, despite exploration expenditure tripling during the 2005-2012 minerals boom (Ali et al., 2017; Schodde, 2017). To reverse this trend and supply the resources necessary to comply with policies such as the Paris Climate Agreement and United Nations' Sustainable Development Goals, improved techniques for locating new deposits are required, particularly those buried under shallow sedimentary cover or ice (The Uncover Group, 2012).

\section{Narrowing the search-space for new deposits}

In mineral exploration, initial area selection at continental scales is arguably the most important step, as successful identification of fertile regions can compensate for many subsequent errors (McCuaig et al., 2010). Over the last two decades, the search for analogues of known deposits has progressed towards a more holistic determination of factors controlling deposit generation and preservation (Wyborn et al., 1994; Bierlein et al., 2006; McCuaig \& Hronsky, 2014; Dentith et al., 2018; Skirrow et al., 2019). Mineral systems analysis has resulted in a growing acceptance that the spatial distribution of deposits associated with magmatic processes is controlled by lithospheric-scale structure (McCuaig et al., 2010; Begg et al., 2010; Griffin et al., 2013). For example, porphyry copper deposits are generated by wet melting in the mantle wedge above a subducting slab, followed by emplacement of these melts into the shallow overlying crust and subsequent concentration by high-temperature hydrothermal circulation (Griffin et al., 2013). Thus, by combining the plate tectonic setting with geological constraints on the location of key mineral system ingredients, the search-space for new magmatic deposits can be substantially reduced (Rosenbaum et al., 2005; Butterworth et al., 2016; O'Reilly et al., 2017).

In the case of sediment-hosted deposits, most assessments to date have focused on their genesis within the context of Earth's secular evolution, as well as past tectonic and geographic settings (McCuaig et al., 2018). The majority are found in failed rift and passive margin settings, and it is generally agreed that basin-scale hydrothermal circulation is required to scavenge sufficient metals to form giant deposits (Figure 1a; Leach et al., 2010; Hitzman et al., 2010; Manning \& Emsbo, 2018). Metals are mobilised and transported by oxidised brines with moderate temperatures $\left(80-250^{\circ} \mathrm{C}\right)$ and moderate-to-high salinity $(10-30 \mathrm{wt} \% \mathrm{NaCl})$, limiting their maximum age to the Great Oxidation Event at $2.4 \mathrm{Ga}$ (Leach et al., 2010; Hitzman et al., 2010). These fluids are sourced from evaporites at low latitudes and remain buffered as they pass through voluminous oxidised terrestrial sediments, allowing them to scavenge lead from arkosic sandstones and felsic volcanics, as well as copper and zinc from mafic rocks (Leach et al., 2010; Hitzman et al., 2010). Transport along faults, either during rifting or basin inversion, focuses these fluids into oxidation-reduction interfaces, such as distal-facies black shales, where metals precipitate (Figures $1 \mathrm{~b}$ and 1c; Huston et al., 2016). 


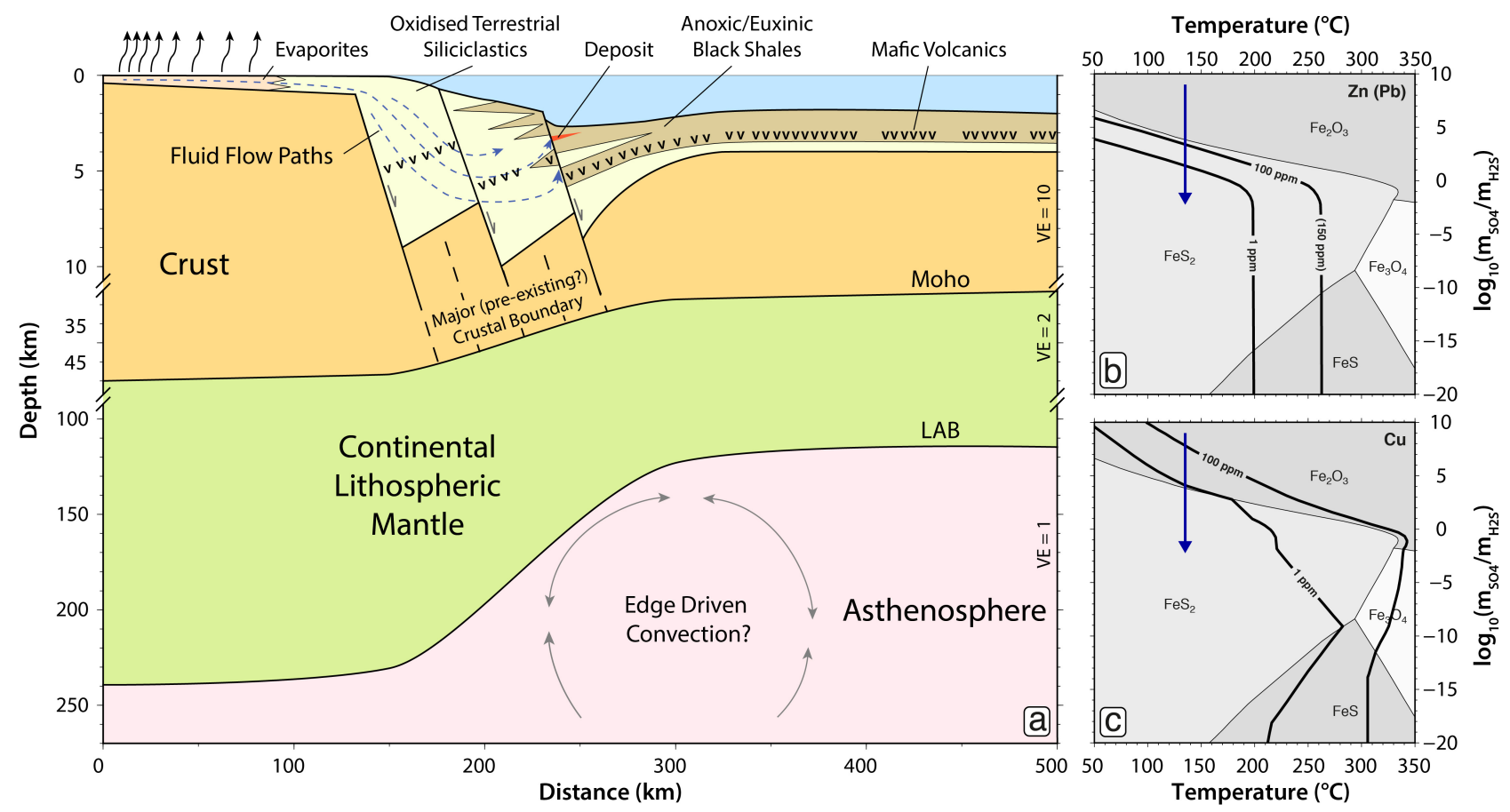

Figure 1: Mineralisation system for genesis of sediment-hosted base metal deposits. (a) Schematic illustration of deposit location in extensional rift settings. Basinal brines sourced from evaporites scavenge metals from oxidised terrestrial sediments and volcanics (v) on route to metal deposition sites in black shales (Manning \& Emsbo, 2018). Notice variable vertical exaggeration (VE) and prominence of the lithosphere-asthenosphere boundary (LAB) edge illustrated at 1:1 scale. Schematic based on architectural constraints from the Australian Carpenteria Zinc Belt and Polish Fore-Sudetic Block. (b) Stability field of Fe-S-O minerals as a function of temperature and redox conditions; $\mathrm{m}_{\mathrm{SO}_{4}}=$ molarity of sulphate; $\mathrm{m}_{\mathrm{H}_{2} \mathrm{~S}}=$ molarity of sulphide; thick black lines = solubility of zinc (and lead) in brine, calculated for fluid salinity $=10 \mathrm{wt} . \% \mathrm{NaCl}$, total concentration of sulphur species $=10^{-2.5} \mathrm{M}$, and $\mathrm{pH}=$ 4.5 (Huston et al., 2016); blue arrow = fluid path for metal precipitation by oxidation-reduction deposition mechanism. (c) Same for copper solubility.

Sediment-hosted base metal deposits are desirable due to their greater quantity of contained metal (in contrast to volcanogenic massive sulfides) and higher grades of ore (in comparison to porphyry copper), resulting in lower environmental degradation during extraction (Dominish et al., 2019; Azadi et al., 2020). However, narrowing the search-space for new sediment-hosted deposits has been less successful than for magmatic mineral systems. Sedimentary basins cover $\sim 75 \%$ of the continental surface, and the key ingredients of evaporites associated with brine formation, felsic and mafic volcanic rocks for sourcing metals, and organic rich shale precipitation sites, are widespread and do not substantially reduce this search-space. The first-order geological control that localises their spatial distribution throughout the continents remains unknown, severely limiting predictive power for identifying new targets. A classic example comes from the Carpentaria Zinc Belt in northern Australia, which contains several world class clastic-dominated lead-zinc deposits formed between 1.8-1.4 Ga (Figure 2a). These deposits lie along an arcuate trend that runs oblique to mapped geology and crustal geological boundaries, as demonstrated by gravity and magnetic datasets (Geoscience Australia, 2018).

Crucially, despite the absence of a clear crustal relationship, the linear distribution of sediment-hosted deposits in the Carpentaria Zinc Belt hints at an underlying regionalscale control. An important advance in understanding the genesis of magmatic mineral systems has come from probing their relationship with major crustal and lithospheric structures (Griffin et al., 2013). Given that sedimentary basins are themselves the result of lithospheric scale processes, we therefore investigate both regional and global-scale links between sediment-hosted base-metal deposits and the most fundamental shallow mantle structure - the lithosphere-asthenosphere boundary (LAB).

\section{Relationship with lithospheric structure}

We begin by collating global inventories of six major basemetal mineral systems from published sources (Methods). Three are magmatic and three are sediment-hosted, which include sedimentary copper (Cu-sed), clastic-dominated leadzinc (PbZn-CD, commonly also referred to as sedimentary exhalative), and Mississippi Valley-type lead-zinc (Pb-ZnMVT). We next refine a method developed by Priestley \& McKenzie (2013) for mapping the thermal LAB from seismic tomography, taking into consideration recent laboratory experiments concerning the effect of anelasticity on shear-wave velocities (Yamauchi \& Takei, 2016; Methods). This benchmarking procedure is necessary in order to increase consistency between LAB maps obtained for different tomography models, which can image surprisingly variable seismic velocities. A high resolution regional LAB map over Australia is obtained from the FR12 model (Fishwick \& Rawlinson, 2012) and is calibrated using nine local paleogeotherms derived from thermobarometry of mantle peridotite xenoliths and xenocrysts. To expand our analysis to other continents, a global LAB is also produced using the SL2013sv model (Schaeffer \& Lebedev, 2013) and calibrated using multiple constraints, including the latest thermal structure of cooling oceanic lithosphere (Richards et al., 2018). This global LAB exhibits a bi-modal thickness distribution, with peaks at $90 \mathrm{~km}$ and $190 \mathrm{~km}$, separated by a minimum at $150 \mathrm{~km}$ (Supplementary Information).

Inspection of the Australian model reveals a striking correlation between major sediment-hosted mineral deposits and the edge of thick lithosphere, defined here by the $170 \mathrm{~km}$ thickness contour (Figure 2b). Major PbZn-CD and sedimentary copper deposits in the Carpentaria Zinc Belt overlie this contour, which runs obliquely to geological boundaries, such that intersections between these two features con- 

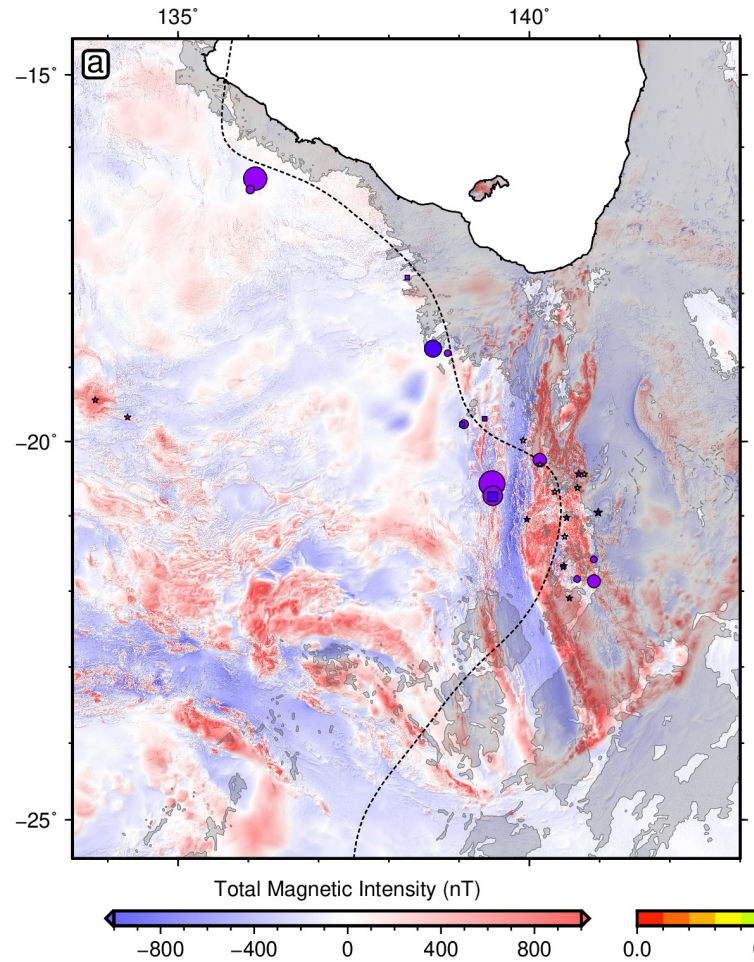

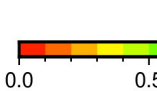

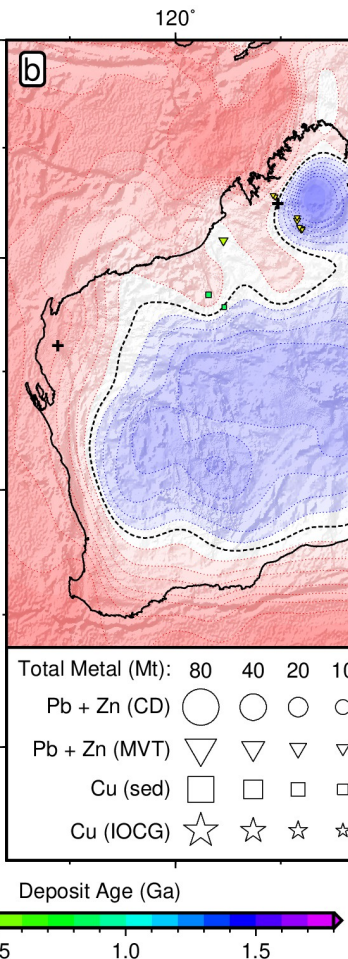

1.0 $130^{\circ}$

140

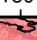

Figure 2: Distribution of sediment-hosted and iron-oxide-copper-gold base metal deposits as a function of Australian lithospheric thickness. (a) Carpentaria Zinc Belt; red/blue = variably reduced to pole aeromagnetic intensity data (Geoscience Australia, 2018); grey polygons = generalised outcrop of Cretaceous marine sediments in Eromanga and Carpentaria Basins (Raymond, 2018 ); black dashed contour = $170 \mathrm{~km} \mathrm{LAB}$ thickness; symbols = deposit locations; symbol area proportional to estimate of total contained mass of metal (either lead plus zinc, or copper) in mega-tonnes (Mt); unknown deposit size given 1 Mt symbol; colour = ore body formation age (billion years); unknown age plotted in grey; circles = clastic-dominated lead-zinc $(\mathrm{PbZn-CD)}$; triangles $=\mathrm{Mississippi}$ Valley-type lead-zinc (PbZn-MVT); squares = sedimentary copper (Cu-sed); stars = iron-oxide-copper-gold (IOCG). (b) Australian LAB mapped by converting FR12 tomography (Fishwick \& Rawlinson, 2012) to temperature using an anelasticity parameterisation (Yamauchi \& Takei, 2016) calibrated on local paleogeotherms (Methods) and illuminated by free-air gravity anomalies (Geoscience Australia, 2018); black/green crosses = geotherms used as constraints/tests in anelasticity calibration (Supplementary Information); box $=$ location of panel (a); large star in South Australia shows location of the Olympic Dam IOCG deposit.

sistently coincide with deposit locations. This behaviour is particularly useful for highlighting new prospective regions for exploration. Other observables that correlate with this lithospheric thickness change include variations in lead isotopes from Proterozoic galena and pyrite minerals (Huston et al., 2019), long-wavelength gravity anomaly gradients (Hobbs et al., 2000), changes in crustal character in deep reflection seismic profiles (Kennett et al., 2016), a topographic ridge, and the western extent of Cretaceous marine sediments (Figure 2a). These latter two associations demonstrate the post-Proterozoic stability of this edge and its influence on local geology and topography. There is also a strong relationship with iron-oxide-copper-gold deposits, including the Olympic Dam mine in South Australia (84 Mt of copper, world's largest known uranium resource; Heinson et al., 2018; Skirrow et al., 2018; Curtis \& Thiel, 2019). However, a lack of consensus on global classification schemes means that we have limited analysis of this deposit type to only Australia.

Extending our analysis globally further confirms the strength of this relationship (Figure 3). The link between the $170 \mathrm{~km}$ lithospheric thickness contour and location of all large sediment-hosted deposits holds regardless of deposit age, which spans the last 2 billion years. Given the $180-220 \mathrm{~km}$ cluster of LAB thicknesses is likely to represent standard cratonic lithosphere, the $170 \mathrm{~km}$ contour therefore demarcates the outer boundary of cratons. Within the PbZn-CD deposit class, those more strongly associated with abundant mafic rocks systematically occur on the thinner lithosphere side of the contour compared to their carbonaterich counterparts (e.g. Carpenteria Zinc Belt and northwest North America). These observations are consistent with an extensional origin of the host basins.

To quantify these visual relationships, the shortest distance is calculated between each deposit and the $170 \mathrm{~km}$ LAB thickness contour and results are plotted in a cumulative distribution function ( $\mathrm{CDF}$ ). Weighting deposits by the mass of contained metal and substituting the Australian LAB from the global model with our high-resolution regional version substantially improves the correlation for $\mathrm{PbZn}-\mathrm{CD}$ (Figure 4a). Globally, we observe that $\sim 95 \%$ of sedimentary copper, $\sim 90 \%$ of clastic-dominated lead-zinc and $\sim 70 \%$ of Mississippi Valley-type lead-zinc resources are located within a $200 \mathrm{~km}$-wide corridor either side of the $170 \mathrm{~km}$ LAB thickness contour (Figure 4b). This region corresponds to only $\sim 35 \%$ of continental surface area. Given that this swath width is similar to the $\sim 280 \mathrm{~km}$ node spacing in SL2013sv, tighter constraints are only possible with higher resolution tomography models. For example, all giant deposits in Australia lie within $100 \mathrm{~km}$ of the $170 \mathrm{~km}$ contour for the higher resolution FR12 model. The significance of the relationship is globally examined using the two-sample Kolmogorov-Smirnov test, which estimates that the probability of these sedimenthosted deposits representing random continental locations is less than 1 in $10^{12}$ (Kolmogorov, 1933; Methods). This relationship holds true for three other global surface wave tomography models (Extended Data Figure 1).

All >10 mega-tonne sediment-hosted deposits are located along the boundary of thick lithosphere, but amongst the smaller deposits, there are some notable exceptions. Minor PbZn-CD outliers occur in Europe, the Caribbean, Indonesia and east China. Anomalous PbZn-MVT deposits are found in Ireland, east China and along the Tethys sub- 


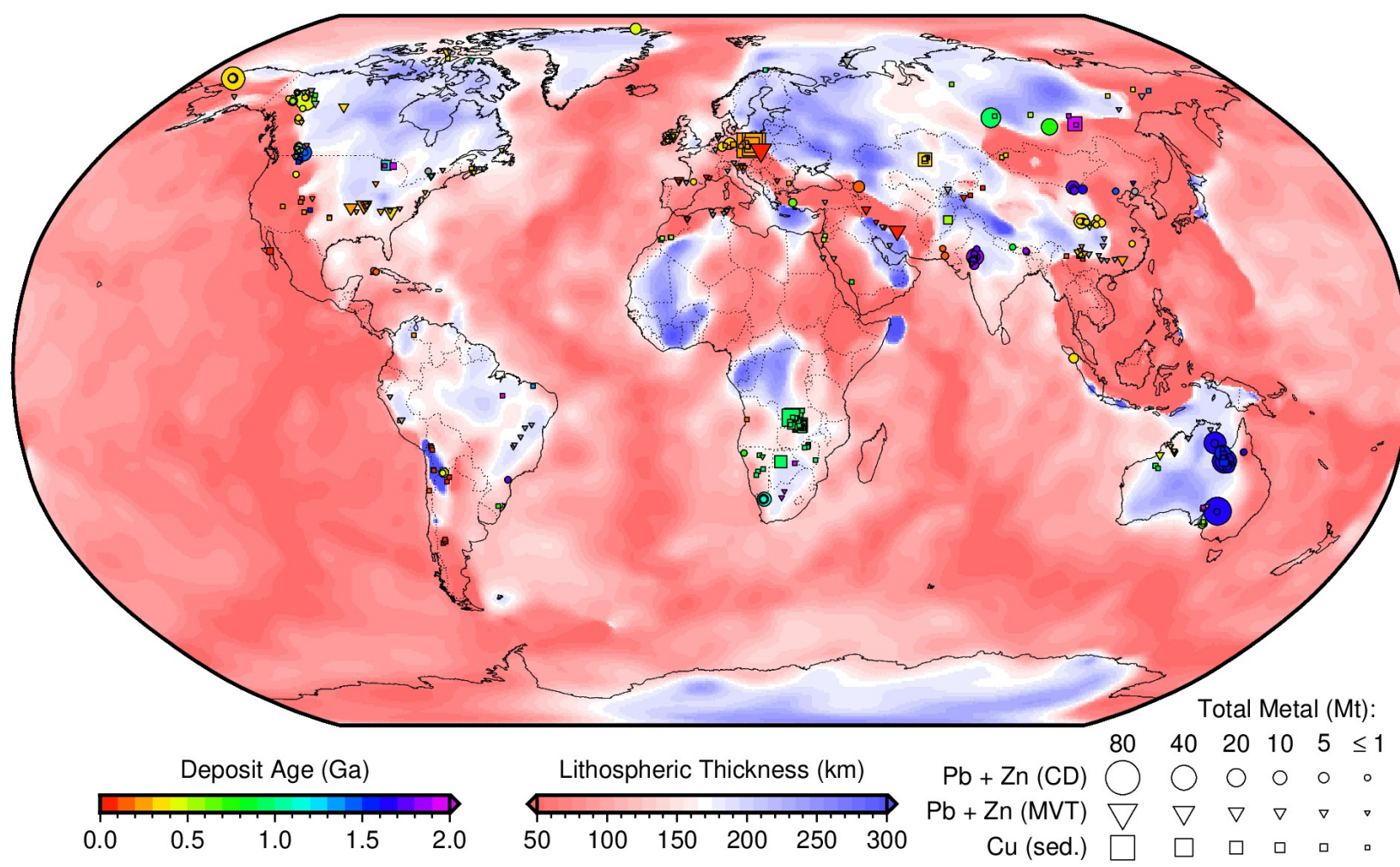

Figure 3: Global distribution of sediment-hosted base metal deposits as a function of lithospheric thickness. LAB derived from SL2013sv tomography model (Schaeffer \& Lebedev, 2013) using a calibrated anelasticity parameterisation (Yamauchi \& Takei, 2016; Methods). Symbols = deposit locations; symbol area proportional to estimate of total contained mass of metal (either lead plus zinc, or copper) in mega-tonnes (Mt); unknown deposit size given $1 \mathrm{Mt}$ symbol; colour = ore body formation age (billion years); unknown age plotted in grey; circles = clastic-dominated lead-zinc (PbZn-CD); triangles = Mississippi Valley type lead-zinc $(\mathrm{PbZn}-\mathrm{MVT}) ;$ squares $=$ sedimentary copper $(\mathrm{Cu}-\mathrm{sed})$.

duction zone across Europe, whilst small sedimentary copper deposits occur in southwestern North America and southern South America. This observation indicates that minor sediment-hosted mineral systems can develop in a variety of basins, whilst giant deposits form only at the edges of cratonic lithosphere. PbZn-MVT deposits are generally more widely distributed, which likely reflects that a subset of these deposits are linked with orogenic processes along basin margins (Leach et al., 2010), resulting in longer hydrothermal fluid flow paths. Nevertheless, not all sediment-hosted outliers were necessarily anomalies at the time of ore formation. The majority now occur in accretionary terranes, whereby plate tectonic processes may have rifted segments off thick lithosphere and transported them into subduction zone settings. Other areas, such as east China, are known to have undergone lithospheric thinning some time after deposit formation, based on thermobarometric constraints (Menzies et al., 2007).

Regardless of age, sediment-hosted base-metal deposits predominantly cluster on the edges of present-day thick lithosphere. Therefore, many of these lithospheric steps appear to be remarkably robust on billion-year timescales, despite the assembly and disaggregation of several supercontinents, the impacts of large igneous provinces and the possible erosional effect of edge-driven convection (Currie \& van Wijk, 2016). Deposit ages in northwestern North America span 1.5-0.5 Ga, pointing to the stability and importance of this boundary in localising multiple deformational and oreforming processes.

\section{Mineral system implications}

Our results indicate that the edges of thick lithosphere place first-order controls on the genesis of extensional basins and their associated mineral systems (Figure 1). Rifting causes localised thinning and produces a lateral transition from oxidising terrestrial environments into marine settings. This transition provides the optimal juxtaposition of the ingredients necessary for deposit formation. The adjacent unstretched cratons provide a bountiful source of oxidised sediments and extensive low-elevation platforms, which enhance evaporite formation. Proximal land masses also aid the development of restricted marine settings that are ideal for accumulating thick evaporite sequences (through periodic cycles of evaporation and flooding), and promote euxinic water conditions that are favourable for deposition of reducing shales that have high organic carbon content. Thinning of the lithosphere in the centre of the basin causes decompression melting, providing mafic and felsic volcanic rocks from which metals are scavenged. Intercalation of proximal and distal facies components is further modulated by transient vertical motions, generally thought to be associated with edge driven convection across lithospheric steps (Davies \& Rawlinson, 2014). Nevertheless, these mineral system components are common to both rifts in thick lithosphere and regular passive margins, and the question remains - what is favourable about rifting cratonic lithosphere for formation of the shallow hydrothermal systems necessary to produce giant deposits?

From a geodynamic perspective, these lithospheric edges represent rheological contrasts that focus strain and localise repeated cycles of extensional deformation and basin contraction, thereby controlling both the spatial distribution of required lithologies and the focusing of mineralising fluids (Sloan et al., 2011; Gibson et al., 2016; O'Reilly et al., 2017). Thick cratonic lithosphere is colder than standard continental lithosphere and has a larger seismogenic thickness, resulting in the development of deeper, longer, and more widely spaced normal faults during rifting (Biggs et al., 2010). This architecture increases the horizontal aspect ratio of hydrothermal cells, providing greater sediment volumes for fluid-rock 

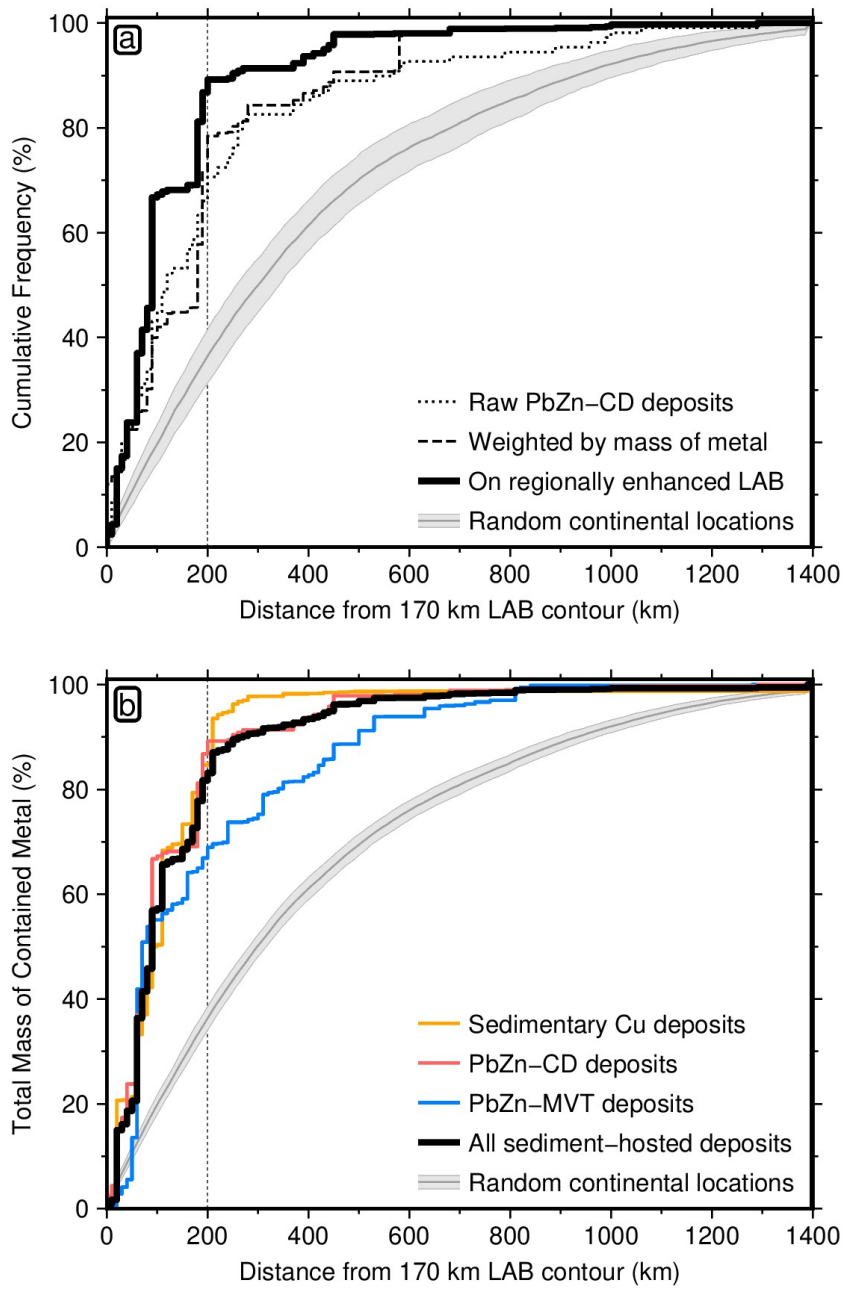

Figure 4: Cumulative distribution functions for global sediment-hosted base metals. (a) Different approaches for counting 109 clastic-dominated lead-zinc deposits (PbZn-CD). Dotted line $=$ simple count of number of deposits with increasing distance from the $170 \mathrm{~km}$ contour in global LAB map (Figure 3); dashed line $=$ weighting by contained mass of lead and zinc; solid black line = mass-weighted deposits where the Australian LAB from the global model has been replaced with the regionally enhanced map (Figure $2 \mathrm{~b}$ ); grey line/bounds = mean and standard deviation of 100 sets of equivalent number (109) of randomly drawn continental locations, with respect to regionally enhanced LAB. (b) Mass-weighted, regionally enhanced CDFs for 139 sedimentary copper deposits (Cu-sed), 109 PbZn-CD, 147 Mississippi Valley-type (PbZn-MVT), and combination of all three. Grey band as before for combined number of deposits (395).

interaction. These faults are active for longer periods of time, and the entire syn-rift phase of basin formation can last 50$100 \mathrm{Myr}$, in contrast to standard continental rifts that typically last $\sim 25 \mathrm{Myr}$, yielding a more extensive time window for mineralisation (Allen \& Armitage, 2012). Furthermore, basins forming in continental interiors are more likely to be restricted, which is not only favourable for high siliciclastic supply and the formation of evaporites and reductants, but also results in laterally continuous sediment packages that trap hydrothermal fluid systems and potentially promote recirculation of brines (Hitzman et al., 2010).

A key observation is that metal precipitation in sedimenthosted base metal deposits is generally driven by oxidationreduction reactions, which become ineffective when brine temperatures exceed $\sim 250^{\circ} \mathrm{C}$ (Figures $1 \mathrm{~b}$ and $1 \mathrm{c}$; Huston et al., 2016). As hydrothermal fluid temperatures are buffered by conditions towards the base of the sediment pile (often where the mafic metal source rocks are located), the basal temperature of the sedimentary pile must not substan- tially exceed this threshold value. Total extension in a basin can be estimated using a stretching factor, $\beta$, which is the ratio of original to final crustal thickness. Failed rifts on standard continental lithosphere such as the North Sea typically have $\beta \approx 2$, and simple thermal modelling assuming pureshear rifting indicates that this produces $\sim 4 \mathrm{~km}$ of syn-rift sediment with basal temperatures cooler than $\sim 250^{\circ} \mathrm{C}$ (Figure 5a; Methods). Given that all the necessary ingredients occur within basins, the likelihood of developing a successful mineral system is higher for a larger sediment pile, which can be achieved by increasing the stretching factor. However, more extreme rifting causes the asthenosphere to upwell to substantially shallower depths, producing elevated basal heat flow that heats the sediment pile above this threshold and so inhibits metal precipitation (Figure $5 \mathrm{~b}$ ).

Two important differences occur during rifting of cratonic lithosphere. First, the greater initial thickness of the lithosphere results in a lower geothermal gradient, such that the basal heat flow spike during rifting is substantially lower than for standard continental rifts (Supplementary Information). Secondly, the density of cratonic lithosphere is reduced by up to $\sim 50 \mathrm{~kg} \mathrm{~m}^{-3}$ by chemical depletion compared to standard lithosphere (Jordan, 1978). This increased buoyancy reduces the dampening effect during syn-rift subsidence that is associated with replacing cold continental lithosphere with lower density asthenosphere, resulting in substantially larger thicknesses of syn-rift sediments for any given stretching factor. Assuming unlimited sediment supply, $\beta \approx 2$ yields a $8-9 \mathrm{~km}$ syn-rift sediment pile, the base of which stays cooler than the threshold $\sim 250^{\circ} \mathrm{C}$ (Figure $5 \mathrm{c}$ ). Thus, rifting cratonic lithosphere produces more than twice the volume of mineral system ingredients without exceeding the thermal conditions necessary for successful precipitation, over a duration of time that can be up to a factor of four more extensive (Figure $5 \mathrm{~d}$ and 5e). This mechanism explains why smaller deposits can occur in any extensional setting (e.g. Irish PbZn-MVT deposits), but giant deposits requiring the largest volumes of fluid-rock interaction are restricted to rift basins at the edges of the thickest lithosphere.

A final consideration is that a setting on the edge of thick lithosphere enhances the preservation potential of deposits through subsequent orogenic events and supercontinent cycles. For example, the Boleo Copper District in Baja California formed only three-million years ago and sits in shallow crust on thin lithosphere, resulting in poor long-term preservation potential. In contrast, the $1.7 \mathrm{Ga}$ Broken Hill deposit in Australia (world's largest known lead deposit) has been metamorphosed to amphibolite-granulite facies, yet survives on the edge of the Curnamona part of the South Australian Craton.

Surprisingly, given the results of previous studies (e.g. Griffin et al., 2013), deposits associated with magmatic systems generally exhibit a weaker association with the edge of cratonic lithosphere than sediment-hosted systems (Supplementary Information). Porphyry copper deposits are predominantly Cenozoic in age and are generally positioned on thin lithosphere $(\leq 100 \mathrm{~km})$. Their formation in subduction zone settings at shallow crustal depths leads to poor preservation potential within the geological record, making this association unsurprising. Volcanogenic massive sulphides have an episodic age distribution from 3.5 Ga to present. Their generation is thought to require moderate-degree partial melting of hydrated mantle in back-arc settings (Huston et al., 2010). We observe that they spatially occur randomly on thick and thin lithosphere, but exhibit systematic temporal ordering, with the oldest positioned over thick lithosphere 

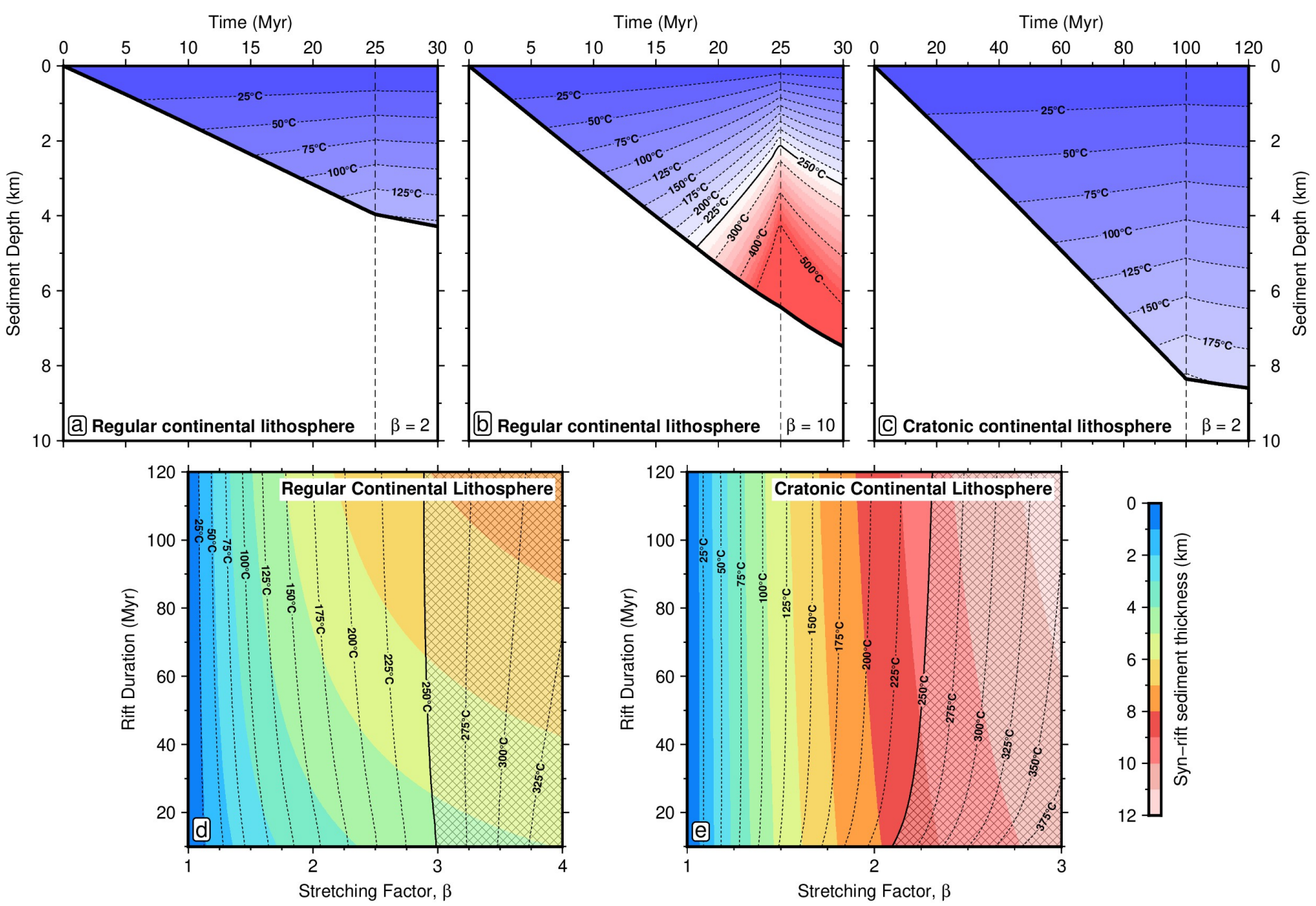

Figure 5: Thermal modelling of basin subsidence histories. (a) Syn-rift sedimentation for $\beta=2$ rift of regular continental lithosphere; dashed line $=$ rift duration; colours = temperature structure of the sediment pile. (b) Same for $\beta=10$ rift of regular continental lithosphere. (c) Same for $\beta=2$ rift of cratonic continental lithosphere. (d) Minerals system operating window for rifting of regular continental lithosphere; colours $=$ syn-rift sediment thickness; contours = basal temperature of the sediment pile; hatched region $=$ location where hydrothermal fluids typically become too hot for metal precipitation by oxidation-reduction mechanisms $\left(>250^{\circ} \mathrm{C}\right)$.

(e) Same for cratonic continental lithosphere.

that are rimmed by progressively younger deposits, consistent with growth of cratons by accretion. Finally, magmatic nickel deposits are mostly Archean and Proterozoic in age and commonly occur on thick lithosphere $(\geq 150 \mathrm{~km})$. Unlike other base metal deposits, their distribution is associated with edges of even thicker lithosphere $(\sim 200 \mathrm{~km})$, broadly consistent with previous studies showing major lithospheric structural controls on these deposit locations (Begg et al., 2010; Regis et al., 2017; Alghamdi et al., 2018). Their generation requires large fraction partial melting of peridotite, indicative of high mantle temperatures (more prevalent in a early, hotter Earth) and decompression melting at shallow depths (Arndt et al., 2005). Therefore, their present distribution suggests lithospheric thickness must have locally increased since formation, simultaneously enhancing preservation potential.

In summary, this work illustrates a new and robust link between giant sediment-hosted base metal mineral systems and the edges of thick lithosphere. Approximately 55\% of the world's lead, $45 \%$ of its zinc and $20 \%$ of known copper is found within $\sim 200 \mathrm{~km}$ of this boundary. We have demonstrated the value of regional seismic arrays to better resolve this edge and enhance the mineral exploration efforts required to sustain ongoing global development. Importantly, deposit ages indicate that, following rifting, the edges of thicklithosphere are generally stable over billion-year timescales. The far-reaching geodynamic and societal implications of these observations highlight the need for extensive further research. To improve resolution of mapped lithospheric structure, higher fidelity seismic imaging needs to be coupled with enhanced mantle xenolith coverage and tighter constraints on seismic anelasticity from mineral physics experiments. More generally, these maps should be integrated with models of basin dynamics, surface processes and reactive transport modelling, and benchmarked against additional geological information, such as sedimentary facies variations, tectonic structures and alteration zones. These multiple research strands will yield fundamental new insights into sedimenthosted mineral systems and lead to substantial improvements in exploration success. 


\section{Methods}

Deposit compilation. Our global inventory of 2166 major base metal deposits are categorised into six main classes. Three are sediment hosted: sedimentary copper (Cu-sed; contains $\sim 20 \%$ of all known copper); clastic-dominated lead-zinc (PbZn-CD; 43\% of all lead and $\sim 33 \%$ of zinc); and Mississippi Valley-type leadzinc (PbZn-MVT; $\sim 25 \%$ lead, $\sim 22 \%$ zinc). The other three are associated with magmatic systems: copper porphyry $(\mathrm{Cu}-$ por; contains $\sim 65 \%$ of all known copper); magmatic nickel-copperplatinum group elements (Ni-Cu-PGE; 45\% nickel, 3\% copper); and volcanogenic massive sulfides (VMS; $\sim 6 \%$ copper, $\sim 23 \%$ lead, $\sim 39 \%$ zinc).

For each deposit, we include the type (based on established classification schemes), location, age (direct measurement or inferred based on geological relationships) and total resource size by combining historical production with estimated resources. Our $\mathrm{Cu}$-sed deposit dataset follows the classification scheme and compilation of Hitzman et al. (2005), cross-checked against Cox et al. (2007). Where these two compilations disagree on deposit size, the larger value has been used. Our PbZn-CD and PbZn-MVT deposit compilations extensively revise and build on the work of Taylor et al. (2009). References for each deposit type were manually checked and additional references have been included. We exploit the compilation of Sillitoe (2010) for $\mathrm{Cu}$-por deposits. Our magmatic Ni-Cu-PGE compilation follows Hoatson et al. (2006), with deposit location populated from disparate sources. Our catalogue of VMS deposits is an extensive revision of the compilation by Franklin et al. (2005). Australian information for all the above deposit types, with the addition of 25 iron-oxide-copper-gold deposits, was updated using the authors' own knowledge building from the Geoscience Australia OZMin database (Sexton, 2011).

We have endeavoured to assemble the most complete deposit dataset possible by revising and extending pre-existing compilations. Our database can be found in the online Supplementary Datasets. Importantly, patchy or absent reporting of mineral deposit information from some countries inevitably means our global database is incomplete, but we do not believe that this will impact the veracity of our main conclusions.

Metal scavenging window. Following Cooke et al. (2000), we have selected a precipitation gradient from $\sim 100 \mathrm{ppm}$ to $1 \mathrm{ppm}$ for the metal scavenging window in Figure 1. Estimates of the metal concentration of mineralising brines are obtained from fluid inclusion studies contained within ore and other gangue minerals. Care must be taken that host minerals formed during the period of ore deposition and that analyses are not contaminated by metals contained within the mineral lattice itself, which is a particular problem in the early stages of LA-ICP-MS analysis when the laser initially vaporises a mixture of mineral and fluid inclusion to produce a mixed signal. Generally, inclusions from European sedimenthosted deposits and Irish and US MVTs hosted by quartz, calcite, and dolomite have values at the lower end of our range, whilst those in sphalerite can sometimes reach several hundred ppm of $\mathrm{Pb}$ (Appold et al., 2004; Kostova et al., 2004; Wilkinson et al., 2005; Kotzeva et al., 2011; Fusswinkel et al., 2014). Values in the several thousands of ppm have been inferred in rare cases for single fluid inclusions (e.g. Wilkinson et al., 2009; Davey, 2019) However, these high values are often found for inclusions with high homogenisation temperatures, whilst those fluids thought to be cooler than $\sim 250^{\circ} \mathrm{C}$ generally return concentrations an order of magnitude or more below 1000 ppm (Davey, 2019). While there remains debate on complexity and exact composition of mineralising fluids (Fusswinkel et al., 2013; Schlegel et al., 2018), for ores deposited via the reduction mechanism, our inference of an enlarged operating window in cratonic rift basins holds regardless of the exact fluid metal concentrations.

Choice of seismic tomography model. Our LAB maps are based on recent shear-wave velocity $\left(V_{S}\right)$ models that contain a lot of surface wave data and have nominal vertical resolution on the order of 25-50 km (Priestley \& McKenzie, 2006). For the global map, we use SL2013sv, which is an upper mantle-only model built from a combination of body and surface waves, including fundamental and higher modes (Schaeffer \& Lebedev, 2013). Periods considered are $11-450 \mathrm{~s}, \sim 750,000$ seismograms are included, and misfits are calculated between synthetics and the full waveform up to the $18^{\text {th }}$ overtone. Crucially, simultaneous inversion for the crustal model results in reduced smearing of slow crustal velocities down into the upper mantle in comparison to other models, thereby allowing us to use more depth slices in our $V_{S}$ to temperature calibration. Checkerboard resolution tests indicate that features $\sim 600 \mathrm{~km}$ in diameter at lithospheric depths are generally well resolved. Finer features should be resolvable in regions with dense ray path coverage, such as North America, Europe and southeast Asia. The SL2013sv model utilises data from only 6 seismometers in Australia, so has limited resolution within this continent. Therefore, we also investigate the FR12 regional seismic tomography model to generate a high resolution map for the Australian continent (Fishwick \& Rawlinson, 2012). FR12 is a radially isotropic $V_{S}$ model derived from Rayleigh wave travel times (Fishwick et al., 2008). Periods considered are 50-120 s and the fundamental and first four higher modes have been used where possible, leading to good sensitivity down to $\sim 250 \mathrm{~km}$ depths. It contains a greater number of source-receiver paths $(>13,000)$ compared to other Australian models. However, it uses an a priori crustal model that remains fixed throughout the inversion, resulting in noticeable smearing of crustal velocities into the upper mantle. Checkerboard tests indicate that features $\sim 300 \mathrm{~km}$ in diameter at lithospheric depths are well resolved, and where higher mode information is included.

For comparison, we include LAB maps derived from three additional upper mantle seismic tomography datasets with global coverage in Extended Data Figure 1. These include the 3D201507Sv model of Debayle et al. (2016), the CAM2016 model of Ho et al. (2016) and Priestley et al. (2018), and a version of SL2013sv into which we have blended the regional updates SL2013NA in North America (Schaeffer \& Lebedev, 2014), AF2019 in Africa (Celli et al., 2020a), and SA2019 in South America and the South Atlantic Ocean (Celli et al., 2020b) to produce a combined model SLNAAFSA. For the continental analyses in Australia, we also consider regional model AuSREM of Kennett et al. (2013) and Y14 of Yoshizawa (2014). Deposit locations are compared with all seven of our new LAB maps in the Supplementary Information, in addition to eleven previously published LAB maps derived from a mixture of heat flow data, seismic tomography datasets, and potential field data. Many giant sediment hosted mineral deposits lie along LAB edges defined by these other studies, testifying to the robustness of the observed relationship.

Parameterising anelasticity. Seismic tomography models provide images of the upper mantle and have been extensively used to constrain its thermomechanical structure, composition, and the depth of the lithosphere-asthenosphere boundary (Priestley \& McKenzie, 2006; An \& Shi, 2006; Goes et al., 2012; Afonso et al., 2016; Cammarano \& Guerri, 2017; Klöcking et al., 2018; Afonso et al., 2019). For accurate mapping from $V_{S}$ into temperature, it is essential to include the effect of anelasticity on this conversion (Karato, 1993; Cammarano et al., 2003). When a viscoelastic material such as the mantle is cold, deformation associated with passage of acoustic energy is predominantly elastic, yielding a linear dependence of $\mathrm{V}_{S}$ on temperature referred to as the anharmonic velocity. As temperature increases, a special case of viscoelastic deformation known as anelasticity becomes increasingly important and gives rise to a strongly non-linear relationship between $\mathrm{V}_{S}$ and temperature. This behaviour has been extensively studied in laboratory experiments on silicates and organic analogues of mantle rocks, revealing that the strength of the anelastic regime varies with both the frequency of seismic waves and as a function of material properties, such as melting temperature and grain size (Jackson et al., 2002; Sundberg \& Cooper, 2010; McCarthy et al., 2011; Takei et al., 2014; Faul \& Jackson, 2015). Several studies have attempted to parameterise these complex dependencies, and have been regularly updated as forced oscillation and creep experiments in the laboratory have been pushed towards increasingly realistic frequencies, pressures, temperatures, grain sizes and strain rates (Faul \& Jackson, 2005; Jackson \& Faul, 2010; Takei, 2017). In this study, we adopt the parameterisation of Yamauchi \& Takei (2016), which includes effects of anelasticity in pre-melt conditions (temperatures above $\sim 90 \%$ of melting temperature) and is outlined in full in the Supplementary Information.

Xenolith and xenocryst thermobarometry. Temperature estimates across a range of depths are required to generate a series of $\mathrm{V}_{S}$-temperature-pressure tie points in order to calibrate the regional seismic tomography models. We therefore assemble a suite of fifteen Australian paleogeotherms derived from thermobarometric analysis of mantle xenoliths and xenocrysts (Supplementary Information). These come from a range of settings within both thick and thin lithosphere. Localities with thin lithosphere tend to have data obtained from whole xenolith samples, typically hosted in basaltic volcanic products. For these cases, the compositions of multiple phases (garnet, clinopyroxene, orthopyroxene and olivine) can be obtained that all equilibrated under the same pressure-temperature $(\mathrm{P}-\mathrm{T})$ conditions. In these samples, we use 

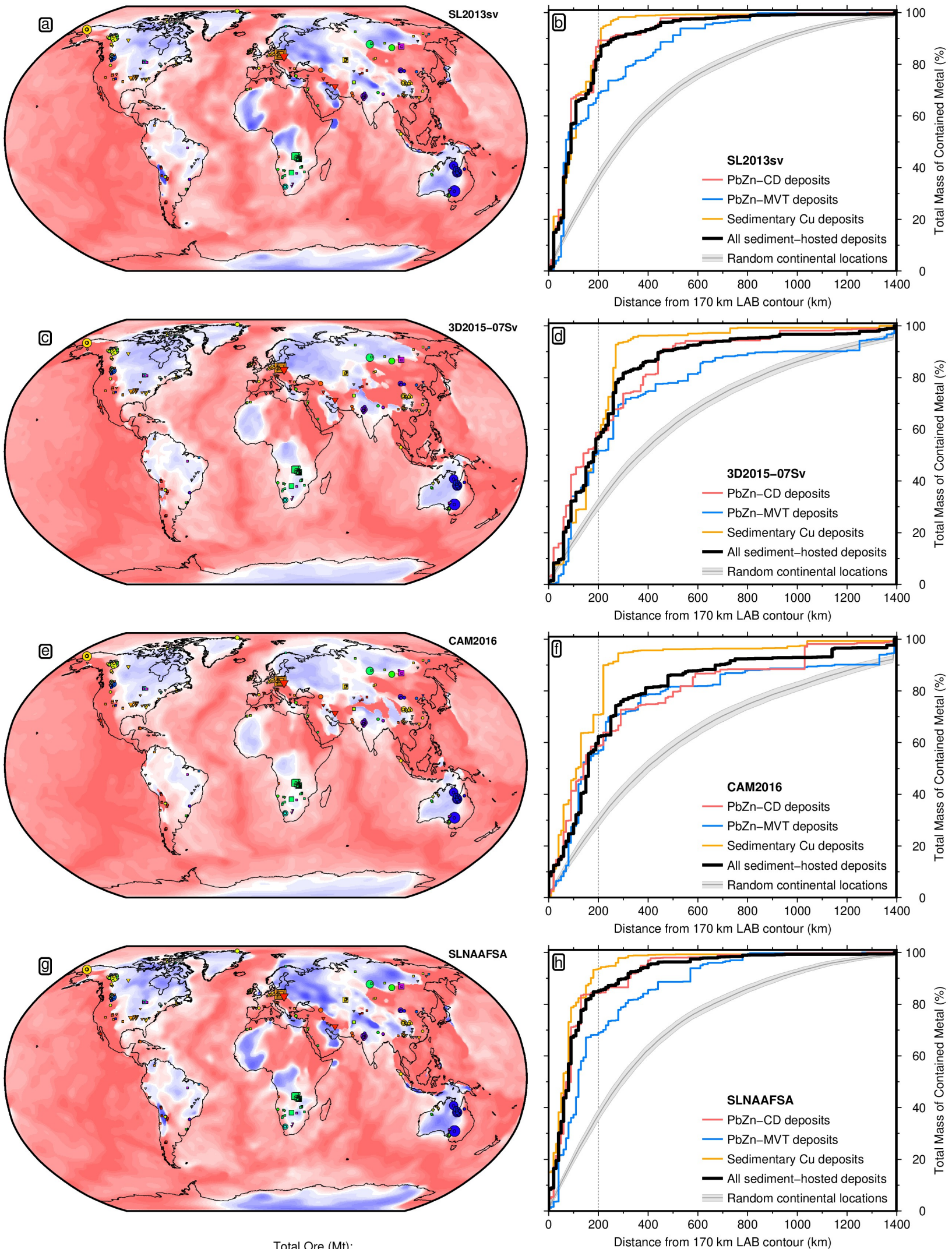

Total Ore (Mt):

$80 \quad 40 \quad 2010 \quad 5 \leq 2$
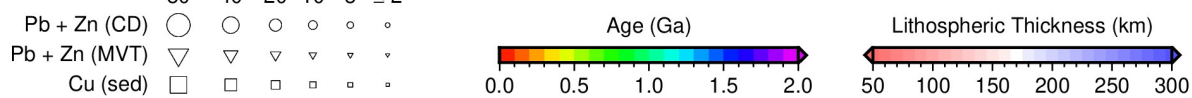

Extended Data Figure 1: Global lithospheric thickness maps obtained from calibration of four upper mantle surface wave tomography models. (a) SL2013sv model (Schaeffer \& Lebedev, 2013). Symbols = deposit locations; area proportional to estimate of total contained mass of metal (either lead plus zinc, or copper) in mega-tonnes (Mt); unknown deposit size given $2 \mathrm{Mt}$ symbol; colour $=$ ore body formation age (billion years); unknown age plotted in grey; circles = clastic-dominated lead-zinc (PbZn-CD); triangles = Mississippi Valley type lead-zinc (PbZn-MVT); squares = sedimentary copper (Cu-sed). (b) Associated CDFs for sediment-hosted deposits and random continental locations. (c-d) Same for the 3D2015-07Sv model (Debayle et al., 2016). (e-f) Same for the CAM2016 model (Ho et al., 2016; Priestley et al., 2018). (g-h) Same for the SLNAAFSA model, generated by blending regional updates from North America (SL2013NA), Africa (AF2019), and South America (SA2019) into the global SL2013sv model (Schaeffer \& Lebedev, 2014; Celli et al., 2020a,b). Note that CDFs for all tomography models show a significant difference from the distribution of random continental locations. 
a thermometer that exploits exchange of calcium and magnesium between orthopyroxene and clinopyroxene (Taylor, 1998), and a barometer based upon aluminium exchange between orthopyroxene and garnet, given by Equation (5) of Nickel \& Green (1985). This approach therefore requires compositions of garnet, diopside (clinopyroxene) and enstatite (orthopyroxene) for each xenolith, and we only use samples with all three of these minerals present. This barometer and thermometer pair both also depend upon the temperature and pressure, respectively. These two equations are therefore solved simultaneously by iteration to obtain equilibration P-T conditions. Samples are discarded if they fail more than one of the eight oxide, cation and equilibration checks suggested by Nimis \& Grütter (2010).

Despite all samples containing garnet, a small number return depths as shallow as $\sim 25 \mathrm{~km}$ (see Bullenmerri, Monaro, Mt St Martin, and Sapphire Hill). The presence of garnet in xenoliths from shallow depths is well documented. The garnet-spinel transition can occur at pressures as low as $1 \mathrm{GPa}(\sim 30 \mathrm{~km}$ depth) in pyroxenite and $1.5 \mathrm{GPa}(\sim 45 \mathrm{~km}$ depth) in lherzolite, with the exact pressure of the transition depending on relative abundance of $\mathrm{Cr}$ and $\mathrm{Al}$ in each assemblage (Gasparik, 1984; Klemme, 2004; Nimis \& Grütter, 2010). Our shallow samples are dominantly pyroxenites and mostly give pressures larger than the $1 \mathrm{GPa}$ lower limit. Of these four sites with shallower samples, we select only Bullenmerri and Monaro for the anelasticity calibration, as these geotherms also contain samples at greater depths. In both cases, the deeper samples are consistent with the shallow results.

Analyses from locations on thicker lithosphere are predominantly obtained from heavy mineral concentrates generated during diamond exploration (plus rare diamond inclusions and occasional whole peridotite xenoliths), where the association of one mineral grain with any other has been lost. Thus, the approach outlined in the preceding paragraphs using multiple phases is unavailable, and we instead turn to single grain combined thermobarometers for deriving equilibration P-T conditions. For these samples, we use the chrome-in-diopside barometer that exploits the exchange of chromium between clinopyroxene and garnet (Equation (9) of Nimis \& Taylor, 2000). It uses only diopside compositions, but requires that garnet was also present in the source region. The associated thermometer exploits enstatite-in-diopside, again using only diopside compositions but requiring that orthopyroxene was present within the source. The temperature is given by Equation (17) of Nimis \& Taylor (2000). Again, these two equations must be solved by iteration to obtain P-T conditions for each diopside grain. Calibration on laboratory experiments has shown that this thermobarometer may become inaccurate at low pressures and at temperatures $<700^{\circ} \mathrm{C}$ (Nimis \& Grütter, 2010). We therefore only use P-T estimates derived from this thermobarometer that yield depths $>60 \mathrm{~km}$ and pass both of the clinopyroxene cation and oxide checks.

There are two sources of error to consider for each suite of P-T estimates. The first is uncertainty in the microprobe analyses of elemental oxide concentrations in each of the mineral samples. For the three-mineral thermobarometer, this introduces uncertainty of $\pm 30^{\circ} \mathrm{C}$ and $\pm 10 \mathrm{~km}$ at low temperatures $\left(\sim 700^{\circ} \mathrm{C}\right)$, reducing to $\pm 10^{\circ} \mathrm{C}$ and $\pm 3 \mathrm{~km}$ by $\sim 1200^{\circ} \mathrm{C}$ (Mather et al., 2011). For the diopside-only thermobarometer, uncertainties are larger at $\pm 70^{\circ} \mathrm{C}$ and $\pm 12 \mathrm{~km}$ for low temperatures $\left(\sim 600^{\circ} \mathrm{C}\right)$ and $\pm 15^{\circ} \mathrm{C}$ and $\pm 3 \mathrm{~km}$ for higher temperatures $\left(\sim 1200^{\circ} \mathrm{C}\right.$ ) (Mather et al., 2011). However, these uncertainties in pressure and temperature are positively correlated, such that samples broadly move up and down the geothermal gradient, with limited effect on the best fitting geotherm. The second and more significant source of uncertainty arises from error in the thermobarometers themselves, which are calibrated on laboratory samples over a range of pressure-temperature conditions and do not necessarily trade-off in the same manner. Quoted uncertainties are $\pm 50^{\circ} \mathrm{C}$ and $\pm 15 \mathrm{~km}$ for the three-mineral, and $\pm 100^{\circ} \mathrm{C}$ and $\pm 15 \mathrm{~km}$ for the diopsideonly thermobarometer (Nimis \& Taylor, 2000; Nimis \& Grütter, 2010; Mather et al., 2011).

Fitting a geotherm to P-T estimates. For each locality, $\mathrm{P}-\mathrm{T}$ estimates derived from thermobarometry are entered into FITPLOT to constrain the best-fitting paleogeotherm (McKenzie et al., 2005; Mather et al., 2011; Supplementary Information). Within the crust, we adopt a constant conductivity of $2.5 \mathrm{~W} \mathrm{~m}{ }^{-1}{ }^{\circ} \mathrm{C}^{-1}$, whilst a pressure- and temperaturedependent parameterisation is used within the mantle (Osako et al., 2004). Bulk crustal radiogenic heat production is assumed to be $0.7 \mu \mathrm{W} \mathrm{m} \mathrm{m}^{-3}$, with a standard deviation of $0.2 \mu \mathrm{W} \mathrm{m}-3$ (Jaupart et al., 2007). Crustal thickness at each location is ob- tained from the AusMoho model with standard deviation assigned as $10 \%$ of the total thickness (Kennett et al., 2011). We assume a potential temperature of $1330 \pm 50^{\circ} \mathrm{C}$, which is consistent with both seismological observations and the thickness and geochemistry of mid-ocean ridge basalts, assuming a dry lherzolite source using a corner-flow melting parameterisation (Dalton et al., 2014; Katz et al., 2003; Shorttle et al., 2014). Kinematic viscosity of the mantle is set to $2 \times 10^{16} \mathrm{~m}^{2} \mathrm{~s}^{-1}$, with a standard deviation of 0.7 orders of magnitude, which is consistent with constraints from glacial isostatic adjustment (Lau et al., 2016). Thermal parameters that are consistent with the melting parameterisation are used to calculate the adiabatic gradient, including a reference density of $\rho_{0}=3.3 \mathrm{Mg} \mathrm{m}^{-3}$, thermal expansivity of $\alpha=3 \times 10^{-5}{ }^{\circ} \mathrm{C}^{-1}$ and specific heat capacity of $C_{P}=1187 \mathrm{~J} \mathrm{~kg}^{-1}{ }^{\circ} \mathrm{C}^{-1}$. Uncertainty in the crustal thickness, radiogenic heat production, mantle potential temperature, and kinematic viscosity are propagated through FITPLOT using a Monte Carlo approach. 1000 combinations of these four parameters are randomly drawn assuming Gaussian distributions of the uncertainties. Geotherms are strongly consistent in the vicinity of $\mathrm{P}-\mathrm{T}$ constraints, but can vary by $\pm 50^{\circ} \mathrm{C}$ when greater than $\sim 30 \mathrm{~km}$ from a P-T estimate (Supplementary Information).

Calibrating $V_{S}$-to-temperature conversion. Some of the anelasticity parameters have been directly constrained by forced oscillation experiments on borneol (Yamauchi \& Takei, 2016). Others, however, are material properties that must be independently determined. A widely adopted approach is to fix these parameters for a given mineral assemblage, often calculated using mineral physics tables and a thermodynamic Gibbs energy minimisation algorithm (Stixrude \& Lithgow-Bertelloni, 2005; Connolly, 2009; Stixrude \& Lithgow-Bertelloni, 2011; Holland \& Powell, 2011; Cottaar et al., 2014). In this manner, an anelastic conversion can be used in a forward sense to map between $\mathrm{V}_{S}$ and temperature (An \& Shi, 2006; Cammarano et al., 2009; Goes et al., 2012; Dannberg et al., 2017; Cammarano \& Guerri, 2017). However, inferred temperature structures are variable as a result of uncertainty in the mantle's chemical composition and grain size, and differences in absolute $\mathrm{V}_{S}$ between tomography models arising from different reference models and regularisation schemes.

An alternative approach to constraining these material properties is to invert real-Earth observations of the relationship between temperature, shear-wave velocity, attenuation and viscosity in the upper mantle (Priestley \& McKenzie, 2006; Afonso et al., 2013a,b; Yamauchi \& Takei, 2016). The general philosophy is that there are certain properties that are 'known' about Earth, including the typical thermal structure of oceanic lithosphere (Richards et al., 2018), the average adiabatic gradient within the convecting mantle (Connolly, 2009), the attenuation structure of the upper mantle beneath old oceanic lithosphere (Dalton et al., 2009), and the bulk diffusion creep viscosity of the upper mantle from studies of glacial isostatic adjustment (Lau et al., 2016). Thus any thermal model inferred from shear-wave velocities should be compatible with these observations. This general approach was pioneered by Priestley \& McKenzie (2006) and Priestley \& McKenzie (2013). The approach has been further refined by (Richards et al., 2020, under review) and we adopt their approach for calibration of global tomography models (see Supplementary Information).

For the Australian regional tomography models, we cannot use oceanic observations for calibration due to insufficient offshore coverage, and instead use the better constrained paleogeotherms derived from thermobarometry on mantle xenoliths (in combination with the adiabatic gradient). Away from three close together sites in South Australia in the vicinity of the Gawler Craton, it is notable that the global SL2013sv model provides a surprisingly good fit to the Australian paleogeotherms, despite being calibrated independently (Supplementary Information). This observation is unexpected for two reasons. First, the nominal resolution of the global model is lower than the local models. There are only six seismometers in Australia (located in the far west, north and east of the continent, with none in South Australia), and the density of crossing ray paths is much lower than in Europe, Asia, North, and South America (Schaeffer \& Lebedev, 2013). Secondly, the Australian geotherms occur in continental lithosphere that is thought to be chemically depleted by melt extraction, reducing the quantity of garnet and clinopyroxene with respect to more fertile oceanic mantle. Nevertheless, the global model calibrated on fertile mantle constraints provides a good match to independent $\mathrm{V}_{S}-\mathrm{T}-\mathrm{P}$ observations in depleted continental lithosphere. This result implies that temperature plays the dominant role in controlling variations in seismic wave speed in the shallow mantle, whilst the effects of compositional variation are substantially smaller (Goes et al., 
2000; Priestley \& McKenzie, 2006; Schutt \& Lesher, 2006).

Mapping the lithosphere-asthenosphere boundary (LAB). A recent study on the thermal structure of oceanic lithosphere found that the $1175 \pm 50^{\circ} \mathrm{C}$ isotherm provides a good match to seismological observations of the lithosphere-asthenosphere boundary (Richards et al., 2018). In this study, we therefore adopt this isotherm as a proxy for lithospheric thickness beneath the continents. The temperature $(T)$ as a function of depth $(z)$ is extracted from the $V_{S}$ model and $\frac{\partial T}{\partial z}$ is calculated over $25 \mathrm{~km}$ increments. Starting from the surface and progressing downwards, when temperature passes the $1175^{\circ} \mathrm{C}$ threshold, LAB depth is calculated using linear interpolation, with one important exception. In locations of thick crust, low $V_{S}$ values at shallow depths arising from crustal bleeding can lead to lithospheric mantle being erroneously interpreted as hot. In the regional seismic tomography models, this crustal bleeding can be observed down to $\sim 125 \mathrm{~km}$ in some locations (see calibration Figure S7 in Supplementary Information). To circumvent this issue, when an inverted temperature gradient is found at shallow depths, we move on to deeper levels until temperature starts to increase with depth. This crustal bleeding is only considered down to $200 \mathrm{~km}$. Maximum LAB depth is limited to $350 \mathrm{~km}$ or the deepest slice in the seismic tomography model. Our $1175^{\circ} \mathrm{C}$ isotherm LAB proxy is shallower than used in some other studies that define the LAB using the intersection of conductive and adiabatic temperature gradients in the thermal boundary layer (typically occurring at temperatures $1350-1450^{\circ} \mathrm{C}$; McKenzie et al., 2005; Mather et al., 2011; Priestley \& McKenzie, 2013). However, in addition to matching oceanic observations, the $1175^{\circ} \mathrm{C}$ isotherm corresponds to lower homologous temperatures, where uncertainty in anelastic parameters has a smaller impact on the recovered LAB.

As in previous studies using seismic tomography (e.g. Priestley \& McKenzie, 2013; Steinberger \& Becker, 2018; Priestley et al., 2018; Afonso et al., 2019), our LAB map exhibits regions of thick lithosphere in some subduction zones (e.g. west coast of South America, south Alaska and Japan). Many of these features are likely to represent subducting slabs rather than cratonic lithosphere. None of the giant ( $>10 \mathrm{Mt}$ of contained metal) sedimenthosted deposits is found in these settings, although some minor sedimentary copper deposits do occur, particularly in the Andes. These deposits may well represent distal components of porphyry coppers, but we have left them in our sedimentary copper dataset in line with pre-existing classification schemes. It is possible to manually exclude potential slab-related features from the analysis utilising the Slab2 model(Hayes et al., 2018; Supplementary Information). Doing so actually improves the results of statistical tests, with the chances of the relationship between sediment-hosted deposits and the edge of cratonic lithosphere being random reducing by a factor of three. This occurs because the continental area within $200 \mathrm{~km}$ of the $170 \mathrm{~km}$ LAB contour decreases from $34.3 \%$ to $31.0 \%$, while only marginally increasing the proportion of small outlier deposits. Nevertheless, we have deliberately retained these regions in the main manuscript in order to avoid introducing subjectivity and bias into our LAB maps, as opinions are likely to differ on which features to exclude. Furthermore, some studies argue that over long periods of time, thick lithosphere may actually be generated at subduction zones by thrust stacking (Cook et al., 1999). Thus, exclusion of these features is potentially unwarranted.

Test suites of random continental locations. In order to test the statistical significance of real deposit locations, a test suite of random points on a sphere have been generated by randomly selecting two variables, $a$ and $b$, in the range $0-1$ and converting into longitude, $\theta$, and latitude, $\phi$, using area-normalised relationships

$$
\begin{gathered}
\theta=360 \times a \\
\phi=\frac{180}{\pi} \times \arcsin (2 b-1)
\end{gathered}
$$

These are subsequently filtered to select only those points that lie onshore (Supplementary Information). For each location, the closest approach to the $170 \mathrm{~km}$ lithospheric thickness contour is calculated and the resulting distances are plotted in a cumulative distribution function ( $\mathrm{CDF})$.

Kolmogorov-Smirnov statistical tests. We use the twosample Kolmogorov-Smirnov test to examine whether the difference between two cumulative distribution functions is significant, given their respective population sizes (Kolmogorov, 1933). The $\mathrm{D}$-value is the maximum magnitude of the difference between two CDFs at any point. The test calculates the probability that a D-value of this magnitude might accidentally occur, had the two
CDFs been randomly selected from the same underlying population. The probability, $P$, is approximated using

$$
P \approx \exp \left(\frac{-2 p q D^{2}}{p+q}\right)
$$

where $p$ and $q$ are the number of samples in each CDF and $D$ is the D-value expressed as a fraction between 0 and 1 . For each Kolmogorov-Smirnov test, a number of random points are generated that is equivalent to the number of real deposits of that type (109 for PbZn-CD, 147 for PbZn-MVT and 139 for sedimentary copper). Given the low sample size for some of the deposit classes, the distribution of this random set can vary somewhat from the true average distribution of random continental locations. We therefore draw a test set in this manner 100 times and report the Kolmogorov-Smirnov statistics associated with each separate test within a histogram. For PbZn-CD deposits, the $\mathrm{D}$-value between the real non-weighted, regionally enhanced CDF and each random CDF is individually calculated, yielding a mean and standard deviation of $D=0.36 \pm 0.05$, with extremes of $0.26-0.46$. For the combined sediment-hosted deposits in Figure 3, the equivalent values are $D=0.27 \pm 0.02$ with extremes of $0.22-0.32$. A D-value of 0.27 for the 395 combined sedimentary-hosted deposits suggests that the probability this CDF is drawn from randomly distributed continental points is less than 1 in $10^{12}$ (Supplementary Information).

Thermal modelling of lithospheric rifting. Rifting of continental lithosphere causes subsidence of the surface to form a basin that progressively infills with sediments. An initial syn-rift subsidence phase occurs during lateral extension and vertical thinning of the crust and lithospheric mantle, which is contemporaneous with normal faulting. Following cessation of extension, faulting stops and post-rift thermal subsidence occurs as hot, upwelled asthenospheric mantle conductively cools back to an equilibrium lithospheric thickness (McKenzie, 1978). To predict the subsidence and basal heat flow of the basin, we model the 1-dimensional thermal evolution of the lithosphere during rifting using a finite difference scheme. Following McKenzie (1978), we assume thinning occurs by pure shear and that vertical heat transfer dominates.

For each rift scenario, we select an initial lithospheric template. For regular continental lithosphere, the crustal thickness is set to $30 \mathrm{~km}$ and the total lithospheric thickness to $140 \mathrm{~km}$, which matches results from plate cooling models of oceanic lithosphere (Richards et al., 2018) and places the $1175^{\circ} \mathrm{C}$ isotherm at $\sim 120 \mathrm{~km}$. Radiogenic heat production in the mantle is set to zero, whilst the crustal value is tuned to $1.0 \mu \mathrm{W} \mathrm{m} \mathrm{m}^{-3}$ such that the steady state geotherm yields a surface heat flow of $\sim 63 \mathrm{~mW} \mathrm{~m}^{-2}$, which is the average for Phanerozoic continental lithosphere ( $\mathrm{Lu}-$ cazeau, 2019) For cratonic lithosphere, we assume an initial crustal thickness of $50 \mathrm{~km}$, lithospheric thickness of $280 \mathrm{~km}\left(1175^{\circ} \mathrm{C}\right.$ isotherm at $\sim 240 \mathrm{~km}$ ), and crustal radiogenic heat production of $0.57 \mu \mathrm{W} \mathrm{m}{ }^{-3}$, which yields an initial surface heat flux consistent with the average of $\sim 48 \mathrm{~mW} \mathrm{~m}^{-2}$ for Archean and cratonic areas (Lucazeau, 2019) Based on the typically low paleowater depth of sediments found in proximal portions of these basins and the high supply of clastic material from adjacent cratons, we assume the basin is constantly filled by sediments. We subsequently predict the temperature of the sediment pile using the basal heat flux and a constant sediment conductivity of $2.5 \mathrm{~W} \mathrm{~m}^{-1} \mathrm{~K}^{-1}$, assuming a steady state conductive geotherm and negligible internal heat generation. Details of the finite difference scheme, thermal parameterisations, and individual model runs are given in the Supplementary Information.

\section{References}

Afonso, J. C., J. Fullea, W. L. Griffin, Y. Yang, A. G. Jones, J. A. Connolly, \& S. Y. Reilly (2013a). 3-D multiobservable probabilistic inversion for the compositional and thermal structure of the lithosphere and upper mantle. I: A priori petrological information and geophysical observables. Journal of Geophysical Research: Solid Earth, 118, 2586-2617.

Afonso, J. C., J. Fullea, Y. Yang, J. A. Connolly, \& A. G. Jones (2013b). 3-D multi-observable probabilistic inversion for the compositional and thermal structure of the lithosphere and upper mantle. II: General methodology and resolution analysis. Journal of Geophysical Research: Solid Earth, 118, 1650-1676.

Afonso, J. C., N. Rawlinson, Y. Yang, D. L. Schutt, A. G. Jones, J. Fullea, \& W. L. Griffin (2016). 3-D multiobservable probabilistic inversion for the compositional and thermal structure of the lithosphere and upper mantle: III. Thermochemical tomography in the Western- 
Central U.S. Journal of Geophysical Research: Solid Earth, 121, 7337-7370.

Afonso, J. C., F. Salajegheh, W. Szwillus, J. Ebbing, \& C. Gaina (2019). A global reference model of the lithosphere and upper mantle from joint inversion and analysis of multiple data sets. Geophysical Journal International, 217, 1602-1628.

Alghamdi, A. H., A. R. Aitken, \& M. C. Dentith (2018). The deep crustal structure of the Warakurna LIP, and insights on Proterozoic LIP processes and mineralisation. Gondwana Research, 56, 1-11.

Ali, S. H., D. Giurco, N. Arndt, E. Nickless, et al. (2017). Mineral supply for sustainable development requires resource governance. Nature, 543 (7645), 367-372.

Allen, P. A. \& J. J. Armitage (2012). Cratonic basins. In: Tectonics of Sedimentary Basins: Recent Advances (edited by C. Busby \& A. Azor), chap. 30, pp. 602-620. Blackwell Publishing Ltd, 1 edn.

An, M. \& Y. Shi (2006). Lithospheric thickness of the Chinese continent. Physics of the Earth and Planetary Interiors, 159, 257-266.

Appold, M. S., T. J. Numelin, T. J. Shepherd, \& S. R. Chenery (2004) Limits on the metal content of fluid inclusions in gangue minerals from the Viburnum Trend, southeast Missouri, determined by laser ablation ICP-MS. Economic Geology, 99, 185-198.

Arndt, N. T., C. M. Lesher, \& G. K. Czamanske (2005). Mantlederived magmas and magmatic Ni-Cu-(PGE) deposits. Economic Geology 100th Anniversary Volume, pp. 5-24.

Azadi, M., S. A. Northey, S. H. Ali, \& M. Edraki (2020). Transparency on greenhouse gas emissions from mining to enable climate change mitigation. Nature Geoscience, 13, 100-104.

Begg, G. C., J. A. M. Hronsky, N. T. Arndt, W. L. Griffin, S. Y O'Reilly, \& N. Hayward (2010). Lithospheric, cratonic, and geodynamic setting of Ni-Cu-PGE sulfide deposits. Economic Geology, 105, 1057-1070.

Bierlein, F. P., D. I. Groves, R. J. Goldfarb, \& B. Dubé (2006). Lithospheric controls on the formation of provinces hosting giant orogenic gold deposits. Mineralium Deposita, 40, 874-886.

Biggs, J., E. Nissen, T. Craig, J. Jackson, \& D. P. Robinson (2010). Breaking up the hanging wall of a rift-border fault: The 2009 Karonga earthquakes, Malawi. Geophysical Research Letters, 37 (L11305).

Butterworth, N., D. Steinberg, R. D. Müller, S. Williams, A. S. Merdith, \& S. Hardy (2016). Tectonic environments of South American porphyry copper magmatism through time revealed by spatiotemporal data mining. Tectonics, 35, 2847-2862.

Cammarano, F., S. Goes, P. Vacher, \& D. Giardini (2003). Inferring upper-mantle temperatures from seismic velocities. Physics of the Earth and Planetary Interiors, 138, 197-222.

Cammarano, F. \& M. Guerri (2017). Global thermal models of the lithosphere. Geophysical Journal International, 210, 56-72.

Cammarano, F., B. Romanowicz, L. Stixrude, C. Lithgow-Bertelloni, $\&$ W. Xu (2009). Inferring the thermochemical structure of the upper mantle from seismic data. Geophysical Journal International, $179,1169-1185$

Celli, N. L., S. Lebedev, A. J. Schaeffer, \& C. Gaina (2020a). African cratonic lithosphere carved by mantle plumes. Nature Communications, 11 (92).

Celli, N. L., S. Lebedev, A. J. Schaeffer, M. Ravenna, \& C. Gaina (2020b). The upper mantle beneath the South Atlantic Ocean, South America and Africa from waveform tomography with massive data sets. Geophysical Journal International, 221, 178-204

Connolly, J. A. (2009). The geodynamic equation of state: What and how. Geochemistry, Geophysics, Geosystems, 10 (Q10014).

Cook, F. A., A. J. Van Der Velden, K. W. Hall, \& B. J. Roberts (1999) Frozen subduction in Canada's Northwest Territories: Lithoprob deep lithospheric reflection profiling of the western Canadian Shield. Tectonics, 18 (1), 1-24.

Cooke, D. R., S. W. Bull, R. R. Large, \& P. J. McGoldrick (2000). The importance of oxidized brines for the formation of Australian Proterozoic stratiform sediment-hosted $\mathrm{Pb}-\mathrm{Zn}$ (sedex) deposits. Economic Geology, 95, 1-18.

Cottaar, S., T. Heister, I. Rose, \& C. Unterborn (2014). BurnMan: A lower mantle mineral physics toolkit. Geochemistry, Geophysics, Geosystems, 15, 1164-1179.

Cox, D. P., D. A. Lindsey, D. A. Singer, B. C. Moring, \& M. F. Diggles (2007). Sediment-hosted copper deposits of the world: Deposit models and database. U.S. Geological Survey Open-File Report 03-107.

Currie, C. A. \& J. van Wijk (2016). How craton margins are preserved Insights from geodynamic models. Journal of Geodynamics, 100 $144-158$.

Curtis, S. \& S. Thiel (2019). Identifying lithospheric boundaries using magnetotellurics and Nd isotope geochemistry: An example from the Gawler Craton, Australia. Precambrian Research, 320, 403423.

Dalton, C. A., G. Ekström, \& A. M. Dziewonski (2009). Global seismological shear velocity and attenuation: A comparison with experimental observations. Earth and Planetary Science Letters, 284 $65-75$.

Dalton, C. A., C. H. Langmuir, \& A. Gale (2014). Geophysical and geochemical evidence for deep temperature variations beneath midocean ridges. Science, 344, 80-83.

Dannberg, J., Z. Eilon, U. Faul, R. Gassmöller, P. Moulik, \& R. Myhill (2017). The importance of grain size to mantle dynamics and seismological observations. Geochemistry, Geophysics, Geosystems, $18,3034-3061$

Davey, J. (2019). Anomalous metal enrichment of basin brines in the Zambian Copperbelt: A comparison of fluid chemistry in con trasting sediment-hosted copper systems. Ph.D. thesis, University of Southampton.

Davies, D. R. \& N. Rawlinson (2014). On the origin of recent intraplate volcanism in Australia. Geology, 42 (12), 1031-1034.

Debayle, E., F. Dubuffet, \& S. Durand (2016). An automatically updated S-wave model of the upper mantle and the depth extent of azimuthal anisotropy. Geophysical Research Letters, 43, 674-682.

Dentith, M., H. Yuan, S. Johnson, R. Murdie, \& P. Piña-Varas (2018) Application of deep-penetrating geophysical methods to mineral exploration: Examples from Western Australia. Geophysics, 83 (3), WC29-WC41.

Dominish, E., S. Teske, \& N. Florin (2019). Responsible minerals sourcing for renewable energy. Tech. rep., Institute for Sustainable Futures, University of Technology Sydney.

Faul, U. H. \& I. Jackson (2005). The seismological signature of temperature and grain size variations in the upper mantle. Earth and Planetary Science Letters, 234, 119-134.

Faul, U. H. \& I. Jackson (2015). Transient creep and strain energy dissipation: An experimental perspective. Annual Review of Earth and Planetary Sciences, 43, 541-569.

Fishwick, S., M. Heintz, B. L. N. Kennett, A. M. Reading, \& K. Yoshizawa (2008). Steps in lithospheric thickness within eastern Australia, evidence from surface wave tomography. Tectonics, 27 (4009).

Fishwick, S. \& N. Rawlinson (2012). 3-D structure of the Australian lithosphere from evolving seismic datasets. Australian Journal of Earth Sciences, 59, 809-826.

Franklin, J. M., H. L. Gibson, I. R. Jonasson, \& A. G. Galley (2005) Volcanogenic massive sulfide deposits. Economic Geology 100th Anniversary Volume, pp. 523-560.

Fusswinkel, T., T. Wagner, M. Wälle, T. Wenzel, C. A. Heinrich, \& G. Markl (2013). Fluid mixing forms basement-hosted Pb-Zn deposits: Insight from metal and halogen geochemistry of individual fluid inclusions. Geology, 41, 679-682.

Fusswinkel, T., T. Wagner, T. Wenzel, M. Wälle, \& J. Lorenz (2014) Red bed and basement sourced fluids recorded in hydrothermal MnFe-As veins, Sailauf (Germany): A LA-ICPMS fluid inclusion study. Chemical Geology, 363, 22-39.

Gasparik, T. (1984). Two-pyroxene thermobarometry with new experimental data in the system $\mathrm{CaO}-\mathrm{MgO}-\mathrm{Al}_{2} \mathrm{O}_{3}-\mathrm{SiO}_{2}$. Contributions to Mineralogy and Petrology, 87, 87-97.

Geoscience Australia (2018). Geophysical Archive Data Delivery System (GADDS). URL geoscience.gov.au/gadds.

Gibson, G. M., A. J. Meixner, I. W. Withnall, R. J. Korsch, et al. (2016). Basin architecture and evolution in the Mount Isa mineral province, northern Australia: Constraints from deep seismic reflection profiling and implications for ore genesis. Ore Geology Reviews, $76,414-441$

Goes, S., J. Armitage, N. Harmon, H. Smith, \& R. Huismans (2012). Low seismic velocities below mid-ocean ridges: Attenuation versus melt retention. Journal of Geophysical Research, 117 (B12403).

Goes, S., R. Govers, \& P. Vacher (2000). Shallow mantle temperatures under Europe from $\mathrm{P}$ and $\mathrm{S}$ wave tomography. Journal of Geophysical Research, 105 (B5), 11,153-11,169.

Griffin, W. L., G. C. Begg, \& S. Y. O'Reilly (2013). Continental-root control on the genesis of magmatic ore deposits. Nature Geoscience, 6 (11), 905-910.

Hayes, G. P., G. L. Moore, D. E. Portner, M. Hearne, H. Flamme M. Furtney, \& G. M. Smoczyk (2018). Slab2, a comprehensive subduction zone geometry model. Science, 362, 58-61.

Heinson, G., Y. Didana, P. Soeffky, S. Thiel, \& T. Wise (2018). The crustal geophysical signature of a world-class magmatic mineral system. Scientific Reports, 8 (10608).

Hitzman, M. W., R. Kirkham, D. Broughton, J. Thorson, \& D. Selley (2005). The sediment-hosted stratiform Copper ore system. Economic Geology 100th Anniversary Volume, pp. 609-642. 
Hitzman, M. W., D. Selley, \& S. Bull (2010). Formation of sedimentary rock-hosted stratiform copper deposits through Earth history. Economic Geology, 105 (3), 627-639.

Ho, T., K. Priestley, \& E. Debayle (2016). A global horizontal shear velocity model of the upper mantle from multimode love wave measurements. Geophysical Journal International, 207, 542-561.

Hoatson, D. M., S. Jaireth, \& A. L. Jaques (2006). Nickel sulfide deposits in Australia: Characteristics, resources, and potential. Ore Geology Reviews, 29, 177-241.

Hobbs, B. E., A. Ord, N. J. Archibald, J. L. Walshe, Y. Zhang, M. Brown, \& C. Zhao (2000). Geodynamic modelling as an exploration tool. In: Australasian Institute of Mining and Metallurgy Publication Series, pp. 34-49. Sydney.

Holland, T. J. \& R. Powell (2011). An improved and extended internally consistent thermodynamic dataset for phases of petrological interest, involving a new equation of state for solids. Journal of Metamorphic Geology, 29, 333-383.

Huston, D. L., D. C. Champion, B. Ware, G. Carr, R. Maas, \& S. Tessalina (2019). Preliminary national-scale lead isotope maps of Australia. Geoscience Australia Record, 01 (127263).

Huston, D. L., T. P. Mernagh, S. G. Hagemann, M. P. Doublier, et al. (2016). Tectono-metallogenic systems - The place of mineral systems within tectonic evolution, with an emphasis on Australian examples. Ore Geology Reviews, 76, 168-210.

Huston, D. L., S. Pehrsson, B. M. Eglington, \& K. Zaw (2010). The geology and metallogeny of volcanic-hosted massive sulfide deposits: Variations through geologic time and with tectonic setting. Economic Geology, 105 (3), 571-591.

IRENA (2019). Global energy transformation: A roadmap to 2050. Abu Dhabi.

Jackson, I. \& U. H. Faul (2010). Grainsize-sensitive viscoelastic relaxation in olivine: Towards a robust laboratory-based model for seismological application. Physics of the Earth and Planetary Interiors, 183, 151-163.

Jackson, I., J. D. Fitz Gerald, U. H. Faul, \& B. H. Tan (2002). Grainsize-sensitive seismic wave attenuation in polycrystalline olivine. Journal of Geophysical Research, 107 (B12), 2360.

Jaupart, C., S. Labrosse, \& J. C. Mareschal (2007). Temperatures, heat and energy in the mantle of the Earth. Treatise on Geophysics, 7, $253-303$.

Jordan, T. H. (1978). Composition and development of the continental tectosphere. Nature, $274,544-548$.

Karato, S. (1993). Importance of anelasticity in the interpretation of seismic tomography. Geophysical Research Letters, 20 (15), 1623 1626 .

Katz, R. F., M. Spiegelman, \& C. H. Langmuir (2003). A new parameterization of hydrous mantle melting. Geochemistry, Geophysics, Geosystems, 4 (1073).

Kennett, B. L. N., A. Fichtner, S. Fishwick, \& K. Yoshizawa (2013). Australian seismological reference model (AuSREM): Mantle component. Geophysical Journal International, 192, 871-887.

Kennett, B. L. N., M. Salmon, E. Saygin, \& A. W. Group (2011). AusMoho: The variation of Moho depth in Australia. Geophysical Journal International, 187 (2), 946-958.

Kennett, B. L. N., E. Saygin, T. Fomin, \& R. Blewett (2016). Deep crustal seismic reflection profiling: Australia 1978-2015. ANU Press and Commonwealth of Australia (Geoscience Australia), Canberra.

Klemme, S. (2004). The influence of $\mathrm{Cr}$ on the garnet-spinel transition in the Earth's mantle: Experiments in the system $\mathrm{MgO}-\mathrm{Cr}_{2} \mathrm{O}_{3}-$ $\mathrm{SiO}_{2}$ and thermodynamic modelling. Lithos, 77 (1-4 SPEC. ISS.) 639-646.

Klöcking, M., N. J. White, J. Maclennan, D. McKenzie, \& J. G. Fitton (2018). Quantitative relationships between basalt geochemistry, shear wave velocity, and asthenospheric temperature beneath western North America. Geochemistry, Geophysics, Geosystems, 19, 3376-3404.

Kolmogorov, A. N. (1933). Sulla determinazione empirica di una legge di distribuzione. Giornale dell'Istituto Italiano degli Attuari, 4, $83-91$

Kostova, B., T. Pettke, T. Driesner, P. Petrov, \& C. A. Heinrich (2004) LA-ICP-MS study of fluid inclusions in quartz from the Yuzhna Petrovitsa deposit, Madan ore field, Bulgaria. Schweizerische Mineralogische und Petrographische Mitteilungen, 84, 25-36.

Kotzeva, B. G., M. Guillong, E. Stefanova, \& N. B. Piperov (2011). LAICP-MS analysis of single fluid inclusions in a quartz crystal (Madan ore district, Bulgaria). Journal of Geochemical Exploration, 108, $163-175$.

Lau, H. C., J. X. Mitrovica, J. Austermann, O. Crawford, D. Al-Attar, \& K. Latychev (2016). Inferences of mantle viscosity based on ice age data sets: Radial structure. Journal of Geophysical Research: Solid Earth, 121 (10), 6991-7012.

Leach, D. L., D. C. Bradley, D. L. Huston, S. A. Pisarevsky, R. D Taylor, \& S. J. Gardoll (2010). Sediment-hosted lead-zinc deposits in Earth history. Economic Geology, 105 (3), 593-625.

Lucazeau, F. (2019). Analysis and mapping of an updated terrestrial heat flow data set. Geochemistry, Geophysics, Geosystems, 20 4001-4024.

Manning, A. H. \& P. Emsbo (2018). Testing the potential role of brine reflux in the formation of sedimentary exhalative (sedex) ore deposits. Ore Geology Reviews, 102, 862-874.

Mather, K. A., D. G. Pearson, D. P. McKenzie, B. A. Kjarsgaard, \& K. Priestley (2011). Constraints on the depth and thermal history of cratonic lithosphere from peridotite xenoliths, xenocrysts and seismology. Lithos, 125, 729-742.

McCarthy, C., Y. Takei, \& T. Hiraga (2011). Experimental study of attenuation and dispersion over a broad frequency range: 2 . The universal scaling of polycrystalline materials. Journal of Geophysical Research, 116 (B09207).

McCuaig, T. C., S. Beresford, \& J. Hronsky (2010). Translating the mineral systems approach into an effective exploration targeting system. Ore Geology Reviews, 38, 128-138.

McCuaig, T. C. \& J. M. A. Hronsky (2014). The mineral system concept: The key to exploration targeting. In: Society of Economic Geologists Special Publication 18, pp. 153-175. Society of Economic Geologists.

McCuaig, T. C., S. Scarselli, T. O. Connor, S. Busuttil, \& N. Mccormack (2018). The power of a systems approach to mineral and petroleum exploration in sedimentary basins. In: SEG Special Publication 21, chap. 3, pp. 39-62. Society of Economic Geologists.

McKenzie, D. P. (1978). Some remarks on the development of sedimentary basins. Earth and Planetary Science Letters, 40, 25-32.

McKenzie, D. P., J. Jackson, \& K. Priestley (2005). Thermal structure of oceanic and continental lithosphere. Earth and Planetary Science Letters, 233, 337-349.

Menzies, M., Y. Xu, H. Zhang, \& W. Fan (2007). Integration of geology, geophysics and geochemistry: A key to understanding the North China Craton. Lithos, 96, 1-21.

Mudd, G. M., T. T. Werner, Z. H. Weng, M. Yellishetty, Y. Yuan S. R. B. McAlpine, R. Skirrow, \& K. Czarnota (2018). Critical minerals in Australia: A review of opportunities and research needs. Tech. rep., Geoscience Australia.

Nassar, N. T., T. E. Graedel, \& E. M. Harper (2015). By-product metals are technologically essential but have problematic supply. Science Advances, 1 (1400180).

Nickel, K. G. \& D. H. Green (1985). Empirical geothermobarometry for garnet peridotites and implications for the nature of the lithosphere, kimberlites and diamonds. Earth and Planetary Science Letters, 73, 158-170.

Nimis, P. \& H. Grütter (2010). Internally consistent geothermometers for garnet peridotites and pyroxenites. Contributions to Mineralogy and Petrology, 159, 411-427.

Nimis, P. \& W. R. Taylor (2000). Single clinopyroxene thermobarometry for garnet peridotites. Part I. Calibration and testing of a $\mathrm{Cr}$ in-Cpx barometer and an enstatite-in-Cpx thermometer. Contributions to Mineralogy and Petrology, 139, 541-554.

O'Reilly, S. Y., W. L. Griffin, \& N. J. Pearson (2017). Geodynamic and geophysical consequences of $\operatorname{stealth}(\mathrm{y})$ mantle metasomatism: Craton evolution and metallogeny. In: 11th International Kimberlite Conference, 4537.

Osako, M., E. Ito, \& A. Yoneda (2004). Simultaneous measurements of thermal conductivity and thermal diffusivity for garnet and olivine under high pressure. Physics of the Earth and Planetary Interiors, 143-144, 311-320.

Priestley, K., D. McKenzie, \& T. Ho (2018). A lithosphereasthenosphere boundary - A global model derived from multimode surface-wave tomography and petrology. In: Geophysical Monograph 239, Lithospheric Discontinuities (edited by H. Yuan \& B. Romanowicz), chap. 6, pp. 111-123. John Wiley and Sons, Washington D.C.

Priestley, K. \& D. P. McKenzie (2006). The thermal structure of the lithosphere from shear wave velocities. Earth and Planetary Science Letters, 244, 285-301.

Priestley, K. \& D. P. McKenzie (2013). The relationship between shear wave velocity, temperature, attenuation and viscosity in the shallow part of the mantle. Earth and Planetary Science Letters, 381, 7891.

Raymond, O. (2018). Australian Geological Provinces 2018.01 edition. Geoscience Australia Dataset, eCat Id: 116823. URL pid.geoscience.gov.au/dataset/ga/116823. 
Regis, D., P. Acosta-Gongora, W. J. Davis, B. Knox, S. J. Pehrsson, E. Martel, \& L. Hulbert (2017). Evidence for Neoarchean Ni-Cubearing mafic intrusions along a major lithospheric structure: A case study from the south Rae craton (Canada). Precambrian Research, $302,312-339$

Richards, F. D., M. J. Hoggard, L. R. Cowton, \& N. J. White (2018). Reassessing the thermal structure of oceanic lithosphere with revised global inventories of basement depths and heat flow measurements. Journal of Geophysical Research: Solid Earth, 123, 91369161.

Richards, F. D., M. J. Hoggard, N. J. White, \& S. Ghelichkhan (2020). Quantifying the relationship between short-wavelength dynamic topography and thermomechanical structure of the upper mantle using calibrated parameterization of anelasticity. Journal of Geophysical Research: Solid Earth

Rosenbaum, G., D. Giles, M. Saxon, P. G. Betts, R. F. Weinberg, \& C. Duboz (2005). Subduction of the Nazca Ridge and the Inca Plateau: Insights into the formation of ore deposits in Peru. Earth and Planetary Science Letters, 239, 18-32.

Schaeffer, A. J. \& S. Lebedev (2013). Global shear speed structure of the upper mantle and transition zone. Geophysical Journal International, 194, 417-449.

Schaeffer, A. J. \& S. Lebedev (2014). Imaging the North American continent using waveform inversion of global and USArray data. Earth and Planetary Science Letters, 402, 26-41.

Schlegel, T. U., T. Wagner, M. Wälle, \& C. A. Heinrich (2018). Hematite breccia-hosted iron oxide copper-gold deposits require magmatic fluid components exposed to atmospheric oxidation: Evidence from Prominent Hill, Gawler Craton, South Australia. Economic Geology, 113, 597-644.

Schodde, R. (2017). Long term trends in global exploration - Are we finding enough metal? In: 11th Fennoscandian Exploration and Mining Conference, 31st October 2017. Levi, Finland. URL minexconsulting.com/publications/oct2017b.

Schutt, D. L. \& C. E. Lesher (2006). Effects of melt depletion on the density and seismic velocity of garnet and spinel lherzolite. Journal of Geophysical Research, 111 (B05401).

Sexton, J. (2011). Australian mineral occurrences collection. Geoscience Australia Dataset, eCat Id 73131. URL pid.geoscience. gov.au/dataset/ga/73131.

Shorttle, O., J. Maclennan, \& S. Lambart (2014). Quantifying lithological variability in the mantle. Earth and Planetary Science Letters, $395,24-40$.

Sillitoe, R. H. (2010). Porphyry copper systems. Economic Geology, $105,3-41$.

Skirrow, R. G., J. Murr, A. Schofield, D. L. Huston, et al. (2019). Mapping iron oxide $\mathrm{Cu}-\mathrm{Au}$ (IOCG) mineral potential in Australia using a knowledge-driven mineral systems-based approach. Ore Geology Reviews, 113 (103011).

Skirrow, R. G., S. E. van der Wielen, D. C. Champion, K. Czarnota, \& S. Thiel (2018). Lithospheric architecture and mantle metasomatism linked to Iron Oxide $\mathrm{Cu}-\mathrm{Au}$ ore formation: Multidisciplinary evidence from the Olympic Dam region, South Australia. Geochemistry, Geophysics, Geosystems, 19 (8), 2673-2705.

Sloan, R. A., J. A. Jackson, D. P. McKenzie, \& K. Priestley (2011). Earthquake depth distributions in central Asia, and their relations with lithosphere thickness, shortening and extension. Geophysical Journal International, 185 (1), 1-29.

Sovacool, B. B. K., S. H. Ali, M. Bazilian, B. Radley, B. Nemery, J. Okatz, \& D. Mulvaney (2020). Sustainable minerals and metals for a low-carbon future. Science, 367 (6473), 30-33.

Steinberger, B. \& T. W. Becker (2018). A comparison of lithospheric thickness models. Tectonophysics, 746, 325-338.

Stixrude, L. \& C. Lithgow-Bertelloni (2005). Thermodynamics of mantle minerals - I. Physical properties. Geophysical Journal International, 162, 610-632.

Stixrude, L. \& C. Lithgow-Bertelloni (2011). Thermodynamics of mantle minerals - II. Phase equilibria. Geophysical Journal International, 184, 1180-1213.

Sundberg, M. \& R. F. Cooper (2010). A composite viscoelastic model for incorporating grain boundary sliding and transient diffusion creep: Correlating creep and attenuation responses for materials with a fine grain size. Philosophical Magazine, 90 (20), 2817-2840.

Takei, Y. (2017). Effects of partial melting on seismic velocity and attenuation: A new insight from experiments. Annual Review of Earth and Planetary Sciences, 45, 447-470.

Takei, Y., F. Karasawa, \& H. Yamauchi (2014). Temperature, grain size, and chemical controls on polycrystal anelasticity over a broad frequency range extending into the seismic range. Journal of Geophysical Research: Solid Earth, 119, 5414-5443.

Taylor, R. D., D. L. Leach, D. C. Bradley, \& S. A. Pisarevsky (2009) Compilation of mineral resource data for Mississippi Valley-type and clastic-dominated sediment-hosted lead-zinc deposits. U.S. Geological Survey Open-File Report, 1297.

Taylor, W. R. (1998). An experimental test of some geothermometer and geobarometer formulations for upper mantle peridotites with application to the thermobarometry of fertile lherzolite and garnet websterite. Neues Jahrbuch für Mineralogie - Abhandlungen, 172 (2-3), 381-408.

The Uncover Group (2012). Searching the deep Earth: A vision for exploration geoscience in Australia. Tech. rep., Australian Academy of Science.

Wilkinson, J. J., C. E. Everett, A. J. Boyce, S. A. Gleeson, \& D. M. Rye (2005). Intracratonic crustal seawater circulation and the genesis of subseafloor zinc-lead mineralization in the Irish orefield. Geology, $33,805-808$.

Wilkinson, J. J., B. Stoffell, C. C. Wilkinson, T. E. Jeffries, \& M. S. Appold (2009). Anomalously metal-rich fluids form hydrothermal ore deposits. Science, 323, 764-767.

Wyborn, L. A. I., C. A. Heinrich, \& A. L. Jaques (1994). Australian Proterozoic mineral systems: Essential ingredients and mappable criteria. Australian Institute of Mining and Metallurgy Annual Conference, pp. 109-115.

Yamauchi, H. \& Y. Takei (2016). Polycrystal anelasticity at nearsolidus temperatures. Journal of Geophysical Research: Solid Earth, 121 (11), 7790-7820.

Yoshizawa, K. (2014). Radially anisotropic 3-D shear wave structure of the Australian lithosphere and asthenosphere from multi-mode surface waves. Physics of the Earth and Planetary Interiors, 235, $33-48$.

Corresponding authors: Correspondence should be addressed to M. Hoggard (mark_hoggard@fas.harvard.edu) and K. Czarnota (karol.czarnota@ga.gov.au).

Acknowledgments: This work is a contribution to the Australian Government's Exploring for the Future program. We are grateful to B. Steinberger, N. Rawlinson, K. Yoshizawa and B. Kennett for sharing lithospheric thickness maps. We thank J.C. Afonso, E. Bastrakov, G. Begg, R. Blewett, A. Bufe, D. Champion, R. Davies, B. Delbridge, A. Dickinson, M. Doublier, R. Fu, S. Goes, A. Gorbatov, B. Hodgin, B. Holtzman, C. Jiang, J. Kingslake, S. Liu, Z. Ma, T. Mackey, P. McFadden, D. McKenzie, D. Müller, P. Nimis, C. O'Malley, E. Powell, K. Priestley, R. Remm, T. Schlegel, D. Schutt, O. Shorttle, R. Skirrow, E. Smith, S. Stephenson, Y. Takei, C.-Y. Tien, N. White, \& J. Winterbourne for their assistance and discussions. S. Lebedev provided helpful feedback on an early draft of this work. $\mathrm{MH}$ acknowledges support from the National Aeronautics and Space Administration (grant NNX17AE17G) and the Donors of the American Chemical Society Petroleum Research Fund (59062-DNI8). FR acknowledges support from the Schmidt Science Fellows program, in partnership with the Rhodes Trust. KC and DH publish with permission of the CEO of Geoscience Australia. Geoscience Australia eCat ID 132624. MH is indebted to J. Austermann \& J. Mitrovica for personal guidance and affording him the freedom to pursue this research.

Author contributions: This relationship was discovered by KC, and the study was conceived and designed by $\mathrm{KC}$ and $\mathrm{MH}$. DH, $\mathrm{KC}, \mathrm{FR}$ and $\mathrm{MH}$ compiled deposit databases. LJ collated Australian xenolith data. Thermobarometry and paleogeotherm modelling was done by LJ, FR and MH. FR and MH developed shearwave to temperature conversion scheme. FR calibrated anelasticity parameterisations. MH generated lithospheric thickness maps, performed statistical tests, made figures and compiled supplementary information. SG, $\mathrm{MH}$ and $\mathrm{KC}$ investigated implications of rifting continental lithosphere. The paper was written by $\mathrm{KC}$ and $\mathrm{MH}$, with guidance from all authors.

Data availability: All data, including digital versions of lithospheric thickness maps and deposit databases, are available in the manuscript or the Supplementary Information, and on the OSF database (https://osf.io/twksd).

Competing interests: The authors declare no competing financial interests. 


\title{
Supplementary Information for "Global distribution of sediment-hosted metals controlled by craton edge stability"
}

\author{
Mark J. Hoggard, ${ }^{*, 1,2}$ Karol Czarnota, ${ }^{*, 3,4}$ Fred D. Richards, ${ }^{1,5}$ \\ David L. Huston, ${ }^{3}$ A. Lynton Jaques, ${ }^{4} \&$ Sia Ghelichkhan ${ }^{4}$ \\ *mark_hoggard@fas.harvard.edu; karol.czarnota@ga.gov.au
}

\begin{abstract}
1. Department of Earth and Planetary Sciences, Harvard University, Cambridge, USA.
2. Lamont-Doherty Earth Observatory, Columbia University, New York, USA.

3. Geoscience Australia, Canberra, Australia.

4. Research School of Earth Sciences, Australian National University, Canberra, Australia.

5. Department of Earth Science and Engineering, Imperial College London, UK.
\end{abstract}

\section{Contents}

1. Descriptive summary and comparison of selected seismic tomography models.

2. Outline of the parameterisation for anelasticity at seismic frequencies.

3. Compilation of fifteen Australian paleogeotherms obtained from xenolith thermobarometry.

4. Calibration and temperature conversion of seismic tomography models.

5. New and previously published global lithospheric thickness maps.

6. New and previously published Australian lithospheric thickness maps.

7. Summary of Kolmogorov-Smirnov statistical analyses.

8. Test of removing possible slab-related features on deposit statistics.

9. Finite difference scheme for modelling continental rifting and examples.

10. Continental maps of lithospheric thickness with known sediment-hosted deposits.

11. Compilations and statistical tests for each major class of base metal deposit.

\section{Additional Supporting Information (Files uploaded separately)}

1. Four global lithospheric thickness maps dervied from SL2013sv, 3D2015-07Sv, CAM2016, and SLNAAFSA in NetCDF, GeoTIFF, and CSV formats.

2. Three Australian lithospheric thickness maps derived from FR12, AuSREM, and Y14 in NetCDF, GeoTIFF, and CSV formats.

3. Database of deposit compilations in Excel spreadsheet.

4. Locations and mineral compositions for xenocryst/xenolith thermobarometry with optimal FITPLOT paleogeotherms in Excel spreadsheet. 


\section{Summary of selected seismic tomography models}

Our LAB maps are based on recent, high-resolution shear wave tomography models that are constructed from large quantities of surface wave data. For the global map, we use vertically polarized shear wave velocity from SL2013sv upper mantle-only model, which represents the isotropic component of their azimuthally anisotropic velocities (Schaeffer \& Lebedev, 2013). The model is constructed from a combination of body and surface waves, including fundamental and higher modes. Periods considered are 11-450 s, 750, 000 seismograms are included, and misfits are calculated between synthetics and the full waveform up to the $18^{\text {th }}$ overtone. Crucially, simultaneous inversion for the crustal model results in minimal smearing of slow crustal velocities down into the upper mantle, thereby allowing us to use more depth slices in our $V_{S}$ to temperature calibration. Checkerboard resolution tests indicate that features $\sim 600 \mathrm{~km}$ in diameter at lithospheric depths are generally well resolved. Finer features should be resolvable in regions with dense ray path coverage, such as North America, Europe and southeast Asia.

The SL2013sv model contains only 6 seismometers in Australia, so has limited resolution within this continent. Therefore, we also investigate three regional seismic tomography models to generate high resolution maps for the Australian continent. The main model used throughout this paper is the radially isotropic $V_{S}$ model FR12 of Fishwick
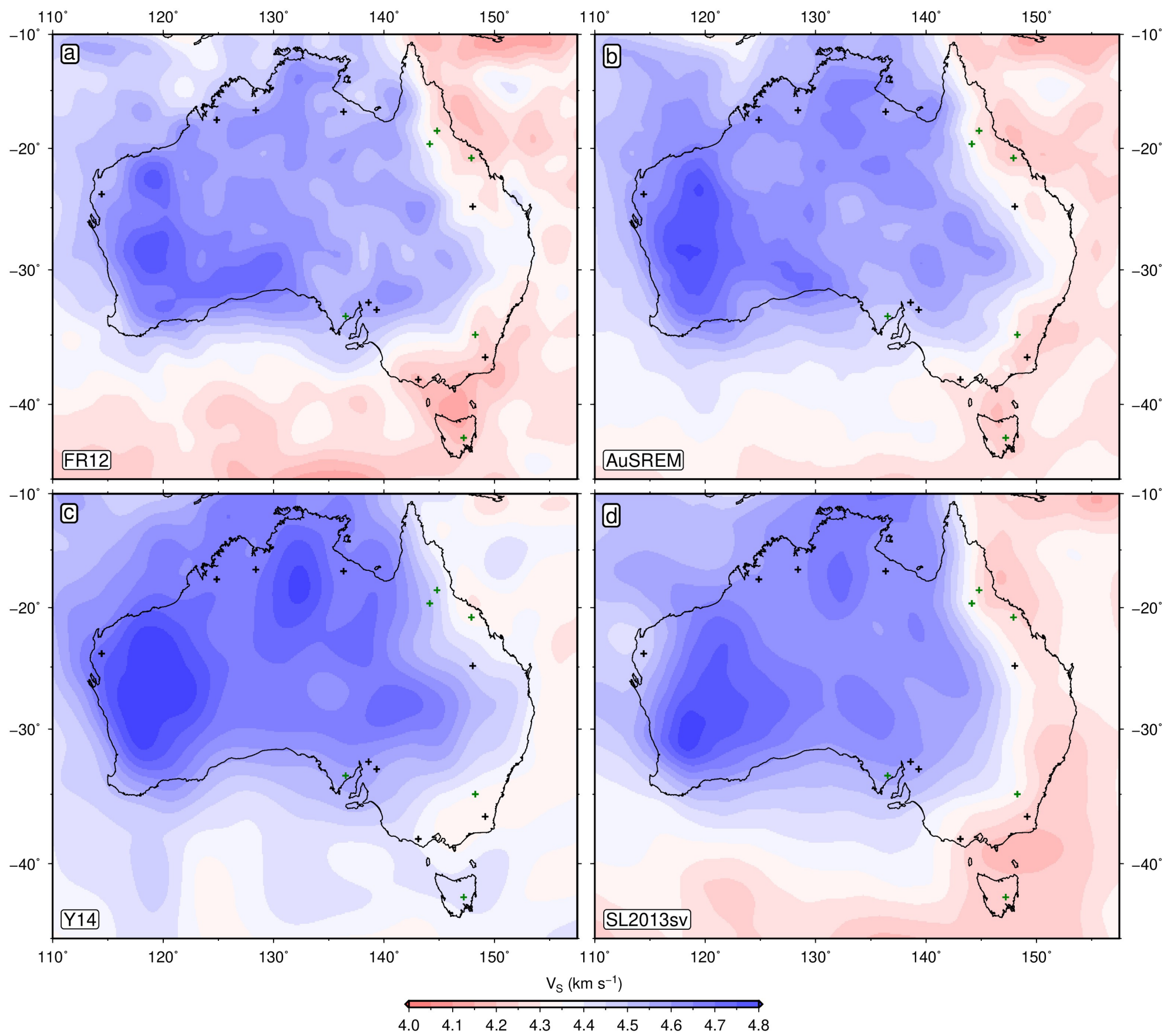

Figure S1: $100 \mathrm{~km}$ depth slice through Australian seismic tomography models. Black/green crosses = paleogeotherms used as constraints/tests in anelasticity calibration. (a) FR12 = regional isotropic $\mathrm{V}_{S}$ (Fishwick \& Rawlinson, 2012). (b) AuSREM = regional V $\mathrm{V}_{S V}$

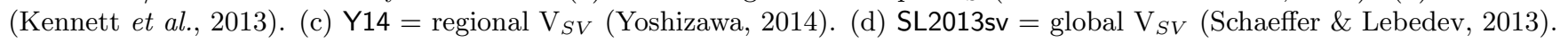



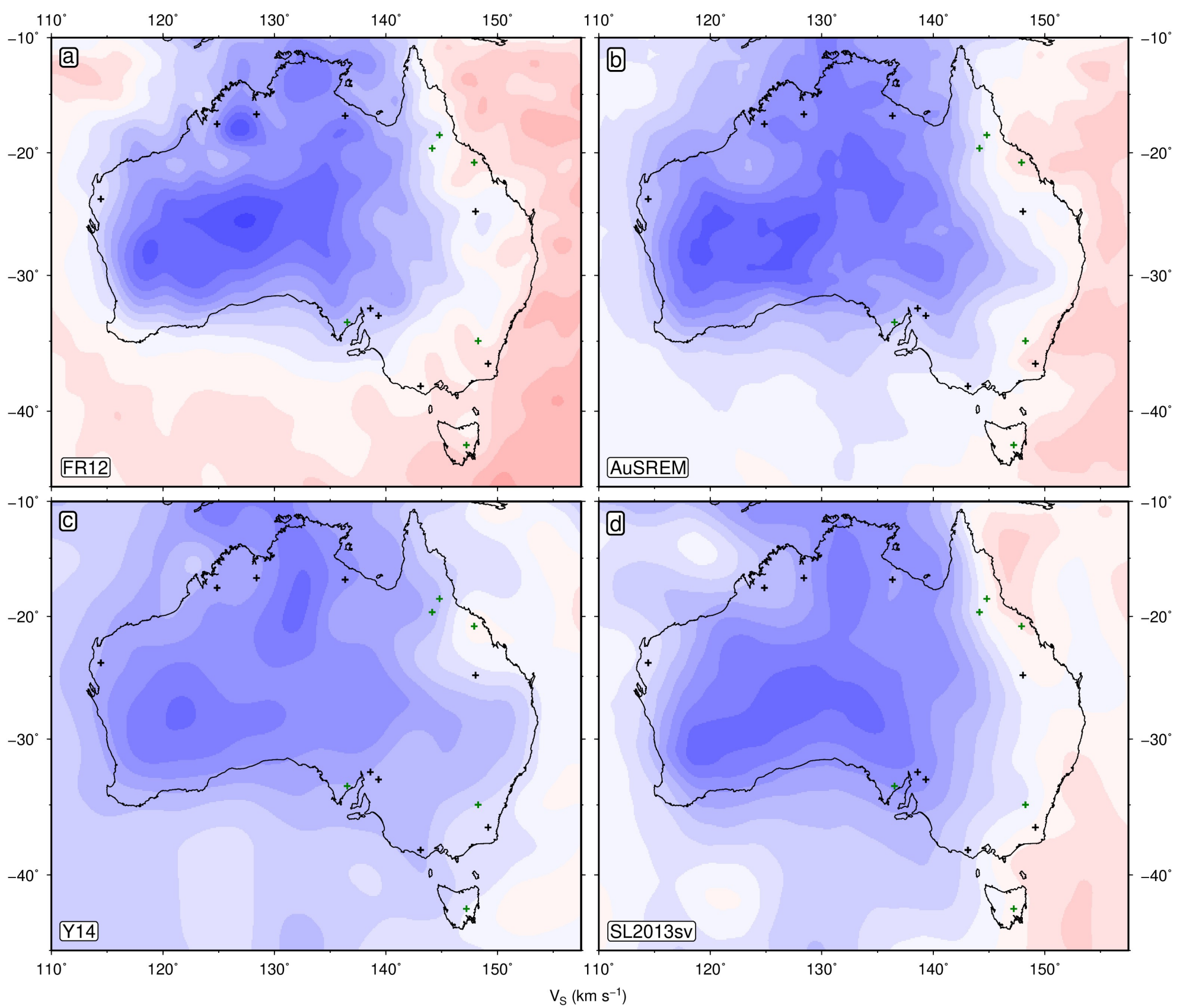

$-10^{\circ}$

$110^{\circ}$

$120^{\circ}$

$130^{\circ}$

$140^{\circ}$

$150^{\circ}$

$\mathrm{V}_{\mathrm{S}}\left(\mathrm{km} \mathrm{s}^{-1}\right)$

$\begin{array}{lllllllll}4.0 & 4.1 & 4.2 & 4.3 & 4.4 & 4.5 & 4.6 & 4.7 & 4.8\end{array}$

Figure S2: $175 \mathrm{~km}$ depth slice through Australian seismic tomography models. Black/green crosses = paleogeotherms used as constraints/tests in anelasticity calibration. (a) FR12 = regional isotropic $\mathrm{V}_{S}$ (Fishwick \& Rawlinson, 2012). (b) AuSREM = regional V $\mathrm{V}_{S}$

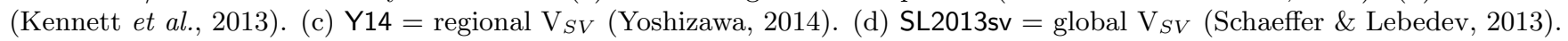

\& Rawlinson (2012), which is derived from Rayleigh wave travel times (Fishwick et al., 2008). Periods considered are 50$120 \mathrm{~s}$ and the fundamental and first four higher modes have been used where possible, leading to good sensitivity down to $\sim 250 \mathrm{~km}$ depths. It contains a greater number of source-receiver paths $(>13,000)$ compared to other Australian models. However, it uses an a priori crustal model that remains fixed throughout the inversion, resulting in noticeable smearing of crustal velocities into the upper mantle. Checkerboard tests indicate that features $\sim 300 \mathrm{~km}$ in diameter at lithospheric depths are well resolved.

The second regional model is AuSREM and is a hybrid model constructed by linear combination of several previous studies (Kennett et al., 2013). It combines FR12 with YK04 and AMSAN.19 (Yoshizawa \& Kennett, 2004; Fichtner et al., 2010). YK04 is a radially anisotropic Rayleigh wave model using $>8000$ ray paths for the fundamental mode and $\sim 2000$ for the first three higher modes, yielding a maximum period range of 40-150 s. It includes off-great circle and finite frequency effects, but also uses a fixed crustal model. AMSAN.19 is a radially anisotropic, 3D waveform, spectral element model that uses an inversion scheme based on the adjoint approach (Fichtner et al., 2009a,b). Periods considered are 30-200 s and a fixed crustal model is used. Due to the computationally intensive methodology, $\sim 3,000$ waveforms are used in this inversion.

The third and final regional model considered in this study is the radially anisotropic Y14 (Yoshizawa, 2014). It 

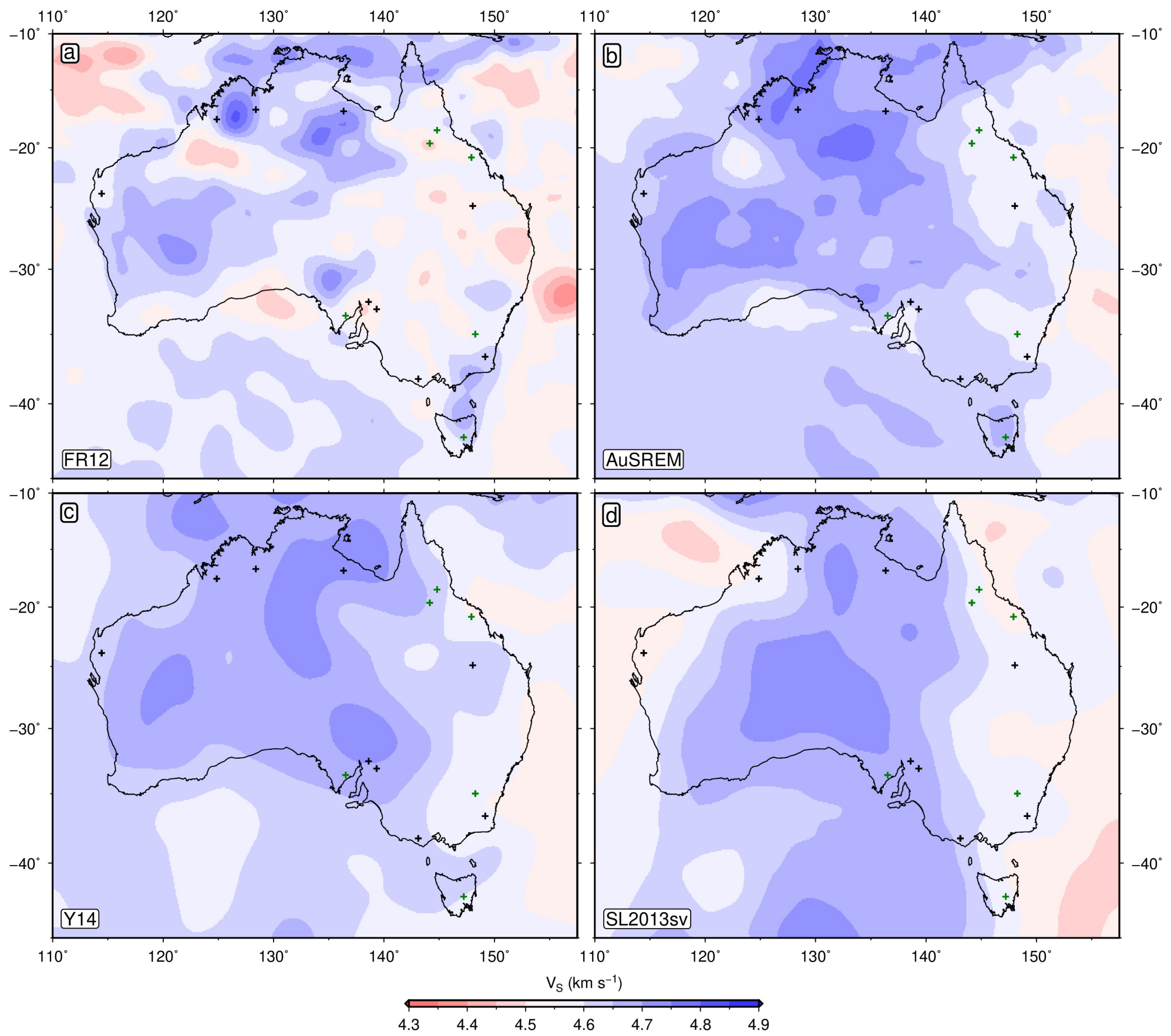

Figure S3: $250 \mathrm{~km}$ depth slice through Australian seismic tomography models. Black/green crosses = paleogeotherms used as constraints/tests in anelasticity calibration. (a) FR12 = regional isotropic $\mathrm{V}_{S}$ (Fishwick \& Rawlinson, 2012). (b) AuSREM = regional V $S V$

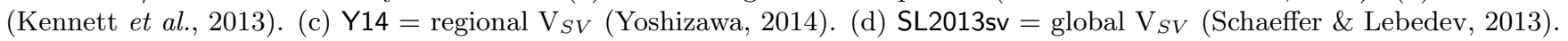

combines Rayleigh waves (8000 fundamental, $\sim 2500$ higher mode) and Love waves (approximately two-thirds as many) with periods $\sim 25-200$ s, corrected for local crustal structure using a fixed crustal model. It adopts the same three-step inversion procedure as YK04 (Yoshizawa \& Kennett, 2004). All three models are plotted alongside the global SL2013sv model in Figures S1, S2 and S3. At any given location within the continent, $V_{S}$ varies between models by $\sim 0.1 \mathrm{~km} \mathrm{~s}^{-1}$. 


\section{Parameterisation for anelasticity at seismic frequencies}

As introduced in the Methods section, we have adopted the parameterisation of Yamauchi \& Takei (2016) to convert shear wave velocity into temperature, which includes effects of anelasticity in pre-melt conditions (temperatures above $\sim 90 \%$ of melting temperature). $V_{S}$ is defined as

$$
V_{S}=\frac{1}{\sqrt{\rho J_{1}}}\left(\frac{1+\sqrt{1+\left(J_{2} / J_{1}\right)^{2}}}{2}\right)^{-\frac{1}{2}} \simeq \frac{1}{\sqrt{\rho J_{1}}}
$$

where $\rho$ is the density and $J_{1}$ and $J_{2}$ represent real and imaginary components of the complex compliance, $J^{*}$, which is a quantity describing the sinusoidal strain resulting from the application of a unit sinusoidal stress. $J_{1}$ represents the strain amplitude in phase with the driving stress, whilst the $J_{2}$ component is $\frac{\pi}{2}$ out of phase, resulting in dissipation. These terms contain a high temperature background absorption band and and an additional low temperature absorption peak, expressed as

$$
\begin{gathered}
J_{1}\left(\tau_{S}^{\prime}\right)=J_{U}\left[1+\frac{A_{B}\left[\tau_{S}^{\prime}\right]^{\alpha_{B}}}{\alpha_{B}}+\frac{\sqrt{2 \pi}}{2} A_{P} \sigma_{P}\left\{1-\operatorname{erf}\left(\frac{\ln \left[\tau_{P}^{\prime} / \tau_{S}^{\prime}\right]}{\sqrt{2} \sigma_{P}}\right)\right\}\right] \\
J_{2}\left(\tau_{S}^{\prime}\right)=J_{U} \frac{\pi}{2}\left[A_{B}\left[\tau_{S}^{\prime}\right]^{\alpha_{B}}+A_{P} \exp \left(-\frac{\ln ^{2}\left[\tau_{P}^{\prime} / \tau_{S}^{\prime}\right]}{2 \sigma_{P}^{2}}\right)\right]+J_{U} \tau_{S}^{\prime}
\end{gathered}
$$

where $J_{U}$ is the unrelaxed compliance and the third term on the right of Equation (3) represents viscous relaxation. $A_{B}$ $=0.664$ and $\alpha_{B}=0.38$ represent the amplitude and slope of the high temperature background stress relaxation, whilst $A_{P}$ and $\sigma_{P}$ represent the amplitude and width of the relaxation peak superimposed on the background trend and are given by

$$
A_{P}\left(T^{\prime}\right)= \begin{cases}0.01 & \text { for } T^{\prime}<0.91 \\ 0.01+0.4\left(T^{\prime}-0.91\right) & \text { for } 0.91 \leq T^{\prime}<0.96 \\ 0.03 & \text { for } 0.96 \leq T^{\prime}<1 \\ 0.03+\beta\left(\phi_{m}\right) & \text { for } T^{\prime} \geq 1\end{cases}
$$

and

$$
\sigma_{P}\left(T^{\prime}\right)= \begin{cases}4 & \text { for } T^{\prime}<0.92 \\ 4+37.5\left(T^{\prime}-0.92\right) & \text { for } 0.92 \leq T^{\prime}<1 \\ 7 & \text { for } T^{\prime} \geq 1\end{cases}
$$

where $T^{\prime}=\frac{T}{T_{s}}$ is homologous temperature, with $T$ the temperature and $T_{s}$ the solidus temperature, both in Kelvin. $\phi_{m}$ is the melt fraction and $\beta\left(\phi_{m}\right)$ describes the direct poroelastic effect of melt, which is assumed to be not important within the upper mantle where only very low volumes of melt are expected to be retained $(\sim 0.1 \%$; McKenzie, 2000 ; Takei, 2017). For this case, $J_{U}$ is the inverse of the unrelaxed shear modulus, $\mu_{U}(P, T)$, such that

$$
J_{U}(P, T)^{-1}=\mu_{U}(P, T)=\mu_{U}^{0}+\frac{\partial \mu_{U}}{\partial T}\left(T-T_{0}\right)+\frac{\partial \mu_{U}}{\partial P}\left(P-P_{0}\right)
$$

where $\mu_{U}^{0}$ is the unrelaxed shear modulus at surface pressure-temperature conditions, the differential terms are assumed to be constant and the pressure, $P$, in GPa is linearly related to the depth, $z$, in $\mathrm{km}$ by $P=\frac{z}{30}$. The normalised shear wave period, $\tau_{S}^{\prime}$, in Equations (2) and (3) is equal to $\frac{\tau_{S}}{2 \pi \tau_{M}}$, where $\tau_{M}=\frac{\eta}{\mu_{U}}$ is the normalised Maxwell relaxation timescale and $\tau_{S}=\frac{z}{1.4}$ is the Rayleigh wave period most sensitive to ambient velocity structure at that depth (Forsyth, 1992). $\tau_{P}^{\prime}$ represents the normalised shear-wave period associated with the centre of the low temperature relaxation peak, assumed to be $6 \times 10^{-5}$. The steady-state diffusion creep viscosity, $\eta$, is

$$
\eta=\eta_{r}\left(\frac{d}{d_{r}}\right)^{m} \exp \left[\frac{E_{a}}{R}\left(\frac{1}{T}-\frac{1}{T_{r}}\right)\right] \exp \left[\frac{V_{a}}{R}\left(\frac{P}{T}-\frac{P_{r}}{T_{r}}\right)\right] A_{\eta}
$$


where $d$ is the grain size, $m$ the grain size exponent (assumed to be 3 for this diffusion creep deformation mechanism), $R$ the gas constant, $E_{a}$ the activation energy and $V_{a}$ the activation volume. Subscripts $[X]_{r}$ refer to reference values, assumed to be $d_{r}=1 \mathrm{~mm}, P_{r}=1.5 \mathrm{GPa}$ and $T_{r}=1200^{\circ} \mathrm{C}$ for the upper mantle. In this study, we make the simplifying assumption that $d=d_{r}$, which indicates an endmember scenario whereby lateral changes in $V_{S}$ within the upper mantle arise purely from variations in temperature rather than grain size. It is also possible that grain size may vary significantly within the shallow mantle, but remains poorly constrained (Behn et al., 2009; Dannberg et al., 2017). $A_{\eta}$ represents the extra reduction of viscosity due to an increase in $E_{a}$ near the solidus, expressed as

$$
A_{\eta}\left(T^{\prime}\right)= \begin{cases}1 & \text { for } T^{\prime}<T_{\eta}^{\prime} \\ \exp \left[-\frac{\left(T^{\prime}-T_{\eta}^{\prime}\right)}{T^{\prime}\left(1-T_{\eta}^{\prime}\right)} \ln (\gamma)\right] & \text { for } T_{\eta}^{\prime} \leq T^{\prime}<1 \\ \gamma^{-1} \exp (\lambda \phi) & \text { for } T^{\prime} \geq 1\end{cases}
$$

where $T_{\eta}^{\prime}=0.94$ is the homologous temperature above which the effective activation energy increases beyond its original value and $\gamma=5$ is the factor of additional viscosity reduction. $\lambda \phi$ describes the direct effect of melt on viscosity, also assumed to be negligible at low melt volumes. The solidus temperature, $T_{s}$, is fixed to a value of $1326^{\circ} \mathrm{C}$ at $50 \mathrm{~km}$ equivalent to the dry peridotite solidus of Hirschmann (2000), and linearly increases below this depth according to

$$
T_{s}(z)=1599+\frac{\partial T_{s}}{\partial z}(z-50)
$$

where $\frac{\partial T_{s}}{\partial z}$ is the solidus gradient. We use a temperature-dependent, compressible density, $\rho(P, T)$, following the approach of Grose \& Afonso (2013). First, we define a linear temperature-dependence on thermal expansivity, $\alpha(T)$, such that

$$
\alpha(T)=\alpha_{0}+\alpha_{1} T
$$

where $\alpha_{0}=2.832 \times 10^{-5} \mathrm{~K}^{-1}$ and $\alpha_{1}=0.758 \times 10^{-8} \mathrm{~K}^{-2}$ are constants calibrated from mineral physics experiments (Bouhifd et al., 1996). To include pressure-dependence, the isothermal volume change, $\left(V_{0} / V\right)_{T}$ is calculated at each pressure using a Brent minimisation algorithm and the third-order Birch-Murnaghan equation of state

$$
P=\frac{3}{2} K_{0}\left[\left(\frac{V_{0}}{V}\right)_{T}^{\frac{7}{3}}-\left(\frac{V_{0}}{V}\right)_{T}^{\frac{5}{3}}\right]\left\{1+\frac{3}{4}\left(K_{T}^{\prime}-4\right)\left[\left(\frac{V_{0}}{V}\right)_{T}^{\frac{2}{3}}-1\right]\right\}
$$

where $K_{0}=130 \mathrm{GPa}$ is the bulk modulus at zero pressure and $K_{T}^{\prime}=4.8$ is the pressure-derivative of the isothermal bulk modulus. The associated isothermal density change with pressure, $\rho(P)$, is given by

$$
\rho(P)=\rho_{0}\left(\frac{V_{0}}{V}\right)_{T}
$$

where $\rho_{0}=3.33 \mathrm{Mg} \mathrm{m}^{-3}$ is the density of mantle at surface pressure and temperature. The effect of pressure on thermal expansivity is included according to

$$
\frac{\alpha(P, T)}{\alpha(T)}=\left(\frac{V_{0}}{V}\right)_{T} \exp \left\{\left(\delta_{T}+1\right)\left[\left(\frac{V_{0}}{V}\right)_{T}^{-1}-1\right]\right\}
$$

where $\delta_{T}=6$ is the Anderson-Grüneisen parameter. Thus, the final density, $\rho(P, T)$, can be calculated using

$$
\rho(P, T)=\rho_{0}\left(\frac{V_{0}}{V}\right)_{T}\left\{1-\left[\frac{\alpha(P, T)}{\alpha(T)}\right]\left[\alpha_{0}\left(T-T_{0}\right)+\frac{\alpha_{1}}{2}\left(T^{2}-T_{0}^{2}\right)\right]\right\}
$$

where $T_{0}=273 \mathrm{~K}$ is temperature at the surface. In a similar manner to Equation (1), the shear-wave attenuation, $Q_{S}^{-1}$, can be defined as

$$
Q_{S}^{-1}=\frac{J_{2}}{J_{1}}\left(\frac{1+\sqrt{1+\left(J_{2} / J_{1}\right)^{2}}}{2}\right)^{-1} \simeq \frac{J_{2}}{J_{1}}
$$




\section{Thermobarometry of mantle xenoliths and xenocrysts}

In order to calibrate the anelasticity parameterisation for Australian regional seismic tomography models, a series of local $V_{S}-T-P$ tie points are required. For temperature estimates, we have assembled a suite of Australian paleogeotherms derived from thermobarometric analysis of mantle xenoliths and xenocrysts from fifteen locations in thick and thin lithosphere (Figure S4; Nickel \& Green, 1985; Nimis \& Taylor, 2000; Taylor, 1998). As outlined in the methods, the resulting P-T estimates are entered into FITPLOT to generate palaeogeotherms (Figure S5; Mather et al., 2011).

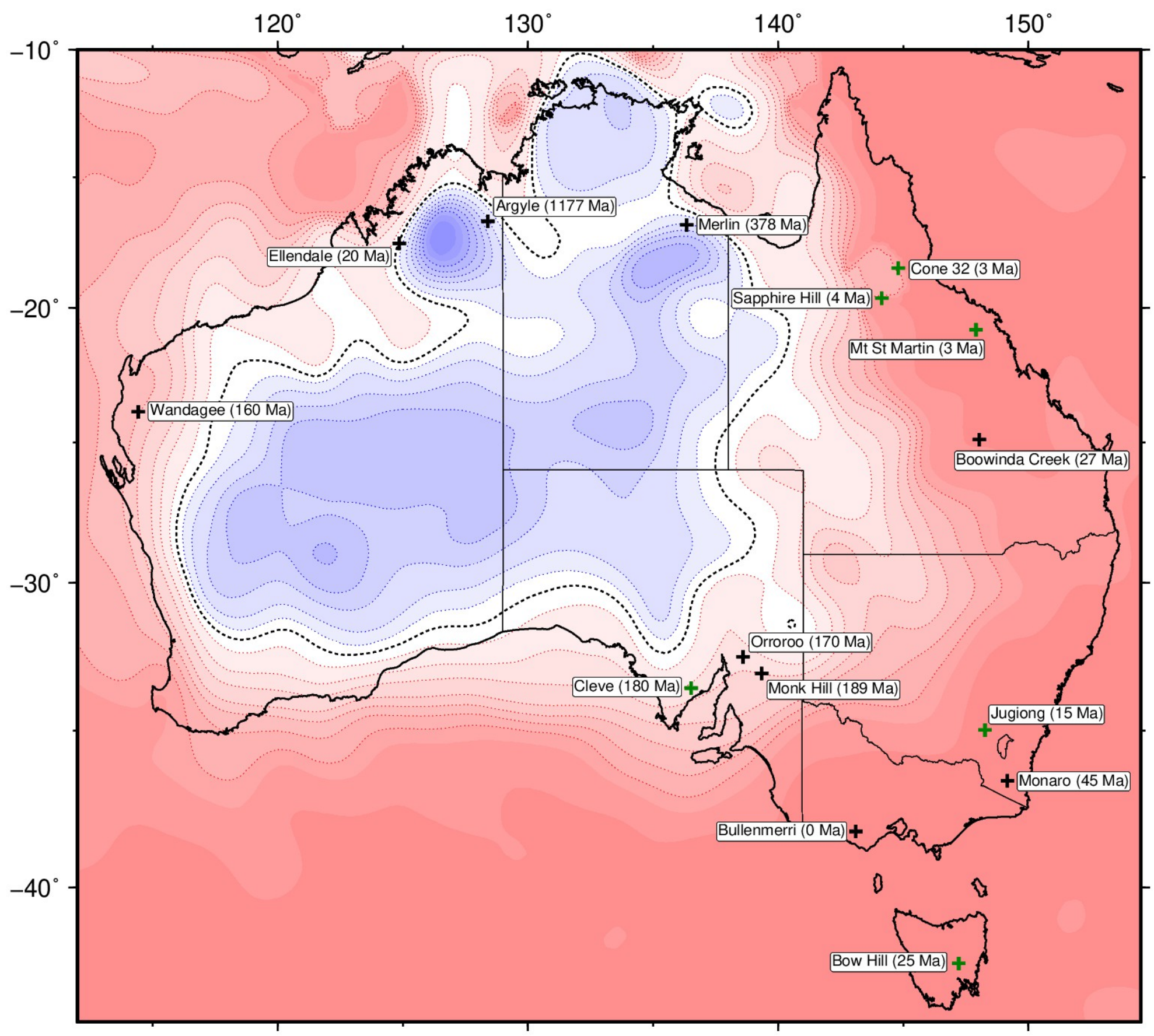

Lithospheric Thickness $(\mathrm{km})$

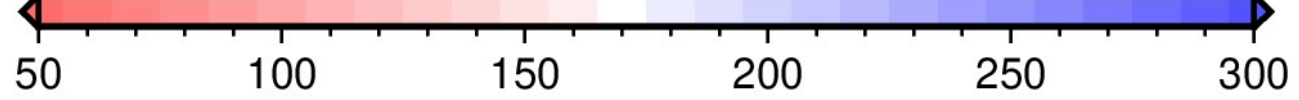

Figure S4: Location of Australian xenolith and xenocryst suites. Labels give site name and age (in million years); black crosses $=$ locations used to constrain anelasticity calibration, green crosses $=$ locations used to visually test validity of results; red/blue colours $=$ lithospheric thickness (from Figure 2b), derived from FR12 seismic tomography model (Fishwick \& Rawlinson, 2012). 

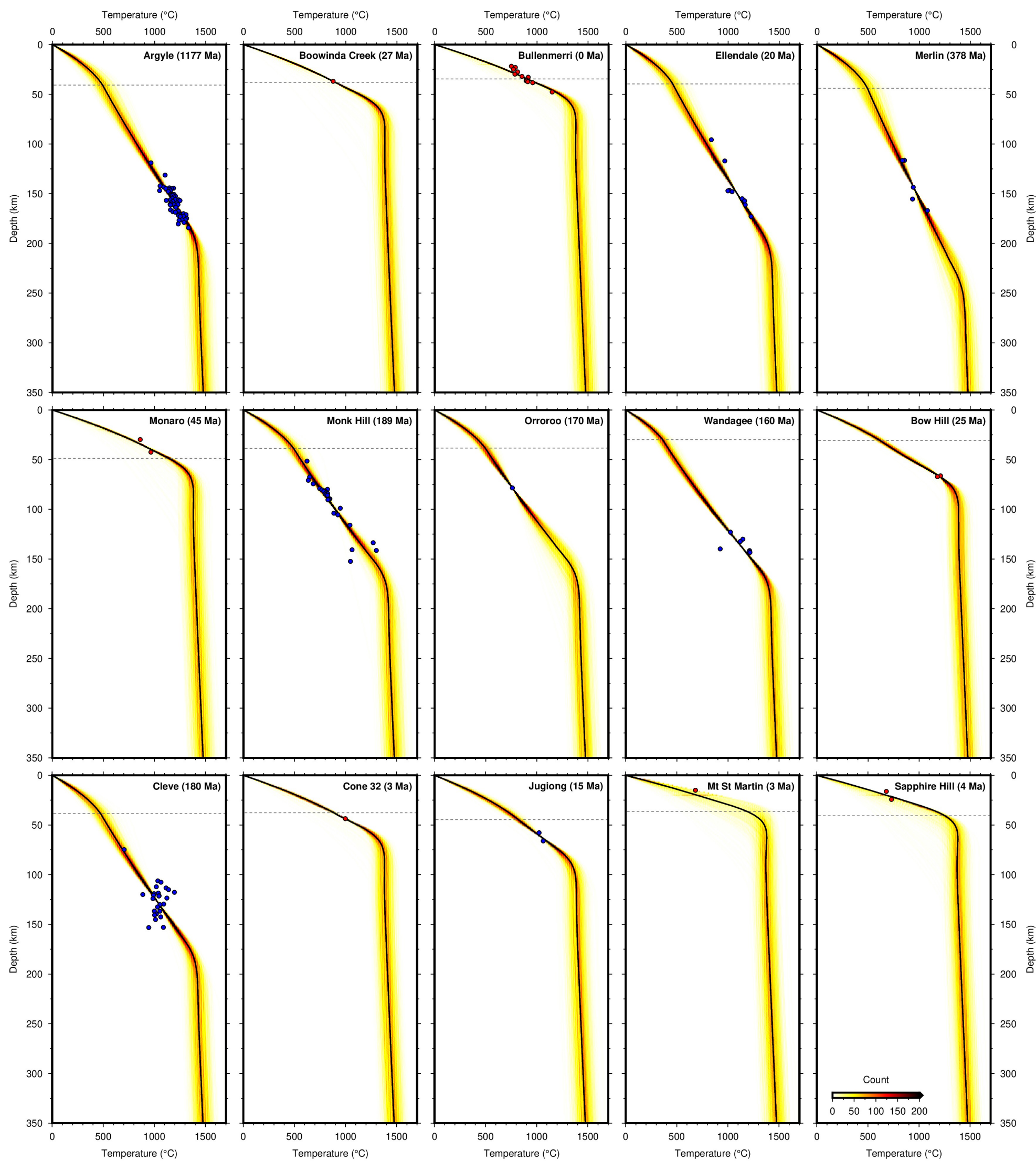

Figure S5: Australian paleogeotherms derived from xenolith and xenocryst thermobarometry. Labels give site name and age (in million years) from Figure S4; red circles = P-T estimates derived from multiphase thermobarometry (Nickel \& Green, 1985; Taylor, 1998); blue circles $=$ P-T estimates derived from single chrome diopside thermobarometry (Nimis \& Taylor, 2000); dashed line $=$ crustal thickness from AusMoho (Kennett et al., 2011); solid line = FITPLOT optimal paleogeotherm (Mather et al., 2011); coloured band = spread of 1000 geotherms from Monte Carlo FITPLOT analysis (Methods). 


\section{Inverse calibration of anelasticity parameterisation}

Anelasticity parameters $A_{B}, \alpha_{B}, \tau_{P}^{\prime}, \beta\left(\phi_{m}\right), \gamma, T_{\eta}^{\prime}$ and $\lambda \phi$ have been directly constrained by forced oscillation experiments on borneol (Yamauchi \& Takei, 2016). However, $\mu_{U}^{0}, \frac{\partial \mu_{U}}{\partial T}, \frac{\partial \mu_{U}}{\partial P}, \eta_{r}, E_{a}, V_{a}$ and $T_{S}(z)$ are material properties that must be independently determined. As outlined in the Methods, we adopt the methodology of Richards et al. (2020) to invert a suite of observational constraints. First, the SL2013sv global $V_{S}$ model is stacked in oceanic regions to calculate average $V_{S}$ as a function of depth and lithospheric age (Schaeffer \& Lebedev, 2013). The age grid and optimal thermal model for a cooling oceanic plate are taken from Richards et al. (2018).

Due to the limited vertical resolution of tomographic models $(25-50 \mathrm{~km})$, we extract a suite of $V_{S}$ versus temperature tie-points by taking the average $V_{S}$ between $75 \mathrm{~km}$ and $100 \mathrm{~km}$ and cross-plotting it with temperature obtained from the thermal model at $87.5 \mathrm{~km}$, which marks the midpoint of this depth range. A second curve is obtained using the $100 \mathrm{~km}$ and $125 \mathrm{~km}$ depth slices. Misfit, $H_{1}$, between predicted and observed $V_{S}$ is

$$
H_{1}=\sqrt{\frac{1}{N} \sum_{i=1}^{N} \frac{1}{M} \sum_{j=1}^{M}\left(\frac{V_{i j}^{o}-V_{i j}^{c}}{\sigma_{i j}}\right)^{2}}
$$

where $V_{i j}^{o}$ are observed shear-wave velocities with associated standard deviation $\sigma_{i j}, V_{i j}^{c}$ is the prediction from Equation (1), $M=76$ is the number of age bins at a given depth and $N$ is the number of depth slices (two in this case). A second suite of tie-points is created by assuming that temperatures are isentropic at depths well below the upper thermal boundary layer. We calculate average $V_{S}$ as a function of depth over oceanic regions in the global model, and over the whole spatial domain in regional models. Over the depth range 225-400 km, beyond which the resolving power of surface waves drops significantly, these values are combined with an isentrope calculated for a potential temperature of $1333{ }^{\circ} \mathrm{C}$ and an adiabatic gradient determined using a reference density of $\rho_{0}=3.3 \mathrm{Mg} \mathrm{m}^{-3}$, thermal expansivity of $\alpha=3 \times 10^{-5}{ }^{\circ} \mathrm{C}^{-1}$ and specific heat capacity of $C_{P}=1187 \mathrm{~J} \mathrm{~kg}^{-1}{ }^{\circ} \mathrm{C}^{-1}$. Misfit for the isentrope, $H_{2}$, is

$$
H_{2}=\sqrt{\frac{1}{N} \sum_{i=1}^{N}\left(\frac{V_{i}^{o}-V_{i}^{c}}{\sigma_{i}}\right)^{2}}
$$

It has been observed that over the depth range 150-400 km, both $V_{S}$ and $Q_{S}^{-1}$ are relatively consistent for oceanic ages $\geq 100 \mathrm{Ma}$ (Adenis et al., 2017). Over this age range, we stack the QRFSI12 attenuation model of Dalton et al. (2009), generating a suite of $Q_{S}^{-1}$ to $V_{S}$ tie-points as a function of depth. Equations (1) and (15) are coupled such that average temperature is obtained from the average $V_{S}$, rather than assuming isentropic temperatures extend up to $150 \mathrm{~km}$. Misfit, $H_{3}$, between observed and predicted attenuation is

$$
H_{3}=\sqrt{\frac{1}{N} \sum_{i=1}^{N}\left(\frac{Q_{i}^{-1 o}-Q_{i}^{-1 c}}{\sigma_{i}}\right)^{2}}
$$

We also adopt a bulk diffusion creep viscosity of $\eta_{r e f}=3 \times 10^{20} \mathrm{~Pa}$ s for the upper mantle $(\sim 100-670 \mathrm{~km})$ obtained from glacial isostatic adjustment studies (Lau et al., 2016), and compare it to the average predicted value for 225-400 km depths obtained from Equation (7). Misfit, $H_{4}$, is calculated using

$$
H_{4}=\sqrt{\frac{1}{\log _{10}\left[\sigma_{i}\right]^{2}}\left(\left\{\frac{1}{N} \sum_{i=1}^{N} \log _{10}\left[\eta_{i}^{c}\right]\right\}-\log _{10}\left[\eta_{r e f}\right]\right)^{2}}
$$

where $\eta_{i}^{c}$ is predicted viscosity and the viscosity uncertainty, $\sigma_{i}$, is assumed to be one order of magnitude. Finally, for calibration of regional tomography models where these global oceanic observations are unavailable, we take the better constrained paleogeotherms derived from thermobarometry on mantle xenoliths. Argyle, Boowinda Creek, Bullenmerri, Ellendale, Merlin, Monaro, Monk Hill, Orroroo and Wandagee are used to directly constrain each anelasticity model. None of these paleogeotherms show evidence of having been perturbed by heating events immediately prior to xenolith entrainment, and we therefore take the calculated P-T conditions to represent ambient mantle conditions immediately 
Table 1: Optimal anelasticity parameters for each seismic tomography model.

\begin{tabular}{lccccccc}
\hline Model & $\mu_{U}^{0}(\mathrm{GPa})$ & $\frac{\partial \mu_{U}}{\partial T}\left(\mathrm{MPa}^{\circ} \mathrm{C}^{-1}\right)$ & $\frac{\partial \mu_{U}}{\partial P}$ & $\eta_{r}(\mathrm{~Pa} \mathrm{~s})$ & $E_{a}\left(\mathrm{~kJ} \mathrm{~mol}^{-1}\right)$ & $V_{a}\left(\mathrm{~cm}^{3} \mathrm{~mol}^{-1}\right)$ & $\frac{\partial T_{s}}{\partial z}\left({ }^{\circ} \mathrm{C} \mathrm{km}^{-1}\right)$ \\
\hline SL2013sv & 78.2 & -20.0 & 2.67 & $4.45 \times 10^{22}$ & 400 & 0.092 & 0.919 \\
CAM2016 & 78.5 & -19.8 & 2.38 & $9.99 \times 10^{22}$ & 467 & 0.012 & 0.886 \\
3D2015-07Sv & 74.1 & -16.0 & 2.29 & $1.45 \times 10^{22}$ & 300 & 0.000 & 0.895 \\
SLNAAFSA $^{a}$ & 74.8 & -16.5 & 2.47 & $1.17 \times 10^{21}$ & 104 & 0.009 & 1.011 \\
FR12 & 69.0 & -11.7 & 2.83 & $1.31 \times 10^{22}$ & 963 & 0.000 & 4.500 \\
AuSREM & 70.5 & -9.6 & 2.18 & $9.31 \times 10^{22}$ & 1000 & 1.831 & 1.249 \\
Y14 & 73.3 & -10.1 & 1.67 & $1.18 \times 10^{21}$ & 100 & 30.00 & 4.500 \\
\hline
\end{tabular}

${ }^{a}$ blend of SL2013sv, SL2013NA, AF2019, and SA2019 (Schaeffer \& Lebedev, 2013, 2014; Celli et al., 2020a,b).

prior to entrainment. Paleogeotherms derived from three-mineral thermobarometer P-T estimates that are either very shallow (Mt St Martin) or pass only seven of the eight oxide and cation checks (Bow Hill, Cone 32, Sapphire Hill) are considered less robust and only used to visually check results of the conversion, as are diopside-only estimates that have a very narrow depth range (Jugiong) or exhibit large spread (Cleve). For each paleogeotherm, we extract temperatures every $5 \mathrm{~km}$ from the base of the thermal boundary layer up to either $125 \mathrm{~km}$ in regions with thick lithosphere, or $50 \mathrm{~km}$ for those with thin $(<100 \mathrm{~km})$ lithosphere. These variable top depths minimise the impact of potential crustal bleeding artefacts. Extracting $V_{S}(z)$ values at each paleogeotherm location yields a suite of $V_{S}$ to temperature tie-points. Misfit, $H_{5}$, is calculated from

$$
H_{5}=\sqrt{\frac{1}{N} \sum_{i=1}^{N} \frac{1}{M} \sum_{j=1}^{M}\left(\frac{V_{i j}^{o}-V_{i j}^{c}}{\sigma_{i j}}\right)^{2}}
$$

where $M$ is the number of paleogeotherms, $\mathrm{N}$ is the number of tie-points associated with each geotherm and $\sigma_{i j}$ reflects uncertainty in the $V_{S}$ measurement, assumed to be a constant $0.1 \mathrm{~km} \mathrm{~s}^{-1}$ which captures typical variations between different tomography models at a given location. Combined misfit, $H$, is given by

$$
H=\frac{w_{1} H_{1}+w_{2} H_{2}+w_{3} H_{3}+w_{4} H_{4}+w_{5} H_{5}}{w_{1}+w_{2}+w_{3}+w_{4}+w_{5}}
$$

where $w$ represents weighting applied to each misfit constraint. $H$ is minimised in two steps. Initially, a parameter sweep is performed to identify the approximate location of the global minimum. $\mu_{U}^{0}$ is varied between $69-82 \mathrm{GPa}$ (in increments of $1 \mathrm{GPa}), \frac{\partial \mu}{\partial T}$ between -20 and $-8 \mathrm{MPa}{ }^{\circ} \mathrm{C}^{-1}\left(2 \mathrm{MPa}{ }^{\circ} \mathrm{C}^{-1}\right.$ increments), $\frac{\partial \mu}{\partial P}$ between $1.5-2.9$ (0.2 increments), $\eta_{r}$ between $10^{17}-10^{23} \mathrm{~Pa} \mathrm{~s}\left(10^{0.5} \mathrm{~Pa}\right.$ s increments), $E_{a}$ between $100-1000 \mathrm{~kJ} \mathrm{~mol}^{-1}\left(100 \mathrm{~kJ} \mathrm{~mol}^{-1}\right.$ increments), $V_{a}$ between 0-30 $\mathrm{cm}^{3} \mathrm{~mol}^{-1}\left(2 \mathrm{~cm}^{3} \mathrm{~mol}^{-1}\right.$ increments $)$ and $\frac{\partial T_{s}}{\partial z}$ between $0-4.5^{\circ} \mathrm{C} \mathrm{km}^{-1}\left(0.25{ }^{\circ} \mathrm{C} \mathrm{km}^{-1}\right.$ increments $)$. These extrema are chosen to exceed the range of previous parameter estimates obtained from laboratory experiments and other studies (Priestley \& McKenzie, 2013; Yamauchi \& Takei, 2016; Jain et al., 2018). Secondly, Powell's conjugate gradient algorithm is used to further minimise $H$ using best-fitting parameters from the initial sweep as the starting point (Press et al., 1992). There are two broad sets of parameter trade-offs. The first occurs between parameters controlling anharmonic velocities $\left(\mu_{U}^{0}, \frac{\partial \mu}{\partial T}\right.$, and $\left.\frac{\partial \mu_{U}}{\partial P}\right)$. The second is between parameters controlling anelastic effects $\left(\eta_{r}, E_{a}, V_{a}\right.$, and $\left.\frac{\partial T_{s}}{\partial z}\right)$. The change in misfit value, $H$, along each of these trade-offs is minor, such that multiple parameter combinations yield similar conversions between $V_{S}$ and temperature (Richards et al., 2020). This effect means that whilst the uncertainty on each anelastic parameter may be high for a given tomography model, the resulting mantle temperature structures remain largely consistent.

For calibration of the four global models, we set $w_{1}=10, w_{2}=1, w_{3}=2, w_{4}=2$ and $w_{5}=0$. In the case of SL2013sv, the minimum misfit is $H=0.568$ and occurs when $\mu_{U}^{0}=78.2 \mathrm{GPa}, \frac{\partial \mu_{U}}{\partial T}=-20.0 \mathrm{MPa}{ }^{\circ} \mathrm{C}^{-1}, \frac{\partial \mu_{U}}{\partial P}=2.67$, $\eta_{r}=4.45 \times 10^{22} \mathrm{~Pa} \mathrm{~s}, E_{a}=400 \mathrm{~kJ} \mathrm{~mol}{ }^{-1}, V_{a}=0.092 \mathrm{~cm}^{3} \mathrm{~mol}^{-1}$ and $\frac{\partial T_{s}}{\partial z}=0.919{ }^{\circ} \mathrm{C} \mathrm{km}^{-1}$. These parameters are then used to convert the full three-dimensional $V_{S}$ model to temperature. Optimal anelasticity parameters for each of the calibrated seismic tomography models are listed in Table 1. For comparison, the optimal misfit for CAM2016 is $H=0.929$ and for 3D2015-07Sv is $H=0.887$, which is partly why we prefer the SL2013sv model. Our blended global model SLNAAFSA achieves the lowest optimal misfit of $H=0.533$.

For Australian regional models, we constrain the calibration using the nine most reliable paleogeotherms. All 


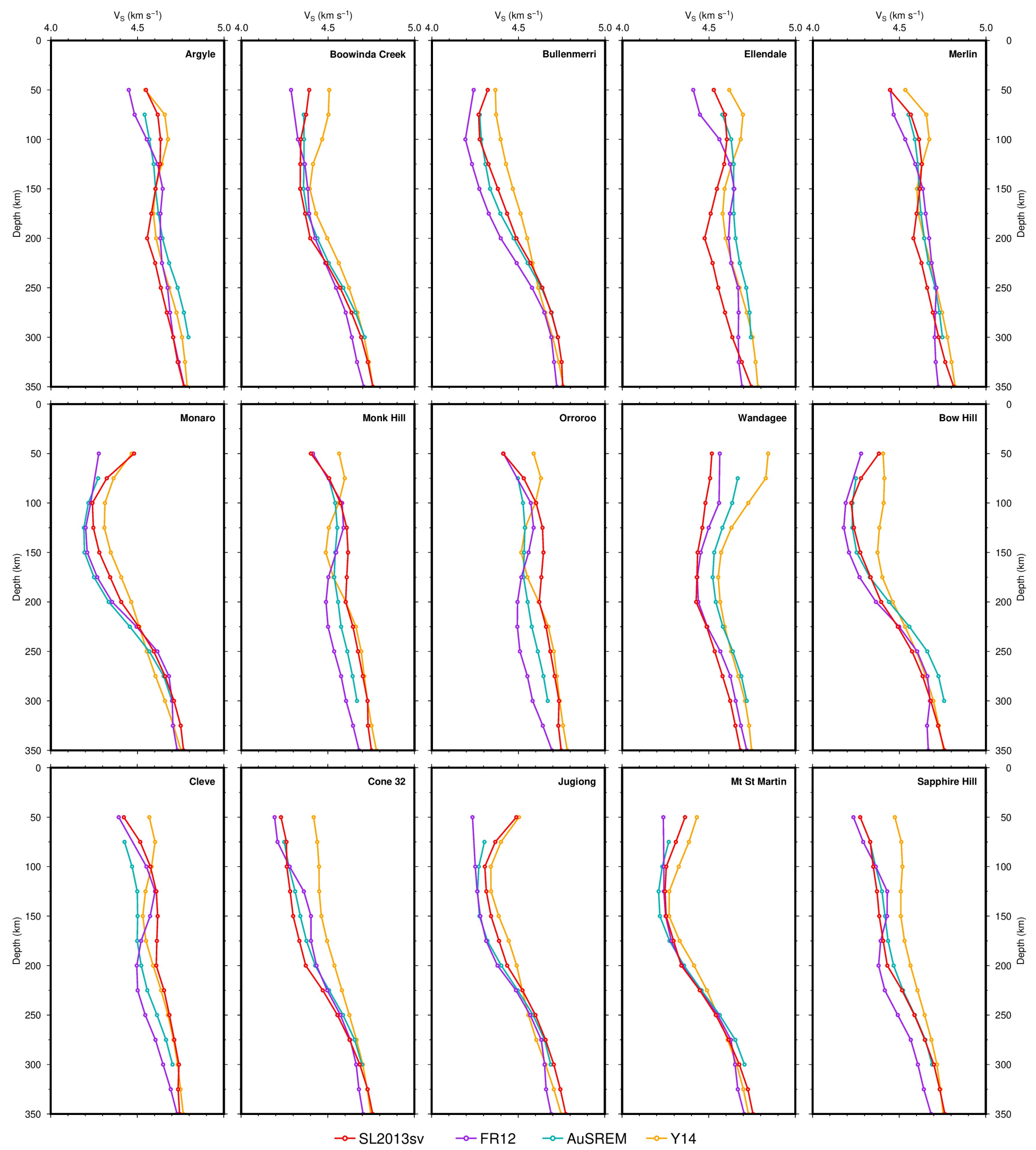

Figure S6: $\mathbf{V}_{S}$ as a function of depth at sites of fifteen Australian paleogeotherms. Labels give site name (locations in Figure S4); red = global SL2013sv modelSchaeffer \& Lebedev (2013); purple = regional FR12 modelFishwick \& Rawlinson (2012); blue = regional AuSREM modelKennett et al. (2013); orange $=$ regional Y14 modelYoshizawa (2014).

weights are set to zero except for $w_{2}=1$ and $w_{5}=10$. The minimum misfit for FR12 is $H=0.590$ and occurs when $\mu_{U}^{0}=69.0 \mathrm{GPa}, \frac{\partial \mu_{U}}{\partial T}=-11.7 \mathrm{MPa}{ }^{\circ} \mathrm{C}^{-1}, \frac{\partial \mu_{U}}{\partial P}=2.83, \eta_{r}=1.31 \times 10^{22} \mathrm{~Pa} \mathrm{~s}, E_{a}=1000 \mathrm{~kJ} \mathrm{~mol}^{-1}, V_{a}=0 \mathrm{~cm}^{3} \mathrm{~mol}^{-1}$ and $\frac{\partial T_{s}}{\partial z}=4.50{ }^{\circ} \mathrm{C} \mathrm{km}^{-1}$.

The predicted geotherm from each tomography model is compared to the paleogeotherms in Figures S6 and S7. Note that the global model SL2013sv yields good fits to paleogeotherms away from south Australia (Monk Hill, Orroroo and Cleve), despite being lower resolution than the local models and being calibrated completely independently of this information (red lines in Figure S7). Conversely, regional models often provide a poorer fit to the full range of the paleogeotherms and can exhibit substantial crustal bleeding artefacts at depths shallower than $\sim 125 \mathrm{~km}$. 

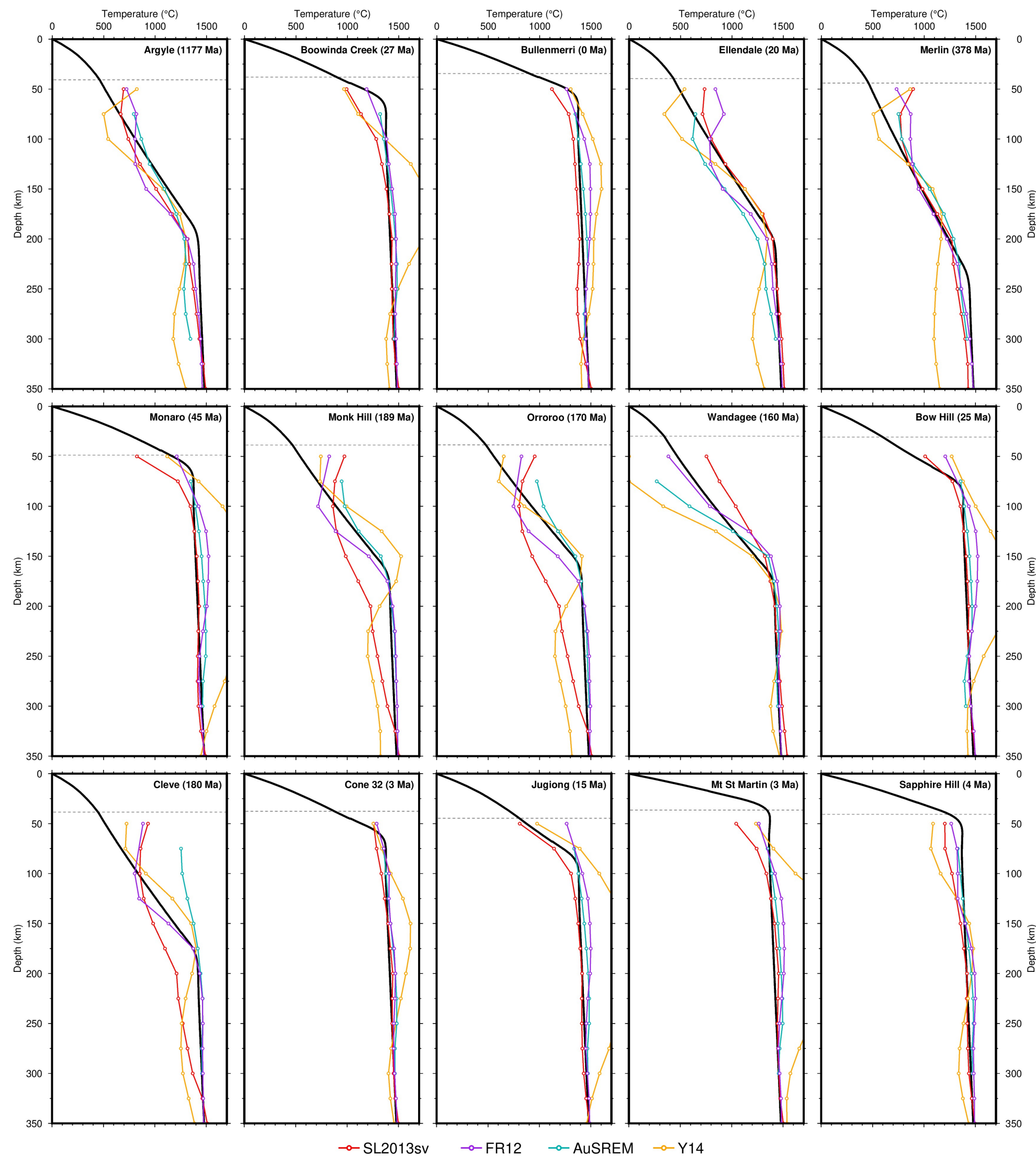

Figure S7: Calibration of anelasticity parameterisation on Australian paleogeotherms. Labels give site name and inferred age of paleogeotherms in million years (locations in Figure S4); sites Argyle to Wandagee are used to constrain calibration; sites Bow Hill to Sapphire Hill are used to visually check output; dashed line $=$ crustal thickness from AusMohoKennett et al. $(2011)$; solid line $=$ optimal FITPLOT geotherm from Figure S5; purple = regional FR12 modelFishwick \& Rawlinson (2012); blue = regional AuSREM modelKennett et al. (2013); orange = regional Y14 modelYoshizawa (2014); red = global SL2013sv modelSchaeffer \& Lebedev (2013), for comparison, calibrated independently of palaeogeotherm constraints. 
It is important to note that of the nine geotherms used to calibrate the anelasticity parameterisation for the regional FR12 model, two are only constrained by a single P-T estimate (Orroroo and Boowinda Creek). We have therefore tested the effect of removing these two sites from the calibration scheme. As Figure S8 shows, there is no discernible effect on the inferred temperature structure. Given this result and that these two samples pass all of the thermobarometry cation and oxide tests, we have chosen to keep Orroroo and Boowinda Creek within the set of nine geotherms used in calibration of local tomography models.
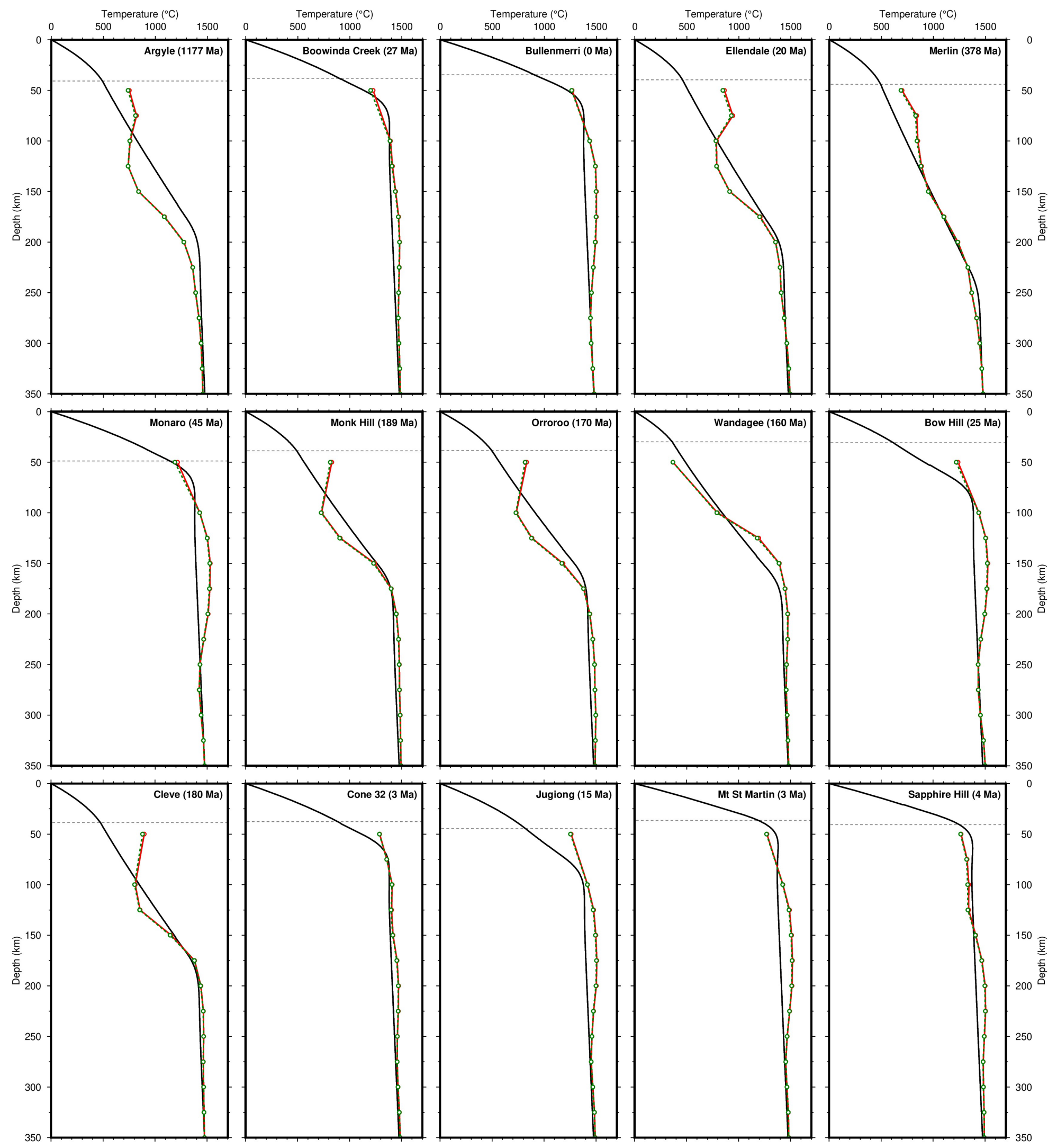

$\rightarrow$ FR12 original

-o- FR12 excl. Orroroo and Boowinda Creek

Figure S8: Calibration of anelasticity parameterisation on Australian paleogeotherms. Labels give site name and inferred age of paleogeotherms in million years (locations in Figure S4); red line = FR12 model calibrated using sites Argyle through Wandagee; green line = same but excluding Boowinda Creek and Orroroo from the calibrations set. 


\section{Global lithospheric thickness maps}

We have calibrated two other recent surface wave tomography models that each have global coverage (3D2015-07Sv and CAM2016; Debayle et al., 2016; Priestley et al., 2018). In addition, we have generated a higher resolution version of SL2013sv, referred to as SLNAAFSA, by blending in three regional updates including SL2013NA in North America, AF2019 in Africa, and SA2019 in the South Atlantic Ocean (Schaeffer \& Lebedev, 2014; Celli et al., 2020a,b). The lithospheric thickness maps for all four global models are visually similar and are shown in the extended data figure of the manuscript and available in ASCII, GeoTIFF and GMT NetCDF formats in the online Supplementary Information. All four exhibit robust relationships with sediment-hosted deposits.

A histogram of global lithospheric thickness derived from the SL2013sv model is shown in Figure S9 and reveals a bi-modal population, with peaks at $\sim 90 \mathrm{~km}$ and $\sim 190 \mathrm{~km}$, separated by a minimum at $150 \mathrm{~km}$. There is also a noticeable drop-off deeper than $200 \mathrm{~km}$, which we attribute to a change in the gradient of $V_{S}$ with depth in the initial starting profile used to construct the tomography model.

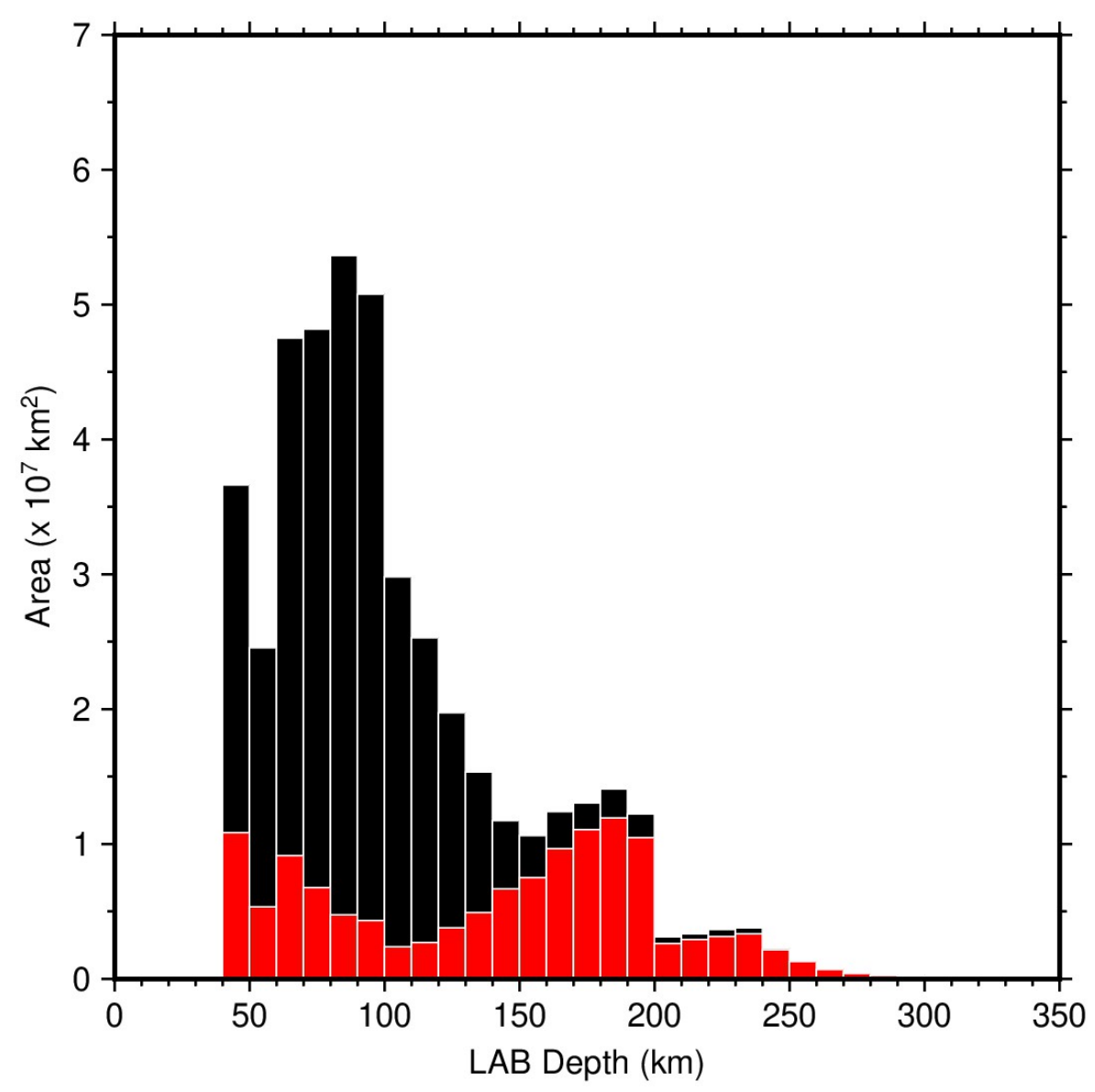

Figure S9: Area-weighted histogram of global LAB depths. LAB derived from the SL2013sv tomography model (Schaeffer \& Lebedev, 2013); black bars = oceanic regions; red bars $=$ continental regions. 
For comparison, we also provide seven previously published global lithosphere-asthenosphere boundary (LAB) maps derived from a mixture of heat flow data, seismic tomography datasets, and potential field data. Interestingly, many giant sediment hosted mineral deposits lie along LAB edges defined by these other studies, testifying to the robustness of the observed relationship.
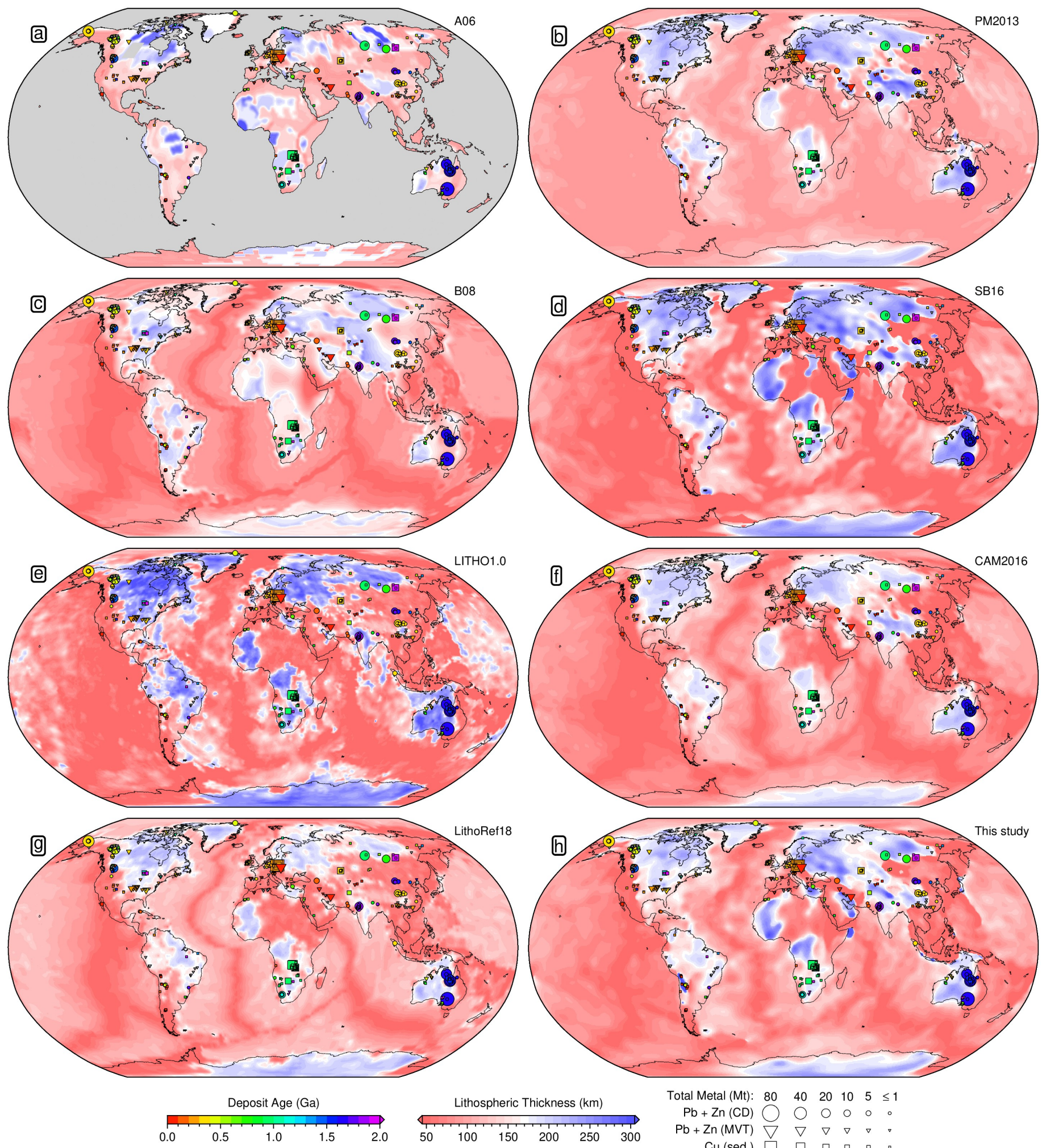

$\begin{array}{rllllll}\text { Total Metal (Mt): } & 80 & 40 & 20 & 10 & 5 & \leq 1 \\ \mathrm{~Pb}+\mathrm{Zn}(\mathrm{CD}) & \bigcirc & \bigcirc & \bigcirc & 0 & \circ & \circ \\ \mathrm{Pb}+\mathrm{Zn}(\mathrm{MVT}) & \nabla & \nabla & \nabla & \nabla & \nabla & \circ \\ \mathrm{Cu} \text { (sed.) } & \square & \square & \square & \square & \square & \circ\end{array}$

Figure S10: Previously published global maps of depth to the lithosphere-asthenosphere boundary. Symbols $=$ sediment-hosted deposit locations; area proportional to estimate of total contained mass of metal (Mt = megatonnes); unknown deposit size given 1 Mt symbol; colour $=$ ore body formation age (billion years); unknown age plotted in grey; circles = clastic-dominated lead-zinc $(\mathrm{PbZn-CD)}$; triangles $=$ Mississippi Valley type lead-zinc (PbZn-MVT); squares = sedimentary copper (Cu-sed). (a) LAB derived from surface heat flow measurements (Artemieva, 2006); (b) LAB derived from surface wave tomography (Priestley \& McKenzie, 2013); (c) LAB derived from vertical shear-wave travel time anomalies in the continents (Bird et al., 2008); (d) LAB derived by Steinberger \& Becker (2018) from SL2013sv tomography model (Schaeffer \& Lebedev, 2013); (e) LAB derived from surface wave tomography (Pasyanos et al., 2014); (f) LAB derived from surface wave tomography (Priestley et al., 2018); (g) LAB derived from joint inversion of seismic, potential field and geochemical data (Afonso et al., 2019); (h) LAB derived in this study using SL2013sv tomography model (Schaeffer \& Lebedev, 2013). 


\section{Australian lithospheric thickness maps}

For each of the Australian regional seismic tomography models considered in this study, we have individually calibrated and mapped out the LAB in a consistent manner. The resulting maps for Australia are shown in Figure S11, whilst in Figure S12 we compare our preferred FR12 regional model to previously published maps of LAB depth beneath Australia.
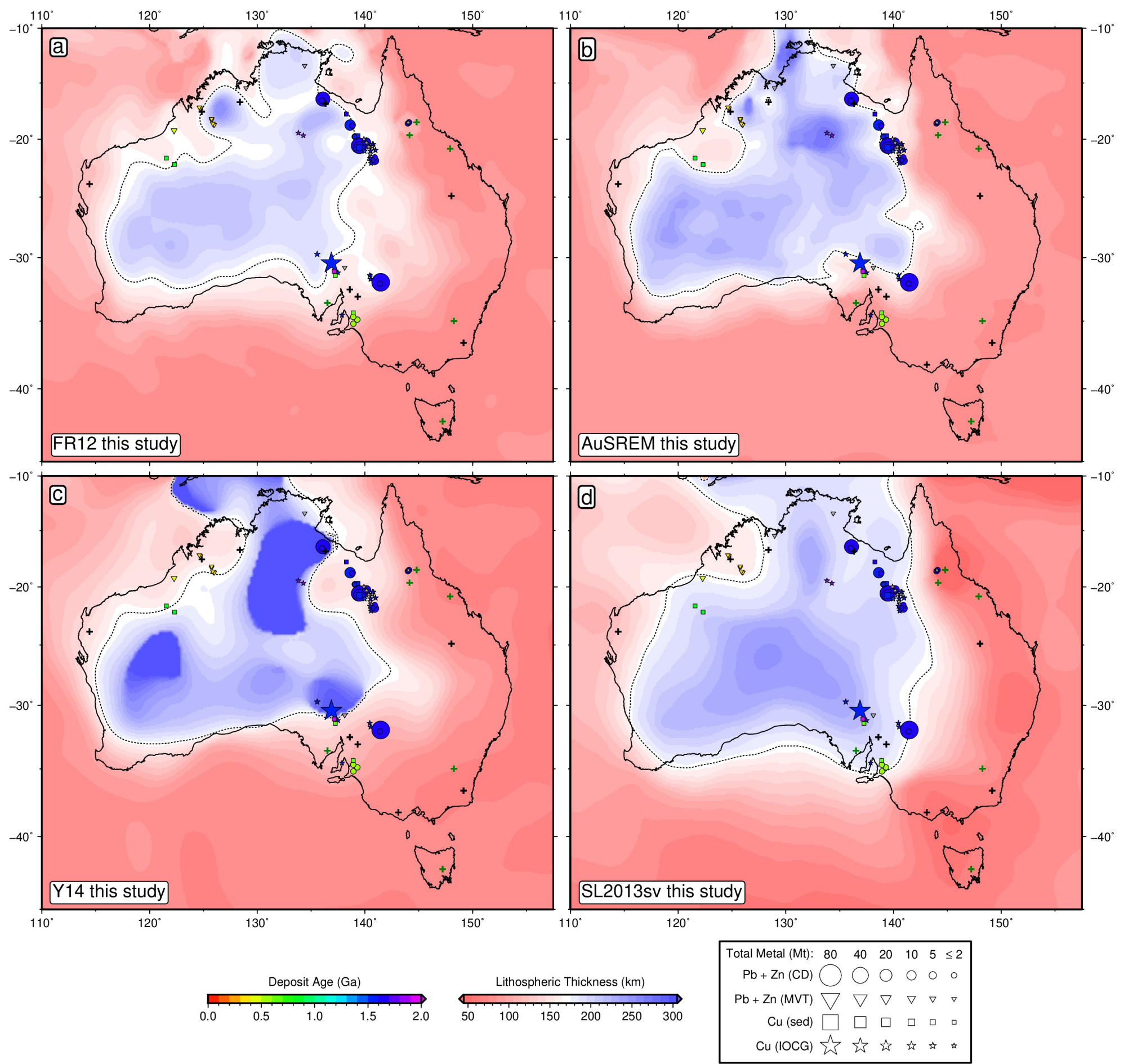

Figure S11: Depth to lithosphere-asthenosphere boundary from individually calibrated Australian seismic tomography models. Black contour $=170 \mathrm{~km}$ LAB thickness; green/black crosses = paleogeotherms used/unused in anelasticity calibration; other symbols $=$ sediment-hosted deposit locations; area proportional to estimate of total contained mass of metal (Mt $=$ megatonnes); unknown deposit size given $2 \mathrm{Mt}$ symbol; colour = ore body formation age (billion years); unknown age plotted in grey; circles = clastic-dominated lead-zinc $(\mathrm{PbZn}-\mathrm{CD})$; triangles = Mississippi Valley type lead-zinc (PbZn-MVT); squares = sedimentary copper $(\mathrm{Cu}$-sed); stars = iron-oxide-coppergold (IOCG). (a) regional calibration of FR12 (Fishwick \& Rawlinson, 2012). (b) regional calibration of AuSREM (Kennett et al., 2013). (c) regional calibration of Y14 (Yoshizawa, 2014). (d) global calibration of SL2013sv (Schaeffer \& Lebedev, 2013). 

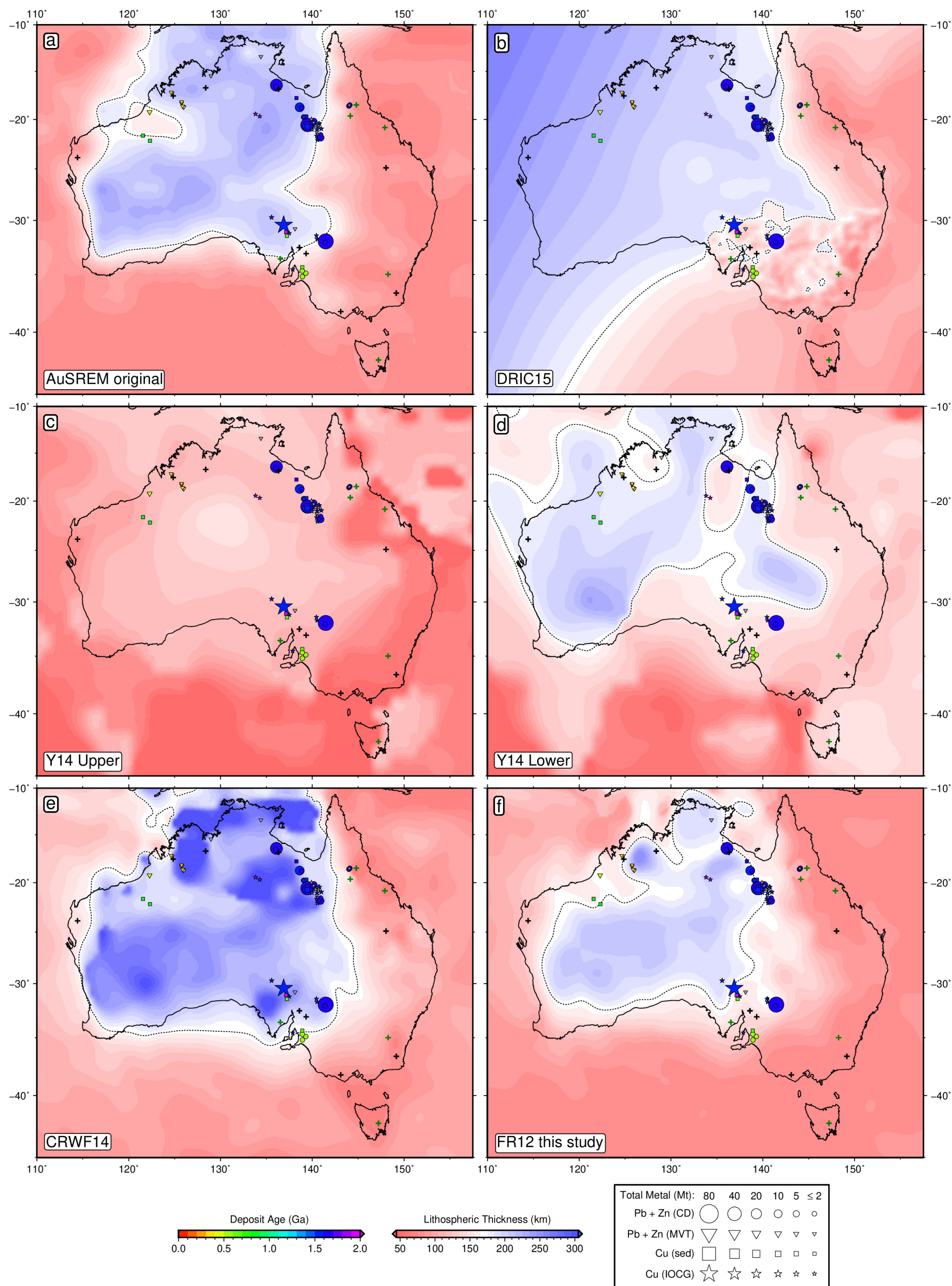

Figure S12: Depth to lithosphere-asthenosphere boundary beneath Australia from previous studies. Black contour $=170 \mathrm{~km}$ LAB thickness; green/white crosses = paleogeotherms used/unused in anelasticity calibration; other symbols = sediment-hosted deposit locations; area proportional to estimate of total contained mass of metal (Mt = megatonnes); unknown deposit size given 2 Mt symbol; colour = ore body formation age (billion years); unknown age plotted in grey; circles = clastic-dominated lead-zinc $(\mathrm{PbZn-CD)}$; triangles $=$ Mississippi Valley type lead-zinc (PbZn-MVT); squares = sedimentary copper (Cu-sed); stars = iron-oxide-copper-gold (IOCG). (a) Original AuSREM (Kennett et al., 2013). (b) DRIC15 (Davies et al., 2015). (c) Upper bound of Y14 (Yoshizawa, 2014). (d) Lower bound of Y14 (Yoshizawa, 2014). (e) CRWF14, derived using FR12 tomography (Czarnota et al., 2014; Fishwick \& Rawlinson, 2012). (f) FR12 LAB model generated in this study. 


\section{Kolmogorov-Smirnov Statistical Tests}

In order to test the statistical significance of real deposit locations, test suites of random points on a sphere are generated (Methods). Example test suites of 100, 1000 and 10,000 points are shown in Figure S13.
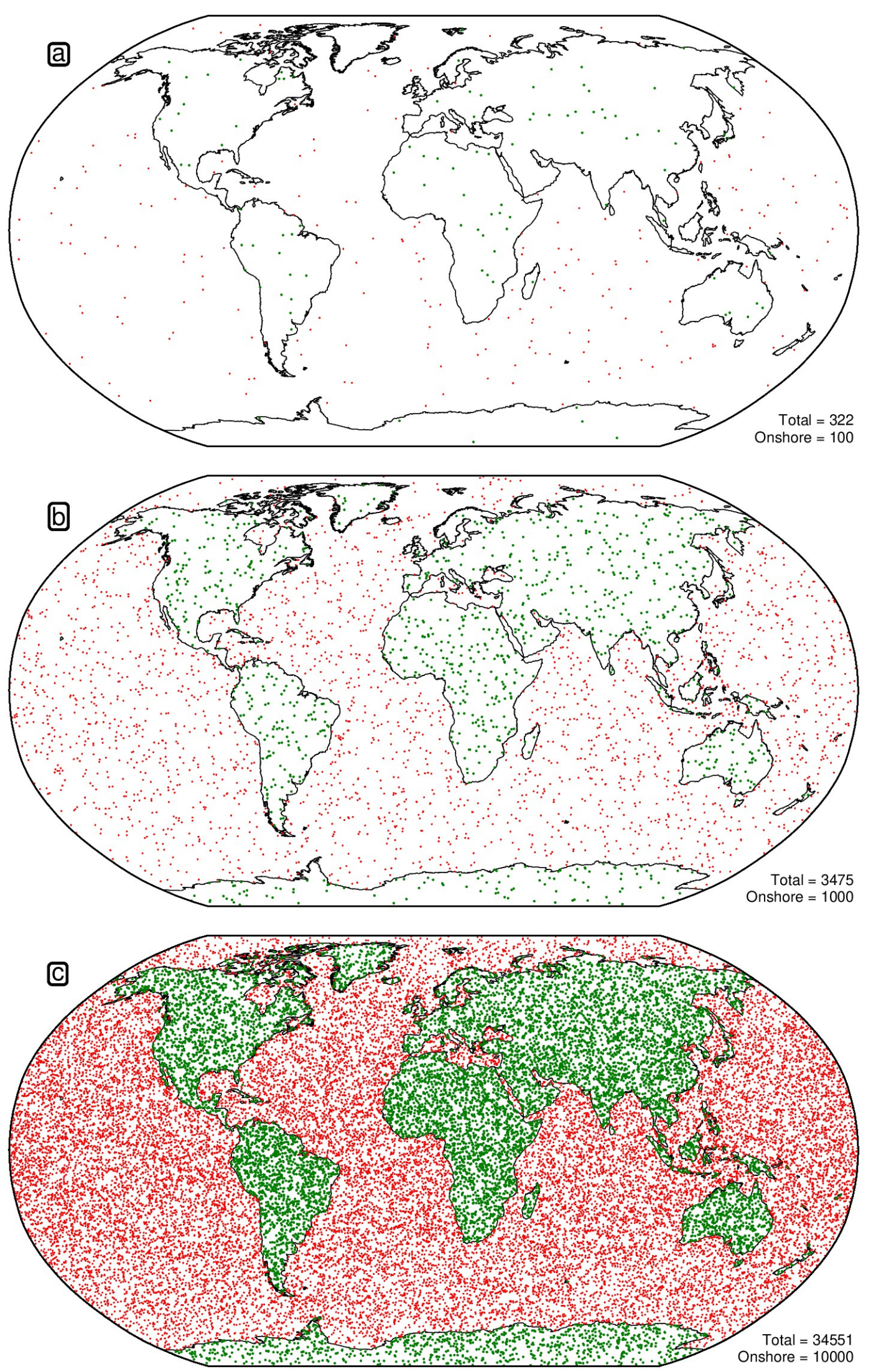

Figure S13: Distribution of random points on the surface of a sphere. Green circles $=$ onshore points; red $=$ offshore. (a) Example set of 100 onshore points. (b) Example set of 1000 onshore points. (c) Example set of 10,000 onshore points. 


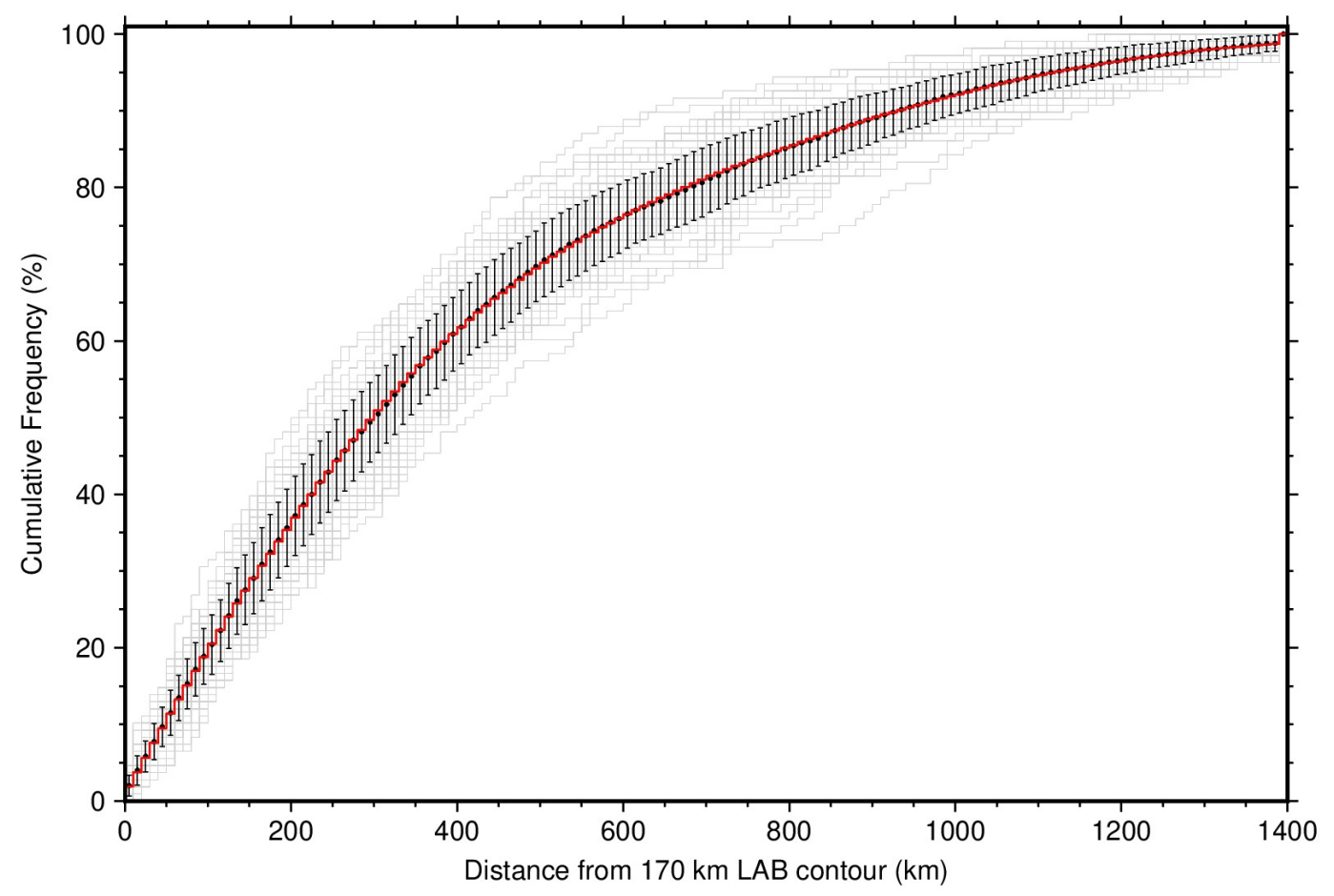

Figure S14: Cumulative distribution functions for random continental points with distance from the SL2013sv-derived $170 \mathrm{~km}$ LAB thickness contour. Grey lines $=100 \mathrm{CDFs}$ for a set of 109 random points in the continents; black points with error bars $=$ mean and standard deviation of all 100 CDFs within each $10 \mathrm{~km}$ bin; red line $=$ CDF for a set of 10,000 random continental points.

For each Kolmogorov-Smirnov test, a number of random points are generated that is equivalent to the number of real deposits of that type (109 for PbZn-CD, 147 for PbZn-MVT and 139 for Cu-sed). Given the low sample size for some of the deposit classes, the distribution of this random set can vary somewhat from the true average distribution of continental locations. We therefore draw a test set in this manner 100 times (Figure S14). These random CDFs are relatively consistent but have some outliers. The D-value and Kolmogorov-Smirnov statistic between each random CDF and the real one is calculated and reported within a histogram (Figure S15).

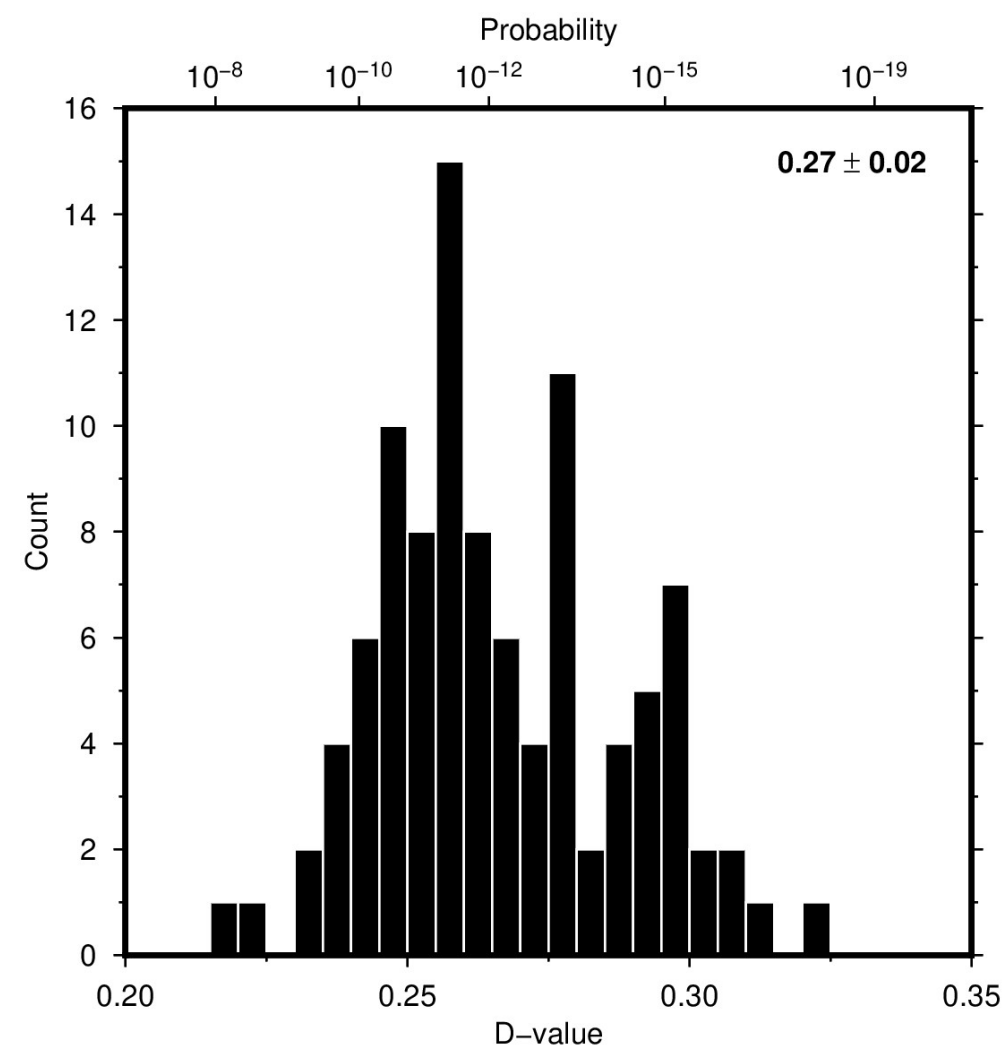

Figure S15: D-values for all 395 sediment-hosted base metal deposits. Histogram of D-values for ensemble of 100 random CDFs calculated for each random test set compared with the non-mass-weighted, locally enhanced CDF; inset lists mean and standard deviation of D-values; associated probabilities shown across top. 


\section{Effect of subducting slabs on deposit statistics}

The relationship between seismic wavespeed and temperature results in a tomography model at depths $>150 \mathrm{~km}$ imaging cold subducting slabs as fast velocities, in addition to those associated with thick, cold cratonic lithosphere. Thus it is possible that some of the features imaged in our LAB maps are not related to cratonic lithosphere. Examples include features along the Andean, Caribbean, Aleutian, Japanese, Philippines, Indonesian, and eastern Mediterranean subduction zones (Figure S16).

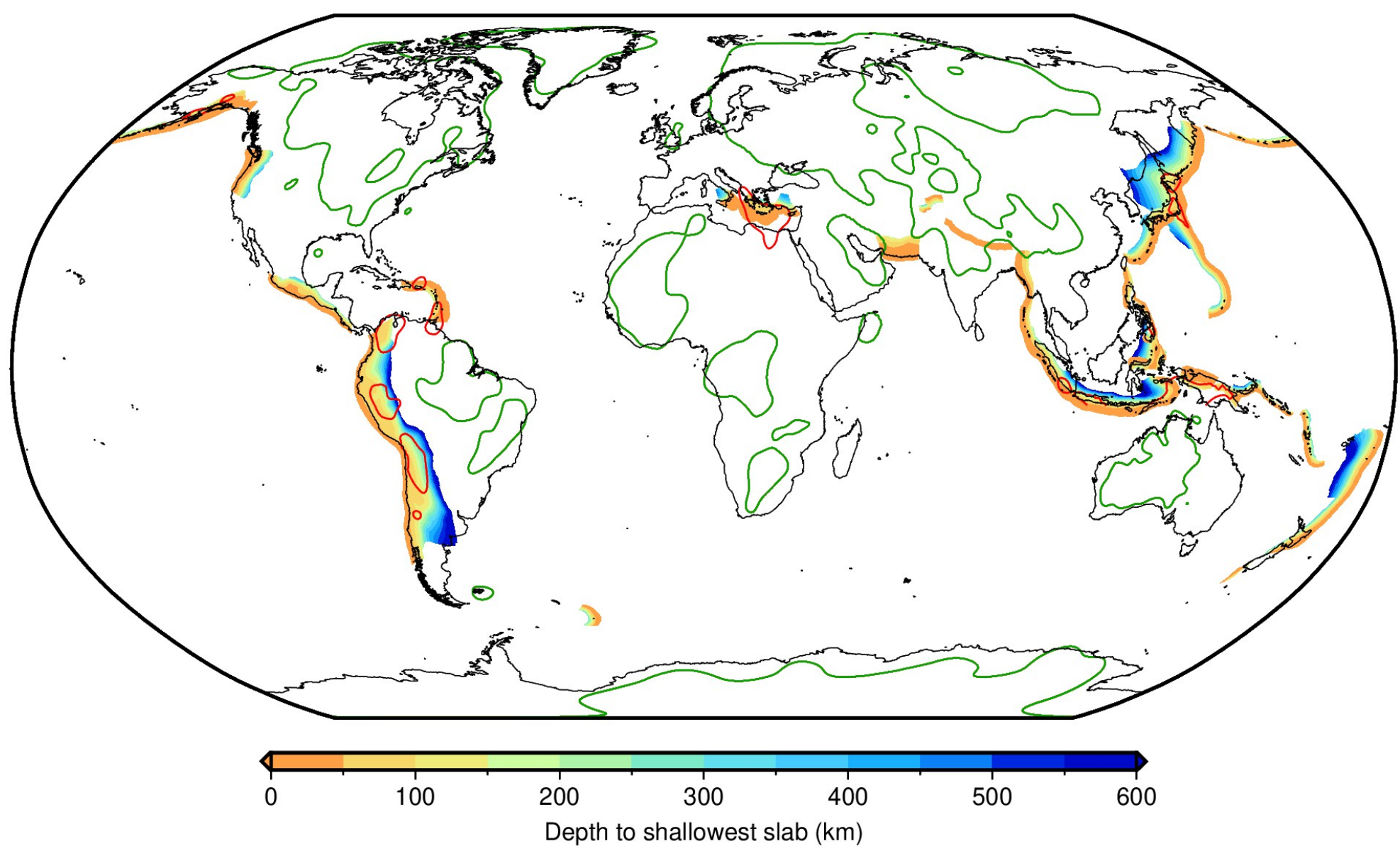

Figure S16: Subduction zones and areas of thick lithosphere. Depth of shallowest subducting slabs in the global Slab2 model (Hayes et al., 2018); red lines $=170 \mathrm{~km}$ thickness contours in LAB derived from SL2013sv that are potentially related to subducting slabs; green lines $=$ other contours of thick cratonic lithosphere.

None of the giant ( $>10 \mathrm{Mt}$ contained metal) sediment-hosted deposits are located at these subduction zones. Nevertheless, some of the smaller deposits can be, such as those in South America, Indonesia and Turkey. We have therefore manually excised $170 \mathrm{~km} \mathrm{LAB}$ contours that may potentially be related to slabs (red polygons on Figure S16) and repeated the statistical tests.

The CDF for all sediment-hosted base metal deposits is essentially unchanged by this procedure, with $\sim 85 \%$ of total metal still found within $200 \mathrm{~km}$ of the $170 \mathrm{~km}$ contour (Figure S17c). However, the deposit statistics are actually improved, with the D-value increasing from $0.270 \pm 0.020$ to $0.276 \pm 0.022$, changing the probability of the relationship occurring by random chance from 1 in 3.35 trillion to 1 in 10.6 trillion. The reason for this is that the reduction in contour extent results in fewer random continental locations falling near the line, with the percentage of total continental area within $200 \mathrm{~km}$ of the $170 \mathrm{~km}$ LAB thickness contour dropping from $34.3 \%$ to $31.0 \%$.

Nevertheless, we have chosen to use the full, non-excised LAB in the paper. Manual identification of potential slabs is a subjective process, with results dependent upon an individual's opinion. Furthermore, it is possible that rifted cratonic fragments may be transported into subduction zone settings (Cook et al., 1999), and thus not all of these subduction zone features are necessarily anomalous. We therefore prefer to keep our testing of the veracity of the observed relationship between LAB thickness and ore deposit locations as objective as possible. 

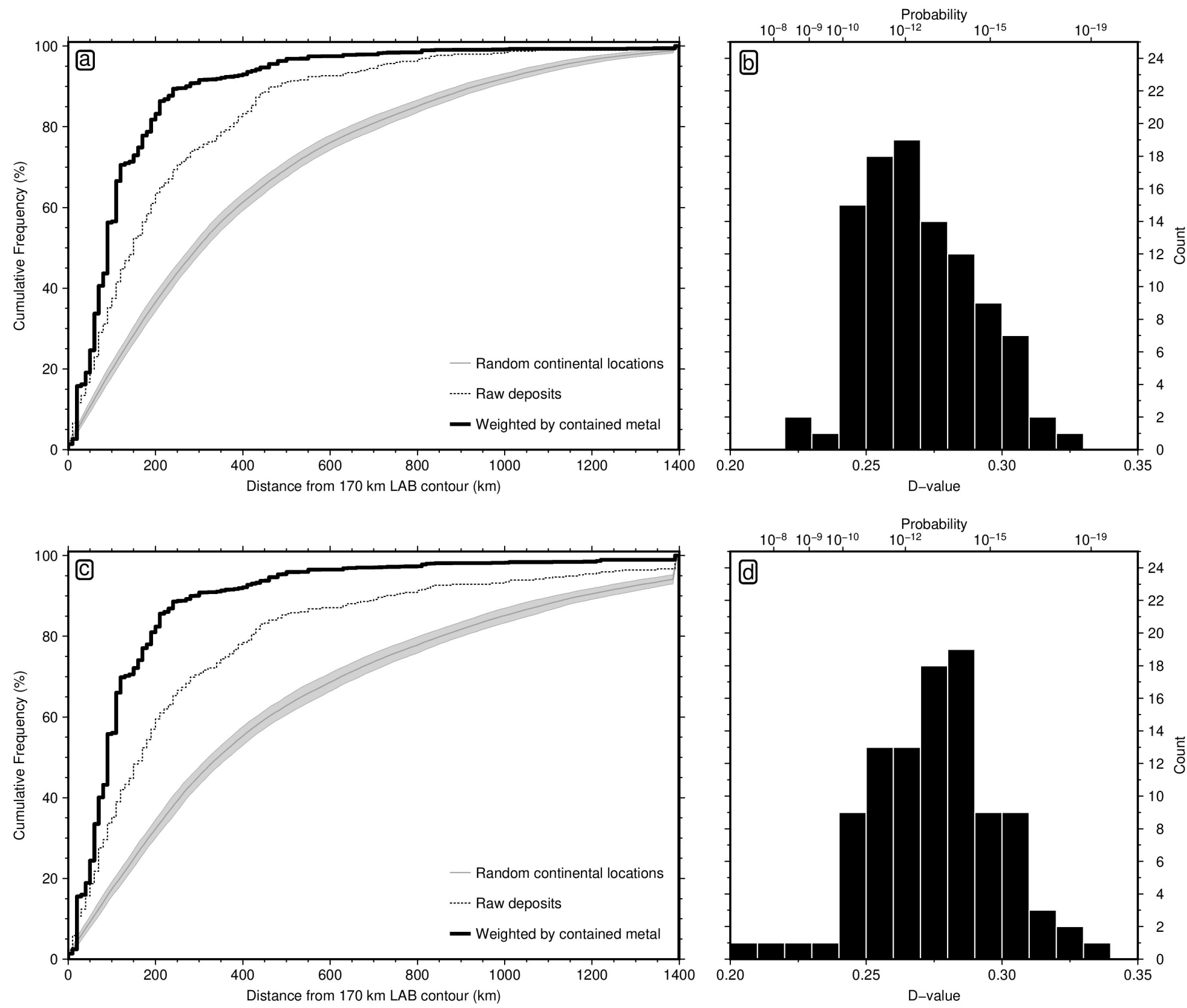

Figure S17: Effect of removing potentially anomalous features in subduction zone settings on deposit statistics. (a) Cumulative distribution functions for global sediment-hosted base metals with respect to all $170 \mathrm{~km}$ LAB thickness contours (green and red polygons in Figure S16); dotted line = simple count of number of deposits with increasing distance from the $170 \mathrm{~km}$ contour; solid black line $=$ deposits weighted by mass of contained metal; grey line/bounds = mean and standard deviation of 100 sets of equivalent number of randomly drawn continental locations. (b) Histogram of D-values for ensemble of 100 random CDFs calculated for a random test set of continental points compared with the non-mass-weighted CDF. (c) and (d) same but using $170 \mathrm{~km}$ LAB thickness contours with potentially anomalous subduction zone features removed (only green polygons in Figure S16). 


\section{$9 \quad$ Rift modelling of continental lithosphere}

To predict the subsidence and basal heat flow of a basin formed by rifting, we model the thermal evolution of the lithosphere during extension. Following McKenzie (1978), we assume thinning occurs by pure shear and that vertical heat transfer dominates. We start with the one-dimensional heat flow equation

$$
\rho(T, P, X) C_{P}(T, X) \frac{\partial T}{\partial t}=\frac{\partial}{\partial z}\left[k(T, P, X) \frac{\partial T}{\partial z}\right]+H(X)
$$

where $t$ is time, $z$ is depth, $T$ is temperature, $P$ is pressure, $X$ is composition, $\rho$ is density, $C_{P}$ is the isobaric specific heat capacity, $k$ is the thermal conductivity, and $H$ is the internal radiogenic heat production.

We solve Equation (22) numerically using an unconditionally stable time- and space-centered Crank-Nicholson finitedifference scheme with a predictor-corrector step (Press et al., 1992). Equation (22) is recast as

$$
\begin{aligned}
& -k_{j-\frac{1}{2}}^{n+1} T_{j-1}^{n+1}+\left[k_{j-\frac{1}{2}}^{n+1}+k_{j+\frac{1}{2}}^{n+1}+\frac{\left(\Delta z^{n+1}\right)^{2}}{\Delta t}\left(\rho_{j}^{n} C_{P j}^{n}+\rho_{j}^{m} C_{P j}^{m}\right)\right] T_{j}^{n+1}-k_{j+\frac{1}{2}}^{n+1} T_{j+1}^{n+1}= \\
& \frac{\left(\Delta z^{m}\right)^{2}}{\left(\Delta z^{n}\right)^{2}}\left\{k_{j-\frac{1}{2}}^{n} T_{j-1}^{n}-\left[k_{j-\frac{1}{2}}^{n}+k_{j+\frac{1}{2}}^{n}-\frac{\left(\Delta z^{n}\right)^{2}}{\Delta t}\left(\rho_{j}^{n} C_{P j}^{n}+\rho_{j}^{m} C_{P j}^{m}\right)\right] T_{j}^{n}+k_{j+\frac{1}{2}}^{n} T_{j+1}^{n}+2\left(\Delta z^{n}\right)^{2} H_{j}\right\}
\end{aligned}
$$

where $\Delta t$ is the time step, $\Delta z$ is the depth spacing between nodes, and $n$ and $j$ are the time and depth indices, respectively. Equation (23) is solved by tridiagonal elimination (Press et al., 1992). For the initial predictor phase of each time step, $m=n$, whilst in the subsequent corrector phases, $m=n+1$. We use a Lagrangian reference frame, whereby $\Delta z$ is initially set to $1 \mathrm{~km}$ and updates using the strain rate for each timestep. Timesteps are calculated using a Courant-Friedrichs-Lewy condition with the Courant number set equal to five, such that

$$
\Delta t=\min _{j}\left[\frac{5 \Delta z^{2} \rho_{j} C_{P j}}{k_{j}}\right]
$$

and $T^{n+1}$ typically convergences to within a tolerance of $0.001^{\circ} \mathrm{C}$ after two corrector phases. The strain rate is constant during rifting and is set by rift duration and a stretching factor, $\beta$, which is the ratio of initial to final crustal thickness.

For the crustal layer, we adopt constant thermal parameters of $C_{P}=750 \mathrm{~J} \mathrm{~kg}^{-1} \mathrm{~K}^{-1}$ and $k=2.5 \mathrm{~W} \mathrm{~m}^{-1} \mathrm{~K}^{-1}$. Crustal density is $\rho=2800 \mathrm{~kg} \mathrm{~m}^{-3}$ for regular continental lithosphere and is $\rho=2900 \mathrm{~kg} \mathrm{~m}^{-3}$ for cratonic lithosphere, in accordance with expectations for an increase in bulk density with increasing crustal thickness (Christensen \& Mooney, 1995). For the mantle, we use temperature and pressure dependent parameters that have been derived from experimental data on olivine. Density is calcuated according to Equation (14), with $\rho_{\circ}=3330 \mathrm{~kg} \mathrm{~m}^{-3}$ in regular lithospheric mantle, and $3280 \mathrm{~kg} \mathrm{~m}^{-3}$ in cratonic lithosphere, which has been chemically depleted by melt extraction. The effect of pressure on heat capacity is minimal throughout the upper $\sim 300 \mathrm{~km}$ of the mantle (Hofmeister, 2007). We therefore use the Korenaga \& Korenaga (2016) purely temperature-dependent parameteristaion

$$
C_{P}(T)=c_{0}-\frac{c_{1}}{\sqrt{T}}-\frac{c_{2}}{T^{3}}
$$

where $c_{0}=1580, c_{1}=12230$ and $c_{2}=1694 \times 10^{6}$. Mantle conductivity is pressure- and temperature-dependent and includes contributions from both phonons (lattice conductivity, $k_{l a t}$ ) and photons (radiative conductivity, $k_{r a d}$, which is poorly constrained by experimental data). Total conductivity is expressed using

$$
k(T, P)=\kappa_{l a t}(T) \rho(T, P) C_{P}(T) \exp \left[\frac{\partial \ln (k)}{\partial P} P\right]+k_{\text {rad }}(T)
$$

where $\frac{\partial \ln (k)}{\partial P}=0.05 \mathrm{~W} \mathrm{~m}^{-1} \mathrm{~K}^{-1} \mathrm{GPa}^{-1}$ (Hofmeister, 2007). $\kappa_{\text {lat }}(T)$ is the temperature-dependent lattice diffusivity and is given by

$$
\kappa_{\text {lat }}(T)=\left[\kappa_{0}+\kappa_{1} \exp \left(-\frac{T-T_{0}}{\kappa_{2}}\right)+\kappa_{3} \exp \left(-\frac{T-T_{0}}{\kappa_{4}}\right)\right] \times 10^{-6}
$$




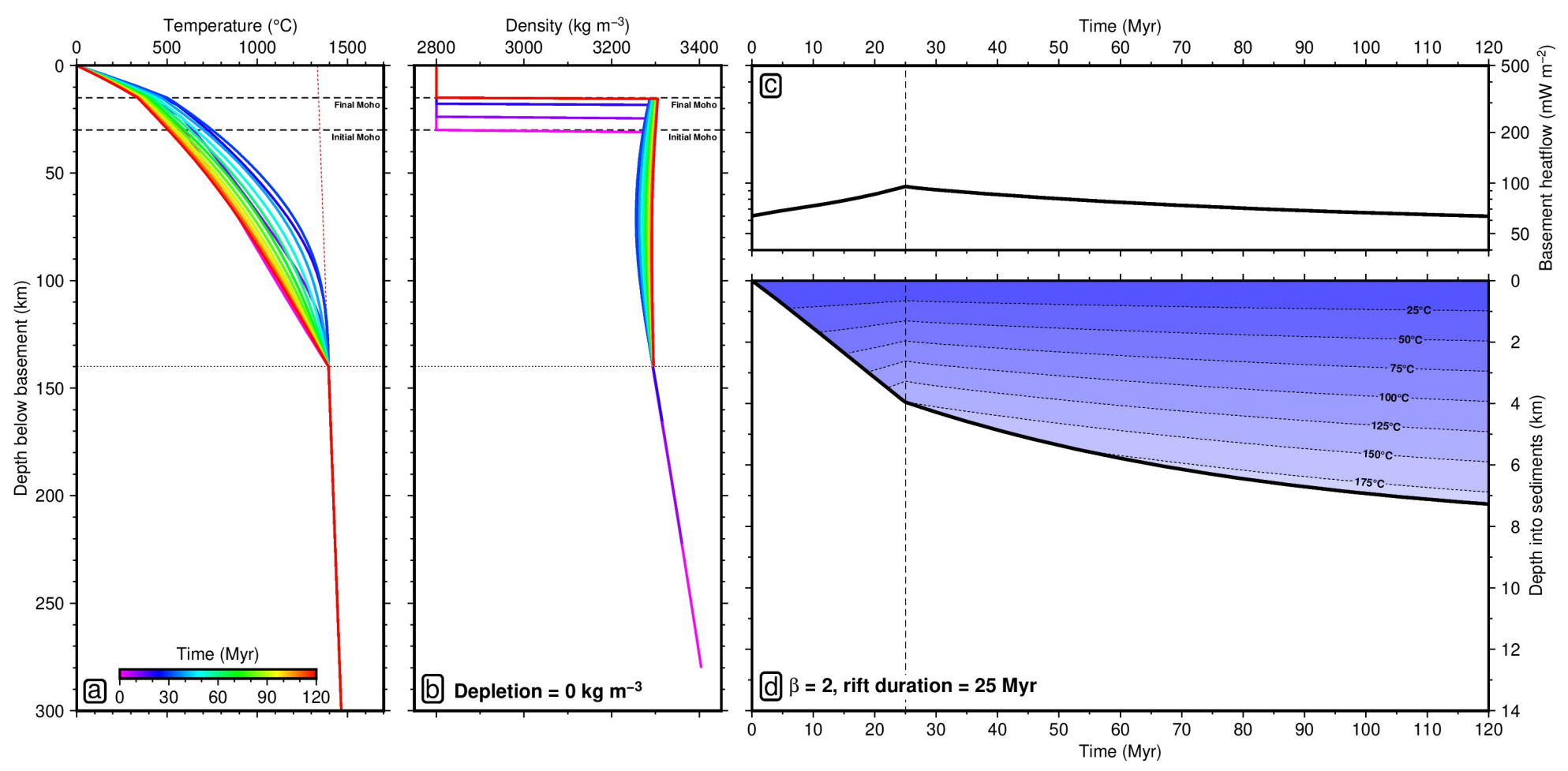

Figure S18: Regular continental lithosphere with $\beta=2$ and 25 Myr rift duration. (a) Thermal evolution of the lithosphere. (b) Density evolution of the lithosphere. (c) Heat flow through the top of the crust. (d) Sediment-loaded subsidence of the basin, coloured by temperature structure of the sedimentary pile.

where $\kappa_{0}=0.565, \kappa_{1}=0.67, \kappa_{2}=590, \kappa_{3}=1.4, \kappa_{4}=135$, and $T_{0}=273 \mathrm{~K}$ (Pertermann \& Hofmeister, 2006). The parameterisation for $k_{\text {rad }}$ is taken from Grose \& Afonso (2013), based on earlier work by Hofmeister (2005), and is given by

$$
k_{\text {rad }}(T)=A_{r} \exp \left[-\frac{\left(T-T_{A}\right)^{2}}{2 x_{A}^{2}}\right]+B_{r} \exp \left[-\frac{\left(T-T_{B}\right)^{2}}{2 x_{B}^{2}}\right]
$$

where

$$
\begin{aligned}
& A_{r}=1.8\left[1-\exp \left(\frac{-d^{1.3}}{0.15}\right)\right]-\left[1-\exp \left(\frac{-\sqrt{d}}{5}\right)\right] \\
& B_{r}=11.7 \exp \left(\frac{-d}{0.159}\right)+6 \exp \left(\frac{-d^{3}}{10}\right) \\
& T_{A}=490+1850 \exp \left(\frac{-d^{0.315}}{0.825}\right)+875 \exp \left(\frac{-d}{0.18}\right) \\
& T_{B}=2700+9000 \exp \left(\frac{-\sqrt{d}}{0.205}\right) \\
& x_{A}=167.5+505 \exp \left(\frac{-\sqrt{d}}{0.85}\right) \\
& x_{B}=465+1700 \exp \left(\frac{-d^{0.94}}{0.175}\right)
\end{aligned}
$$

and $d$ is the grain size in centimeters, assumed to be $d=0.5 \mathrm{~cm}$.

For the finite difference scheme boundary conditions, we fix the surface node to have $T_{0}^{n}=T_{0}=273 \mathrm{~K}$, whilst the initial basal node has an adiabatic value of $(1606+0.44 z) \mathrm{K}$, equivalent to a potential temperature of $1333^{\circ} \mathrm{C}$. In cratonic areas, the lithospheric mantle is thicker than standard continental lithosphere and has been chemically depleted. During the rift phase, this basal node shallows through time and non-depleted asthenospheric mantle rises adiabatically beneath. If this basal node becomes shallower than the initial thickness of standard continental lithosphere, we update the index at which this lower boundary condition is applied to the node closest to this standard depth. Heat flow 

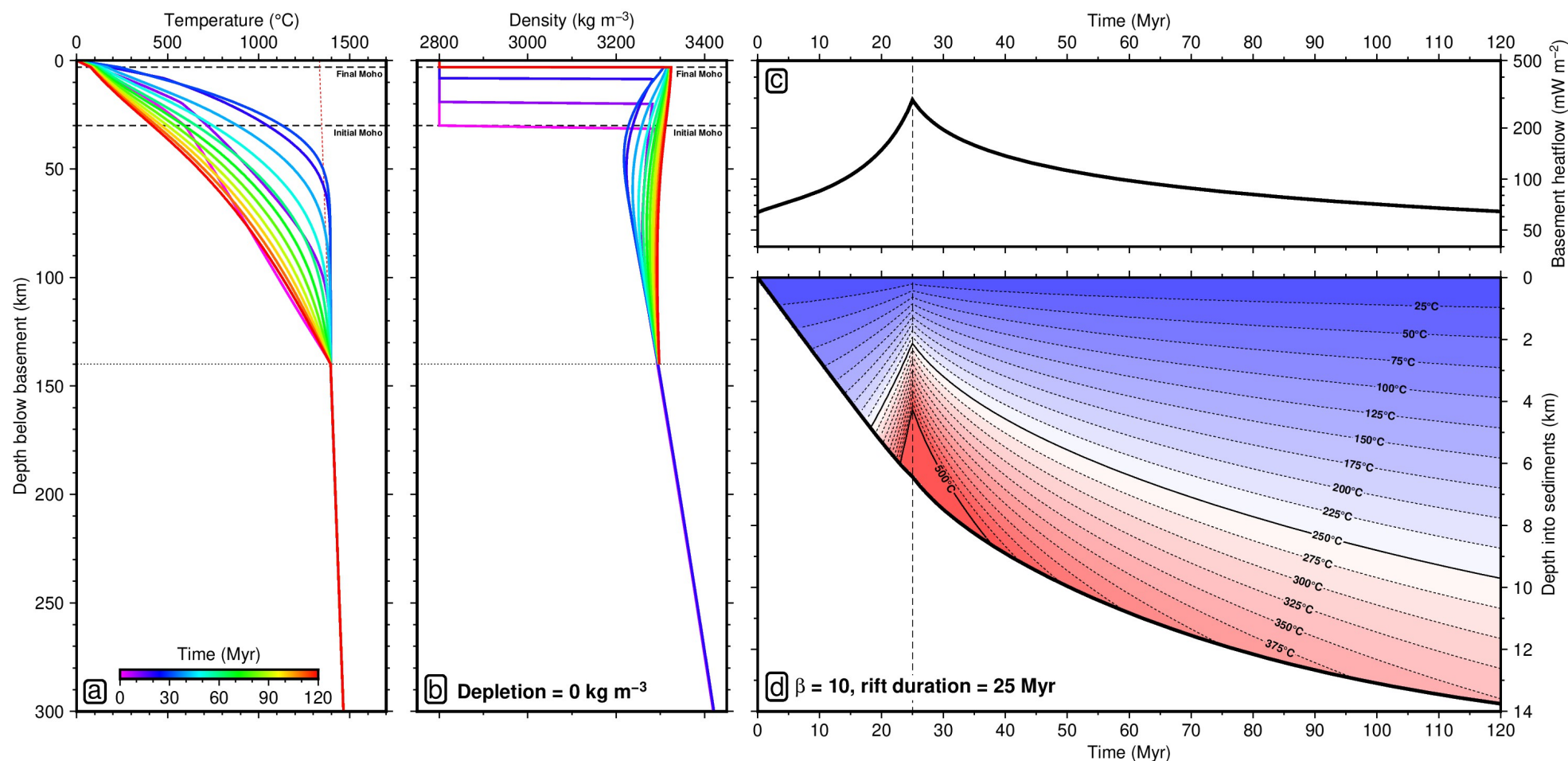

Figure S19: Regular continental lithosphere with $\beta=10$ and 25 Myr rift duration. (a) Thermal evolution of the lithosphere. (b) Density evolution of the lithosphere. (c) Heat flow through the top of the crust. (d) Sediment-loaded subsidence of the basin, coloured by temperature structure of the sedimentary pile.

through the top of the crust, $Q_{H}(t)$, and subsidence, $S(t)$, are calculated according to

$$
\begin{gathered}
Q_{H}^{n}=\frac{\left(k_{0}^{n}+k_{1}^{n}\right)\left(T_{1}^{n}-T_{0}^{n}\right)}{2 \Delta z} \\
S^{n}=\frac{\sum_{j} \rho_{j}^{n} \Delta z^{n}-\sum_{j}^{\mathrm{J}} \rho_{j}^{0} \Delta z^{0}}{\rho_{\mathrm{J}}-\rho_{\text {infill }}}
\end{gathered}
$$

where $J$ is the index of the node at the depth of the original lithospheric thickness, $\rho_{\mathrm{J}}$ is the adiabatic density of standard mantle at this depth, and $\rho_{\text {infill }}=2200 \mathrm{~kg} \mathrm{~m}^{-3}$ is the density of material that infills the basin, which we assume to be
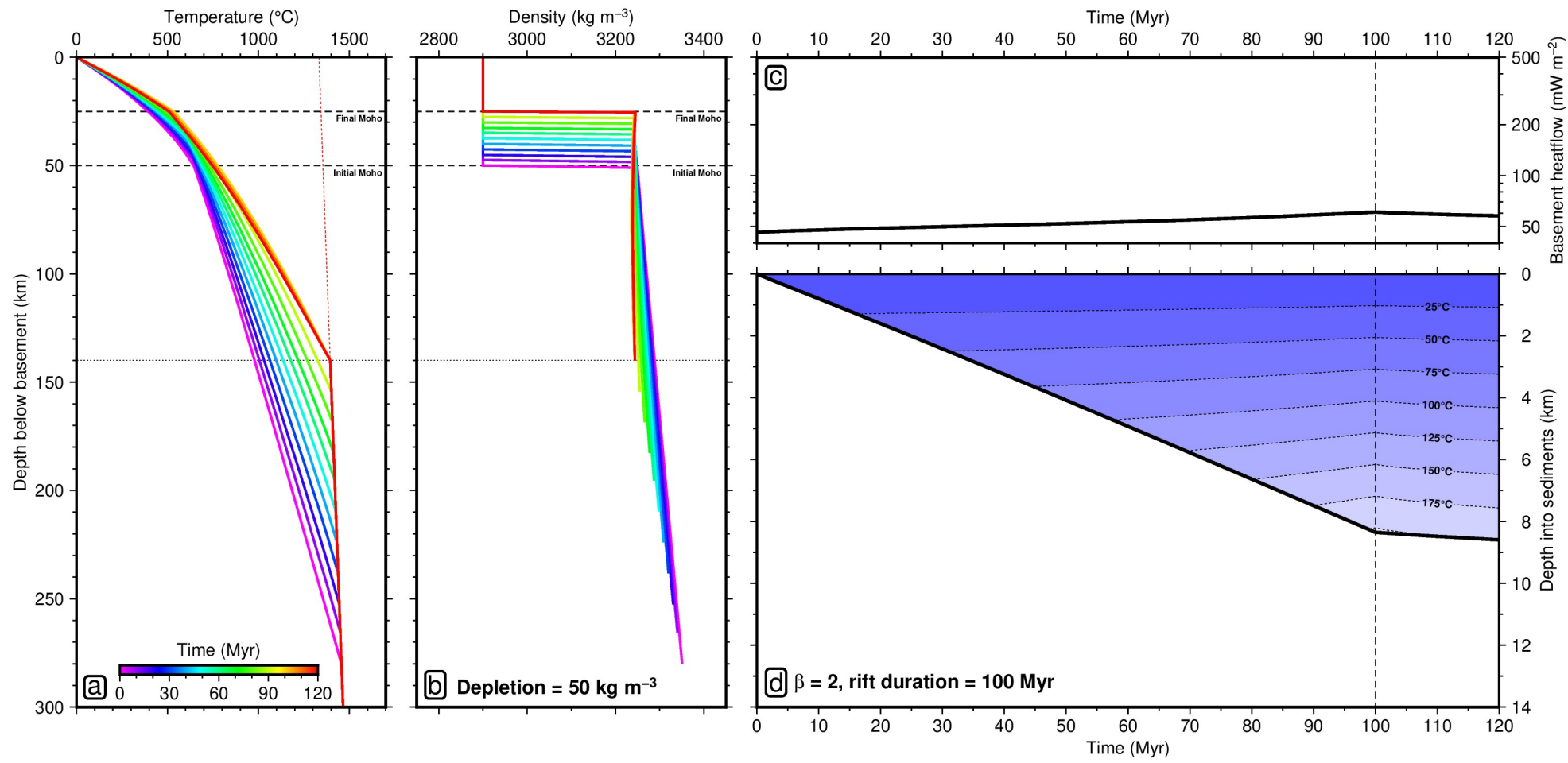

Figure S20: Cratonic continental lithosphere with $\beta=2$ and 100 Myr rift duration. (a) Thermal evolution of the lithosphere. (b) Density evolution of the lithosphere. (c) Heat flow through the top of the crust. (d) Sediment-loaded subsidence of the basin, coloured by temperature structure of the sedimentary pile. 
sediments. Figures S18-S20 show the results of thermal modelling of rifting continental lithosphere on basin subsidence and temperature of the sedimentary pile.

\section{Regional deposit maps}

Regional maps of Africa, Europe, Asia, Australia, Antarctica, North and South America are provided, showing the global SL2013sv LAB model (except for Australia) with known sediment-hosted base metal deposits.

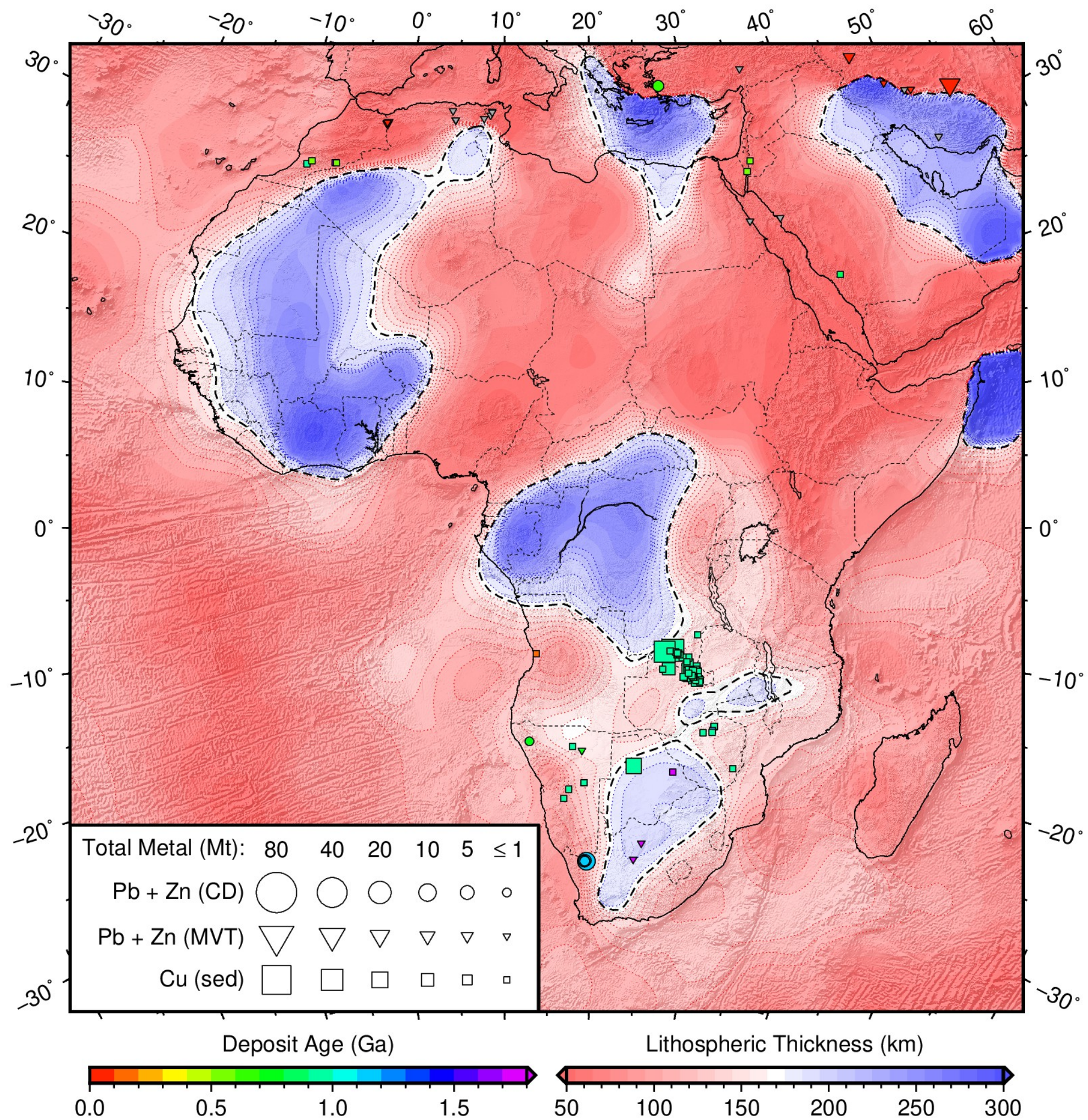

Figure S21: Distribution of sediment-hosted base metal deposits as a function of lithospheric thickness in Africa. Global LAB derived from SL2013sv tomography model using a calibrated anelasticity parameterisation (Schaeffer \& Lebedev, 2013; Yamauchi \& Takei, 2016); black dashed contour $=170 \mathrm{~km}$ LAB thickness; symbols = deposit locations; area proportional to estimate of total contained mass of metal (Mt = megatonnes); unknown deposit size given $1 \mathrm{Mt}$ symbol; colour = ore body formation age (billion years); unknown age plotted in grey; circles = clastic-dominated lead-zinc $(\mathrm{PbZn-CD})$; triangles = Mississippi Valley type lead-zinc $(\mathrm{PbZn-MVT})$; squares $=$ sedimentary copper $(\mathrm{Cu}-\mathrm{sed})$. 


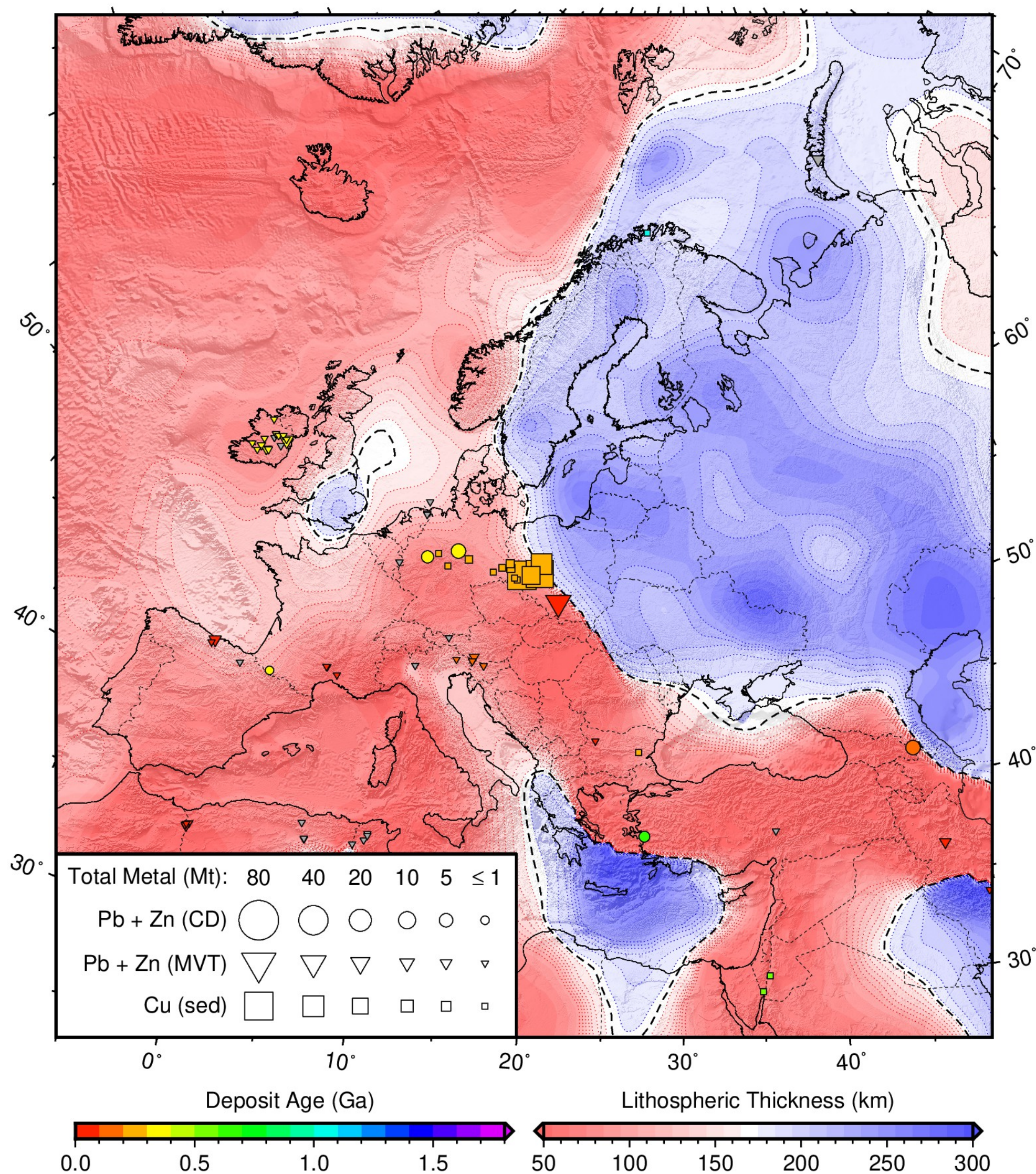

Figure S22: Distribution of sediment-hosted base metal deposits as a function of lithospheric thickness in Europe. Global LAB derived from SL2013sv tomography model using a calibrated anelasticity parameterisation (Schaeffer \& Lebedev, 2013; Yamauchi \& Takei, 2016); black dashed contour $=170 \mathrm{~km}$ LAB thickness; symbols = deposit locations; area proportional to estimate of total contained mass of metal $(\mathrm{Mt}=$ megatonnes); unknown deposit size given $1 \mathrm{Mt}$ symbol; colour = ore body formation age (billion years); unknown age plotted in grey; circles = clastic-dominated lead-zinc $(\mathrm{PbZn}-\mathrm{CD})$; triangles = Mississippi Valley type lead-zinc $(\mathrm{PbZn-MVT})$; squares = sedimentary copper $(\mathrm{Cu}-\mathrm{sed})$. 


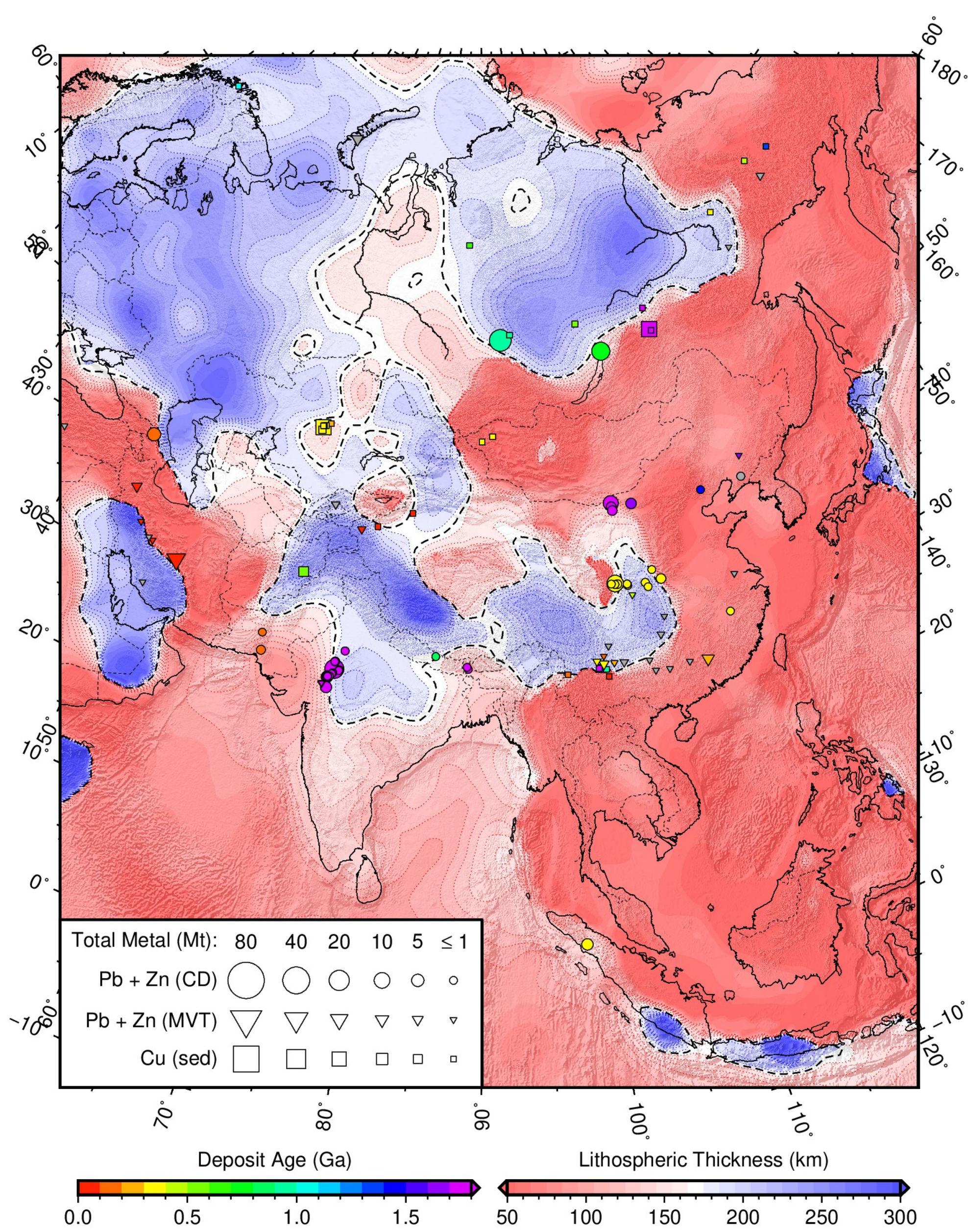

Figure S23: Distribution of sediment-hosted base metal deposits as a function of lithospheric thickness in Asia. Global LAB derived from SL2013sv tomography model using a calibrated anelasticity parameterisation (Schaeffer \& Lebedev, 2013; Yamauchi \& Takei, 2016); black dashed contour $=170 \mathrm{~km}$ LAB thickness; symbols $=$ deposit locations; area proportional to estimate of total contained mass of metal $(\mathrm{Mt}=$ megatonnes); unknown deposit size given $1 \mathrm{Mt}$ symbol; colour = ore body formation age (billion years); unknown age plotted in grey; circles = clastic-dominated lead-zinc (PbZn-CD); triangles = Mississippi Valley type lead-zinc (PbZn-MVT); squares = sedimentary copper (Cu-sed). 


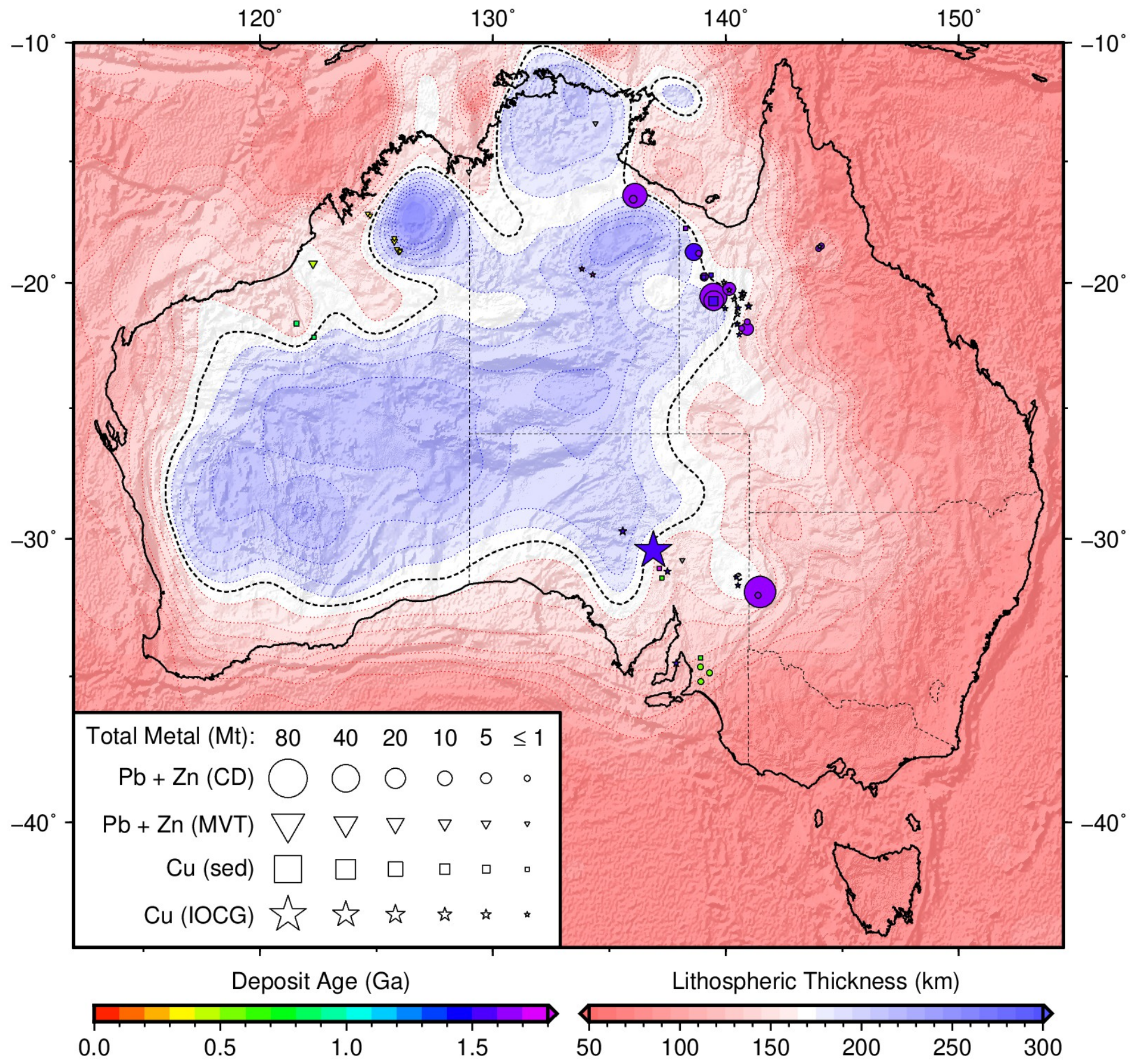

Figure S24: Distribution of sediment-hosted and IOCG base metal deposits as a function of lithospheric thickness in Australia. Regional LAB derived from FR12 tomography model using a calibrated anelasticity parameterisation (Fishwick \& Rawlinson, 2012; Yamauchi $\&$ Takei, 2016); black dashed contour $=170 \mathrm{~km}$ LAB thickness; symbols $=$ deposit locations; area proportional to estimate of total contained mass of metal ( $\mathrm{Mt}=$ megatonnes); unknown deposit size given $1 \mathrm{Mt}$ symbol; colour = ore body formation age (billion years); unknown age plotted in grey; circles = clastic-dominated lead-zinc $(\mathrm{PbZn}-\mathrm{CD})$; triangles = Mississippi Valley type lead-zinc $(\mathrm{PbZn-MVT})$; squares $=$ sedimentary copper (Cu-sed); stars = iron-oxide-copper-gold (IOCG). 


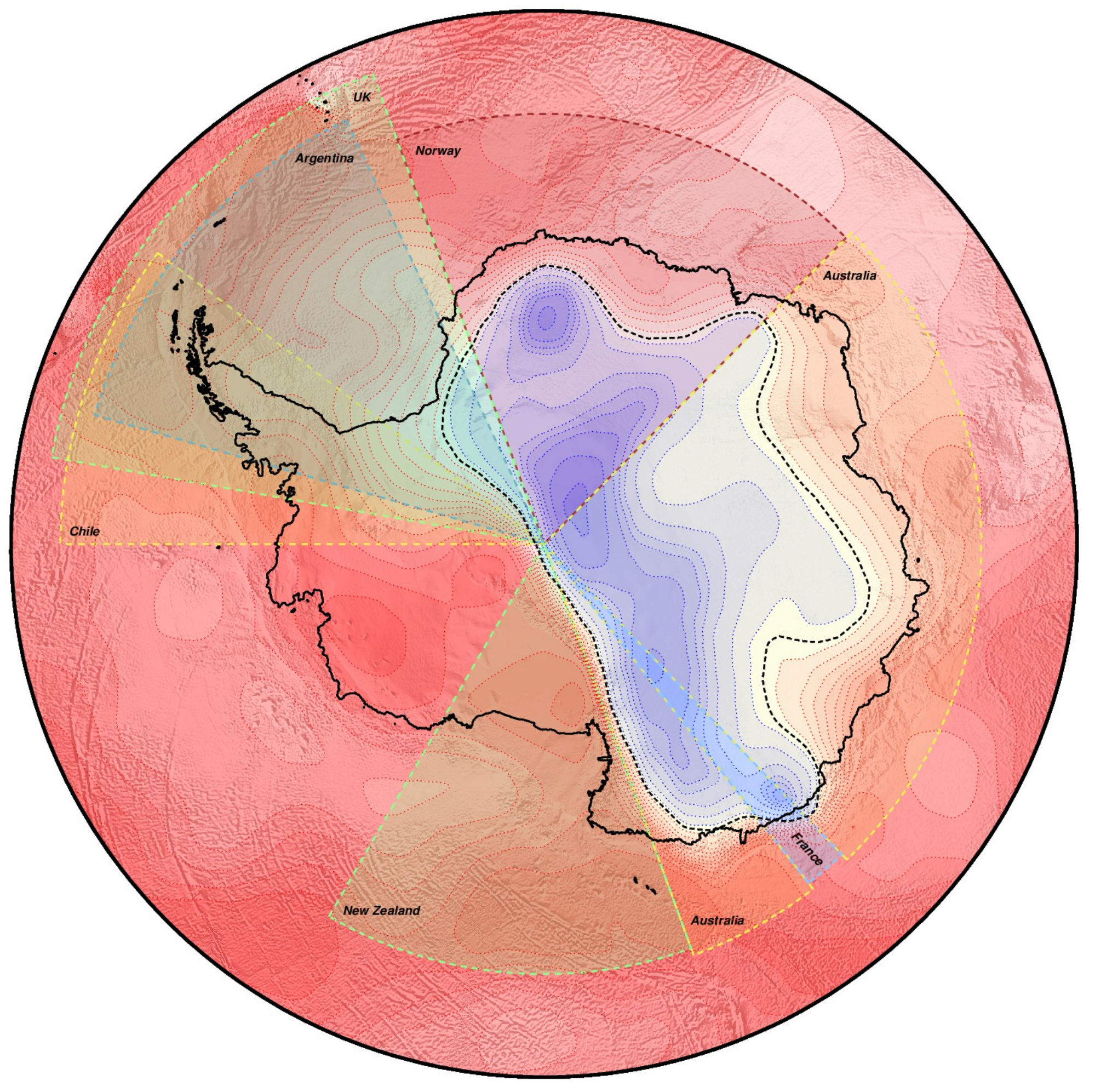

Lithospheric Thickness $(\mathrm{km})$

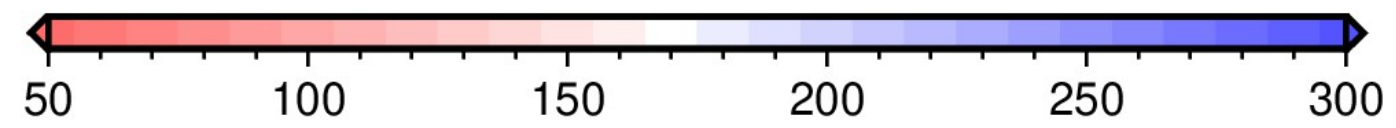

Figure S25: Lithospheric thickness in Antarctica. Global LAB derived from SL2013sv tomography model using a calibrated anelasticity parameterisation (Schaeffer \& Lebedev, 2013; Yamauchi \& Takei, 2016); black dashed contour = 170 km LAB thickness; coloured segments $=$ approximate extent of principal territorial claims by sovereign states. 


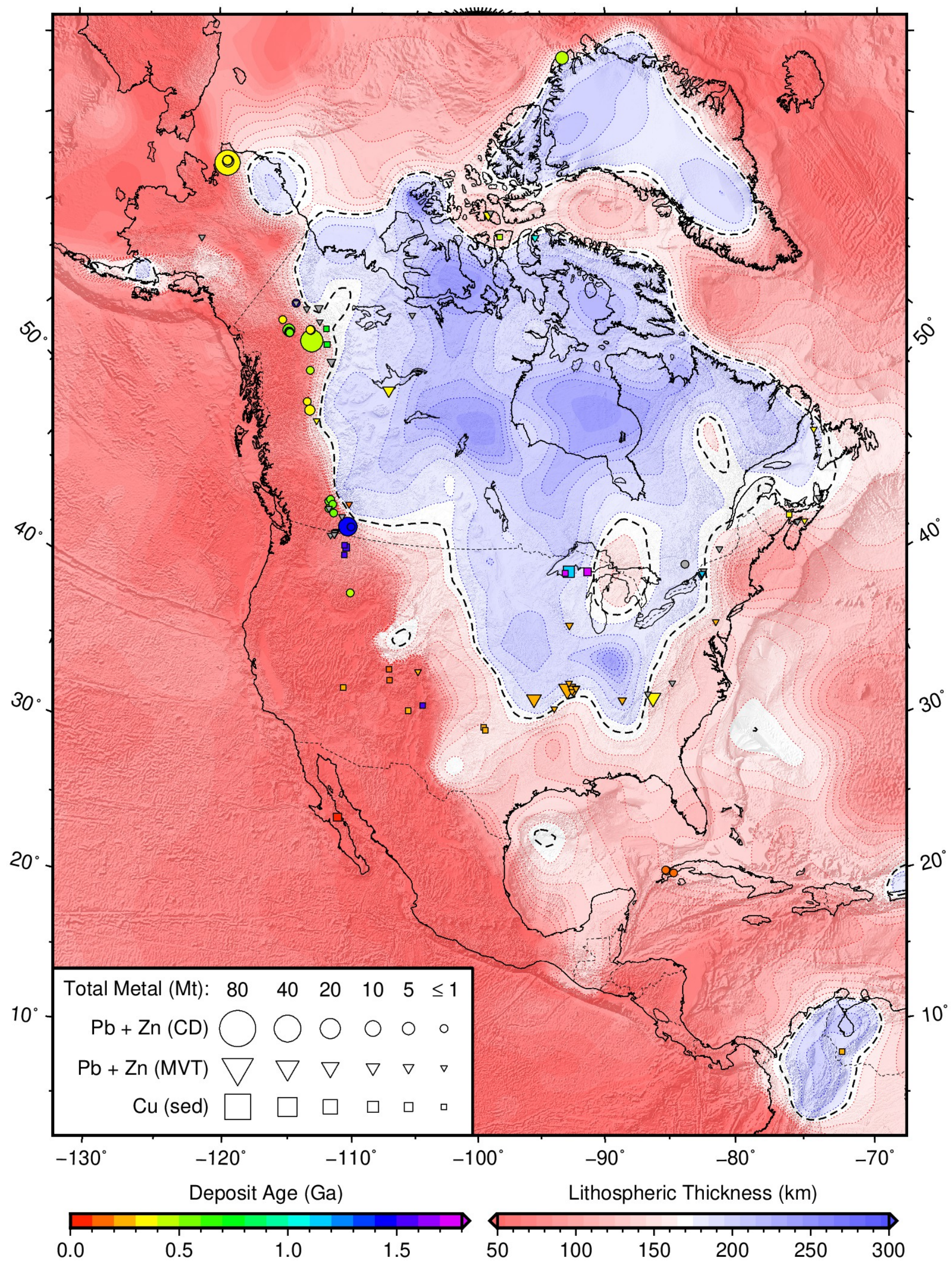

Figure S26: Distribution of sediment-hosted base metal deposits as a function of lithospheric thickness in North America. Global LAB derived from SL2013sv tomography model using a calibrated anelasticity parameterisation (Schaeffer \& Lebedev, 2013; Yamauchi $\&$ Takei, 2016); black dashed contour $=170 \mathrm{~km} \mathrm{LAB}$ thickness; symbols = deposit locations; area proportional to estimate of total contained mass of metal ( $\mathrm{Mt}=$ megatonnes); unknown deposit size given $1 \mathrm{Mt}$ symbol; colour = ore body formation age (billion years); unknown age plotted in grey; circles = clastic-dominated lead-zinc $(\mathrm{PbZn}-\mathrm{CD})$; triangles = Mississippi Valley type lead-zinc $(\mathrm{PbZn-MVT})$; squares $=$ sedimentary copper (Cu-sed). 


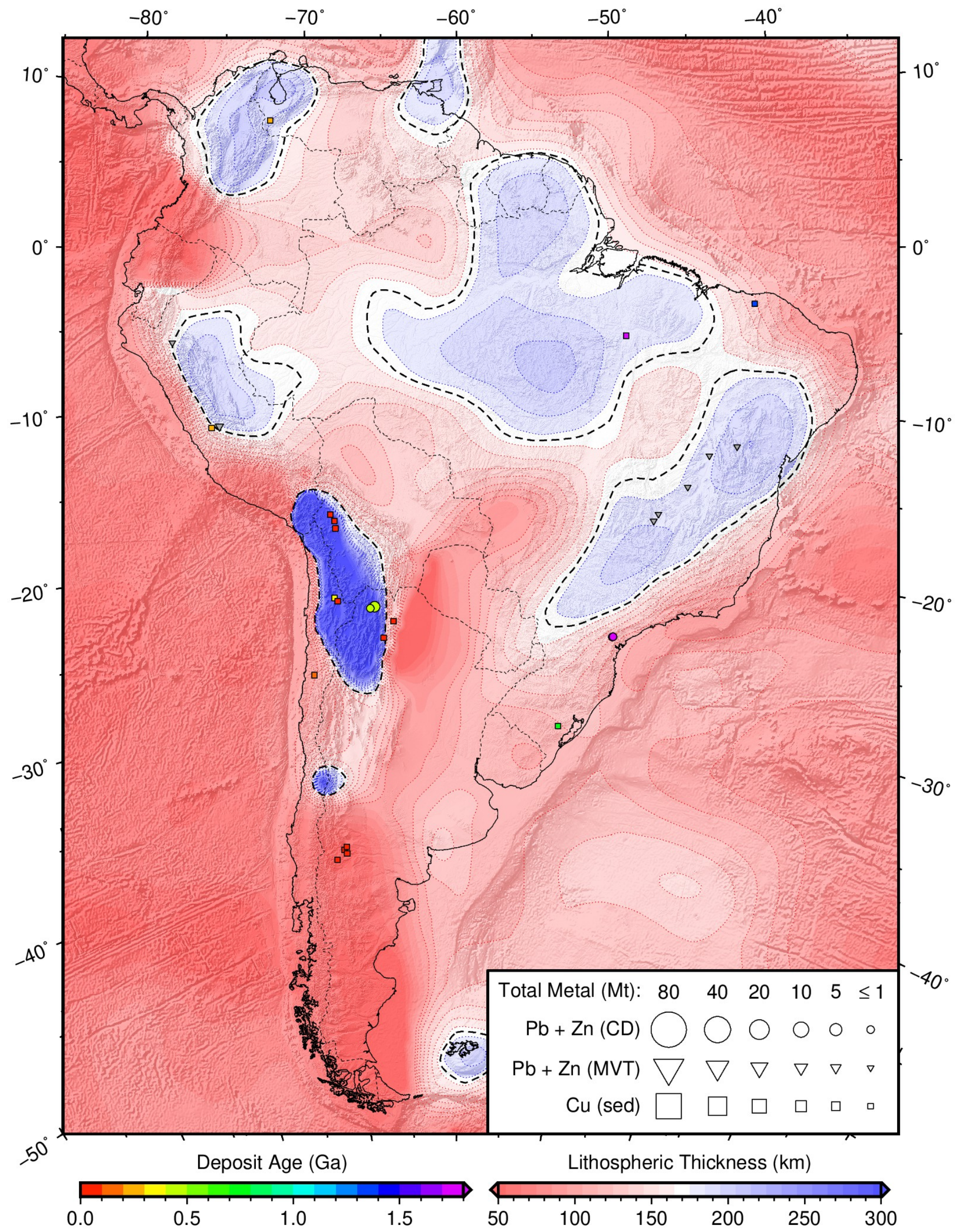

Figure S27: Distribution of sediment-hosted base metal deposits as a function of lithospheric thickness in South America. Global LAB derived from SL2013sv tomography model using a calibrated anelasticity parameterisation (Schaeffer \& Lebedev, 2013; Yamauchi $\&$ Takei, 2016); black dashed contour $=170 \mathrm{~km} \mathrm{LAB}$ thickness; symbols = deposit locations; area proportional to estimate of total contained mass of metal ( $\mathrm{Mt}=$ megatonnes); unknown deposit size given $1 \mathrm{Mt}$ symbol; colour = ore body formation age (billion years); unknown age plotted in grey; circles = clastic-dominated lead-zinc $(\mathrm{PbZn-CD})$; triangles = Mississippi Valley type lead-zinc $(\mathrm{PbZn-MVT})$; squares $=$ sedimentary copper ( $\mathrm{Cu}$-sed). 


\section{Inventory of base metal deposits}

Figures S30-S32 show deposit locations, age distributions with respect to lithospheric thickness, and KolmogorovSmirnov statistical test results for each individual deposit type compiled in this study (Methods). These are followed by tabulated information and associated references for each individual deposit, which is also available as a spreadsheet through the online Supplementary Information.

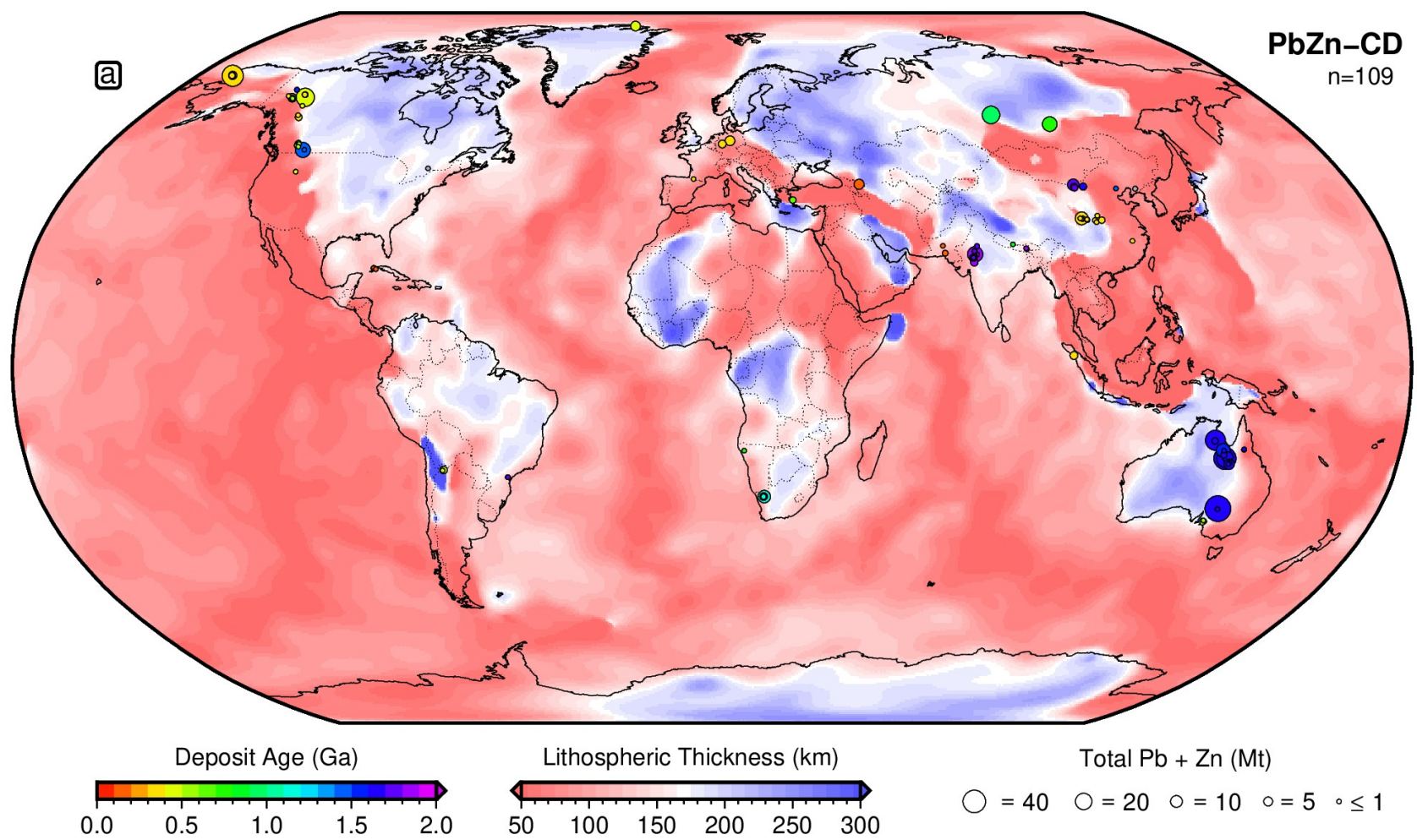

Probability
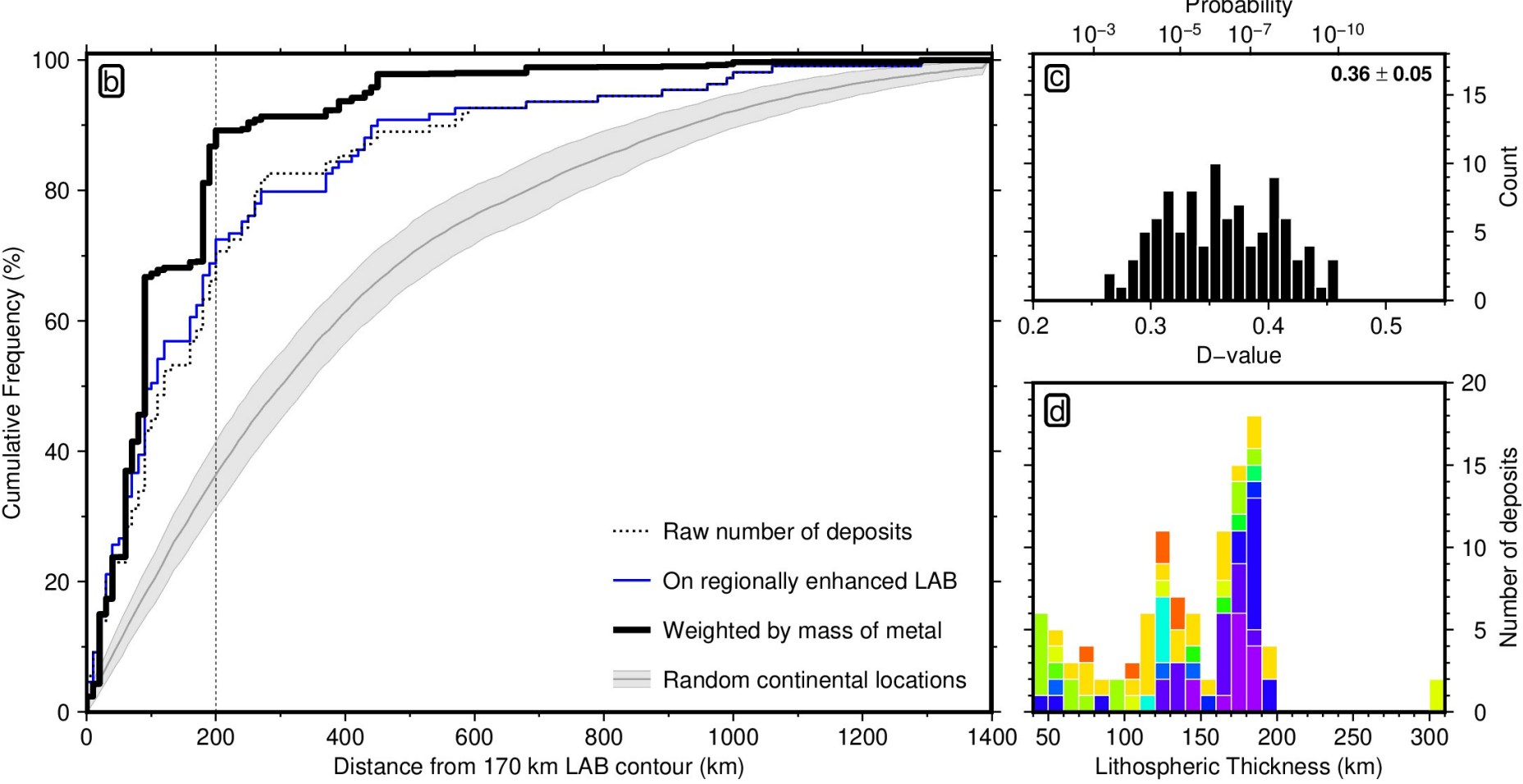

Figure S28: 109 clastic-dominated lead-zinc deposits from Table 2. (a) LAB derived from SL2013sv tomography model using a calibrated anelasticity parameterisation (Schaeffer \& Lebedev, 2013; Yamauchi \& Takei, 2016). Circles = deposit locations; area proportional to estimate of total contained mass of metal ( $\mathrm{Mt}=$ megatonnes); unknown deposit size given $1 \mathrm{Mt}$ symbol; colour $=$ ore body formation age (billion years); unknown age plotted in grey. (b) Different approaches for generating cumulative distribution functions. Dotted line = simple count of number of deposits with increasing distance from the $170 \mathrm{~km}$ contour in global LAB map; blue line $=$ simple count where Australian LAB has been replaced with regionally enhanced map (Figure S11a); solid black line = deposits weighted by mass of contained lead and zinc on regionally enhanced map; grey line/bounds = mean and standard deviation of 100 sets of equivalent number of randomly drawn continental locations, with respect to regionally enhanced LAB. (c) Histogram of 100 D-values calculated for each random test set and a non-mass-weighted, locally enhanced CDF (blue CDF); inset lists mean and standard deviation of D-values; associated probabilities shown across top. (d) Histogram of deposit occurrence as a function of lithospheric thickness, coloured by deposit age. 

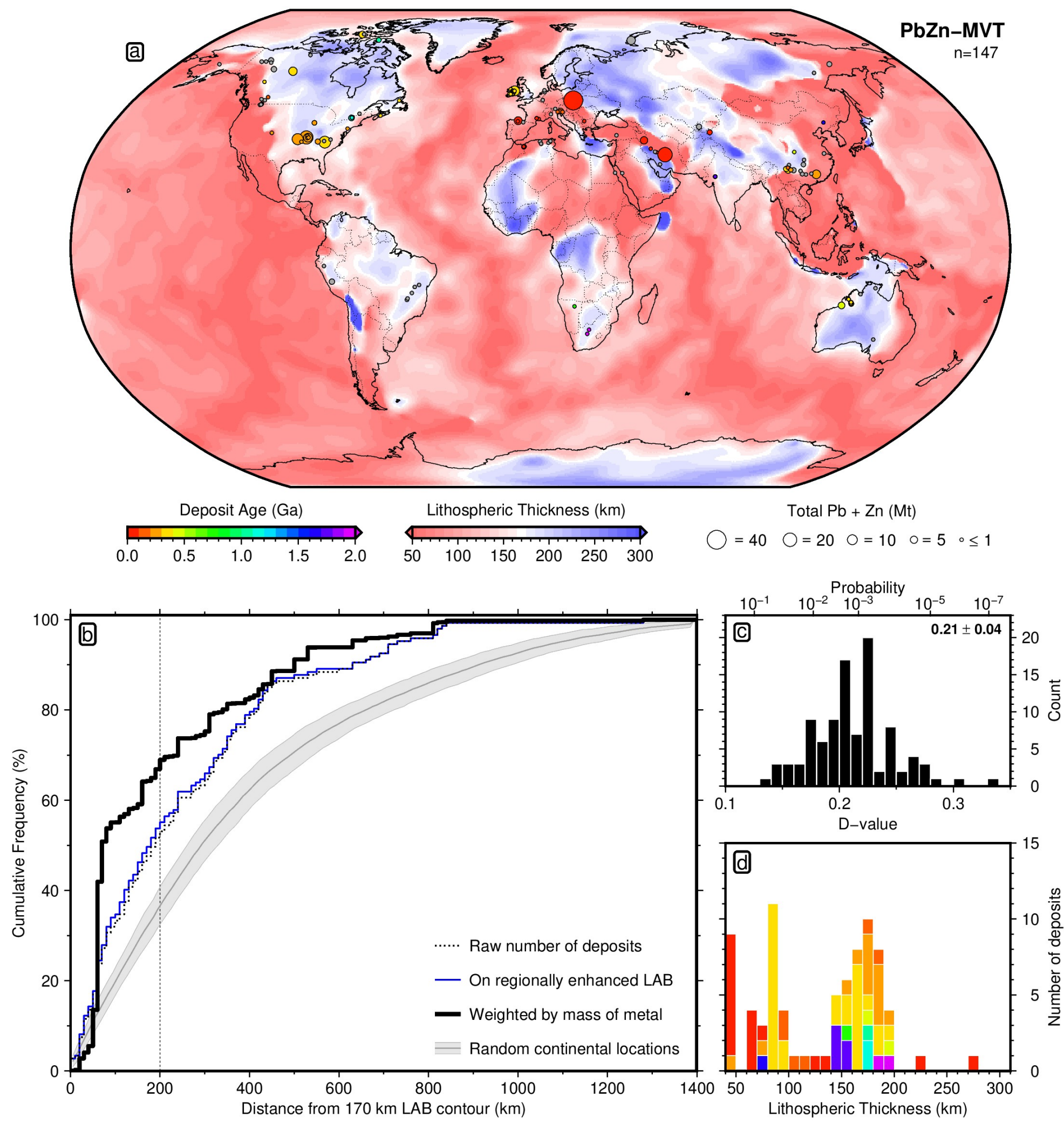

Figure S29: 147 Mississippi Valley-type lead-zinc deposits from Table 3. (a) LAB derived from SL2013sv tomography model using a calibrated anelasticity parameterisation (Schaeffer \& Lebedev, 2013; Yamauchi \& Takei, 2016). Circles = deposit locations; area proportional to estimate of total contained mass of metal ( $\mathrm{Mt}=$ megatonnes); unknown deposit size given $1 \mathrm{Mt}$ symbol; colour $=$ ore body formation age (billion years); unknown age plotted in grey. (b) Different approaches for generating cumulative distribution functions. Dotted line $=$ simple count of number of deposits with increasing distance from the $170 \mathrm{~km}$ contour in global LAB map; blue line $=$ simple count where Australian LAB has been replaced with regionally enhanced map (Figure S11a); solid black line = deposits weighted by mass of contained lead and zinc on regionally enhanced map; grey line/bounds = mean and standard deviation of 100 sets of equivalent number of randomly drawn continental locations, with respect to regionally enhanced LAB. (c) Histogram of 100 D-values calculated for each random test set and a non-mass-weighted, locally enhanced CDF (blue CDF); inset lists mean and standard deviation of D-values; associated probabilities shown across top. (d) Histogram of deposit occurrence as a function of lithospheric thickness, coloured by deposit age. 


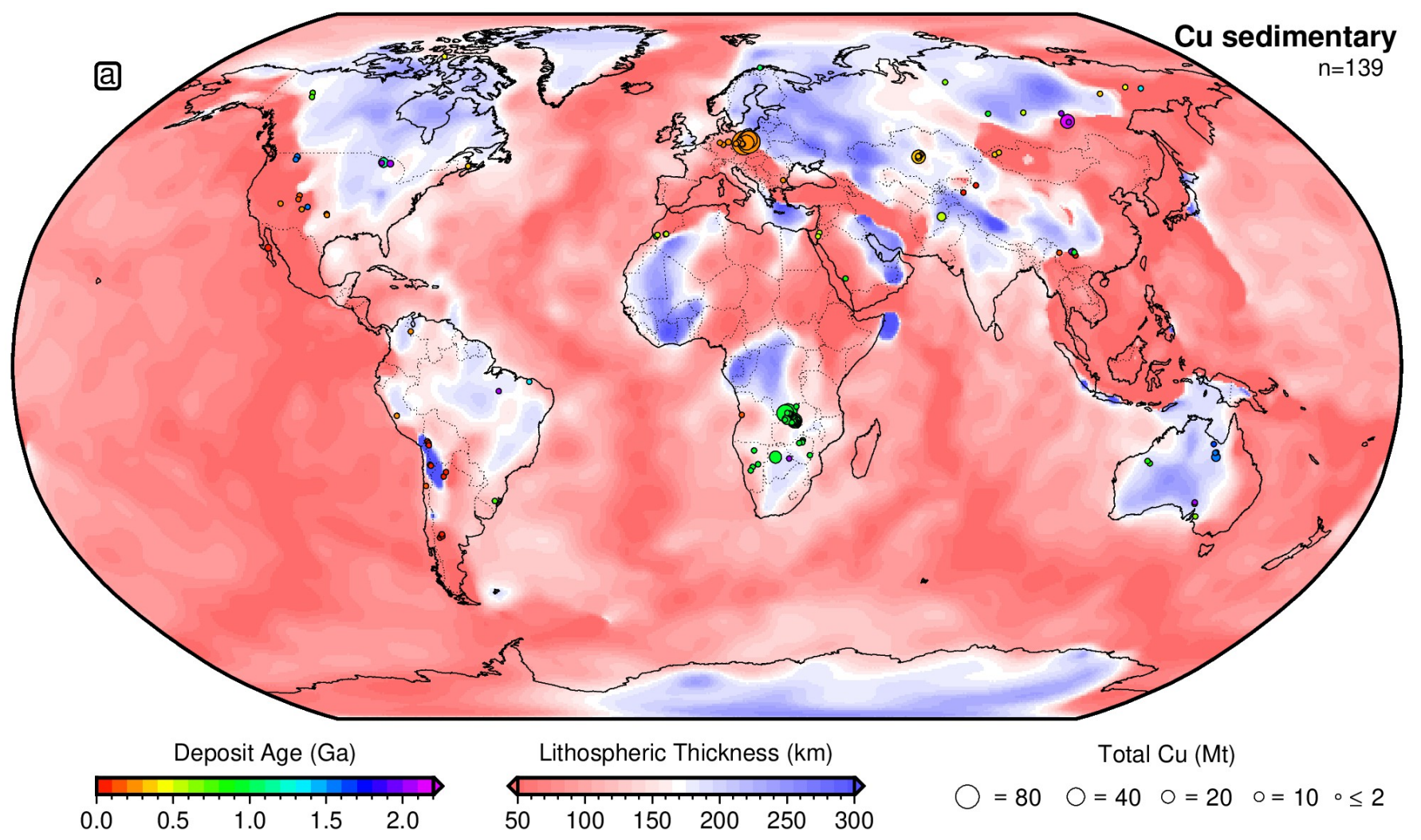

Probability
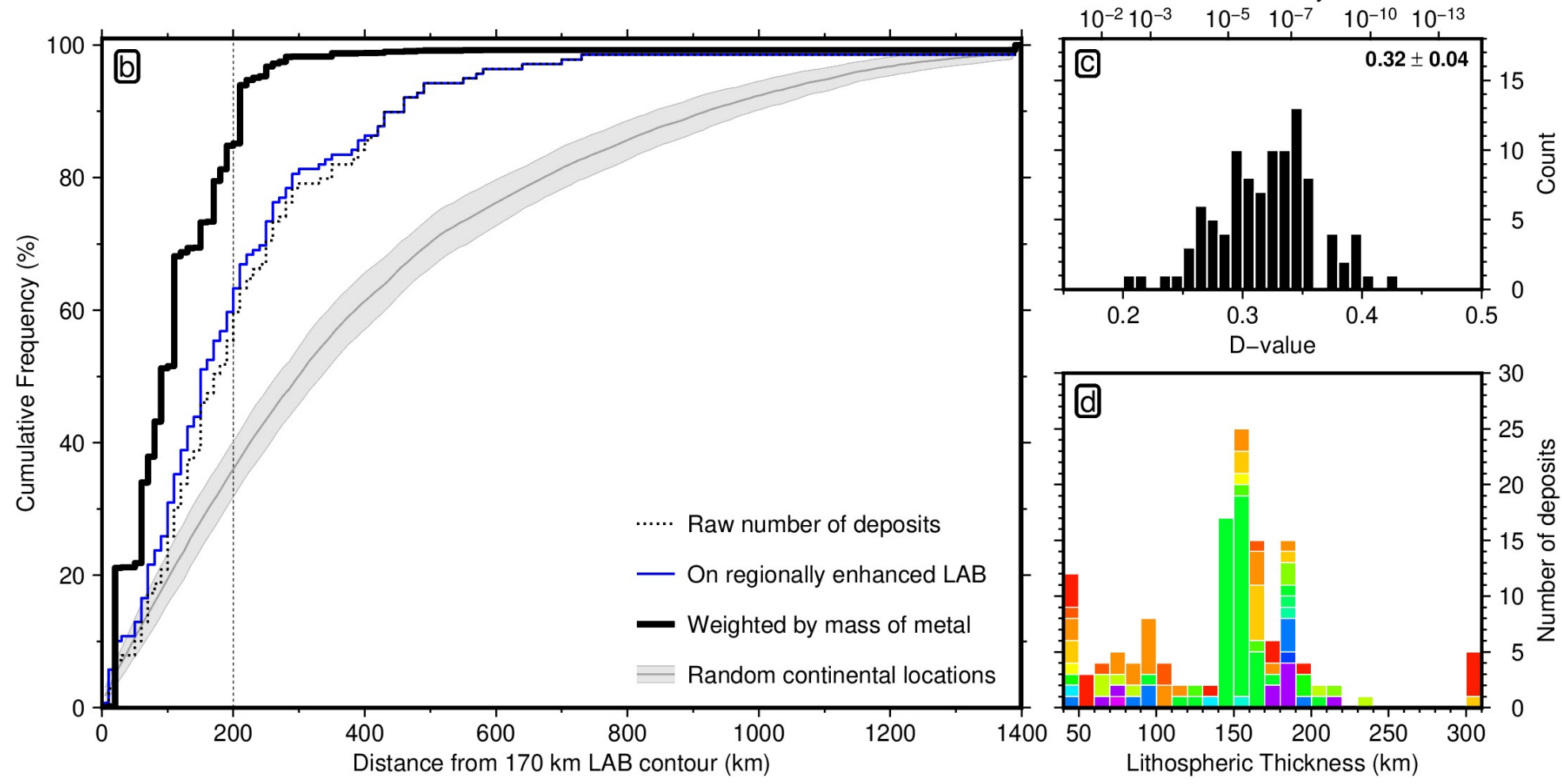

Figure S30: 139 sedimentary copper deposits from Table 4. (a) LAB derived from SL2013sv tomography model using a calibrated anelasticity parameterisation (Schaeffer \& Lebedev, 2013; Yamauchi \& Takei, 2016). Circles = deposit locations; area proportional to estimate of total contained mass of metal (Mt = megatonnes); unknown deposit size given $2 \mathrm{Mt}$ symbol; colour = ore body formation age (billion years); unknown age plotted in grey. (b) Different approaches for generating cumulative distribution functions. Dotted line $=$ simple count of number of deposits with increasing distance from the $170 \mathrm{~km}$ contour in global LAB map; blue line = simple count where Australian LAB has been replaced with regionally enhanced map (Figure S11a); solid black line = deposits weighted by mass of contained copper on regionally enhanced map; grey line/bounds = mean and standard deviation of 100 sets of equivalent number of randomly drawn continental locations, with respect to regionally enhanced LAB. (c) Histogram of 100 D-values calculated for each random test set and a non-mass-weighted, locally enhanced CDF (blue CDF); inset lists mean and standard deviation of D-values; associated probabilities shown across top. (d) Histogram of deposit occurrence as a function of lithospheric thickness, coloured by deposit age. 


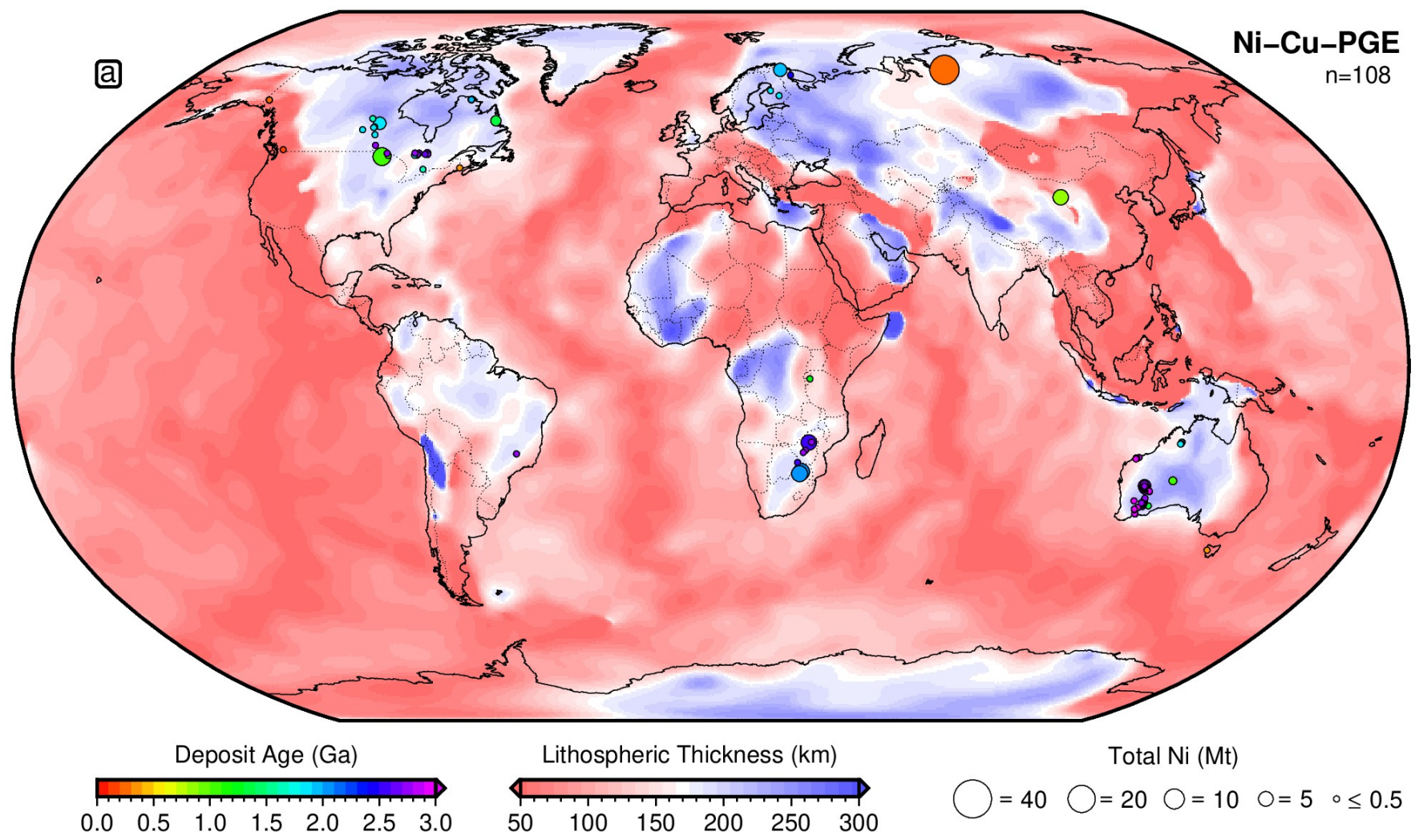

Probability
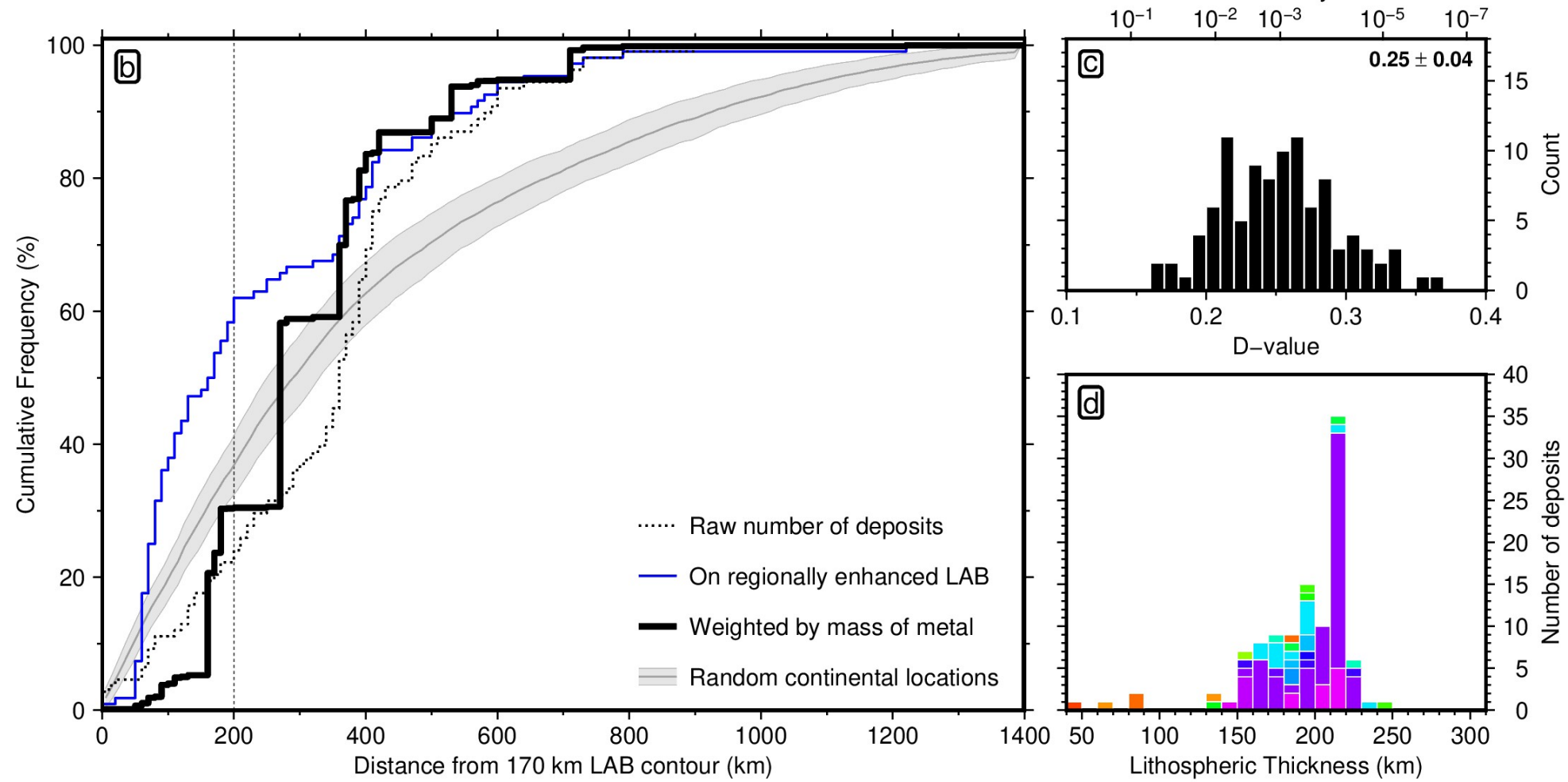

Figure S31: 108 magmatic nickel-copper-platinum group element deposits from Table 5. (a) LAB derived from SL2013sv tomography model using a calibrated anelasticity parameterisation (Schaeffer \& Lebedev, 2013; Yamauchi \& Takei, 2016). Circles = deposit locations; area proportional to estimate of total contained mass of metal $(\mathrm{Mt}=$ megatonnes $)$; unknown deposit size given $0.5 \mathrm{Mt}$ symbol; colour $=$ ore body formation age (billion years); unknown age plotted in grey. (b) Different approaches for generating cumulative distribution functions. Dotted line $=$ simple count of number of deposits with increasing distance from the $170 \mathrm{~km}$ contour in global LAB map; blue line $=$ simple count where Australian LAB has been replaced with regionally enhanced map (Figure S11a); solid black line = deposits weighted by mass of contained nickel on regionally enhanced map; grey line/bounds = mean and standard deviation of 100 sets of equivalent number of randomly drawn continental locations, with respect to regionally enhanced LAB. (c) Histogram of 100 D-values calculated for each random test set and a non-mass-weighted, locally enhanced CDF (blue CDF); inset lists mean and standard deviation of D-values; associated probabilities shown across top. (d) Histogram of deposit occurrence as a function of lithospheric thickness, coloured by deposit age. 


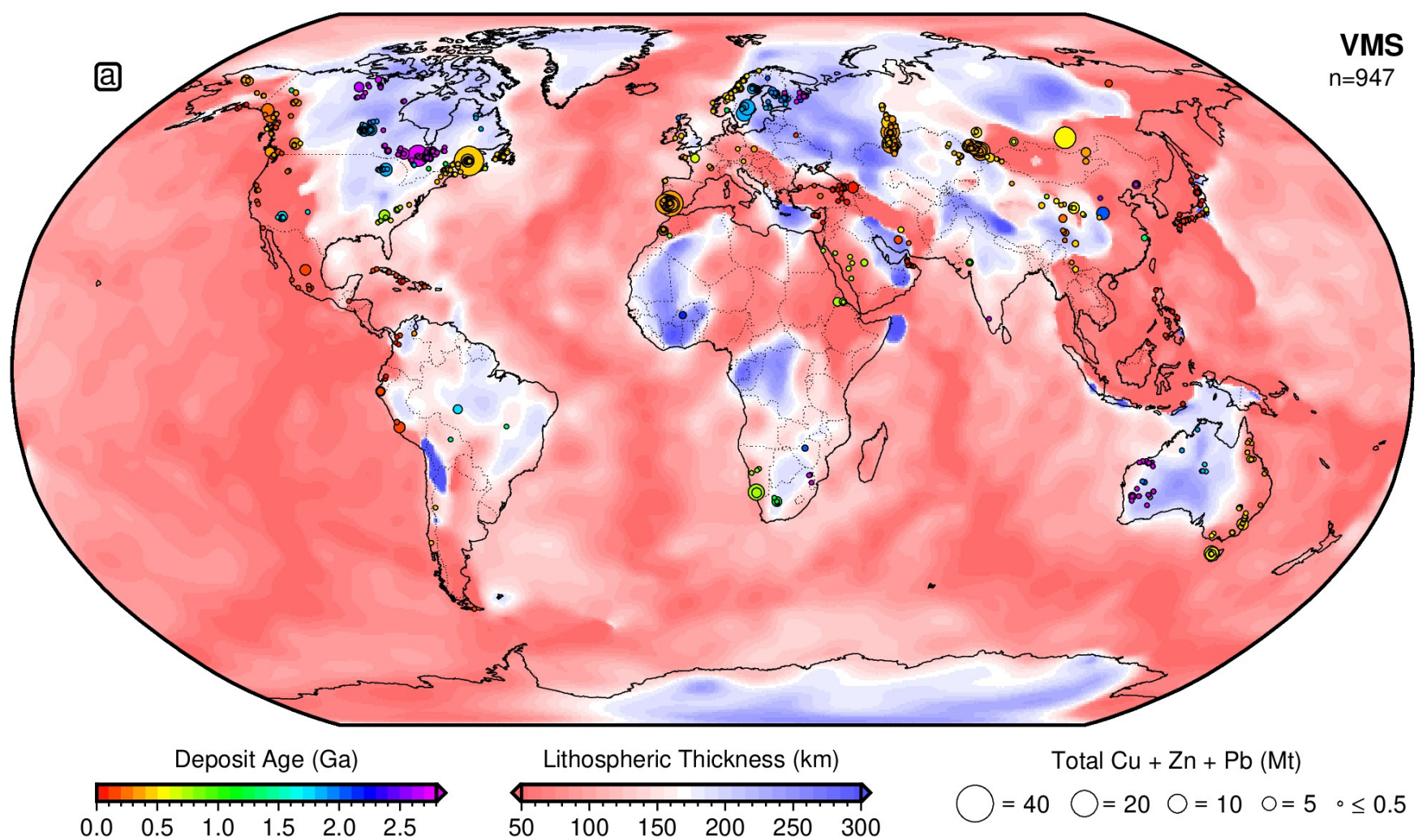

Probability
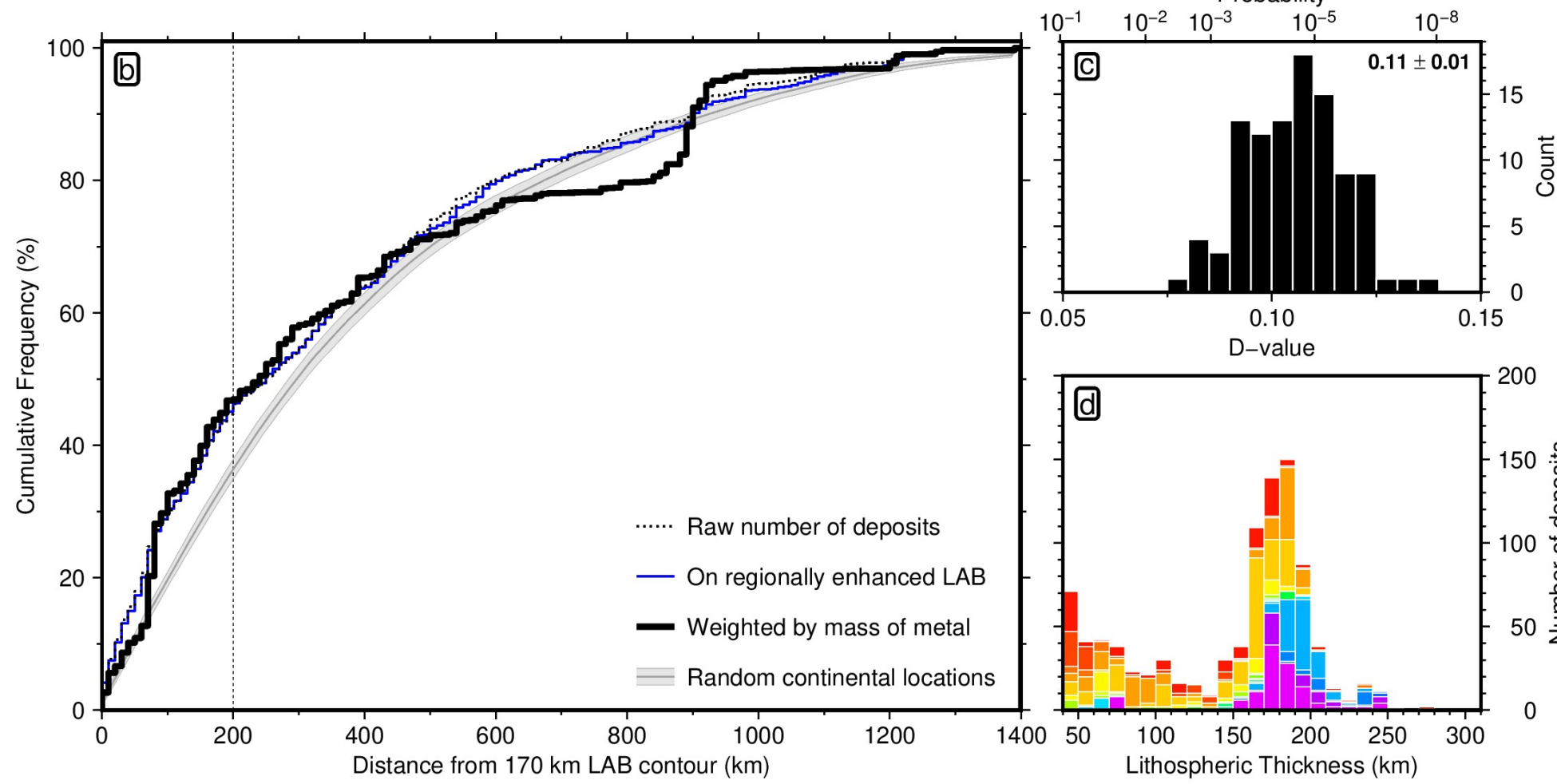

Figure S32: 947 volcanogenic massive sulphide deposits from Table 6. (a) LAB derived from SL2013sv tomography model using a calibrated anelasticity parameterisation (Schaeffer \& Lebedev, 2013; Yamauchi \& Takei, 2016). Circles = deposit locations; area proportional to estimate of total contained mass of metal $(\mathrm{Mt}=$ megatonnes); unknown deposit size given $0.5 \mathrm{Mt}$ symbol; colour = ore body formation age (billion years); unknown age plotted in grey. (b) Different approaches for generating cumulative distribution functions. Dotted line = simple count of number of deposits with increasing distance from the $170 \mathrm{~km}$ contour in global LAB map; blue line = simple count where Australian LAB has been replaced with regionally enhanced map (Figure S11a); solid black line = deposits weighted by mass of contained copper, lead and zinc on regionally enhanced map; grey line/bounds = mean and standard deviation of 100 sets of equivalent number of randomly drawn continental locations, with respect to regionally enhanced LAB. (c) Histogram of 100 D-values calculated for each random test set and a non-mass-weighted, locally enhanced CDF (blue CDF); inset lists mean and standard deviation of D-values; associated probabilities shown across top. (d) Histogram of deposit occurrence as a function of lithospheric thickness, coloured by deposit age. 

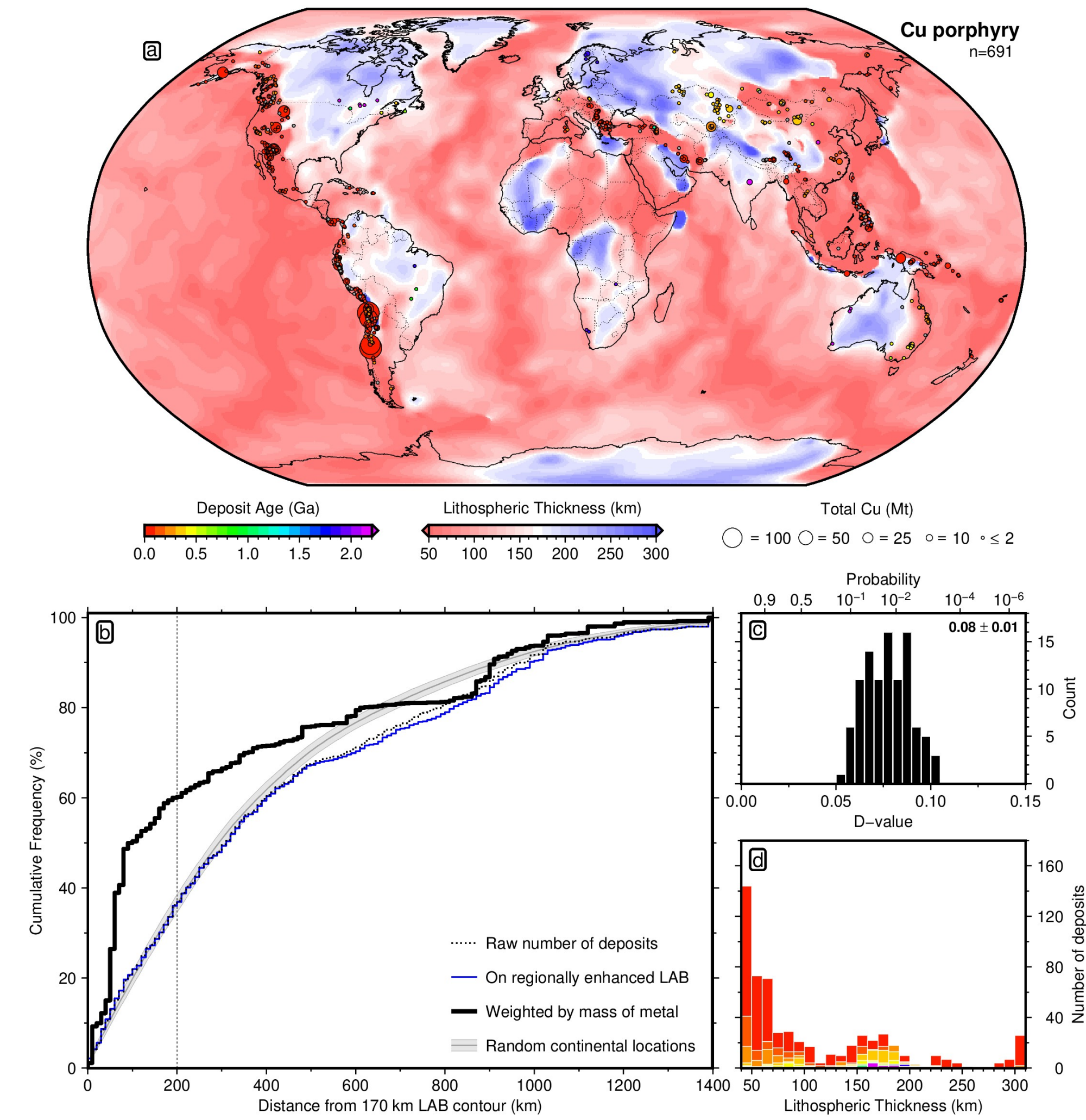

Figure S33: 691 copper porphyry deposits from Table 7. (a) LAB derived from SL2013sv tomography model using a calibrated anelasticity parameterisation (Schaeffer \& Lebedev, 2013; Yamauchi \& Takei, 2016). Circles = deposit locations; area proportional to estimate of total contained mass of metal ( $\mathrm{Mt}=$ megatonnes); unknown deposit size given $2 \mathrm{Mt}$ symbol; colour = ore body formation age (billion years); unknown age plotted in grey. (b) Different approaches for generating cumulative distribution functions. Dotted line $=$ simple count of number of deposits with increasing distance from the $170 \mathrm{~km}$ contour in global LAB map; blue line = simple count where Australian LAB has been replaced with regionally enhanced map (Figure S11a); solid black line = deposits weighted by mass of contained copper on regionally enhanced map; grey line/bounds = mean and standard deviation of 100 sets of equivalent number of randomly drawn continental locations, with respect to regionally enhanced LAB. (c) Histogram of 100 D-values calculated for each random test set and a non-mass-weighted, locally enhanced CDF (blue CDF); inset lists mean and standard deviation of D-values; associated probabilities shown across top. (d) Histogram of deposit occurrence as a function of lithospheric thickness, coloured by deposit age. 
Table 2: Global compilation of 109 clastic-dominated $\mathrm{Pb}-\mathrm{Zn}$ deposits shown in Figure S28, building extensively on Taylor et al. (2009). Ga $=$ billion years; $\mathrm{Mt}=$ million tonnes; $\mathrm{ND}=$ no data.

\begin{tabular}{|c|c|c|c|c|c|c|c|c|c|c|c|c|c|}
\hline Deposit & State/Region & Country & Lon. ${ }^{a}$ & Lat. $^{a}$ & $\begin{array}{l}\text { Age } \\
(\mathrm{Ga})\end{array}$ & $\begin{array}{l}\text { Ore } \\
(\mathrm{Mt})\end{array}$ & $\begin{array}{l}\mathrm{Cu} \\
(\%)\end{array}$ & $\begin{array}{c}\mathrm{Zn} \\
(\%)\end{array}$ & $\begin{array}{l}\mathrm{Pb} \\
(\%)\end{array}$ & $\begin{array}{c}\mathrm{Cu} \\
(\mathrm{Mt})\end{array}$ & $\begin{array}{c}\mathrm{Zn} \\
(\mathrm{Mt})\end{array}$ & $\begin{array}{l}\mathrm{Pb} \\
(\mathrm{Mt})\end{array}$ & References \\
\hline Aguilar & Jujuy & Argentina & -65.70 & -23.20 & 0.483 & 30.0 & ND & 6.20 & 5.50 & ND & 1.9 & 1.7 & $\begin{array}{l}\text { Sureda \& Martin (1990); Gemmell et al. (1992); } \\
\text { Singer et al. (2009) }\end{array}$ \\
\hline Esperanza & Jujuy & Argentina & -66.00 & -23.29 & 0.483 & 0.0 & ND & ND & ND & ND & ND & ND & $\begin{array}{l}\text { Sureda \& Martin (1990); Gemmell et al. (1992); } \\
\text { Singer et al. (2009) }\end{array}$ \\
\hline $\begin{array}{l}\text { HYC (McArthur } \\
\text { River) }\end{array}$ & $\begin{array}{l}\text { Northern } \\
\text { Territory }\end{array}$ & Australia & 136.10 & -16.43 & 1.637 & 227.0 & 0.20 & 9.25 & 4.10 & 0.5 & 21.0 & 9.3 & $\begin{array}{l}\text { Smith \& Croxford (1973); Williams (1978a,b); } \\
\text { Rye \& Williams (1981); Logan et al. (1990); } \\
\text { Eldridge et al. (1993); Cooke et al. (1998); Page } \\
\text { et al. (2000); Carr et al. (2001); Ireland et al. } \\
\text { (2004); Symons (2007) }\end{array}$ \\
\hline Myrtle & $\begin{array}{l}\text { Northern } \\
\text { Territory }\end{array}$ & Australia & 136.03 & -16.58 & 1.639 & 43.6 & ND & 4.09 & 0.95 & ND & 1.8 & 0.4 & Rox Resources (2020) \\
\hline Cannington & Queensland & Australia & 140.92 & -21.87 & 1.665 & 43.8 & ND & 4.40 & 11.60 & ND & 1.9 & 5.1 & $\begin{array}{l}\text { Walters \& Bailey (1998); Bodon (1998); Carr } \\
\text { et al. (2001) }\end{array}$ \\
\hline Century & Queensland & Australia & 138.63 & -18.75 & 1.573 & 94.6 & ND & 13.10 & 1.80 & ND & 12.4 & 1.7 & Broadbent et al. (1998); Carr et al. (2001) \\
\hline $\begin{array}{l}\text { Chloe-Jackson-Stella } \\
\text { (Mt Misery) }\end{array}$ & Queensland & Australia & 143.99 & -18.61 & 1.673 & 4.6 & 0.20 & 4.80 & 2.00 & 0.0 & 0.2 & 0.1 & Kositcin et al. (2009) \\
\hline Dugald River & Queensland & Australia & 140.15 & -20.25 & 1.662 & 53.0 & ND & 12.50 & 1.90 & ND & 6.6 & 1.0 & $\begin{array}{l}\text { Connor (1990); Davidson \& Dixon (1992); } \\
\text { Dixon \& Davidson (1996); Carr et al. (2001); } \\
\text { MMG (2020) }\end{array}$ \\
\hline Einasleigh barite & Queensland & Australia & 144.10 & -18.51 & 1.686 & ND & ND & ND & ND & ND & ND & ND & $\begin{array}{l}\text { Denaro et al. (1997); Evins et al. (2007); Lees \& } \\
\text { Buckle (2009); Kositcin et al. (2009) }\end{array}$ \\
\hline $\begin{array}{l}\text { Hilton-George } \\
\text { Fisher }\end{array}$ & Queensland & Australia & 139.47 & -20.57 & 1.655 & 227.0 & ND & 11.31 & 5.40 & ND & 25.7 & 12.3 & $\begin{array}{l}\text { Page et al. (2000); Carr et al. (2001); Chapman } \\
(2004)\end{array}$ \\
\hline Kamarga & Queensland & Australia & 138.84 & -18.81 & 1.614 & 10.4 & ND & 2.70 & 0.20 & ND & 0.3 & 0.0 & $\begin{array}{l}\text { Jones et al. (1999); Carr et al. (2001); } \\
\text { Geological Survey of Queensland (2020) }\end{array}$ \\
\hline Lady Loretta & Queensland & Australia & 139.07 & -19.77 & 1.633 & 12.7 & ND & 14.20 & 4.80 & ND & 1.8 & 0.6 & $\begin{array}{l}\text { Carr \& Smith (1977); Carr (1984); Hancock \& } \\
\text { Purvis (1990); Carr et al. (2001); Glencore } \\
(2020)\end{array}$ \\
\hline Maramungee & Queensland & Australia & 140.92 & -21.58 & 1.675 & 1.8 & ND & 4.40 & ND & ND & 0.1 & ND & $\begin{array}{l}\text { Williams \& Heinemann (1993); Carr et al. } \\
\text { (2001) }\end{array}$ \\
\hline Mount Isa & Queensland & Australia & 139.48 & -20.73 & 1.652 & 150.0 & ND & 7.00 & 6.00 & ND & 10.5 & 9.0 & $\begin{array}{l}\text { Smith et al. (1978); Forrestal (1990); Painter } \\
\text { et al. (1999); Page et al. (2000); Carr et al. } \\
\text { (2001) }\end{array}$ \\
\hline Pegmont & Queensland & Australia & 140.68 & -21.84 & 1.664 & 8.6 & ND & 3.50 & 7.70 & ND & 0.3 & 0.7 & $\begin{array}{l}\text { Vaughan \& Stanton (1986); Williams et al. } \\
\text { (1998); Carr et al. (2001); Pegmont (2020) }\end{array}$ \\
\hline Broken Hill & $\begin{array}{l}\text { South } \\
\text { Australia }\end{array}$ & Australia & 141.47 & -31.97 & 1.685 & 280.0 & 0.14 & 8.50 & 10.00 & 0.4 & 23.8 & 28.0 & $\begin{array}{l}\text { Lawrence \& Rafter (1962); Both \& Smith } \\
\text { (1975); Plimer (1977, 1986); Page et al. (2005); } \\
\text { Parr et al. (2004); Huston et al. (2006); Groves } \\
\text { et al. (2008) }\end{array}$ \\
\hline Mount Torrens & $\begin{array}{l}\text { South } \\
\text { Australia }\end{array}$ & Australia & 139.30 & -34.88 & 0.518 & 0.7 & ND & 1.60 & 6.40 & ND & 0.0 & 0.0 & $\begin{array}{l}\text { Belperio et al. (1998); Haines et al. (2009); } \\
\text { Skwarnecki \& Fitzpatrick (2003) }\end{array}$ \\
\hline Pinnacles & $\begin{array}{l}\text { South } \\
\text { Australia }\end{array}$ & Australia & 141.39 & -32.09 & 1.695 & 0.8 & ND & 2.50 & 11.00 & ND & 0.0 & 0.1 & Parr (1994); Parr et al. (2004) \\
\hline Wheal Ellen & $\begin{array}{c}\text { South } \\
\text { Australia }\end{array}$ & Australia & 138.93 & -35.19 & 0.518 & 0.1 & ND & 25.00 & 20.00 & ND & 0.0 & 0.0 & $\begin{array}{l}\text { Belperio et al. (1998); Both (1990); Seccombe } \\
\text { et al. (1985); Haines et al. (2009) }\end{array}$ \\
\hline Filizchai & Zaqatala & Azerbaijan & 46.47 & 41.79 & 0.181 & 100.0 & 0.64 & 4.50 & 2.00 & 0.6 & 4.5 & 2.0 & Singer et al. (2009); Taylor et al. (2009) \\
\hline Canoas & Paran & Brazil & -48.95 & -24.83 & 1.700 & 1.3 & ND & 3.26 & 3.02 & ND & 0.0 & 0.0 & $\begin{array}{l}\text { Daitx (1996); Misi et al. (1999); Singer et al. } \\
\text { (2009); Taylor et al. (2009) }\end{array}$ \\
\hline Perau & Paran & Brazil & -49.00 & -24.85 & 1.700 & 3.3 & ND & 1.88 & 4.13 & ND & 0.1 & 0.1 & $\begin{array}{l}\text { Daitx (1996); Singer et al. (2009); Taylor et al. } \\
\text { (2009) }\end{array}$ \\
\hline Big Ledge & $\begin{array}{l}\text { British } \\
\text { Columbia }\end{array}$ & Canada & -118.05 & 50.48 & 0.560 & 6.5 & ND & 3.00 & 3.00 & ND & 0.2 & 0.2 & $\begin{array}{l}\text { Höy (1975); Kuiper et al. (2011); British } \\
\text { Columbia Geological Survey (2020a); StratDB } \\
(2020)\end{array}$ \\
\hline Cirque & $\begin{array}{l}\text { British } \\
\text { Columbia }\end{array}$ & Canada & -125.15 & 57.51 & 0.366 & 22.1 & ND & 9.40 & 2.80 & ND & 2.1 & 0.6 & $\begin{array}{l}\text { Goodfellow (2007); Paradis et al. (1998); } \\
\text { British Columbia Geological Survey (2020b) }\end{array}$ \\
\hline Cottonbelt & $\begin{array}{l}\text { British } \\
\text { Columbia }\end{array}$ & Canada & -118.82 & 51.45 & 0.560 & 0.7 & ND & 6.00 & 5.00 & ND & 0.0 & 0.0 & $\begin{array}{l}\text { Kuiper et al. (2011); British Columbia } \\
\text { Geological Survey (2020c); StratDB (2020) }\end{array}$ \\
\hline Driftpile & $\begin{array}{l}\text { British } \\
\text { Columbia }\end{array}$ & Canada & -125.95 & 58.05 & 0.366 & 2.4 & ND & 11.90 & 3.10 & ND & 0.3 & 0.1 & $\begin{array}{l}\text { Goodfellow (2007); Paradis et al. (1998); } \\
\text { Thorpe (2008); British Columbia Geological } \\
\text { Survey (2020d) }\end{array}$ \\
\hline Kingfisher (Colby) & $\begin{array}{l}\text { British } \\
\text { Columbia }\end{array}$ & Canada & -118.73 & 50.73 & 0.560 & 1.7 & ND & 2.60 & 0.58 & ND & 0.0 & 0.0 & $\begin{array}{l}\text { Kuiper et al. (2011); British Columbia } \\
\text { Geological Survey (2020e); StratDB (2020) }\end{array}$ \\
\hline Kootenay King & $\begin{array}{l}\text { British } \\
\text { Columbia }\end{array}$ & Canada & -115.61 & 49.74 & 1.470 & 0.0 & ND & 6.65 & 5.36 & ND & 0.0 & 0.0 & $\begin{array}{l}\text { Kuiper et al. (2011); British Columbia } \\
\text { Geological Survey (2020f); StratDB (2020) }\end{array}$ \\
\hline River Jordan & $\begin{array}{l}\text { British } \\
\text { Columbia }\end{array}$ & Canada & -118.41 & 51.13 & 0.560 & 2.6 & ND & 5.60 & 5.10 & ND & 0.1 & 0.1 & $\begin{array}{l}\text { Kuiper et al. (2011); British Columbia } \\
\text { Geological Survey (2020g) }\end{array}$ \\
\hline Ruddock Creek & $\begin{array}{l}\text { British } \\
\text { Columbia }\end{array}$ & Canada & -118.98 & 51.27 & 0.560 & 3.8 & ND & 7.29 & 1.47 & ND & 0.3 & 0.1 & $\begin{array}{l}\text { Kuiper et al. (2011); British Columbia } \\
\text { Geological Survey (2020h); StratDB (2020) }\end{array}$ \\
\hline Sullivan & $\begin{array}{l}\text { British } \\
\text { Columbia }\end{array}$ & Canada & -116.01 & 49.71 & 1.468 & 150.5 & 0.00 & 5.28 & 5.59 & 0.0 & 7.9 & 8.4 & $\begin{array}{l}\text { Campbell et al. (1978); Lydon (2007); Anderson } \\
\text { \& Parrish (2000); Thorpe (2008); British } \\
\text { Columbia Geological Survey (2020i) }\end{array}$ \\
\hline
\end{tabular}




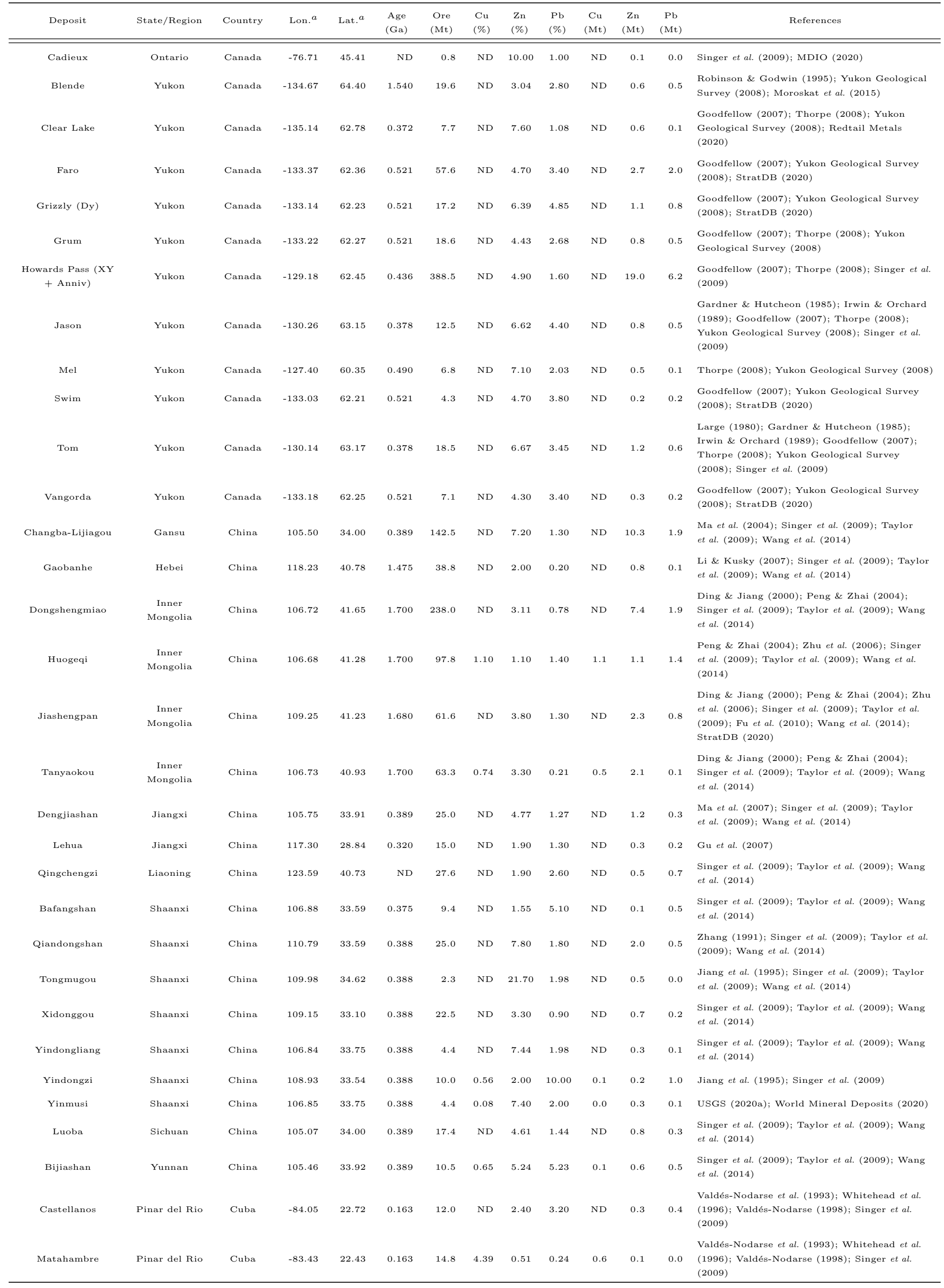


Santa Lucia

Pinar del Rio

Cuba

$\begin{array}{lll}-83.98 & 22.65 & 0.163\end{array}$

Arrens

Rammelsberg

$$
\begin{aligned}
& \text { Hautes } \\
& \text { Pyrnes }
\end{aligned}
$$$$
\text { Pyrnes }
$$

France

Lower Saxony

Germany

$-0.22$

$42.95 \quad 0.375$

$19.4 \quad$

$\begin{array}{lll} & & \end{array}$

orth Rhine-

Meggen

Westphalia

Citronen Fjord

Northeast

Greenland

Bajta Central

Bamnia Kalan

Rajasthan

Rajasthan

Bethumni

Rajasthan

Devpura

Rajasthan

Ganeshpura

Kankariya

Rajasthan

Rajasthan

Kayar

Madarpura

Mokanpura North

Rajasthan

Rajasthan

Rajasthan

Rajpura-Dariba

Rajasthan

Rampura-Agucha

Rajasthan

Rewara

Saladipura

Rajasthan

Rajasthan

Samodi

Sawar

Sindesar Kalan East

Sindesar Khurd

South Dedwas

Rajasthan

Rajasthan

Rajasthan

Rajasthan

Rajasthan

Tikhi

Tiranga

Rangpo

Gorubathan

West Bengal

Rajasthan

Rajasthan

Sikkim

German

Greenland $\quad-28.25$

India

India

India

India

India

India

India

India

India

India

India

India

India

India

India

India

India

India

India

India

India

India

Sopokomil

North

Sumatra

Tsongoari

Ganesh Himal

Kunene

Bagmat

Pradesh

Duddar

Balochistan

Indonesia

Namibia

Nepal

Pakistan

Balochistan

Pakistan

Krasnoyarsk

Krai

Gorevsk

Kholodninskoye

Republic of Buryatia

Northern

Cape

Big Syncline

Black Mountain

(Swartberg)

Broken Hill

Northern

Cape

Northern

Cape

$\begin{array}{lll}10.42 & 51.88 & 0.395\end{array}$

ND $\quad 6.60 \quad 0.90$

$-28.25$

$83.08 \quad 0.444$

$\begin{array}{lll}75.27 & 25.83 & 1.800\end{array}$

$0.6 \quad N$

4.18

$25.04 \quad 1.799$

5.1

$25.07 \quad 1.799$

74.63

$25.45 \quad 1.800$

$0.2 \quad \mathrm{ND}$

ND $1.00 \quad 1.64$

$17.5 \quad N$

$25.80 \quad 1.800$

0.8

ND $4.60 \quad 1.15$

$\begin{array}{llll}.0 & \text { ND } & 3.22 & 2.56\end{array}$

$26.51 \quad 1.780$

74.69

$26.53 \quad 1.780$

10.0

74.67

$26.50 \quad 1.780$

6.6

74.13

$25.00 \quad 1.799$

74.13

$24.98 \quad 1.799$

74.73

25.83

74.37

$25.10 \quad 1.800$

75.53

27.65

$25.35 \quad 1.800$

75.22

$25.75 \quad 1.800$

74.17

$25.00 \quad 1.799$

74.23

$24.01 \quad 1.800$

74.57

25.35

75.24

$25.76 \quad 1.800$

$\begin{array}{lll}74.54 & 25.34 & 1.800\end{array}$

88.53

$27.17 \quad 1.850$

ND $\quad 5.51 \quad$ ND

ND $\quad 2.20 \quad 0.70$

45.0

$\begin{array}{lll}66.82 & 26.09 & 0.180\end{array}$

$8 \quad N D$
$\mathrm{ND}$

$.4 \quad(199$

Singer et al. (2009)

Escande \& Majesté-Menjoulas (1985); Pouit \& Bois (1986)

Anger et al. (1966); Large \& Walcher (1999); Mueller (2008); StratDB (2020)

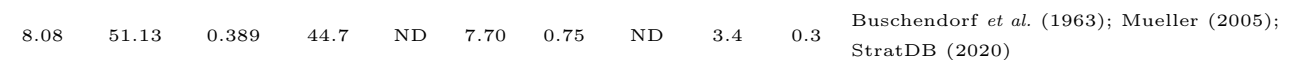

$131.1 \quad \mathrm{ND} \quad 4.10 \quad 0.50$

D $\quad 6.50 \quad 2.40$

D

2

Deb (1986); Deb et al. (1989); Deb \& Sarkar

(1990); Deb \& Pal (2004); Deb \& Thorpe

(2004); Ramakrishnan \& Vaidyanathan (2008)

Deb et al. (1989); Deb \& Sarkar (1990); Deb \&

Thorpe (2004); Roy et al. (2004); Shah (2004);

Ramakrishnan \& Vaidyanathan (2008)

Bhawan (2006)

Deb et al. (1989); Deb \& Sarkar (1990);

Ramakrishnan \& Vaidyanathan (2008); Thorpe (2008)

Raghu Nundan et al. (1981)

Raghu Nundan et al. (1981); Deb \& Thorpe

(2004)

Deb \& Pal (2004)

Deb \& Thorpe (2004); Ameta \& Sharma (2008)

Raghu Nundan et al. (1981); Geological Survey of India (1994)

Raghu Nundan et al. (1981); Geological Survey of India (1994); Thorpe (2008)

Raghu Nundan et al. (1981); Deb et al. (1989);

Thorpe (2008)

Borodaev et al. (2002); Long et al. (2011);

Raghu Nundan et al. (1981); Sarkar et al. (2000)

Anonymous (1985); Long et al. (2011);

Raghu Nundan et al. (1981); Saha (1985);

Sarkar et al. (2000)

Reynolds \& Geerdts (2012); Middleton (2004,

2020)

Hoffman et al. (1996); Gauert (2005); Singer

et al. (2009)

Ghosh et al. (2005); Thorpe (2008); Singer et al. (2009)

Ahsan \& Quraishi (1997); Ahsan \& Mallick

(1999); Singer et al. (2009); PorterGeo (2020a)

Ahsan \& Quraishi (1997); Ahsan \& Mallick

(1999); Husain et al. (2002); Singer et al. (2009)

Khiltova \& Pleskach (1997); PorterGeo

(2020b); Smirnov \& Gorzhevsk (1977)

Karpenko et al. (1981); Seltmann et al. (2010);

PorterGeo (2020c)

Ryan et al. (1986); Reid et al. (1997); McClung et al. (2007)

Ryan et al. (1986); Reid et al. (1997); McClung et al. (2007)

Ryan et al. (1986); Reid et al. (1997); McClung et al. (2007) 


\begin{tabular}{|c|c|c|c|c|c|c|c|c|c|c|c|c|c|}
\hline Deposit & State/Region & Country & Lon. ${ }^{a}$ & Lat. $^{a}$ & $\begin{array}{l}\text { Age } \\
(\mathrm{Ga})\end{array}$ & $\begin{array}{l}\text { Ore } \\
(\mathrm{Mt})\end{array}$ & $\begin{array}{l}\mathrm{Cu} \\
(\%)\end{array}$ & $\begin{array}{l}\mathrm{Zn} \\
(\%)\end{array}$ & $\begin{array}{l}\mathrm{Pb} \\
(\%)\end{array}$ & $\begin{array}{c}\mathrm{Cu} \\
(\mathrm{Mt})\end{array}$ & $\begin{array}{c}\mathrm{Zn} \\
(\mathrm{Mt})\end{array}$ & $\begin{array}{c}\mathrm{Pb} \\
(\mathrm{Mt})\end{array}$ & References \\
\hline Broken Hill Deeps & $\begin{array}{l}\text { Northern } \\
\text { Cape }\end{array}$ & $\begin{array}{l}\text { South } \\
\text { Africa }\end{array}$ & 18.81 & -29.24 & 1.197 & 18.8 & 0.74 & 3.94 & 3.98 & 0.1 & 0.7 & 0.7 & McClung et al. (2007) \\
\hline Gamsberg & $\begin{array}{l}\text { Northern } \\
\text { Cape }\end{array}$ & $\begin{array}{l}\text { South } \\
\text { Africa }\end{array}$ & 18.97 & -29.25 & 1.197 & 199.3 & ND & 5.51 & ND & ND & 11.0 & ND & $\begin{array}{l}\text { Rozendaal (1986); Reid et al. (1997); Stalder \& } \\
\text { Rozendaal (2005); McClung et al. (2007); } \\
\text { Cornell et al. (2009) }\end{array}$ \\
\hline Bayindir & Izmir & Turkey & 27.35 & 38.17 & 0.600 & 27.6 & ND & 7.50 & 1.50 & ND & 2.1 & 0.4 & Dora (1977); Taylor et al. (2009) \\
\hline Anarraaq & Alaska & USA & -162.96 & 68.16 & 0.338 & 18.0 & ND & 18.00 & 5.40 & ND & 3.2 & 1.0 & $\begin{array}{l}\text { Ayuso et al. (2004); Kelley et al. (2004a); } \\
\text { Johnson et al. (2004); Young (2004) }\end{array}$ \\
\hline Lik & Alaska & USA & -163.20 & 68.17 & 0.338 & 23.9 & ND & 2.76 & 8.44 & ND & 0.7 & 2.0 & $\begin{array}{l}\text { Young (2004); Singer et al. (2009); Taylor et al. } \\
(2009)\end{array}$ \\
\hline Red Dog & Alaska & USA & -162.80 & 68.07 & 0.338 & 165.0 & ND & 16.60 & 4.60 & ND & 27.4 & 7.6 & $\begin{array}{l}\text { Ayuso et al. (2004); Kelley et al. (2004b); } \\
\text { Johnson et al. (2004); Morelli et al. (2004); Slack } \\
\text { et al. (2004); Young (2004); Taylor et al. (2009) }\end{array}$ \\
\hline Su (Lik South) & Alaska & USA & -163.21 & 68.16 & 0.338 & 20.1 & ND & 7.90 & 2.55 & ND & 1.6 & 0.5 & $\begin{array}{l}\text { Johnson et al. (2004); Young (2004); Singer } \\
\text { et al. (2009); Taylor et al. (2009) }\end{array}$ \\
\hline Triumph & Idaho & USA & -114.25 & 44.67 & 0.400 & 3.1 & 0.06 & 5.40 & 4.20 & 0.0 & 0.2 & 0.1 & $\begin{array}{l}\text { Hall (1985); Howe \& Hall (1985); Turner \& } \\
\text { Otto (1995); Singer et al. (2009) }\end{array}$ \\
\hline
\end{tabular}

${ }^{a}$ In decimal degrees

Table 3: Global compilation of 147 Mississippi Valley-type Pb-Zn deposits shown in Figure S29, building on original database of Taylor et al. (2009). $\mathrm{Ga}=$ billion years; $\mathrm{Mt}=$ million tonnes; $\mathrm{ND}=$ no data.

\begin{tabular}{|c|c|c|c|c|c|c|c|c|c|c|c|c|}
\hline Deposit & Country & Lon. ${ }^{a}$ & Lat. ${ }^{a}$ & $\begin{array}{l}\text { Age } \\
(\mathrm{Ga})\end{array}$ & $\begin{array}{l}\text { Ore } \\
(\mathrm{Mt})\end{array}$ & $\begin{array}{l}\mathrm{Cu} \\
(\%)\end{array}$ & $\begin{array}{c}\mathrm{Zn} \\
(\%)\end{array}$ & $\begin{array}{l}\mathrm{Pb} \\
(\%)\end{array}$ & $\begin{array}{c}\mathrm{Cu} \\
(\mathrm{Mt})\end{array}$ & $\begin{array}{c}\mathrm{Zn} \\
(\mathrm{Mt})\end{array}$ & $\begin{array}{c}\mathrm{Pb} \\
(\mathrm{Mt})\end{array}$ & References \\
\hline Ain Khala & Algeria & 5.29 & 35.43 & ND & 7.1 & ND & 1.90 & 1.20 & ND & 0.1 & 0.1 & Mosier et al. (2009); Taylor et al. (2009) \\
\hline Boukdema-Kef Semmah & Algeria & 4.89 & 36.21 & $\mathrm{ND}$ & 12.0 & ND & 6.50 & 2.07 & ND & 0.8 & 0.2 & Singer et al. (2009); Taylor et al. (2009) \\
\hline El Abed & Algeria & -1.63 & 34.52 & 0.008 & 30.0 & ND & 4.50 & 1.00 & ND & 1.4 & 0.3 & Bouabdellah et al. $(1999,2012)$ \\
\hline Kherzet Youcef & Algeria & 5.28 & 35.46 & $\mathrm{ND}$ & 1.6 & ND & 18.40 & 3.60 & ND & 0.3 & 0.1 & Singer et al. (2009); Taylor et al. (2009) \\
\hline Admiral Bay & Australia & 122.28 & -19.23 & 0.420 & 72.0 & ND & 3.10 & 2.90 & ND & 2.2 & 2.1 & McCracken et al. (1996); Kagara Ltd. (2008) \\
\hline Bulman & Australia & 134.41 & -13.42 & ND & 0.4 & ND & 15.00 & 2.00 & ND & 0.1 & 0.0 & Taylor et al. (2009) \\
\hline Cadjebut Trend & Australia & 125.96 & -18.71 & 0.357 & 16.4 & ND & 8.90 & 5.00 & ND & 1.5 & 0.8 & $\begin{array}{l}\text { Tompkins et al. (1994); Vearncombe et al. } \\
\text { (1995b); Tompkins et al. (1997) }\end{array}$ \\
\hline Ediacara & Australia & 138.13 & -30.80 & ND & 29.0 & ND & ND & 1.07 & ND & ND & 0.3 & USGS (2020b) \\
\hline Fossil Downs & Australia & 125.77 & -18.19 & 0.357 & 2.2 & ND & 9.50 & 2.10 & ND & 0.2 & 0.0 & Ltd. (2009) \\
\hline $\begin{array}{c}\text { Goongewa (Twelve Mile } \\
\text { Bore) }\end{array}$ & Australia & 125.88 & -18.63 & 0.351 & 2.4 & ND & 10.10 & 2.70 & ND & 0.2 & 0.1 & Brannon et al. (1996) \\
\hline Kapok & Australia & 126.01 & -18.73 & 0.351 & 5.9 & ND & 7.80 & 8.70 & ND & 0.5 & 0.5 & Symons \& Arne (2003) \\
\hline Napier Range (Narlarla) & Australia & 124.73 & -17.26 & 0.357 & 0.6 & ND & 8.50 & 8.00 & ND & 0.1 & 0.0 & Ringrose (1984) \\
\hline Pillara (Blendevale) & Australia & 125.77 & -18.32 & 0.357 & 19.3 & ND & 7.80 & 2.60 & ND & 1.5 & 0.5 & $\begin{array}{l}\text { Christensen et al. (1995); Vearncombe et al. } \\
\text { (1995a); Gwatkin \& Muccilli (2002); Symons \& } \\
\text { Arne (2005) }\end{array}$ \\
\hline Sorby Hills & Australia & 128.97 & -15.45 & $\mathrm{ND}$ & 16.7 & ND & 0.70 & 4.50 & ND & 0.1 & 0.8 & KBL Mining Ltd. (2017) \\
\hline Wagon Pass & Australia & 124.63 & -17.18 & 0.357 & 0.5 & ND & ND & ND & ND & ND & ND & Taylor et al. (2009) \\
\hline Bleiberg & Austria & 13.67 & 46.67 & 0.180 & 43.0 & ND & 5.88 & 1.09 & ND & 2.5 & 0.5 & Schroll \& Rantitsch (2005); Schroll et al. (2006) \\
\hline Lafatsch & Austria & 11.45 & 47.36 & ND & 1.0 & ND & 6.00 & 1.00 & ND & 0.1 & 0.0 & Taylor et al. (2009) \\
\hline Raibl & Austria & 13.60 & 46.44 & 0.180 & 18.1 & ND & 5.97 & 1.22 & ND & 1.1 & 0.2 & Taylor et al. (2009) \\
\hline Schmalgraf & Belgium & 6.02 & 50.42 & ND & 0.7 & ND & 24.00 & 2.10 & ND & 0.2 & 0.0 & Taylor et al. (2009) \\
\hline Fagundes & Brazil & -46.52 & -16.87 & ND & 3.0 & ND & 4.50 & ND & ND & 0.1 & $\mathrm{ND}$ & Taylor et al. (2009) \\
\hline Januaria & Brazil & -44.75 & -15.05 & ND & 0.1 & ND & 4.00 & 7.50 & ND & 0.0 & 0.0 & Taylor et al. (2009) \\
\hline Morro Agudo & Brazil & -46.80 & -17.32 & ND & 17.0 & ND & 5.14 & 1.53 & ND & 0.9 & 0.3 & Hitzman et al. (1995); Misi et al. (2005) \\
\hline Nova Redencao & Brazil & -43.50 & -13.00 & ND & 2.5 & ND & 0.50 & 6.30 & ND & 0.0 & 0.2 & Misi et al. (2005) \\
\hline Tres Irmas & Brazil & -41.80 & -12.33 & ND & 7.0 & ND & 7.60 & 1.40 & ND & 0.5 & 0.1 & Taylor et al. (2009) \\
\hline Sedmochislenitsi & Bulgaria & 23.54 & 43.15 & 0.043 & 16.7 & 0.30 & 1.11 & 1.41 & 0.1 & 0.2 & 0.2 & Minčeva-Stefanova (1972); Taylor et al. (2009) \\
\hline Bear-Twit & Canada & -129.42 & 64.03 & ND & 7.3 & ND & 5.42 & 2.60 & ND & 0.4 & 0.2 & Paradis et al. (2007) \\
\hline Blende & Canada & -134.67 & 64.40 & ND & 19.6 & ND & 3.04 & 2.80 & ND & 0.6 & 0.5 & Paradis et al. (2007) \\
\hline Colby & Canada & -118.73 & 50.73 & $\mathrm{ND}$ & 1.0 & ND & ND & ND & ND & ND & ND & USGS (2020b) \\
\hline Duncan & Canada & -116.95 & 50.37 & ND & 2.8 & ND & 3.10 & 3.30 & ND & 0.1 & 0.1 & Taylor et al. (2009) \\
\hline Eclipse & Canada & -96.20 & 75.57 & ND & 0.9 & ND & 11.31 & ND & ND & 0.1 & ND & Taylor et al. (2009) \\
\hline Esker & Canada & -113.43 & 66.97 & ND & 1.9 & ND & 3.50 & 1.20 & ND & 0.1 & 0.0 & Paradis et al. (2007) \\
\hline
\end{tabular}




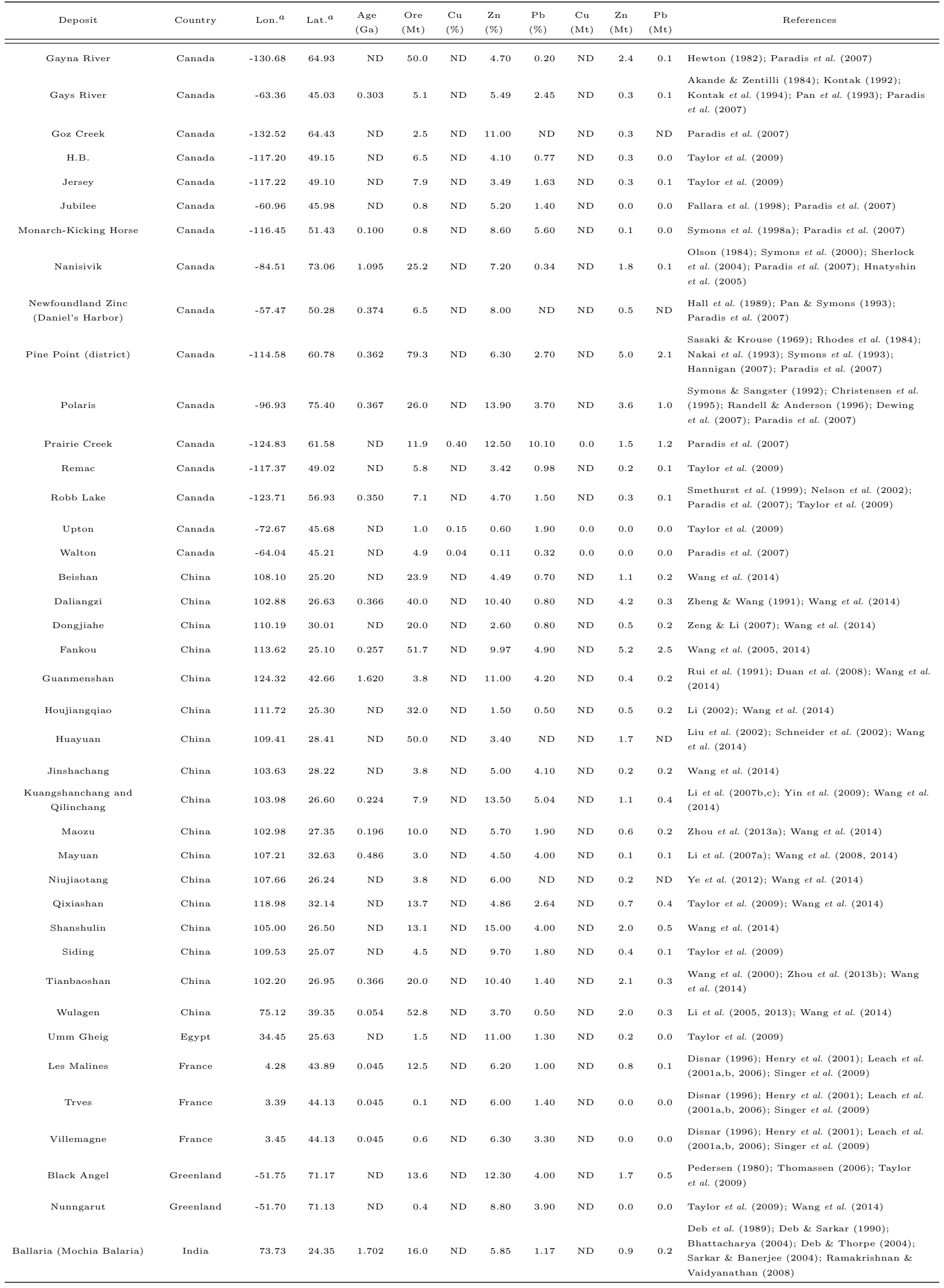


Zawarmala

Angouran

Anjireh-Vejin

Emarat

Irankuh

Kuh-e-Surmeh

Mehdiabad

Abbeytown

Allenwood West

\section{Ballinalack}

Boston Hill

Carrickittle

Courtbrown

Galmoy

Garrycam

Harberton Bridge

$$
\text { Keel }
$$

Lisheen

Moyvoughly

$$
\text { Navan }
$$

Oldcastle

Rickardstown

Silvermines

Tatestown

Tynagh

$$
\text { Gorno }
$$

Salafossa

Sumsar

Beddiane

Bou Beker

\section{Mekta}

Touissit

Berg Aukas

Florida Canyon

San Vicente

Silesian-Crakow district

Pavlovskoye

Sardana

Urultun

Jabal Dhaylan

$$
\text { Mezica }
$$

Bushy Park

Pering
India

\subsection{8}

Iran

Iran

Iran

Iran

Iran$$
\text { Iran }
$$

Ireland

Ireland

Ireland

Ireland

Ireland

Ireland

Ireland

Ireland

Ireland

Ireland

Ireland

Ireland

Ireland

Ireland

Ireland

Ireland

Ireland

Ireland

Italy

Italy

Kyrgyzstan

Morocco

Morocco

Morocco

Morocco

Namibia

Peru

Peru

Poland

Russia

Russia

Russia

Saudi Arabia

$$
\text { Slovenia }
$$

South Africa

South Africa
$47.41 \quad 36.62$

$51.15 \quad 32.71$

$49.61 \quad 33.75$

51.68

52.50

54.99

$-8.53$

6.90

$-7.47$

6.94

$-8.37$

$-8.98$

$-7.59$

$-7.72$

$-6.86$

$-7.73$

$-7.75$

$-7.68$

$-6.68$

$-7.13$

6.82

$-8.27$

$-6.74$

$-8.34$

9.50

12.40

71.34

$-1.80$

$-1.71$

$-1.82$

$-1.76$

18.26

$-78.06$

$-75.35$

(19.53

55.17

136.48

136.48

148.42

37.25

14.52

23.60

24.27
32.55

$28.50 \quad$ ND

31.73

54.22

53.29

53.65

53.22

52.51

52.64

52.80

53.65

53.27

53.65

52.75

53.45

53.66

53.77

53.90

52.79

53.69

53.16

45.52

46.34

41.22

34.40

34.30

34.38

34.46

$-19.57$

$-5.92$

$-11.23$

50.29

72.92

60.19

63.48

25.50

4.30

8.88

$-27.43$
1.712

0.021

ND

0.056

0.056

0.056

0.360

ND

0.360

ND

0.360

0.360

0.360

0.360

ND

0.360

0.350

ND

0.360

0.360

ND

0.360

0.360

0.360

ND

0.180

ND

0.008

0.008

0.008

0.008

0.750

ND$$
\text { ND }
$$

0.04

ND

ND

ND

ND

0.180

2.049

1.980

0.015

$\begin{array}{lllll}17.0 & \text { ND } & 4.26 & 1.75 & \text { ND }\end{array}$

Deb et al. (1989); Deb \& Sarkar (1990);

Bhattacharya (2004); Deb \& Thorpe (2004);

Sarkar \& Banerjee (2004); Ramakrishnan \&

Vaidyanathan (2008)

Deb et al. (1989); Deb \& Sarkar (1990);

Bhattacharya (2004); Sarkar \& Banerjee (2004); Ramakrishnan \& Vaidyanathan (2008)

Deb et al. (1989); Deb \& Sarkar (1990);

Bhattacharya (2004); Deb \& Thorpe (2004);

Sarkar \& Banerjee (2004); Ramakrishnan \&

Vaidyanathan (2008)

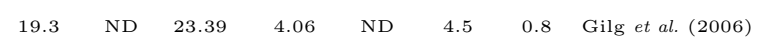

1.2 ND ND ND ND

ND ND Taylor et al. (2009)

$0.0 \quad \mathrm{ND} \quad 6.00 \quad 2.26$

ND

$0.6 \quad 0.2 \quad$ Ehya et al. (2010)

$\begin{array}{lllll}10.0 & \text { ND } & 7.40 & 2.40 & \text { ND }\end{array}$

0.7 0.2 Ghazban et al. (1994)

$0.9 \quad$ ND $\quad 12.10 \quad 5.40$

ND

$0.1 \quad 0.0 \quad$ Taylor et al. (2009)

394.0 ND $\quad 4.20 \quad 1.60$

ND

6.5 Reichert (2007); Taylor et al. (2009)

$\begin{array}{lllll}2.2 & \text { ND } & 3.80 & 1.50 & \text { ND }\end{array}$

$\begin{array}{lll}0.1 & 0.0 \quad \text { Taylor et al. (2009) }\end{array}$

$\begin{array}{llll}10.1 & \text { ND } & 1.60 & 0.40\end{array}$

$\begin{array}{llll}3.5 & \text { ND } & 5.90 \quad 1.10\end{array}$

ND

ND

0.2 $0.0 \quad$ Taylor et al. (2009)

$0.2 \quad 0.0 \quad$ Taylor et al. (2009)

$\begin{array}{llll}0.8 \quad N D & 2.70 \quad 1.10\end{array}$

ND

0.0 


\begin{tabular}{|c|c|c|c|c|c|c|c|c|c|c|c|c|}
\hline Deposit & Country & Lon. ${ }^{a}$ & Lat. ${ }^{a}$ & $\begin{array}{l}\text { Age } \\
(\mathrm{Ga})\end{array}$ & $\begin{array}{l}\text { Ore } \\
(\mathrm{Mt})\end{array}$ & $\begin{array}{l}\mathrm{Cu} \\
(\%)\end{array}$ & $\begin{array}{c}\mathrm{Zn} \\
(\%)\end{array}$ & $\begin{array}{l}\mathrm{Pb} \\
(\%)\end{array}$ & $\begin{array}{c}\mathrm{Cu} \\
(\mathrm{Mt})\end{array}$ & $\begin{array}{c}\mathrm{Zn} \\
(\mathrm{Mt})\end{array}$ & $\begin{array}{c}\mathrm{Pb} \\
(\mathrm{Mt})\end{array}$ & References \\
\hline Reocin & Spain & -4.41 & 43.28 & 0.015 & 62.5 & ND & 8.70 & 1.00 & ND & 5.4 & 0.6 & Velasco et al. (2003); Symons et al. (2009) \\
\hline Troya & Spain & -2.28 & 42.77 & ND & 3.5 & 0.20 & 13.10 & 1.00 & 0.0 & 0.5 & 0.0 & $\begin{array}{l}\text { Velasco et al. (1996); Singer et al. (2009); Taylor } \\
\text { et al. (2009) }\end{array}$ \\
\hline Bou Grine & Tunisia & 8.94 & 36.11 & ND & 5.5 & ND & 12.00 & 2.50 & ND & 0.7 & 0.1 & $\begin{array}{l}\text { Sainfeld (1956); Orgeval (1995); Taylor et al. } \\
\text { (2009); Jemmali et al. (2013) }\end{array}$ \\
\hline Bou Jabeur & Tunisia & 8.28 & 35.78 & ND & 8.8 & ND & 2.17 & 0.99 & ND & 0.2 & 0.1 & $\begin{array}{l}\text { Sainfeld (1956); Charef et al. (2009); Taylor } \\
\text { et al. (2009) }\end{array}$ \\
\hline Djebba & Tunisia & 9.09 & 36.47 & ND & 4.0 & ND & 6.00 & 4.00 & ND & 0.2 & 0.2 & $\begin{array}{l}\text { Sainfeld (1956); Singer et al. (2009); Taylor } \\
\text { et al. (2009) }\end{array}$ \\
\hline Fedj-el Adoum & Tunisia & 9.10 & 36.37 & ND & 3.0 & ND & 6.00 & 2.00 & ND & 0.2 & 0.1 & $\begin{array}{l}\text { Sainfeld (1956); Charef \& Sheppard (1987); } \\
\text { Singer et al. (2009); Taylor et al. (2009) }\end{array}$ \\
\hline Yahyali (district) & Turkey & 36.32 & 38.33 & ND & 2.4 & ND & 21.00 & 3.60 & ND & 0.5 & 0.1 & $\begin{array}{l}\text { Koptagel et al. (2007); Singer et al. (2009); } \\
\text { Taylor et al. (2009) }\end{array}$ \\
\hline Annapolis & USA & -90.68 & 37.36 & 0.273 & 1.1 & ND & ND & 2.30 & ND & ND & 0.0 & Harper \& Borrok (2007) \\
\hline $\begin{array}{l}\text { Austinville-Ivanhoe } \\
\text { (district) }\end{array}$ & USA & -80.92 & 36.85 & ND & 22.6 & ND & 3.70 & 0.70 & ND & 0.8 & 0.2 & Jones et al. (1996) \\
\hline Balmat & USA & -75.40 & 44.25 & 1.150 & 31.7 & ND & 8.88 & 0.25 & ND & 2.8 & 0.1 & $\begin{array}{l}\text { Lea \& Dill Jr. (1968); Fletcher \& Farquhar } \\
(1977,1982) ; \text { Whelan et al. (1984); Steers } \\
(2003)\end{array}$ \\
\hline $\begin{array}{l}\text { Central Tennesse } \\
\quad(\text { district })\end{array}$ & USA & -85.93 & 36.20 & 0.255 & 71.0 & ND & 3.31 & ND & ND & 2.4 & ND & Kesler et al. (1994); Harper \& Borrok (2007) \\
\hline Edwards & USA & -75.26 & 44.34 & 1.150 & 6.0 & ND & 10.80 & 0.31 & ND & 0.6 & 0.0 & $\begin{array}{l}\text { Lea \& Dill Jr. (1968); Fletcher \& Farquhar } \\
(1977,1982) \text {; Steers (2003) }\end{array}$ \\
\hline Fredricktown & USA & -90.27 & 37.55 & 0.273 & 13.6 & ND & ND & 3.90 & ND & ND & 0.5 & Harper \& Borrok (2007) \\
\hline Friedensville & USA & -75.38 & 40.56 & 0.273 & 2.6 & ND & 6.50 & ND & ND & 0.2 & ND & Harper \& Borrok (2007) \\
\hline Hyatt & USA & -75.33 & 44.30 & ND & 0.9 & ND & 8.60 & ND & ND & 0.1 & ND & USGS (2020b) \\
\hline Idol & USA & -83.41 & 36.37 & ND & 6.8 & ND & 3.00 & ND & ND & 0.2 & ND & USGS (2020b) \\
\hline Indian Creek & USA & -90.91 & 38.04 & 0.273 & 26.4 & 0.14 & 0.40 & 3.50 & 0.0 & 0.1 & 0.9 & Harper \& Borrok (2007) \\
\hline $\begin{array}{l}\text { Mascott-Jefferson City } \\
\quad \text { (East Tennessee) } \\
\text { (district) }\end{array}$ & USA & -83.00 & 36.00 & 0.362 & 500.0 & ND & 3.00 & ND & ND & 15.0 & ND & Harper \& Borrok (2007) \\
\hline Metaline (district) & USA & -117.36 & 48.87 & $\mathrm{ND}$ & 7.5 & ND & 2.77 & 1.34 & ND & 0.2 & 0.1 & St Marie \& Kesler (2000) \\
\hline $\begin{array}{l}\text { Northern Arkansas } \\
\quad \text { (district) }\end{array}$ & USA & -92.56 & 36.13 & 0.265 & ND & ND & ND & ND & ND & ND & ND & Harper \& Borrok (2007) \\
\hline Old Lead Belt (district) & USA & -90.50 & 37.50 & 0.273 & 239.0 & ND & 0.30 & 2.90 & ND & 0.7 & 6.9 & Harper \& Borrok (2007) \\
\hline Pend Oreille-Yellowhead & USA & -117.30 & 48.90 & ND & 8.8 & ND & 6.75 & 1.34 & ND & 0.6 & 0.1 & Taylor et al. (2009) \\
\hline Pierrepont & USA & -75.02 & 44.50 & $\mathrm{ND}$ & 2.3 & ND & 16.40 & ND & ND & 0.4 & ND & USGS (2020b) \\
\hline Reef Ridge & USA & -154.25 & 63.41 & ND & 11.8 & ND & 0.99 & ND & ND & 0.1 & ND & Taylor et al. (2009) \\
\hline Sherman & USA & -106.17 & 39.14 & 0.272 & 0.7 & 0.10 & 4.00 & 0.80 & 0.0 & 0.0 & 0.0 & Taylor et al. (2009) \\
\hline Tri-state (district) & USA & -94.50 & 37.00 & 0.258 & 453.6 & ND & 2.33 & 0.57 & ND & 10.6 & 2.6 & Taylor et al. (2009) \\
\hline $\begin{array}{l}\text { Upper Mississippi Valley } \\
\text { (district) }\end{array}$ & USA & -90.23 & 42.57 & 0.270 & 40.2 & ND & 2.73 & 1.86 & ND & 1.1 & 0.7 & $\begin{array}{l}\text { Brannon et al. (1992); Harper \& Borrok (2007); } \\
\text { Taylor et al. (2009) }\end{array}$ \\
\hline Van Stone & USA & -117.76 & 48.76 & ND & 6.2 & ND & 4.16 & 0.04 & ND & 0.3 & 0.0 & Taylor et al. (2009) \\
\hline Viburnum Trend (distict) & USA & -91.13 & 37.58 & 0.273 & 276.3 & 0.20 & 1.05 & 5.72 & 0.6 & 2.9 & 15.8 & $\begin{array}{l}\text { Sverjensky (1981); Symons et al. (1998b); } \\
\text { Harper \& Borrok (2007); Taylor et al. (2009); } \\
\text { Lori (2014) }\end{array}$ \\
\hline
\end{tabular}

$a^{a}$ In decimal degrees

Table 4: Global compilation of 139 sedimentary copper deposits shown in Figure S30. Primarily compiled from Hitzman et al. (2005), cross-checked against Cox et al. (2007), with original references reported where available. Ga = billion years; Mt = million tonnes; ND = no data.

\begin{tabular}{|c|c|c|c|c|c|c|c|}
\hline Deposit & State/Region & Country & Lon. $^{a}$ & Lat. $^{a}$ & $\begin{array}{l}\text { Age } \\
(\mathrm{Ga})\end{array}$ & $\begin{array}{c}\mathrm{Cu} \\
(\mathrm{Mt})\end{array}$ & References \\
\hline Aynak & Logar & Afganistan & 69.30 & 34.27 & 0.570 & 7.00 & Abdullah S. et al. (1977); Sillitoe (1980) \\
\hline Cachoeiras de Binga & Cuanza Sul & Angola & 14.09 & -11.08 & 0.115 & 0.13 & Van Eden (1978) \\
\hline Martin Bronce & Jujuy & Argentina & -64.42 & -24.17 & 0.090 & 0.09 & Zappettini (1999) \\
\hline Barda Gonzalez & Neuqun & Argentina & -68.98 & -38.88 & 0.090 & 0.13 & Northern Miner (1995) \\
\hline Cerro Granito & Neuqun & Argentina & -69.82 & -39.22 & 0.090 & 0.01 & Yamana Resources Inc. (1996) \\
\hline Sauzal Bonito & Neuqun & Argentina & -69.18 & -38.63 & 0.090 & 0.25 & Yamana Resources Inc. (1996) \\
\hline Tordillos & Neuqun & Argentina & -68.97 & -38.45 & 0.090 & 0.04 & Northern Miner (1995) \\
\hline
\end{tabular}




\begin{tabular}{|c|c|c|c|c|c|c|c|}
\hline Deposit & State/Region & Country & Lon. ${ }^{a}$ & Lat. $^{a}$ & $\begin{array}{l}\text { Age } \\
(\mathrm{Ga})\end{array}$ & $\begin{array}{c}\mathrm{Cu} \\
(\mathrm{Mt})\end{array}$ & References \\
\hline Juramento & Salta & Argentina & -65.15 & -25.22 & 0.090 & 0.09 & Durieux \& Brown (2001) \\
\hline Redbank & Northern Territory & Australia & 137.74 & -17.19 & 1.600 & 0.14 & Sexton (2011) \\
\hline Gunpowder & Queensland & Australia & 139.37 & -19.70 & 1.550 & 0.27 & Scott \& Taylor (1977, 1982); Clark (2001) \\
\hline Lady Annie & Queensland & Australia & 139.04 & -19.77 & 1.550 & 0.46 & Sexton (2011) \\
\hline Mt Isa Copper & Queensland & Australia & 139.48 & -20.74 & 1.523 & 7.43 & $\begin{array}{l}\text { Perkins (1984); Heinrich et al. (1995); Waring } \\
\text { et al. (1998); Matthäi et al. (2004) }\end{array}$ \\
\hline Walford Creek & Queensland & Australia & 138.27 & -17.78 & 1.600 & 0.20 & Sexton (2011) \\
\hline Emmie Bluff & South Australia & Australia & 137.15 & -31.11 & 2.050 & 0.33 & Geological Survey of South Australia (2020) \\
\hline Kapunda & South Australia & Australia & 138.92 & -34.35 & 0.650 & 0.12 & $\begin{array}{l}\text { Terramin Australia Ltd. (2018); Geological } \\
\text { Survey of South Australia (2020) }\end{array}$ \\
\hline Mount Gunson & South Australia & Australia & 137.25 & -31.45 & 0.630 & 0.31 & Geological Survey of South Australia (2020) \\
\hline Maroochydore & Western Australia & Australia & 122.31 & -22.20 & 0.820 & 0.39 & Anderson et al. (2001) \\
\hline Nifty & Western Australia & Australia & 121.57 & -21.65 & 0.822 & 1.68 & Anderson et al. (2001) \\
\hline Chacarilla & La Paz & Bolivia & -68.20 & -17.58 & 0.028 & 0.06 & Cox et al. (1992); Long (1992) \\
\hline Corocoro & La Paz & Bolivia & -68.45 & -17.16 & 0.040 & 0.50 & Drummond (1996) \\
\hline Azurita & Oruro & Bolivia & -68.15 & -18.07 & 0.013 & 0.52 & Northern Miner (1996a) \\
\hline Thakadu & Central & Botswana & 26.75 & -21.08 & 2.050 & 0.18 & Mining Magazine (1998a) \\
\hline Ngwako Pan & Ngamiland & Botswana & 23.10 & -20.75 & 0.900 & 17.52 & $\begin{array}{l}\text { Anglo American Corp. (1989); Schwartz et al. } \\
\text { (1995); Gencor (1995); Delta Gold (2000) }\end{array}$ \\
\hline Pedra Verde & Cear & Brazil & -41.12 & -3.50 & 1.300 & 0.12 & Brizzi \& Roberto (1988) \\
\hline Bahia & Par & Brazil & -49.08 & -5.67 & 2.050 & 0.79 & Dayton \& Sassos (1985) \\
\hline Camaqua & Rio Grande do Sul & Brazil & -52.40 & -30.78 & 0.700 & 0.08 & Teixeira \& Gonzalez (1988) \\
\hline Venesta & Razgrad & Bulgaria & 26.75 & 42.67 & 0.200 & 0.01 & Todorov (1997) \\
\hline Dorchester & New Brunswick & Canada & -64.48 & 45.93 & 0.300 & 0.05 & Canerpa-Amax (1974) \\
\hline Jay & Northwest Territories & Canada & -127.83 & 63.77 & 0.750 & 0.03 & Ruelle (1982) \\
\hline Redstone & Northwest Territories & Canada & -126.62 & 62.69 & 0.750 & 1.32 & Gourlay (2003) \\
\hline Storm & Nunavut & Canada & -94.07 & 73.62 & 0.450 & 0.10 & Hitzman et al. (2005) \\
\hline San Bartolo & Antofagasta & Chile & -68.23 & -22.73 & 0.012 & 0.03 & Camus (1986) \\
\hline San Jose de Tuina & Antofagasta & Chile & -68.45 & -22.52 & 0.300 & 0.12 & Northern Miner (1997); Hitzman et al. (2005) \\
\hline Teresita & Atacama & Chile & -70.23 & -27.35 & 0.120 & 0.02 & Hitzman et al. (2005) \\
\hline LaoXue & Sichuan & China & 102.33 & 26.29 & 2.050 & 0.50 & Hitzman et al. (2005) \\
\hline TangDan & Sichuan & China & 102.67 & 26.25 & 1.500 & 3.60 & Ren (1994); Hitzman et al. (2005) \\
\hline Dishui & Xinjiang & China & 81.25 & 41.50 & 0.013 & 0.09 & Hitzman et al. (2005) \\
\hline Jiashi & Xinjiang & China & 77.08 & 39.83 & 0.004 & 0.15 & Hitzman et al. (2005) \\
\hline Jinman & Yunnan & China & 99.05 & 26.05 & 0.170 & ND & Hitzman et al. (2005) \\
\hline Lanniping & Yunnan & China & 103.07 & 26.10 & 0.900 & $\mathrm{ND}$ & Hitzman et al. (2005) \\
\hline LiuZu & Yunnan & China & 103.25 & 25.42 & 0.070 & 0.85 & Hitzman et al. (2005) \\
\hline Dikulushi & Haut-Katanga & Democratic Republic of Congo & 28.25 & -9.17 & 0.900 & 0.15 & $\begin{array}{l}\text { Anvil Mining NL (2003); Northern Miner } \\
\text { (2004a) }\end{array}$ \\
\hline Etoile & Haut-Katanga & Democratic Republic of Congo & 27.58 & -11.65 & 0.900 & 4.16 & Northern Miner (1996c); Hitzman et al. (2005) \\
\hline Kamatanda & Haut-Katanga & Democratic Republic of Congo & 26.78 & -10.95 & 0.900 & 0.50 & Hitzman et al. (2005) \\
\hline Kambove & Haut-Katanga & Democratic Republic of Congo & 26.61 & -10.88 & 0.900 & 2.78 & Northern Miner (1996b); Hitzman et al. (2005) \\
\hline Kimbwe & Haut-Katanga & Democratic Republic of Congo & 27.51 & -11.14 & 0.900 & 2.00 & Hitzman et al. (2005) \\
\hline Kinsenda & Haut-Katanga & Democratic Republic of Congo & 27.97 & -12.28 & 0.900 & 1.75 & $\begin{array}{l}\text { U.S. Bureau of Mines (1974); Hitzman et al. } \\
\text { (2005) }\end{array}$ \\
\hline Lonshi & Haut-Katanga & Democratic Republic of Congo & 28.94 & -13.18 & 0.900 & 0.27 & Northern Miner (2004b) \\
\hline Lufua & Haut-Katanga & Democratic Republic of Congo & 28.50 & -12.75 & 0.900 & 1.02 & Northern Miner (2004c) \\
\hline Luishia & Haut-Katanga & Democratic Republic of Congo & 27.01 & -11.17 & 0.900 & 1.81 & Hitzman et al. (2005) \\
\hline Luiswishi & Haut-Katanga & Democratic Republic of Congo & 27.42 & -11.51 & 0.900 & 0.20 & Hitzman et al. (2005) \\
\hline M'Sesa & Haut-Katanga & Democratic Republic of Congo & 26.61 & -10.85 & 0.900 & 0.46 & Hitzman et al. (2005) \\
\hline Musoshi (see Konkola) & Haut-Katanga & Democratic Republic of Congo & 27.71 & -12.27 & 0.900 & 3.57 & Hitzman et al. (2005) \\
\hline Kakanda & Lualaba & Democratic Republic of Congo & 26.41 & -10.73 & 0.900 & 1.11 & Hitzman et al. (2005) \\
\hline Kalukundi & Lualaba & Democratic Republic of Congo & 25.92 & -10.63 & 0.900 & 0.51 & Northern Miner (2004d) \\
\hline Kamfundwa & Lualaba & Democratic Republic of Congo & 26.59 & -10.81 & 0.900 & 0.28 & Hitzman et al. (2005) \\
\hline Kolwezi & Lualaba & Democratic Republic of Congo & 25.42 & -10.73 & 0.900 & 39.40 & Northern Miner (2002a); Hitzman et al. (2005) \\
\hline
\end{tabular}




\begin{tabular}{|c|c|c|c|c|c|c|c|}
\hline Deposit & State/Region & Country & Lon. $^{a}$ & Lat. $^{a}$ & $\begin{array}{l}\text { Age } \\
(\mathrm{Ga})\end{array}$ & $\begin{array}{c}\mathrm{Cu} \\
(\mathrm{Mt})\end{array}$ & References \\
\hline Tenke-Fungurume & Lualaba & Democratic Republic of Congo & 26.15 & -10.58 & 0.900 & 43.15 & $\begin{array}{l}\text { Mining Magazine (1998b); Tenke Mining Corp. } \\
(2003)\end{array}$ \\
\hline Spremberg & Brandenburg & Germany & 14.37 & 51.58 & 0.260 & 1.50 & Hitzman et al. (2005) \\
\hline Richelsdorf & Hesse & Germany & 9.90 & 50.98 & 0.260 & 0.42 & Walther (1986) \\
\hline Marsberg & North Rhine-Westphalia & Germany & 8.89 & 51.47 & 0.260 & 0.06 & Walther (1986) \\
\hline Mansfeld & Saxony-Anhalt & Germany & 11.47 & 51.60 & 0.260 & 2.63 & Hitzman et al. (2005) \\
\hline Timna & Southern & Israel & 34.95 & 29.77 & 0.530 & 0.29 & Vered-Weiss et al. (1971) \\
\hline Fenan & Tafilah & Jordan & 35.42 & 30.60 & 0.560 & 0.78 & U.S. Bureau of Mines (1984) \\
\hline Dzhezkazgan & Karagandy & Kazakstan & 67.39 & 48.12 & 0.320 & 22.00 & Hitzman et al. (2005) \\
\hline East Saryoba & Karagandy & Kazakstan & 67.43 & 48.28 & 0.320 & 0.78 & Hitzman et al. (2005) \\
\hline Itauz & Karagandy & Kazakstan & 67.33 & 48.27 & 0.300 & 0.87 & Hitzman et al. (2005) \\
\hline Karashoshak & Karagandy & Kazakstan & 67.72 & 48.34 & 0.300 & 0.49 & Hitzman et al. (2005) \\
\hline Taskura & Karagandy & Kazakstan & 68.33 & 48.63 & 0.270 & 0.01 & Abdulin et al. (1998); Hitzman et al. (2005) \\
\hline West Saryoba & Karagandy & Kazakstan & 67.40 & 48.28 & 0.320 & 0.77 & Hitzman et al. (2005) \\
\hline Zhaman-Aibat & Karagandy & Kazakstan & 67.30 & 47.87 & 0.320 & 2.90 & Abdulin et al. (1998); Hitzman et al. (2005) \\
\hline Boleo & Baja California Sur & Mexico & -112.50 & 27.17 & 0.003 & 4.04 & Bailes et al. (2001) \\
\hline Khatuugiin & Khovd & Mongolia & 90.15 & 48.65 & 0.350 & $\mathrm{ND}$ & Nokleberg et al. (2003) \\
\hline Omnogobi & Uvs & Mongolia & 91.68 & 49.13 & 0.350 & $\mathrm{ND}$ & Nokleberg et al. (2003) \\
\hline Bleida & Dra-Tafilalet & Morocco & -6.17 & 30.33 & 2.050 & 0.18 & Hitzman et al. (2005) \\
\hline Jbel Hassel & Dra-Tafilalet & Morocco & -6.00 & 30.33 & 0.510 & 0.05 & Hitzman et al. (2005) \\
\hline Talat N'Ouamane & Souss-Massa & Morocco & -8.35 & 30.09 & 0.530 & 0.02 & Hitzman et al. (2005) \\
\hline Tazalaght & Souss-Massa & Morocco & -8.75 & 29.77 & 0.900 & 0.03 & Hitzman et al. (2005) \\
\hline Klein Aub & Hardap & Namibia & 16.63 & -23.80 & 0.900 & 0.18 & Hitzman et al. (2005) \\
\hline Oamites & Khomas & Namibia & 17.10 & -22.98 & 0.900 & 0.08 & Lee \& Glenister (1976) \\
\hline Witvlei & Omaheke & Namibia & 18.53 & -22.38 & 0.900 & 0.12 & Hitzman et al. (2005) \\
\hline Tschudi & Oshikoto & Namibia & 17.51 & -19.26 & 0.900 & 0.14 & Hitzman et al. (2005) \\
\hline Repparfjord & Troms og Finnmark & Norway & 24.22 & 70.43 & 1.000 & 0.08 & Bjørlykke et al. (1985); Stribrny (1985) \\
\hline Negra Huanusha & Junn & Peru & -75.85 & -11.30 & 0.260 & $\mathrm{ND}$ & Kobe (1960) \\
\hline Kaleje & Greater Poland & Poland & 17.62 & 52.18 & 0.260 & 40.00 & Hitzman et al. (2005) \\
\hline Sulmierzyce & Greater Poland & Poland & 17.62 & 51.65 & 0.260 & 74.00 & $\begin{array}{l}\text { Oszczepalski \& Rydzewski (1997); Hitzman } \\
\text { et al. (2005) }\end{array}$ \\
\hline Borzecin- Janowo & Lower Silesia & Poland & 16.90 & 51.48 & 0.260 & 28.00 & $\begin{array}{l}\text { Oszczepalski \& Rydzewski (1997); Hitzman } \\
\text { et al. (2005) }\end{array}$ \\
\hline Konrad & Lower Silesia & Poland & 13.72 & 51.25 & 0.260 & 0.67 & $\begin{array}{l}\text { Oszczepalski \& Rydzewski (1997); Hitzman } \\
\text { et al. (2005) }\end{array}$ \\
\hline Lena & Lower Silesia & Poland & 15.82 & 51.11 & 0.260 & 0.12 & Hitzman et al. (2005) \\
\hline Lubin & Lower Silesia & Poland & 16.13 & 51.40 & 0.260 & 82.80 & $\begin{array}{l}\text { Wodzicki \& Piestrzyński (1994); Przeniosło } \\
\text { (2000); Piestrzyński \& Wodzicki (2000) }\end{array}$ \\
\hline Wartowice & Lower Silesia & Poland & 15.58 & 51.18 & 0.260 & 0.70 & Hitzman et al. (2005) \\
\hline Zary Pericline & Lower Silesia & Poland & 14.97 & 51.88 & 0.260 & 3.20 & Oszczepalski \& Rydzewski (1997) \\
\hline Zary & Lubusz & Poland & 15.09 & 51.64 & 0.270 & 3.20 & Oszczepalski \& Rydzewski (1997) \\
\hline Lena & Irkutsk & Russia & 106.50 & 58.77 & 0.520 & 1.35 & Narkelyun et al. (1971) \\
\hline Sakinskoye & Irkutsk & Russia & 118.50 & 58.58 & 2.050 & $\mathrm{ND}$ & Volodin et al. (1994); Nokleberg et al. (2003) \\
\hline Graviisk & Krasnoyarsk Krai & Russia & 87.55 & 66.52 & 0.600 & $\mathrm{ND}$ & $\begin{array}{l}\text { Rzhevskii et al. (1988); Dodin et al. (2000); } \\
\text { Hitzman et al. (2005) }\end{array}$ \\
\hline Kunshskoye & Krasnoyarsk Krai & Russia & 94.97 & 58.50 & 0.900 & 0.02 & Nokleberg et al. (2003) \\
\hline Oroek & Magadan & Russia & 152.80 & 64.90 & 1.300 & $\mathrm{ND}$ & Nockleberg et al. (1997); Hitzman et al. (2005) \\
\hline Agyndja & Sakha Republic & Russia & 148.00 & 65.22 & 0.480 & $\mathrm{ND}$ & Shpikerman (1990); Nockleberg et al. (1997) \\
\hline Kurpandja & Sakha Republic & Russia & 137.02 & 63.52 & 0.385 & 0.50 & Nockleberg et al. (1997) \\
\hline Pravo-Ingamakitsk & Zabaykalsky Krai & Russia & 118.67 & 56.42 & 2.000 & $\mathrm{ND}$ & Volodin et al. (1994); Nokleberg et al. (2003) \\
\hline Udokan & Zabaykalsky Krai & Russia & 118.43 & 56.59 & 2.100 & 24.00 & $\begin{array}{l}\text { Kirkham et al. (1994); Volodin et al. (1994); } \\
\text { Nokleberg et al. (2003) }\end{array}$ \\
\hline Jabal Murryyi & Al Bahah & Saudi Arabia & 41.57 & 20.11 & 0.800 & 0.01 & Hitzman et al. (2005) \\
\hline Cashin & Colorado & USA & -108.95 & 38.30 & 0.170 & 0.06 & Tanaka (2004) \\
\hline Snowstorm & Idaho & USA & -115.72 & 47.48 & 1.500 & 0.03 & Hitzman et al. (2005) \\
\hline Kona Dolomite & Michigan & USA & -87.45 & 46.53 & 2.000 & 3.50 & Wilband (1978); Hitzman et al. (2005) \\
\hline Presque Isle & Michigan & USA & -89.98 & 46.68 & 2.050 & 1.18 & Hitzman et al. (2005) \\
\hline
\end{tabular}




\begin{tabular}{|c|c|c|c|c|c|c|c|}
\hline Deposit & State/Region & Country & Lon. $^{a}$ & Lat. ${ }^{a}$ & $\begin{array}{l}\text { Age } \\
(\mathrm{Ga})\end{array}$ & $\begin{array}{c}\mathrm{Cu} \\
(\mathrm{Mt})\end{array}$ & References \\
\hline White Pine & Michigan & USA & -89.57 & 46.77 & 1.100 & 10.13 & $\begin{array}{l}\text { Mining Journal of London (1989); Seasor \& } \\
\text { Brown (1989); Hitzman et al. (2005) }\end{array}$ \\
\hline Rock Creek & Montana & USA & -115.68 & 48.08 & 1.500 & 2.42 & Northern Miner (2002b); Hitzman et al. (2005) \\
\hline Spar Lake & Montana & USA & -115.90 & 48.23 & 1.500 & 0.46 & Balla (1982); Hitzman et al. (2005) \\
\hline Champion & New Mexico & USA & -105.50 & 36.50 & 1.500 & 0.25 & $\begin{array}{l}\text { Northern Miner (1996d); U.S. Bureau of Mines } \\
\text { (1998) }\end{array}$ \\
\hline Nacimiento & New Mexico & USA & -106.88 & 36.01 & 0.220 & 0.06 & Ahlness \& Pojar (1983) \\
\hline Creta & Oklahoma & USA & -99.35 & 34.65 & 0.270 & 0.04 & Hitzman et al. (2005) \\
\hline Mangum & Oklahoma & USA & -99.50 & 34.88 & 0.270 & 0.07 & Hitzman et al. (2005) \\
\hline Lisbon Valley & Utah & USA & -109.10 & 39.15 & 0.130 & 0.58 & Summo Minerals Corp. (2001) \\
\hline Silver Reef & Utah & USA & -113.42 & 37.28 & 0.220 & 0.04 & James \& Newman (1986); Hitzman et al. (2005) \\
\hline Seboruco & Los Andes & Venezuela & -72.00 & 8.00 & 0.200 & 0.18 & Rodriguez (1990) \\
\hline Baluba (see Luanshya) & Copperbelt & Zambia & 28.38 & -13.05 & 0.900 & 1.32 & Lungu (1998); Hitzman et al. (2005) \\
\hline Bwana Mkubwa & Copperbelt & Zambia & 28.69 & -13.02 & 0.900 & 0.35 & Northern Miner (1998) \\
\hline Chambishi & Copperbelt & Zambia & 28.05 & -12.68 & 0.900 & 10.40 & Hitzman et al. (2005) \\
\hline Chibuluma South & Copperbelt & Zambia & 28.05 & -12.83 & 0.900 & 0.34 & McGregor (1991); Northern Miner (2000a) \\
\hline $\begin{array}{c}\text { Chibuluma-Chibuluma } \\
\text { West }\end{array}$ & Copperbelt & Zambia & 28.13 & -12.83 & 0.900 & 0.74 & $\begin{array}{l}\text { McGregor (1991); Crew Development Corp. } \\
\text { (1998) }\end{array}$ \\
\hline Fituaola & Copperbelt & Zambia & 27.88 & -12.41 & 0.900 & 0.13 & Hitzman et al. (2005) \\
\hline Konkola-Kirila Bombwe & Copperbelt & Zambia & 27.83 & -12.39 & 0.900 & 27.22 & Northern Miner (1998); Hitzman et al. (2005) \\
\hline Luanshya & Copperbelt & Zambia & 28.38 & -13.13 & 0.900 & 7.41 & Lungu (1998); Hitzman et al. (2005) \\
\hline Mindola-Nkana N-S & Copperbelt & Zambia & 28.17 & -12.80 & 0.900 & 12.16 & McGregor (1991); Northern Miner (2000c) \\
\hline Mufulira & Copperbelt & Zambia & 28.24 & -12.52 & 0.900 & 8.14 & McGregor (1991); Northern Miner (2000b) \\
\hline Muliashi (see Luanshiya) & Copperbelt & Zambia & 28.28 & -13.08 & 0.900 & 0.21 & McGregor (1991) \\
\hline Mutundu North & Copperbelt & Zambia & 27.62 & -12.50 & 0.900 & 0.06 & McGregor (1991) \\
\hline Nchanga & Copperbelt & Zambia & 27.87 & -12.53 & 0.900 & 18.29 & Hitzman et al. (2005) \\
\hline Nkana West Limb & Copperbelt & Zambia & 27.18 & -12.83 & 0.900 & 1.88 & McGregor (1991) \\
\hline Chimiwungo-Lumwana & North-Western & Zambia & 25.85 & -12.18 & 0.900 & 10.00 & Northern Miner (2004e) \\
\hline Kalumbila & North-Western & Zambia & 25.33 & -12.25 & 0.900 & 0.26 & Steven \& Armstrong (2003) \\
\hline Alaska area & Mashonaland West & Zimbabwe & 30.01 & -17.43 & 0.900 & 0.17 & Maiden et al. (1984); Newham (1986) \\
\hline Mangula & Mashonaland West & Zimbabwe & 30.15 & -16.88 & 0.900 & 0.74 & Maiden et al. (1984); Newham (1986) \\
\hline Norah & Mashonaland West & Zimbabwe & 30.15 & -16.93 & 0.900 & 0.12 & Maiden et al. (1984); Newham (1986) \\
\hline Shackleton & Mashonaland West & Zimbabwe & 30.04 & -17.27 & 1.250 & 0.04 & Maiden et al. (1984); Newham (1986) \\
\hline Umkondo & Masvingo & Zimbabwe & 32.15 & -20.32 & 0.900 & 0.03 & Newham (1986) \\
\hline Copper Queen & Midlands & Zimbabwe & 29.22 & -17.52 & 0.900 & 0.19 & U.S. Bureau of Mines (1980) \\
\hline
\end{tabular}

${ }^{a}$ In decimal degrees

Table 5: Global compilation of 108 magmatic nickel deposits shown in Figure S31. Primarily compiled from Hoatson et al. (2006), with original references reported where available. $\mathrm{Ga}=$ billion years; $\mathrm{Mt}=$ million tonnes.

\begin{tabular}{|c|c|c|c|c|c|c|c|c|c|}
\hline Deposit & State/Region & Country & Lon. ${ }^{a}$ & Lat. ${ }^{a}$ & $\begin{array}{l}\text { Age } \\
(\mathrm{Ga})\end{array}$ & Ore (Mt) & $\begin{array}{c}\mathrm{Ni} \\
(\%)\end{array}$ & $\begin{array}{c}\mathrm{Ni} \\
(\mathrm{Mt})\end{array}$ & References \\
\hline Avebury & Tasmania & Australia & 145.25 & -41.92 & 0.360 & 11.59 & 1.02 & 0.118 & Newnham (2003) \\
\hline Armstrong (formerly Moore) & Western Australia & Australia & 121.53 & -31.42 & 2.705 & 2.06 & 1.22 & 0.025 & Nelson (1997a) \\
\hline Beta & Western Australia & Australia & 121.69 & -31.24 & 2.705 & 7.60 & 3.63 & 0.276 & Nelson (1997a) \\
\hline $\begin{array}{c}\text { Black Swan (incl. Silver Swan, } \\
\text { Cygnet) }\end{array}$ & Western Australia & Australia & 121.65 & -30.39 & 2.706 & 11.10 & 1.93 & 0.214 & Kositcin et al. (2008) \\
\hline Blair & Western Australia & Australia & 121.72 & -30.91 & 2.705 & 1.33 & 2.64 & 0.035 & Nelson (1997a) \\
\hline Carnilya Hill & Western Australia & Australia & 121.86 & -31.05 & 2.705 & 0.52 & 2.68 & 0.014 & Nelson (1997a) \\
\hline Carr Boyd Rocks & Western Australia & Australia & 121.63 & -30.07 & 2.700 & 1.02 & 1.17 & 0.012 & Groenewald et al. (2009) \\
\hline Cliffs-Charterhall & Western Australia & Australia & 120.55 & -27.31 & 2.705 & 2.40 & 4.04 & 0.097 & Nelson (1997a) \\
\hline Copernicus & Western Australia & Australia & 127.99 & -17.66 & 1.844 & 0.24 & 1.50 & 0.004 & Page \& Hoatson (2000) \\
\hline Corkwood & Western Australia & Australia & 128.19 & -17.30 & 1.844 & 0.23 & 0.65 & 0.001 & Page \& Hoatson (2000) \\
\hline Cosmos & Western Australia & Australia & 120.58 & -27.60 & 2.705 & 1.02 & 7.77 & 0.079 & Nelson (1997a) \\
\hline East Scotia & Western Australia & Australia & 121.46 & -31.18 & 2.705 & 0.08 & 2.00 & 0.002 & Nelson (1997a) \\
\hline
\end{tabular}




\begin{tabular}{|c|c|c|c|c|c|c|c|c|c|}
\hline Deposit & State/Region & Country & Lon. $^{a}$ & Lat. ${ }^{a}$ & $\begin{array}{l}\text { Age } \\
(\mathrm{Ga})\end{array}$ & Ore $(\mathrm{Mt})$ & $\begin{array}{c}\mathrm{Ni} \\
(\%)\end{array}$ & $\begin{array}{c}\mathrm{Ni} \\
(\mathrm{Mt})\end{array}$ & References \\
\hline Emily Ann & Western Australia & Australia & 120.48 & -32.20 & 2.921 & 2.08 & 3.62 & 0.075 & Wang et al. (1996) \\
\hline $\begin{array}{l}\text { Forrestania Nickel (incl. Cosmic Boy, } \\
\text { Daybreak, Digger Rocks, Flying Fox, } \\
\text { New Morning) }\end{array}$ & Western Australia & Australia & 119.81 & -32.72 & 3.000 & 7.57 & 1.91 & 0.145 & Wang et al. (1996) \\
\hline Gibb & Western Australia & Australia & 121.68 & -31.18 & 2.705 & 0.25 & 2.04 & 0.005 & Nelson (1997a) \\
\hline $\begin{array}{c}\text { Honeymoon Well (incl. Harrier, } \\
\text { Wedgetail) }\end{array}$ & Western Australia & Australia & 120.38 & -26.92 & 2.705 & 134.80 & 0.75 & 1.011 & Nelson (1997a) \\
\hline Jericho & Western Australia & Australia & 120.58 & -27.39 & 2.705 & ND & ND & 0.405 & Nelson (1997a) \\
\hline $\begin{array}{c}\text { Kambalda (incl. Kambalda Dome St } \\
\text { Ives-Tramways) }\end{array}$ & Western Australia & Australia & 121.65 & -31.18 & 2.705 & 42.06 & 3.30 & 1.388 & Nelson (1997b) \\
\hline Lanfranchi & Western Australia & Australia & 121.84 & -31.51 & 2.705 & 3.65 & 2.02 & 0.074 & Nelson (1997b) \\
\hline Long & Western Australia & Australia & 121.68 & -31.18 & 2.705 & 1.16 & 5.79 & 0.067 & Nelson (1997b) \\
\hline Maggie Hays & Western Australia & Australia & 120.52 & -32.22 & 2.921 & 12.27 & 1.41 & 0.173 & Wang et al. (1996) \\
\hline Mariners & Western Australia & Australia & 121.66 & -31.63 & 2.705 & 1.58 & 2.91 & 0.046 & Nelson (1997a) \\
\hline Marriott & Western Australia & Australia & 120.99 & -28.45 & 2.705 & 0.72 & 1.10 & 0.008 & Nelson (1997a) \\
\hline McEwen (formerly Mt Edwards 360N) & Western Australia & Australia & 121.52 & -31.40 & 2.705 & 0.73 & 0.86 & 0.006 & Nelson (1997a) \\
\hline Melon & Western Australia & Australia & 120.73 & -27.86 & 2.705 & 0.35 & 2.00 & 0.007 & Nelson (1997a) \\
\hline Miitel (incl. North) & Western Australia & Australia & 121.64 & -31.58 & 2.705 & 1.64 & 3.60 & 0.059 & Nelson (1997a) \\
\hline Miriam & Western Australia & Australia & 121.09 & -31.07 & 2.705 & 0.23 & 1.70 & 0.004 & Nelson (1997a) \\
\hline Mt Edwards (incl. Mt Edwards $14 \mathrm{~N}$ ) & Western Australia & Australia & 121.54 & -31.45 & 2.705 & 1.08 & 1.21 & 0.013 & Nelson (1997a) \\
\hline Mt Edwards $132 \mathrm{~N}$ & Western Australia & Australia & 121.54 & -31.45 & 2.705 & 0.28 & 3.45 & 0.010 & Nelson (1997a) \\
\hline Mt Edwards $166 \mathrm{~N}$ & Western Australia & Australia & 121.53 & -31.44 & 2.705 & 0.13 & 1.85 & 0.002 & Nelson (1997a) \\
\hline Mt Edwards 26N & Western Australia & Australia & 121.54 & -31.48 & 2.705 & 1.70 & 2.50 & 0.043 & Nelson (1997a) \\
\hline Mt Keith & Western Australia & Australia & 120.54 & -27.23 & 2.705 & 599.18 & 0.57 & 3.415 & Nelson (1997a) \\
\hline Mt Martin & Western Australia & Australia & 121.68 & -31.01 & 2.500 & 0.07 & 2.00 & 0.001 & Nelson (1997a) \\
\hline Mt Sholl & Western Australia & Australia & 116.89 & -20.92 & 2.892 & 3.03 & 0.75 & 0.023 & Frick et al. (2001) \\
\hline Mt Windarra & Western Australia & Australia & 122.23 & -28.49 & 2.900 & 12.71 & 1.42 & 0.181 & Barley \& Groves (1990) \\
\hline Munda & Western Australia & Australia & 121.53 & -31.50 & 2.705 & 0.05 & 2.53 & 0.001 & Nelson (1997a) \\
\hline Munni Munni & Western Australia & Australia & 116.83 & -21.12 & 2.927 & 23.60 & 0.09 & 0.021 & Hoatson \& Sun (2002) \\
\hline Nebo-Babel & Western Australia & Australia & 127.73 & -26.10 & 1.078 & 283.33 & 0.36 & 1.020 & Huston et al. (2007) \\
\hline Nepean & Western Australia & Australia & 121.09 & -31.16 & 2.705 & 1.55 & 3.16 & 0.049 & Nelson (1997a) \\
\hline Nova & Western Australia & Australia & 123.19 & -31.82 & 1.300 & 11.40 & 2.40 & 0.274 & PorterGeo (2020d) \\
\hline Panton & Western Australia & Australia & 127.83 & -17.75 & 1.856 & 33.60 & 0.16 & 0.054 & Page \& Hoatson (2000) \\
\hline $\begin{array}{c}\text { Perseverance (incl. Rocky's Reward, } \\
\text { Leinster) }\end{array}$ & Western Australia & Australia & 120.70 & -27.79 & 2.705 & 236.45 & 1.05 & 2.483 & Nelson (1997b) \\
\hline Pioneer & Western Australia & Australia & 121.64 & -31.97 & 2.705 & 0.03 & 1.11 & 0.000 & Nelson (1997a) \\
\hline Prospero & Western Australia & Australia & 120.58 & -27.63 & 2.705 & 1.06 & 5.72 & 0.061 & Nelson (1997a) \\
\hline Radio Hill & Western Australia & Australia & 116.86 & -20.98 & 2.892 & 2.76 & 1.53 & 0.042 & Frick et al. (2001) \\
\hline Ratbat & Western Australia & Australia & 119.74 & -32.55 & 3.000 & 0.25 & 1.10 & 0.003 & Wang et al. (1996) \\
\hline Rav 8 & Western Australia & Australia & 120.30 & -33.60 & 2.958 & 0.51 & 3.56 & 0.018 & Nelson (1997a) \\
\hline $\begin{array}{l}\text { Ravensthorpe Nickel (incl. Rav } 1,4 \\
5,4 \mathrm{w})\end{array}$ & Western Australia & Australia & 120.40 & -33.64 & 2.958 & 1.58 & 0.87 & 0.014 & Nelson (1997a) \\
\hline Redross & Western Australia & Australia & 121.65 & -31.68 & 2.705 & 0.77 & 3.99 & 0.031 & Nelson (1997a) \\
\hline Ruth Well & Western Australia & Australia & 116.87 & -20.87 & 2.876 & 0.03 & 2.00 & 0.001 & Meisel et al. (2001) \\
\hline Savannah (Sally Malay) & Western Australia & Australia & 128.02 & -17.35 & 1.844 & 3.74 & 1.74 & 0.065 & Page \& Hoatson (2000) \\
\hline Scotia & Western Australia & Australia & 121.46 & -31.18 & 2.705 & 1.92 & 2.71 & 0.052 & Nelson (1997a) \\
\hline Seagull & Western Australia & Australia & 119.74 & -32.55 & 3.000 & 0.97 & 1.31 & 0.013 & Wang et al. (1996) \\
\hline Sherlock Bay & Western Australia & Australia & 117.54 & -20.81 & 2.866 & 25.42 & 0.40 & 0.102 & Hoatson \& Sun (2002) \\
\hline South Windarra & Western Australia & Australia & 122.24 & -28.61 & 2.900 & 10.27 & 1.44 & 0.148 & Barley \& Groves (1990) \\
\hline Spargoville (1a) & Western Australia & Australia & 121.49 & -31.32 & 2.705 & 1.02 & 2.45 & 0.025 & Nelson (1997a) \\
\hline $\begin{array}{c}\text { Tapinos (formerly Anomaly } 4 \text { near } \\
\text { Prospero) }\end{array}$ & Western Australia & Australia & 120.58 & -27.63 & 2.705 & 0.14 & 7.40 & 0.011 & Nelson (1997a) \\
\hline Trough Well & Western Australia & Australia & 118.89 & -30.67 & 3.000 & 0.02 & 2.50 & 0.001 & Wang et al. (1996) \\
\hline Victor & Western Australia & Australia & 121.68 & -31.14 & 2.705 & 0.36 & 5.71 & 0.021 & Nelson (1997a) \\
\hline Victor Shoot & Western Australia & Australia & 121.68 & -31.19 & 2.705 & 0.23 & 5.11 & 0.012 & Nelson (1997a) \\
\hline Wannaway & Western Australia & Australia & 121.52 & -31.60 & 2.705 & 0.57 & 2.81 & 0.016 & Nelson (1997a) \\
\hline Weebo Bore & Western Australia & Australia & 120.82 & -28.05 & 2.705 & 12.00 & 0.70 & 0.084 & Nelson (1997a) \\
\hline
\end{tabular}




\begin{tabular}{|c|c|c|c|c|c|c|c|c|c|}
\hline Deposit & State/Region & Country & Lon. ${ }^{a}$ & Lat. $^{a}$ & $\begin{array}{l}\text { Age } \\
(\mathrm{Ga})\end{array}$ & Ore (Mt) & $\begin{array}{l}\mathrm{Ni} \\
(\%)\end{array}$ & $\begin{array}{c}\mathrm{Ni} \\
(\mathrm{Mt})\end{array}$ & References \\
\hline Widgie 3 & Western Australia & Australia & 121.59 & -31.52 & 2.705 & 0.09 & 1.89 & 0.002 & Nelson (1997a) \\
\hline Widgie Townsite & Western Australia & Australia & 121.57 & -31.50 & 2.705 & 2.19 & 1.48 & 0.032 & Nelson (1997a) \\
\hline Yakabindie & Western Australia & Australia & 120.58 & -27.46 & 2.705 & 290.00 & 0.58 & 1.682 & Nelson (1997a) \\
\hline Zabel & Western Australia & Australia & 121.51 & -31.39 & 2.705 & 0.98 & 1.93 & 0.019 & Nelson (1997a) \\
\hline SelebiPhikwe & Central & Botswana & 27.86 & -21.95 & 2.500 & 49.44 & 1.04 & 0.514 & Eckstrand (1995) \\
\hline O'Toole & Minas Gerais & Brazil & -46.00 & -20.00 & 2.700 & 6.60 & 2.20 & 0.145 & Brenner et al. (1990) \\
\hline Giant Mascot & British Columbia & Canada & -121.51 & 49.46 & 0.100 & 2.05 & 1.40 & 0.029 & Eckstrand \& Hulbert (2007) \\
\hline Amax area 1 (Nose) & Manitoba & Canada & -81.89 & 48.16 & 1.880 & 7.30 & 1.33 & 0.097 & Hulbert et al. (2005) \\
\hline Bowden & Manitoba & Canada & -97.00 & 53.00 & 1.880 & 80.00 & 0.60 & 0.480 & Hulbert et al. (2005) \\
\hline Bucko & Manitoba & Canada & -98.66 & 54.88 & 1.880 & 2.50 & 2.23 & 0.056 & Hulbert et al. (2005) \\
\hline Lynn Lake & Manitoba & Canada & -101.04 & 56.86 & 1.600 & 20.15 & 1.02 & 0.206 & Eckstrand \& Hulbert (2007) \\
\hline Manibridge & Manitoba & Canada & -98.84 & 54.72 & 1.880 & 1.41 & 2.55 & 0.036 & Hulbert et al. (2005) \\
\hline Namew Lake & Manitoba & Canada & -101.79 & 54.20 & 1.847 & 2.60 & 2.44 & 0.063 & Cumming \& Krstic (1991) \\
\hline Thompson & Manitoba & Canada & -97.80 & 55.73 & 1.880 & 150.30 & 2.32 & 3.487 & Hulbert et al. (2005) \\
\hline St. Stephen (3 zones) & New Brunswick & Canada & -67.30 & 45.22 & 0.387 & 1.00 & 1.05 & 0.011 & Paktunc (1987) \\
\hline Voisey's Bay & $\begin{array}{c}\text { Newfoundland and } \\
\text { Labrador }\end{array}$ & Canada & -62.08 & 56.33 & 1.333 & 136.70 & 1.59 & 2.174 & Amelin et al. (1999) \\
\hline Alexo & Ontario & Canada & -80.81 & 48.66 & 2.707 & 0.06 & 3.58 & 0.002 & Barrie et al. (1999) \\
\hline Gordon Lake & Ontario & Canada & -94.93 & 50.46 & 2.724 & 1.07 & 1.62 & 0.017 & Ayer et al. (2002) \\
\hline Great Lakes & Ontario & Canada & -89.58 & 48.08 & 1.109 & 45.60 & 0.18 & 0.082 & Davis \& Sutcliffe (1985) \\
\hline Langmuir (No. 1 and 2) & Ontario & Canada & -81.03 & 48.34 & 2.707 & 1.60 & 2.09 & 0.033 & Ayer et al. (2002) \\
\hline Macassa & Ontario & Canada & -77.72 & 44.87 & 1.600 & 1.80 & 0.91 & 0.016 & Eckstrand \& Hulbert (2007) \\
\hline Montcalm & Ontario & Canada & -82.09 & 48.66 & 2.702 & 3.56 & 1.44 & 0.051 & Barrie \& Naldrett (1989) \\
\hline Redstone & Ontario & Canada & -81.16 & 48.31 & 2.707 & 1.22 & 2.39 & 0.029 & Ayer et al. (2002) \\
\hline Shebandowan & Ontario & Canada & -90.24 & 48.59 & 2.724 & 15.00 & 1.50 & 0.225 & Ayer et al. (2002) \\
\hline Texmont & Ontario & Canada & -81.20 & 48.16 & 2.707 & 3.19 & 0.93 & 0.030 & Ayer et al. (2002) \\
\hline Dumont & Qubec & Canada & -78.44 & 48.65 & 2.710 & 150.00 & 0.50 & 0.750 & Naldrett (1989) \\
\hline Expo-Ungava & Qubec & Canada & -73.44 & 61.55 & 1.918 & 6.30 & 0.86 & 0.054 & Parrish (1989) \\
\hline Lorraine & Qubec & Canada & -78.94 & 48.36 & 2.694 & 0.66 & 0.39 & 0.003 & Barnes et al. (1993) \\
\hline Marbridge & Qubec & Canada & -78.18 & 48.34 & 2.715 & 0.77 & 2.82 & 0.022 & Ayer et al. (2002) \\
\hline Raglan & Qubec & Canada & -73.45 & 61.55 & 1.918 & 24.70 & 2.72 & 0.672 & Parrish (1989) \\
\hline Canalask & Yukon & Canada & -139.53 & 61.47 & 0.232 & 0.50 & 1.68 & 0.008 & Hulbert (1997) \\
\hline Wellgreen & Yukon & Canada & -139.52 & 61.46 & 0.232 & 0.67 & 2.04 & 0.014 & Hulbert (1997) \\
\hline Jinchuan & Gansu & China & 102.16 & 38.46 & 0.827 & 515.00 & 1.06 & 5.459 & Li et al. (2004) \\
\hline Hitura & North Ostrobothnia & Finland & 25.04 & 63.84 & 1.877 & 12.30 & 0.56 & 0.069 & Papunen \& Gorbunov (1985) \\
\hline Kotalahti & North Savo & Finland & 27.63 & 62.56 & 1.883 & 23.20 & 0.70 & 0.162 & Papunen \& Gorbunov (1985) \\
\hline Noril'sk-Talnakh & Krasnoyarsk Krai & Russia & 88.18 & 69.33 & 0.251 & 1257.00 & 1.84 & 23.129 & Kamo et al. (2003) \\
\hline Monchegorsk & Murmansk Oblast & Russia & 32.95 & 67.92 & 2.493 & 47.00 & 0.70 & 0.329 & Neradovsky et al. (1997) \\
\hline Pechenga & Murmansk Oblast & Russia & 29.73 & 69.33 & 1.977 & 339.00 & 1.18 & 4.000 & Hanski et al. (1990) \\
\hline Merensky Reef & Limpopo & South Africa & 28.50 & -24.49 & 2.060 & 4209.00 & 0.15 & 6.314 & Kruger et al. (1986) \\
\hline Platreef & Limpopo & South Africa & 28.96 & -24.08 & 2.060 & 1597.00 & 0.41 & 6.548 & Kruger et al. (1986) \\
\hline Kabanga & Kagera & Tanzania & 30.57 & -2.88 & 1.275 & 11.70 & 1.72 & 0.201 & Deblond \& Tack (1999) \\
\hline Duluth & Minnesota & USA & -91.25 & 47.83 & 1.099 & 4000.00 & 0.20 & 8.000 & Paces \& Miller Jr. (1993) \\
\hline Trojan & Mashonaland Central & Zimbabwe & 31.33 & -17.29 & 2.700 & 20.35 & 0.68 & 0.138 & Prendergast (2003) \\
\hline Great Dyke & Midlands & Zimbabwe & 30.63 & -17.39 & 2.587 & 2574.00 & 0.21 & 5.405 & Mukasa et al. (1998) \\
\hline Hunter's Road & Midlands & Zimbabwe & 29.83 & -19.16 & 2.700 & 30.00 & 0.70 & 0.210 & Prendergast (2003) \\
\hline Shangani & Midlands & Zimbabwe & 29.25 & -19.66 & 2.700 & 22.00 & 0.71 & 0.156 & Prendergast (2003) \\
\hline
\end{tabular}

$a$ In decimal degrees 
Table 6: Global compilation of 947 volcanogenic massive sulphide deposits shown in Figure S32, revised starting from Franklin et al. (2005). $\mathrm{Ga}=$ billion years; $\mathrm{Mt}=$ million tonnes; $\mathrm{ND}=$ no data.

\begin{tabular}{|c|c|c|c|c|c|c|c|}
\hline Deposit & Country & Lon. $^{a}$ & Lat. ${ }^{a}$ & $\begin{array}{l}\text { Age } \\
(\mathrm{Ga})\end{array}$ & $\begin{array}{c}\mathrm{Cu} \\
(\mathrm{Mt})\end{array}$ & $\begin{array}{c}\mathrm{Zn} \\
(\mathrm{Mt})\end{array}$ & $\begin{array}{c}\mathrm{Pb} \\
(\mathrm{Mt})\end{array}$ \\
\hline Gjegjani & Albania & 20.01 & 41.94 & 0.164 & 0.186 & 0.040 & $\mathrm{ND}$ \\
\hline Arroyo Rojo & Argentina & -68.10 & -54.75 & 0.153 & ND & ND & ND \\
\hline Santa Elena & Argentina & -69.42 & -31.33 & 0.444 & ND & ND & ND \\
\hline Anaconda & Australia & 121.77 & -28.97 & ND & 0.008 & 0.017 & $\mathrm{ND}$ \\
\hline Anomaly A & Australia & 130.72 & -13.61 & 1.862 & 0.014 & 0.076 & 0.001 \\
\hline Avoca Tank & Australia & 146.84 & -31.20 & 0.479 & 0.042 & ND & $\mathrm{ND}$ \\
\hline Ayshia & Australia & 116.94 & -21.07 & 3.114 & 0.003 & 0.018 & ND \\
\hline Balcooma & Australia & 144.71 & -18.77 & 0.480 & 0.095 & 0.106 & 0.050 \\
\hline Bentley & Australia & 121.17 & -28.48 & 2.692 & 0.041 & 0.226 & 0.014 \\
\hline Bernts & Australia & 119.28 & -21.23 & 3.238 & 0.002 & 0.047 & 0.010 \\
\hline Big Stubby & Australia & 119.75 & -21.22 & 3.465 & 0.000 & 0.028 & 0.009 \\
\hline Budgery & Australia & 146.68 & -31.53 & 0.479 & 0.021 & ND & ND \\
\hline Budgerygar & Australia & 146.72 & -31.38 & 0.479 & 0.033 & ND & $\mathrm{ND}$ \\
\hline Captains Flat & Australia & 149.44 & -35.59 & 0.424 & 0.028 & 0.400 & 0.240 \\
\hline Catalpa & Australia & 116.96 & -28.77 & 2.953 & ND & 0.259 & 0.021 \\
\hline Coles Hill & Australia & 133.78 & -23.06 & 1.809 & ND & ND & ND \\
\hline Commonwealth & Australia & 149.05 & -32.59 & 0.425 & 0.001 & 0.011 & 0.004 \\
\hline Coondamar Creek & Australia & 120.67 & -21.93 & 2.905 & ND & ND & $\mathrm{ND}$ \\
\hline Cow Flat & Australia & 149.54 & -33.57 & 0.425 & 0.082 & 0.190 & $\mathrm{ND}$ \\
\hline Currawang & Australia & 149.50 & -34.99 & 0.424 & 0.013 & 0.104 & 0.018 \\
\hline Currawong & Australia & 147.91 & -36.98 & 0.425 & 0.207 & 0.413 & 0.083 \\
\hline DeGrussa & Australia & 119.25 & -25.57 & 2.027 & 0.659 & ND & $\mathrm{ND}$ \\
\hline Dianne & Australia & 144.52 & -16.10 & 0.388 & 0.018 & ND & $\mathrm{ND}$ \\
\hline Discovery & Australia & 118.78 & -20.78 & 3.253 & 0.001 & 0.029 & 0.012 \\
\hline Dresser & Australia & 119.44 & -21.15 & 3.481 & ND & ND & ND \\
\hline Dry River South-Surveyor & Australia & 144.69 & -18.79 & 0.480 & 0.023 & 0.267 & 0.090 \\
\hline Edwards Creek & Australia & 134.03 & -23.01 & 1.802 & ND & ND & $\mathrm{ND}$ \\
\hline Fisher Well & Australia & 122.27 & -27.71 & 2.805 & $\mathrm{ND}$ & ND & $\mathrm{ND}$ \\
\hline Freddie Well & Australia & 118.68 & -28.75 & 2.814 & 0.001 & 0.050 & ND \\
\hline Gossan Hill & Australia & 116.96 & -28.78 & 2.953 & 0.413 & 0.865 & 0.132 \\
\hline Halls Peak & Australia & 152.03 & -30.75 & 0.285 & 0.000 & 0.005 & 0.003 \\
\hline Hammerhead & Australia & 120.24 & -21.04 & 3.465 & 0.003 & 0.085 & 0.022 \\
\hline Handcuff & Australia & 146.21 & -20.35 & 0.479 & 0.006 & 0.100 & 0.004 \\
\hline Hartman & Australia & 146.85 & -31.22 & 0.479 & 0.009 & ND & ND \\
\hline Hellyer & Australia & 145.72 & -41.57 & 0.500 & 0.063 & 2.294 & 1.188 \\
\hline Henty & Australia & 145.56 & -41.87 & 0.500 & ND & ND & ND \\
\hline Hercules & Australia & 145.51 & -41.85 & 0.503 & 0.013 & 0.576 & 0.183 \\
\hline Highway-Reward & Australia & 146.20 & -20.36 & 0.479 & 0.073 & $\mathrm{ND}$ & $\mathrm{ND}$ \\
\hline Home of Bullion & Australia & 134.16 & -21.51 & 1.728 & 0.045 & 0.050 & 0.030 \\
\hline Horseshoe Lights & Australia & 118.62 & -25.36 & 1.922 & 0.185 & ND & $\mathrm{ND}$ \\
\hline Jaguar & Australia & 121.16 & -28.44 & 2.692 & 0.050 & 0.187 & 0.012 \\
\hline John Fardy & Australia & 149.42 & -34.11 & 0.425 & 0.003 & 0.028 & 0.006 \\
\hline Kangaroo Caves & Australia & 119.24 & -21.21 & 3.238 & 0.032 & 0.208 & $\mathrm{ND}$ \\
\hline Kempfield & Australia & 149.26 & -33.79 & 0.425 & $\mathrm{ND}$ & 0.205 & 0.098 \\
\hline Larsens & Australia & 146.85 & -31.22 & 0.479 & 0.031 & ND & $\mathrm{ND}$ \\
\hline Lewis Ponds & Australia & 149.25 & -33.27 & 0.417 & 0.013 & 0.152 & 0.089 \\
\hline Liontown & Australia & 146.07 & -20.41 & 0.479 & 0.009 & 0.112 & 0.040 \\
\hline Magpie & Australia & 146.74 & -20.32 & 0.479 & 0.005 & 0.038 & 0.005 \\
\hline McPhillamys & Australia & 149.32 & -33.49 & 0.417 & 0.049 & $\mathrm{ND}$ & $\mathrm{ND}$ \\
\hline Mons Cupri & Australia & 117.81 & -20.88 & 2.954 & 0.053 & 0.062 & 0.026 \\
\hline Mount Ararat & Australia & 142.93 & -37.20 & 0.518 & 0.024 & 0.005 & $\mathrm{ND}$ \\
\hline Mount Bulga & Australia & 149.20 & -33.28 & 0.425 & 0.009 & 0.031 & 0.009 \\
\hline Mount Chalmers & Australia & 150.65 & -23.30 & 0.277 & 0.024 & 0.023 & 0.010 \\
\hline Mount Gibson & Australia & 117.16 & -29.78 & 2.934 & $\mathrm{ND}$ & ND & $\mathrm{ND}$ \\
\hline Mount Lyell - Cu-Au & Australia & 145.58 & -42.06 & 0.500 & 3.017 & ND & $\mathrm{ND}$ \\
\hline $\begin{array}{c}\text { Mount Lyell - Tasman and Crown } \\
\text { Lyell }(\mathrm{Zn}-\mathrm{Pb})\end{array}$ & Australia & 145.59 & -42.05 & 0.500 & 0.001 & 0.014 & 0.012 \\
\hline Mount Molloy & Australia & 145.34 & -16.70 & 0.388 & 0.004 & ND & ND \\
\hline Mount Morgan & Australia & 150.37 & -23.64 & 0.381 & 0.374 & 0.052 & $\mathrm{ND}$ \\
\hline Mount Mulcahy & Australia & 117.70 & -27.05 & 2.752 & 0.006 & 0.004 & $\mathrm{ND}$ \\
\hline Murrawombie (Girilambone) & Australia & 146.87 & -31.26 & 0.479 & 0.209 & ND & $\mathrm{ND}$ \\
\hline Nimbus & Australia & 121.65 & -30.79 & 2.708 & 0.000 & 0.034 & 0.005 \\
\hline North East & Australia & 146.85 & -31.22 & 0.479 & 0.021 & ND & $\mathrm{ND}$ \\
\hline OK & Australia & 144.25 & -16.60 & 0.388 & 0.008 & ND & $\mathrm{ND}$ \\
\hline Onedin & Australia & 127.54 & -18.32 & 1.843 & 0.027 & 0.097 & 0.045 \\
\hline Oonagalabi & Australia & 134.86 & -23.13 & 1.765 & 0.125 & 0.250 & $\mathrm{ND}$ \\
\hline Orchard Tank-Acacia & Australia & 118.80 & -20.77 & 3.253 & 0.001 & 0.040 & 0.016 \\
\hline Peelwood & Australia & 149.42 & -34.12 & 0.425 & 0.001 & 0.007 & 0.003 \\
\hline Pincher Well & Australia & 118.78 & -28.72 & 2.814 & 0.041 & 0.446 & $\mathrm{ND}$ \\
\hline Que River & Australia & 145.70 & -41.60 & 0.500 & 0.023 & 0.439 & 0.244 \\
\hline Rosebery & Australia & 145.54 & -41.77 & 0.503 & 0.190 & 4.742 & 1.439 \\
\hline Salt Creek & Australia & 117.70 & -20.76 & 2.945 & 0.011 & 0.100 & 0.034 \\
\hline Sandiego & Australia & 127.49 & -18.36 & 1.843 & 0.035 & 0.127 & 0.018 \\
\hline Scuddles & Australia & 116.94 & -28.75 & 2.953 & 0.126 & 1.229 & 0.084 \\
\hline
\end{tabular}




\begin{tabular}{|c|c|c|c|c|c|c|c|}
\hline Deposit & Country & Lon. ${ }^{a}$ & Lat. ${ }^{a}$ & $\begin{array}{l}\text { Age } \\
(\mathrm{Ga})\end{array}$ & $\begin{array}{c}\mathrm{Cu} \\
(\mathrm{Mt})\end{array}$ & $\begin{array}{c}\mathrm{Zn} \\
(\mathrm{Mt})\end{array}$ & $\begin{array}{c}\mathrm{Pb} \\
(\mathrm{Mt})\end{array}$ \\
\hline South Hercules & Australia & 145.51 & -41.85 & 0.503 & 0.001 & 0.021 & 0.011 \\
\hline Sulphur Springs & Australia & 119.21 & -21.15 & 3.239 & 0.202 & 0.543 & ND \\
\hline Teutonic Bore & Australia & 121.15 & -28.41 & 2.692 & 0.076 & 0.244 & 0.017 \\
\hline Thalanga & Australia & 145.77 & -20.34 & 0.479 & 0.140 & 0.782 & 0.248 \\
\hline Tritton & Australia & 146.72 & -31.39 & 0.479 & 0.669 & ND & ND \\
\hline Tuff Hill & Australia & 122.22 & -27.64 & 2.805 & ND & ND & ND \\
\hline Waterloo & Australia & 146.11 & -20.38 & 0.479 & 0.013 & 0.073 & 0.010 \\
\hline Wet Lagoon & Australia & 149.46 & -34.81 & 0.425 & 0.008 & 0.083 & 0.045 \\
\hline Whim Creek & Australia & 117.83 & -20.85 & 2.948 & 0.041 & 0.003 & ND \\
\hline Whundo-West Whundo & Australia & 116.93 & -21.08 & 3.114 & 0.022 & 0.017 & ND \\
\hline Wickliffe & Australia & 142.68 & -37.69 & 0.501 & $\mathrm{ND}$ & ND & ND \\
\hline Wilga & Australia & 147.89 & -37.00 & 0.425 & 0.084 & 0.179 & 0.015 \\
\hline Woodlawn & Australia & 149.57 & -35.06 & 0.423 & 0.401 & 2.286 & 0.911 \\
\hline Walchen & Austria & 14.07 & 47.43 & 0.475 & 0.035 & 0.052 & 0.048 \\
\hline Miguela A-zone & Bolivia & -63.04 & -15.87 & 1.450 & 0.061 & 0.005 & ND \\
\hline Aripuan & Brazil & -60.67 & -8.99 & 1.762 & 0.101 & 1.445 & 0.513 \\
\hline Palmierpolis & Brazil & -48.32 & -12.92 & 1.300 & 0.049 & 0.186 & 0.029 \\
\hline Perkoa (Boromo) & Burkino Faso & -2.65 & 12.35 & 2.195 & ND & 1.254 & 0.019 \\
\hline 777 (Triple Seven) & Canada & -101.88 & 54.78 & 1.889 & 0.567 & 0.962 & 0.002 \\
\hline Aldermac & Canada & -79.23 & 48.22 & 2.700 & 0.044 & 0.118 & ND \\
\hline Amulet 11 & Canada & -79.07 & 48.31 & 2.698 & 0.016 & 0.011 & ND \\
\hline Amulet A - Upper and Lower & Canada & -79.08 & 48.32 & 2.698 & 0.243 & 0.255 & ND \\
\hline Amulet $\mathrm{C}$ & Canada & -79.07 & 48.31 & 2.698 & 0.013 & 0.048 & ND \\
\hline Amulet F Shaft & Canada & -79.05 & 48.33 & 2.698 & 0.009 & 0.023 & ND \\
\hline Anderson Lake & Canada & -99.99 & 54.86 & 1.895 & 0.086 & 0.003 & 0.000 \\
\hline Ansil & Canada & -79.12 & 48.35 & 2.698 & 0.114 & 0.015 & ND \\
\hline Armstrong A & Canada & -66.05 & 47.60 & 0.470 & 0.010 & 0.076 & 0.014 \\
\hline Armstrong B & Canada & -66.06 & 47.59 & 0.470 & 0.002 & 0.001 & 0.000 \\
\hline Austin Brook & Canada & -65.82 & 47.40 & 0.470 & 0.001 & 0.028 & 0.023 \\
\hline Barvalle & Canada & -77.66 & 48.43 & 2.725 & 0.002 & 0.012 & ND \\
\hline $\begin{array}{c}\text { Barvue-Abcourt (incl. Peshcourt, } \\
\text { Frebert) }\end{array}$ & Canada & -77.68 & 48.52 & 2.706 & ND & 0.487 & ND \\
\hline Bear & Canada & -112.39 & 62.89 & 2.705 & ND & 0.056 & 0.024 \\
\hline Belfort (Roymont) & Canada & -77.68 & 48.43 & 2.725 & 0.000 & 0.004 & ND \\
\hline Bell Allard & Canada & -77.73 & 49.69 & 2.726 & 0.045 & 0.491 & ND \\
\hline Bell Allard Sud & Canada & -77.69 & 49.69 & 2.726 & 0.003 & 0.021 & ND \\
\hline Big Bull & Canada & -133.55 & 58.67 & 0.327 & 0.003 & 0.048 & 0.020 \\
\hline Bigstone & Canada & -103.20 & 54.58 & 1.875 & 0.038 & 0.003 & 0.004 \\
\hline Birch Lake & Canada & -102.03 & 54.66 & 1.900 & 0.017 & 0.000 & ND \\
\hline Bob Lake & Canada & -101.04 & 55.16 & 1.853 & 0.077 & 0.065 & ND \\
\hline Bobby's Pond & Canada & -56.84 & 48.64 & 0.498 & 0.013 & 0.085 & 0.006 \\
\hline Bomber & Canada & -100.18 & 54.86 & 1.890 & 0.000 & 0.006 & ND \\
\hline Bonanza & Canada & -129.85 & 55.39 & 0.186 & 0.014 & ND & ND \\
\hline Boot Lake & Canada & -108.44 & 65.91 & 2.690 & 0.013 & 0.225 & 0.045 \\
\hline Boundary & Canada & -56.45 & 48.66 & 0.509 & 0.018 & 0.020 & 0.005 \\
\hline Bousquet 1 & Canada & -78.47 & 48.25 & 2.698 & 0.028 & ND & ND \\
\hline Bousquet 2 & Canada & -78.44 & 48.25 & 2.698 & 0.046 & ND & ND \\
\hline Boylen-Koke & Canada & -69.45 & 57.66 & 1.880 & 0.007 & 0.073 & 0.011 \\
\hline Brabant Lake & Canada & -103.70 & 56.12 & 1.850 & 0.028 & 0.300 & 0.007 \\
\hline Bracemac-McLeod & Canada & -77.66 & 49.67 & 2.726 & 0.088 & 0.496 & ND \\
\hline Britannia & Canada & -123.14 & 49.61 & 0.112 & 0.537 & 0.317 & ND \\
\hline Brompton & Canada & -72.11 & 45.48 & 0.504 & 0.011 & ND & ND \\
\hline Brunswick 12 & Canada & -65.89 & 47.48 & 0.470 & 1.057 & 17.600 & 6.916 \\
\hline Brunswick 6 & Canada & -65.82 & 47.41 & 0.470 & 0.084 & 0.758 & 0.296 \\
\hline Buchans & Canada & -56.86 & 48.83 & 0.465 & 0.009 & 0.094 & 0.048 \\
\hline Caber & Canada & -78.08 & 49.74 & 2.726 & 0.008 & 0.068 & 0.001 \\
\hline Caber North & Canada & -78.11 & 49.75 & 2.726 & 0.041 & 0.111 & ND \\
\hline Callinan & Canada & -101.88 & 54.78 & 1.889 & 0.106 & 0.311 & 0.004 \\
\hline Canadian Jamieson & Canada & -81.57 & 48.54 & 2.700 & 0.017 & 0.029 & ND \\
\hline Canoe Landing Lake & Canada & -66.11 & 47.41 & 0.470 & 0.118 & 0.354 & 0.126 \\
\hline Captain & Canada & -65.88 & 47.28 & 0.470 & 0.004 & ND & ND \\
\hline Captain North & Canada & -65.88 & 47.30 & 0.470 & 0.001 & 0.022 & 0.008 \\
\hline Caribou & Canada & -66.30 & 47.56 & 0.470 & 0.354 & 2.981 & 1.112 \\
\hline Centennial & Canada & -101.67 & 54.71 & 1.880 & 0.037 & 0.052 & 0.006 \\
\hline Champagne & Canada & -70.22 & 46.59 & 0.466 & 0.001 & 0.007 & 0.001 \\
\hline Chance & Canada & -81.39 & 48.70 & 2.714 & ND & 0.023 & 0.006 \\
\hline Chester & Canada & -66.22 & 47.10 & 0.470 & 0.121 & 0.189 & 0.082 \\
\hline Chisel Lake & Canada & -100.12 & 54.83 & 1.890 & 0.043 & 0.960 & 0.032 \\
\hline Chisel Lake North & Canada & -100.12 & 54.83 & 1.890 & 0.043 & 0.960 & 0.032 \\
\hline Chu Chua & Canada & -120.06 & 51.38 & 0.315 & 0.051 & 0.008 & ND \\
\hline Clinton River & Canada & -70.91 & 45.46 & 0.480 & 0.037 & 0.029 & ND \\
\hline Colchester & Canada & -56.08 & 49.64 & 0.505 & 0.013 & ND & ND \\
\hline Cold Lake & Canada & -101.10 & 55.14 & 1.853 & 0.018 & 0.035 & ND \\
\hline Coniagas & Canada & -76.17 & 49.50 & 2.725 & 0.000 & 0.077 & 0.007 \\
\hline Copper lode $\mathrm{A}$ and $\mathrm{E}$ & Canada & -92.91 & 50.97 & 2.739 & 0.010 & 0.013 & ND \\
\hline Copper Reef (Mink Narrows) & Canada & -101.59 & 54.62 & 1.905 & 0.007 & 0.002 & 0.000 \\
\hline Corbet & Canada & -79.10 & 48.30 & 2.698 & 0.081 & 0.045 & ND \\
\hline
\end{tabular}




\begin{tabular}{|c|c|c|c|c|c|c|c|}
\hline Deposit & Country & Lon. ${ }^{a}$ & Lat. $^{a}$ & $\begin{array}{l}\text { Age } \\
(\mathrm{Ga})\end{array}$ & $\begin{array}{c}\mathrm{Cu} \\
(\mathrm{Mt})\end{array}$ & $\begin{array}{c}\mathrm{Zn} \\
(\mathrm{Mt})\end{array}$ & $\begin{array}{c}\mathrm{Pb} \\
(\mathrm{Mt})\end{array}$ \\
\hline Coronation & Canada & -102.00 & 54.58 & 1.900 & 0.054 & 0.003 & ND \\
\hline Cupra D'estrie & Canada & -71.31 & 45.77 & 0.460 & 0.067 & 0.080 & 0.005 \\
\hline Cuprus & Canada & -101.71 & 54.72 & 1.880 & 0.015 & 0.029 & 0.001 \\
\hline Daniel's Pond & Canada & -56.90 & 48.63 & 0.498 & 0.005 & 0.069 & 0.032 \\
\hline Deb & Canada & -111.23 & 64.00 & 2.701 & 0.008 & 0.030 & 0.002 \\
\hline Delbridge & Canada & -78.97 & 48.27 & 2.698 & 0.002 & 0.031 & ND \\
\hline Devils Elbow & Canada & -66.40 & 47.43 & 0.470 & 0.004 & ND & ND \\
\hline DH-FL Groups & Canada & -101.01 & 56.83 & 1.905 & 0.005 & 0.011 & ND \\
\hline Dickstone & Canada & -100.49 & 54.86 & 1.890 & 0.043 & 0.237 & ND \\
\hline Domergue-Lessard & Canada & -74.64 & 50.64 & 2.774 & 0.014 & 0.026 & ND \\
\hline Double Ed & Canada & -129.88 & 55.41 & 0.186 & 0.030 & 0.019 & ND \\
\hline Duck Pond & Canada & -56.49 & 49.63 & 0.509 & 0.168 & 0.310 & 0.057 \\
\hline Dumagami & Canada & -78.44 & 48.26 & 2.698 & 0.034 & 0.005 & ND \\
\hline Dunraine & Canada & -77.57 & 48.07 & 2.704 & 0.036 & ND & ND \\
\hline Dyce Siding-Sylvia & Canada & -100.15 & 54.41 & 1.890 & 0.009 & 0.012 & 0.004 \\
\hline East Cleaver Lake & Canada & -108.46 & 65.92 & 2.690 & ND & 0.315 & 0.004 \\
\hline East Sullivan & Canada & -77.71 & 48.07 & 2.704 & 0.172 & 0.117 & ND \\
\hline East Waite & Canada & -79.08 & 48.34 & 2.698 & 0.062 & 0.049 & ND \\
\hline Ecstall & Canada & -129.51 & 53.87 & 0.393 & 0.027 & 0.071 & 0.006 \\
\hline Empire-Le Tac & Canada & -76.14 & 49.43 & 2.725 & 0.001 & 0.007 & ND \\
\hline Errington & Canada & -81.26 & 46.54 & 1.848 & 0.069 & 0.311 & 0.090 \\
\hline Eskay Creek & Canada & -130.43 & 56.65 & 0.175 & 0.013 & 0.216 & 0.088 \\
\hline Esso West & Canada & -128.39 & 58.21 & 0.246 & 0.045 & 0.072 & ND \\
\hline Estrades & Canada & -79.20 & 49.45 & 2.720 & 0.008 & 0.092 & 0.008 \\
\hline Eustis & Canada & -71.92 & 45.32 & 0.460 & 0.108 & ND & ND \\
\hline F Group & Canada & -91.05 & 49.87 & 2.736 & 0.002 & 0.032 & 0.002 \\
\hline Farewell Lake & Canada & -100.05 & 54.49 & 1.890 & 0.005 & ND & ND \\
\hline Flat Landing Brook North & Canada & -65.88 & 47.38 & 0.470 & 0.000 & 0.071 & 0.016 \\
\hline Flexar & Canada & -102.03 & 54.68 & 1.900 & 0.012 & 0.002 & 0.000 \\
\hline Flin Flon & Canada & -101.88 & 54.77 & 1.889 & 1.381 & 2.568 & 0.006 \\
\hline FON & Canada & -102.50 & 54.75 & 1.890 & 0.013 & 0.174 & 0.000 \\
\hline Fox Lake & Canada & -101.65 & 56.63 & 1.905 & 0.218 & 0.213 & 0.001 \\
\hline Frederickson Lake & Canada & -66.27 & 55.05 & 1.880 & 0.002 & 0.012 & ND \\
\hline Fyre Lake & Canada & -131.49 & 61.34 & 0.365 & 0.185 & ND & ND \\
\hline Gallen & Canada & -78.95 & 48.33 & 2.698 & 0.006 & 0.272 & ND \\
\hline Garon Lake & Canada & -77.57 & 49.77 & 2.726 & 0.007 & 0.010 & ND \\
\hline Geco & Canada & -85.79 & 49.15 & 2.720 & 1.086 & 2.015 & 0.088 \\
\hline Gmini-Turgeon & Canada & -79.18 & 49.50 & 2.736 & 0.020 & 0.066 & 0.007 \\
\hline Genex (Mordey) & Canada & -81.57 & 48.48 & 2.699 & 0.015 & 0.029 & ND \\
\hline Ghost Lake and Lost Lake & Canada & -100.10 & 54.83 & 1.890 & 0.008 & 0.050 & 0.002 \\
\hline Goldstream & Canada & -118.43 & 51.63 & 0.510 & 0.067 & 0.007 & ND \\
\hline Gondor & Canada & -111.80 & 65.56 & 2.668 & 0.015 & 0.350 & 0.029 \\
\hline Gonzague-Langlois & Canada & -76.67 & 49.25 & 2.718 & 0.055 & 1.279 & ND \\
\hline GPF 4 & Canada & -131.51 & 61.45 & 0.363 & 0.002 & 0.096 & 0.047 \\
\hline Granduc & Canada & -130.35 & 56.21 & 0.223 & 0.449 & 0.025 & 0.005 \\
\hline Great Burnt Lake & Canada & -56.17 & 48.33 & 0.466 & 0.019 & ND & ND \\
\hline Gullbridge & Canada & -56.16 & 49.20 & 0.472 & 0.042 & ND & ND \\
\hline Hackett (Jo) & Canada & -108.36 & 65.92 & 2.690 & 0.002 & 0.034 & ND \\
\hline Hackett River A & Canada & -108.37 & 65.92 & 2.690 & 0.024 & 0.683 & 0.079 \\
\hline Halfmile Lake & Canada & -66.32 & 47.31 & 0.470 & 0.009 & 0.762 & 0.241 \\
\hline Handcamp & Canada & -56.08 & 49.28 & 0.472 & 0.059 & ND & ND \\
\hline Hanson Lake & Canada & -103.70 & 56.12 & 1.870 & 0.001 & 0.015 & 0.009 \\
\hline Harper Creek & Canada & -119.82 & 51.52 & 0.361 & 3.550 & ND & ND \\
\hline Hart River & Canada & -136.83 & 64.63 & 1.381 & 0.008 & 0.020 & 0.005 \\
\hline Headvue (Headway-Coulee) & Canada & -87.66 & 50.02 & 2.764 & ND & 0.013 & 0.000 \\
\hline Headway & Canada & -65.90 & 47.45 & 0.470 & 0.004 & 0.016 & 0.006 \\
\hline Heath Steele & Canada & -66.04 & 47.30 & 0.470 & 0.685 & 1.880 & 0.622 \\
\hline Heninga Gemex & Canada & -96.20 & 61.77 & 2.685 & 0.029 & 0.452 & ND \\
\hline Hidden Creek & Canada & -129.82 & 55.44 & 0.186 & 0.627 & ND & ND \\
\hline High Lake & Canada & -110.86 & 67.38 & 2.705 & 0.387 & 0.576 & 0.053 \\
\hline Homestake & Canada & -119.83 & 51.11 & 0.361 & 0.001 & 0.006 & 0.003 \\
\hline Hood River No 10 & Canada & -112.75 & 66.06 & 2.700 & 0.096 & 0.112 & ND \\
\hline Hood River No 41 & Canada & -112.75 & 66.06 & 2.700 & 0.004 & 0.011 & 0.001 \\
\hline Horne - $\mathrm{H}$ and $\mathrm{G}$ lenses & Canada & -79.01 & 48.26 & 2.702 & 1.205 & $\mathrm{ND}$ & ND \\
\hline Horne - No 5 zone & Canada & -79.02 & 48.23 & 2.702 & 0.150 & 1.350 & ND \\
\hline Hudvam (Vamp Lake) & Canada & -101.17 & 54.94 & 1.890 & 0.014 & 0.022 & 0.001 \\
\hline Huntington & Canada & -72.33 & 45.26 & 0.504 & 0.016 & ND & ND \\
\hline Hyers Island & Canada & -96.02 & 54.76 & 2.832 & 0.009 & ND & ND \\
\hline Ice & Canada & -131.42 & 61.88 & 0.275 & 0.067 & ND & ND \\
\hline $\begin{array}{l}\text { Indian Mountain Lake (incl. BB, } \\
\text { Kennedy Lake, Kennedy Lake West } \\
\text { Copper) }\end{array}$ & Canada & -110.96 & 63.03 & 2.680 & 0.006 & 0.087 & 0.007 \\
\hline Isle Dieu & Canada & -77.74 & 49.73 & 2.726 & 0.031 & 0.544 & ND \\
\hline Izok Lake & Canada & -115.08 & 65.45 & 2.681 & 0.377 & 1.887 & 0.185 \\
\hline Jameland & Canada & -81.59 & 48.58 & 2.701 & 0.005 & 0.006 & ND \\
\hline Jay Copper (Conigo) & Canada & -78.06 & 48.60 & 2.700 & 0.014 & 0.012 & ND \\
\hline Joannie & Canada & -100.03 & 54.83 & 1.890 & 0.006 & 0.000 & ND \\
\hline
\end{tabular}




\begin{tabular}{|c|c|c|c|c|c|c|c|}
\hline Deposit & Country & Lon. ${ }^{a}$ & Lat. $^{a}$ & $\begin{array}{l}\text { Age } \\
(\mathrm{Ga})\end{array}$ & $\begin{array}{c}\mathrm{Cu} \\
(\mathrm{Mt})\end{array}$ & $\begin{array}{c}\mathrm{Zn} \\
(\mathrm{Mt})\end{array}$ & $\begin{array}{l}\mathrm{Pb} \\
(\mathrm{Mt})\end{array}$ \\
\hline Joutel & Canada & -78.35 & 49.45 & 2.728 & 0.037 & 0.066 & ND \\
\hline Jungle Lake & Canada & -100.97 & 55.17 & 1.853 & 0.050 & 0.052 & 0.000 \\
\hline Kam Kotia & Canada & -81.59 & 48.60 & 2.701 & 0.071 & 0.063 & ND \\
\hline Kamad-7 & Canada & -119.81 & 51.14 & 0.361 & 0.002 & 0.023 & 0.018 \\
\hline Kelly-Desmond & Canada & -78.32 & 49.43 & 2.725 & 0.007 & 0.069 & ND \\
\hline Kendon Copper & Canada & -87.59 & 50.42 & 2.739 & 0.027 & 0.094 & ND \\
\hline Key Anacon & Canada & -65.70 & 47.44 & 0.470 & 0.004 & 0.130 & 0.049 \\
\hline Kidd Creek & Canada & -81.37 & 48.69 & 2.714 & 3.416 & 9.139 & 0.325 \\
\hline Knobby-McBride & Canada & -99.98 & 56.87 & 1.800 & 0.006 & 0.160 & 0.001 \\
\hline Koff Zone & Canada & -100.21 & 54.06 & 1.890 & 0.006 & ND & ND \\
\hline Konuto & Canada & -102.06 & 54.66 & 1.900 & 0.069 & 0.027 & 0.000 \\
\hline Kudz Ze Kayah & Canada & -131.61 & 61.46 & 0.363 & 0.130 & 0.722 & 0.169 \\
\hline Kutcho Creek & Canada & -128.36 & 58.21 & 0.246 & 0.207 & 0.271 & ND \\
\hline La Gauchetiere (Phelps Dodge) & Canada & -78.18 & 49.78 & 2.725 & 0.017 & 0.076 & ND \\
\hline La Ronde-Penna & Canada & -78.44 & 48.25 & 2.698 & 0.194 & 1.275 & ND \\
\hline Lake Bond & Canada & -56.19 & 49.03 & 0.472 & 0.003 & 0.023 & ND \\
\hline Lalor & Canada & -100.14 & 54.87 & 1.890 & 0.117 & 1.392 & 0.000 \\
\hline Lar & Canada & -101.88 & 56.64 & 1.905 & 0.011 & 0.029 & ND \\
\hline Lara & Canada & -123.91 & 48.88 & 0.366 & 0.018 & 0.050 & 0.010 \\
\hline Lemarchant & Canada & -56.72 & 48.53 & 0.509 & 0.013 & 0.116 & 0.026 \\
\hline Lemoine & Canada & -74.12 & 49.75 & 2.728 & 0.032 & 0.072 & ND \\
\hline Linda & Canada & -99.93 & 54.83 & 1.895 & 0.035 & 0.094 & ND \\
\hline Lingwick & Canada & -71.38 & 45.66 & 0.460 & 0.002 & 0.020 & 0.000 \\
\hline Little Bay & Canada & -55.94 & 49.60 & 0.505 & 0.062 & ND & ND \\
\hline Little Deer & Canada & -56.02 & 49.59 & 0.505 & 0.125 & ND & ND \\
\hline Lockport & Canada & -55.50 & 49.46 & 0.486 & 0.004 & 0.007 & ND \\
\hline Long Lake & Canada & -57.17 & 48.43 & 0.511 & 0.016 & 0.106 & 0.013 \\
\hline Lost Lake & Canada & -101.08 & 55.13 & 1.853 & 0.019 & 0.061 & ND \\
\hline Louvem-Zinc & Canada & -77.52 & 48.10 & 2.704 & 0.005 & 0.132 & 0.002 \\
\hline Louvicourt & Canada & -65.93 & 47.39 & 0.470 & 0.001 & 0.001 & 0.002 \\
\hline Louvicourt & Canada & -77.50 & 48.10 & 2.704 & 0.598 & 0.328 & ND \\
\hline Lucky Strike & Canada & -56.87 & 48.82 & 0.465 & 0.118 & 1.478 & 0.744 \\
\hline Lyon Lake & Canada & -90.89 & 49.89 & 2.736 & 0.081 & 0.426 & 0.041 \\
\hline Maclean & Canada & -56.88 & 48.83 & 0.465 & 0.038 & 0.437 & 0.243 \\
\hline Mag Lake & Canada & -95.93 & 61.89 & 2.685 & 0.004 & 0.027 & ND \\
\hline Magusi River & Canada & -79.37 & 48.44 & 2.702 & 0.038 & 0.055 & ND \\
\hline Manitou-Barvue (Golden Manitou) & Canada & -77.61 & 48.09 & 2.704 & 0.010 & 0.050 & 0.010 \\
\hline Marg & Canada & -134.47 & 64.01 & 0.376 & 0.149 & 0.379 & 0.182 \\
\hline Marshall Lake (Billiton) & Canada & -87.58 & 50.41 & 2.739 & 0.024 & 0.084 & ND \\
\hline Mattabi & Canada & -90.98 & 49.88 & 2.736 & 0.084 & 0.944 & 0.097 \\
\hline Mattagami Lake & Canada & -77.72 & 49.72 & 2.726 & 0.144 & 2.102 & ND \\
\hline McIlvenna Bay & Canada & -102.85 & 54.68 & 1.888 & 0.132 & 0.882 & 0.058 \\
\hline McMaster & Canada & -66.24 & 47.61 & 0.470 & 0.002 & ND & ND \\
\hline Memphremagog & Canada & -72.31 & 45.15 & 0.489 & 0.030 & ND & ND \\
\hline Millenbach & Canada & -79.05 & 48.30 & 2.698 & 0.123 & 0.154 & ND \\
\hline Mobrun-Bouchard-Hebert & Canada & -78.87 & 48.38 & 2.696 & 0.155 & 0.695 & ND \\
\hline Mokoman Lake & Canada & -102.74 & 55.87 & 1.870 & 0.012 & 0.022 & ND \\
\hline Montauban (incl. Ttrault; & & & & & & & \\
\hline $\begin{array}{c}\text { Montauban Anacon and Au-rich } \\
\text { zones) }\end{array}$ & Canada & -72.35 & 46.84 & 1.280 & ND & 0.124 & 0.041 \\
\hline Moulton Hill & Canada & -71.81 & 45.43 & 0.460 & 0.003 & ND & ND \\
\hline Murray Brook & Canada & -66.43 & 47.53 & 0.470 & 0.079 & 0.396 & 0.139 \\
\hline Musk & Canada & -107.60 & 65.32 & 2.689 & 0.004 & 0.034 & 0.005 \\
\hline Myra Falls Group & Canada & -125.59 & 49.57 & 0.366 & 0.537 & 1.833 & 0.161 \\
\hline Nash Creek & Canada & -66.10 & 47.88 & 0.416 & ND & 0.245 & 0.049 \\
\hline Nepisiguit & Canada & -66.03 & 47.38 & 0.470 & 0.014 & 0.099 & 0.021 \\
\hline New Calumet & Canada & -76.68 & 45.70 & 1.115 & ND & 0.219 & 0.065 \\
\hline New Hosco & Canada & -77.84 & 49.79 & 2.726 & 0.032 & 0.032 & ND \\
\hline New Insco (Fabie Bay) & Canada & -79.35 & 48.44 & 2.702 & 0.023 & ND & ND \\
\hline Newconex-Figuery & Canada & -78.17 & 48.48 & 2.706 & ND & 0.023 & ND \\
\hline Norbec & Canada & -79.06 & 48.35 & 2.698 & 0.123 & 0.212 & ND \\
\hline Norita & Canada & -77.66 & 49.78 & 2.726 & 0.071 & 0.153 & ND \\
\hline Norita East & Canada & -77.64 & 49.78 & 2.726 & 0.009 & 0.110 & ND \\
\hline Normtal & Canada & -79.37 & 49.00 & 2.725 & 0.215 & 0.512 & ND \\
\hline Normetmar & Canada & -79.37 & 49.00 & 2.725 & ND & 0.067 & ND \\
\hline North Star and Don Jon & Canada & -101.57 & 54.76 & 1.885 & 0.017 & ND & ND \\
\hline Old Waite & Canada & -79.09 & 48.34 & 2.698 & 0.053 & 0.033 & 0.000 \\
\hline Orchan & Canada & -77.71 & 49.71 & 2.726 & 0.046 & 0.444 & ND \\
\hline Orchan West & Canada & -77.74 & 49.72 & 2.726 & 0.005 & 0.048 & ND \\
\hline Oriental & Canada & -56.83 & 48.83 & 0.465 & 0.049 & 0.472 & 0.263 \\
\hline Orvan Brook & Canada & -66.12 & 47.63 & 0.470 & 0.010 & 0.160 & 0.046 \\
\hline Osbourne Lake & Canada & -99.72 & 54.95 & 1.895 & 0.088 & 0.042 & 0.000 \\
\hline Pabineau & Canada & -65.92 & 47.45 & 0.470 & ND & 0.004 & 0.001 \\
\hline PD1 & Canada & -78.14 & 49.76 & 2.726 & 0.020 & 0.079 & ND \\
\hline Persvrance & Canada & -77.79 & 49.76 & 2.726 & 0.061 & 0.809 & ND \\
\hline Photo Lake & Canada & -100.10 & 54.86 & 1.890 & 0.032 & 0.044 & 0.004 \\
\hline Pic Lake & Canada & -87.39 & 48.97 & 2.723 & 0.012 & 0.220 & ND \\
\hline
\end{tabular}




\begin{tabular}{|c|c|c|c|c|c|c|c|}
\hline Deposit & Country & Lon. ${ }^{a}$ & Lat. $^{a}$ & $\begin{array}{l}\text { Age } \\
(\mathrm{Ga})\end{array}$ & $\begin{array}{c}\mathrm{Cu} \\
(\mathrm{Mt})\end{array}$ & $\begin{array}{c}\mathrm{Zn} \\
(\mathrm{Mt})\end{array}$ & $\begin{array}{c}\mathrm{Pb} \\
(\mathrm{Mt})\end{array}$ \\
\hline Pilley's Island & Canada & -55.72 & 49.51 & 0.472 & 0.025 & ND & ND \\
\hline Pinebay & Canada & -101.61 & 54.77 & 1.880 & 0.020 & 0.001 & 0.000 \\
\hline Point Leamington (New Bay Pond) & Canada & -55.63 & 49.28 & 0.487 & 0.069 & 0.276 & ND \\
\hline Poirier & Canada & -80.75 & 48.32 & 2.728 & 0.138 & 0.189 & ND \\
\hline Potterdoal & Canada & -80.21 & 48.60 & 2.713 & 0.024 & 0.066 & ND \\
\hline Prud'Homme No 1 & Canada & -69.91 & 58.26 & 1.880 & 0.086 & 0.109 & 0.011 \\
\hline Quandt (Ramsay; Keputch) & Canada & -102.75 & 54.74 & 1.870 & 0.016 & 0.013 & 0.004 \\
\hline Quemont & Canada & -79.01 & 48.26 & 2.702 & 0.200 & 0.300 & 0.003 \\
\hline Radiore No. 2 & Canada & -77.56 & 49.74 & 2.726 & 0.002 & 0.002 & ND \\
\hline Rail Lake & Canada & -100.59 & 54.75 & 1.875 & 0.025 & 0.007 & ND \\
\hline Rambler Main & Canada & -56.06 & 49.90 & 0.487 & 0.007 & 0.012 & ND \\
\hline Rambler-Ming & Canada & -56.08 & 49.91 & 0.487 & 0.384 & 0.023 & ND \\
\hline Rea Gold & Canada & -119.82 & 51.15 & 0.361 & 0.001 & 0.009 & 0.008 \\
\hline Reed Lake & Canada & -100.55 & 54.64 & 1.875 & 0.083 & 0.013 & 0.000 \\
\hline Restigouche & Canada & -66.55 & 47.50 & 0.470 & 0.003 & 0.121 & 0.097 \\
\hline Rocky Turn & Canada & -66.07 & 47.63 & 0.470 & 0.000 & 0.011 & 0.004 \\
\hline Rod & Canada & -99.92 & 54.86 & 1.895 & 0.046 & 0.020 & 0.000 \\
\hline Rothermere & Canada & -56.88 & 48.82 & 0.465 & 0.038 & 0.416 & 0.252 \\
\hline Ruttan & Canada & -99.92 & 54.86 & 1.880 & 1.087 & 2.433 & 0.065 \\
\hline Samatosum & Canada & -119.81 & 51.14 & 0.361 & 0.005 & 0.015 & 0.008 \\
\hline Schist Lake and Mandy & Canada & -101.83 & 54.72 & 1.889 & 0.093 & 0.158 & 0.001 \\
\hline Schotts Lake & Canada & -102.23 & 55.10 & 1.870 & 0.012 & 0.027 & 0.000 \\
\hline Scotia & Canada & -129.67 & 54.08 & 0.393 & 0.001 & 0.038 & 0.004 \\
\hline Scott Lake & Canada & -74.63 & 49.86 & 2.728 & 0.068 & 0.297 & ND \\
\hline Selbaie & Canada & -78.96 & 49.80 & 2.729 & 0.619 & 0.930 & ND \\
\hline Seneca & Canada & -121.95 & 49.32 & 0.166 & 0.009 & 0.054 & 0.002 \\
\hline Sherridon & Canada & -101.11 & 55.14 & 1.853 & 0.183 & 0.176 & 0.002 \\
\hline Shunsby (Grandora) & Canada & -82.66 & 47.72 & 2.730 & 0.009 & 0.052 & ND \\
\hline Skidder & Canada & -56.92 & 48.73 & 0.465 & 0.018 & 0.018 & ND \\
\hline Solbec Copper & Canada & -71.27 & 45.81 & 0.460 & 0.162 & 0.442 & 0.056 \\
\hline Soucy & Canada & -69.87 & 58.32 & 1.880 & 0.081 & 0.098 & 0.011 \\
\hline Sourdough Bay & Canada & -101.62 & 54.76 & 1.880 & 0.004 & 0.005 & 0.000 \\
\hline South Bay & Canada & -92.68 & 51.11 & 2.739 & 0.035 & 0.223 & ND \\
\hline South Pond & Canada & -56.14 & 48.43 & 0.466 & 0.004 & ND & ND \\
\hline Spruce Point & Canada & -100.40 & 54.57 & 1.890 & 0.039 & 0.046 & 0.000 \\
\hline Stall Lake & Canada & -99.44 & 54.85 & 1.895 & 0.282 & 0.032 & 0.001 \\
\hline Stirling (Mindamar) & Canada & -60.44 & 45.73 & 0.681 & 0.009 & 0.079 & 0.018 \\
\hline Stralak & Canada & -81.71 & 46.80 & 2.730 & 0.003 & 0.022 & 0.003 \\
\hline Stratmat & Canada & -66.11 & 47.32 & 0.466 & 0.040 & 0.499 & 0.219 \\
\hline Strickland & Canada & -58.30 & 47.81 & 0.466 & ND & 0.010 & 0.010 \\
\hline Sturgeon Lake & Canada & -90.89 & 49.88 & 2.736 & 0.053 & 0.190 & 0.025 \\
\hline Suffield & Canada & -71.96 & 45.32 & 0.460 & 0.002 & 0.009 & ND \\
\hline Sunrise Lake & Canada & -112.38 & 62.90 & 2.670 & 0.004 & 0.245 & 0.096 \\
\hline Sunro & Canada & -124.03 & 48.45 & 0.045 & 0.014 & ND & ND \\
\hline Susu Lake & Canada & -110.79 & 63.01 & 2.680 & 0.001 & ND & ND \\
\hline Terra Nova & Canada & -56.23 & 49.92 & 0.487 & 0.011 & ND & ND \\
\hline Tilt Cove & Canada & -55.62 & 49.89 & 0.489 & 0.490 & ND & ND \\
\hline Trout Lake (Embury) & Canada & -101.82 & 54.83 & 1.870 & 0.376 & 1.074 & 0.013 \\
\hline Tulk's East & Canada & -57.13 & 48.54 & 0.498 & 0.015 & 0.093 & 0.007 \\
\hline Tulk's Hill & Canada & -57.20 & 48.51 & 0.498 & 0.009 & 0.040 & 0.014 \\
\hline Tulsequah Chief & Canada & -133.60 & 58.74 & 0.327 & 0.082 & 0.406 & 0.076 \\
\hline Turnback Lake (XL) & Canada & -112.64 & 62.73 & 2.680 & 0.004 & 0.011 & 0.003 \\
\hline Twin $\mathrm{J}$ & Canada & -123.79 & 48.87 & 0.366 & 0.005 & 0.023 & 0.002 \\
\hline Vauze & Canada & -79.08 & 48.36 & 2.698 & 0.010 & 0.003 & ND \\
\hline Vendme (Mogador) & Canada & -77.66 & 48.43 & 2.725 & 0.003 & 0.051 & ND \\
\hline Vermilion Lake & Canada & -81.36 & 46.52 & 1.848 & 0.040 & 0.138 & 0.035 \\
\hline Wedge & Canada & -66.13 & 47.40 & 0.470 & 0.053 & 0.052 & 0.019 \\
\hline Weedon & Canada & -71.37 & 45.70 & 0.460 & 0.043 & 0.007 & 0.001 \\
\hline Westarm & Canada & -101.84 & 54.64 & 1.875 & 0.045 & 0.021 & 0.001 \\
\hline Westwood & Canada & -78.44 & 48.25 & 2.698 & ND & ND & ND \\
\hline Whalesback & Canada & -56.01 & 49.60 & 0.505 & 0.036 & ND & ND \\
\hline White Lake & Canada & -101.72 & 54.71 & 1.880 & 0.017 & 0.039 & 0.002 \\
\hline Willecho & Canada & -85.88 & 49.18 & 2.720 & 0.010 & 0.087 & 0.004 \\
\hline Willroy & Canada & -85.83 & 49.16 & 2.720 & 0.065 & 0.112 & 0.012 \\
\hline Wim & Canada & -100.04 & 55.03 & 1.895 & 0.058 & 0.010 & ND \\
\hline Windy Craggy & Canada & -137.67 & 59.73 & 0.218 & 4.099 & ND & ND \\
\hline Winston Lake & Canada & -87.37 & 48.98 & 2.722 & 0.031 & 0.480 & ND \\
\hline Wolf (Hasselberg) & Canada & -131.49 & 61.34 & 0.350 & ND & 0.234 & 0.086 \\
\hline Wolverine & Canada & -130.13 & 61.43 & 0.348 & 0.073 & 0.747 & 0.099 \\
\hline Yava Lake & Canada & -107.93 & 65.60 & 2.690 & 0.013 & 0.064 & 0.021 \\
\hline York Harbour & Canada & -58.31 & 49.05 & 0.486 & 0.006 & 0.016 & ND \\
\hline Zenith & Canada & -87.36 & 48.98 & 2.722 & 0.027 & 0.506 & ND \\
\hline Pirn Alto & Chile & -73.10 & -39.35 & 0.400 & 0.005 & 0.000 & ND \\
\hline Ashele (No. 1) & China & 86.31 & 48.25 & 0.401 & 0.853 & 1.013 & ND \\
\hline Bizigou & China & 124.98 & 42.15 & 2.980 & 0.007 & 0.026 & ND \\
\hline Chenjianiao & China & 106.28 & 35.05 & 0.770 & 0.104 & ND & ND \\
\hline
\end{tabular}




\begin{tabular}{|c|c|c|c|c|c|c|c|}
\hline Deposit & Country & Lon. ${ }^{a}$ & Lat. $^{a}$ & $\begin{array}{l}\text { Age } \\
(\mathrm{Ga})\end{array}$ & $\begin{array}{c}\mathrm{Cu} \\
(\mathrm{Mt})\end{array}$ & $\begin{array}{c}\mathrm{Zn} \\
(\mathrm{Mt})\end{array}$ & $\begin{array}{c}\mathrm{Pb} \\
(\mathrm{Mt})\end{array}$ \\
\hline Dadongguo & China & 88.00 & 47.96 & 0.408 & ND & ND & ND \\
\hline Dahuanggou & China & 124.76 & 42.20 & 2.980 & 0.003 & 0.038 & ND \\
\hline Dapingzhang (includes Dawaz) & China & 100.52 & 22.78 & 0.429 & 0.563 & 0.216 & 0.086 \\
\hline Deerni & China & 100.30 & 34.32 & 0.284 & 0.664 & 0.848 & $\mathrm{ND}$ \\
\hline Dongnanshan & China & 124.63 & 42.11 & 2.980 & 0.008 & 0.013 & ND \\
\hline Gacun & China & 99.53 & 31.18 & 0.217 & 0.018 & 0.216 & 0.148 \\
\hline Gayiqiong & China & 99.30 & 31.57 & 0.219 & ND & ND & ND \\
\hline Guomisi & China & 100.12 & 38.28 & 0.509 & 0.078 & 0.296 & 0.270 \\
\hline Honggou & China & 101.02 & 37.37 & 0.478 & 0.135 & ND & ND \\
\hline Hongqishan & China & 124.38 & 42.04 & 2.980 & 0.013 & 0.027 & ND \\
\hline Hongtoushan & China & 124.53 & 42.02 & 2.980 & 0.700 & 0.960 & ND \\
\hline Huashugou (Jingtieshan) & China & 97.93 & 39.32 & 0.770 & 0.226 & ND & ND \\
\hline Huoyanshan & China & 104.25 & 36.68 & 0.503 & 0.260 & ND & ND \\
\hline Jiaolongzhang & China & 106.07 & 35.32 & 0.503 & ND & 0.065 & 0.043 \\
\hline Keketale (Koktal) & China & 89.20 & 47.35 & 0.409 & 0.002 & 0.095 & 0.045 \\
\hline Langlike & China & 101.95 & 37.52 & 0.478 & 0.033 & ND & ND \\
\hline Liwu & China & 101.80 & 28.60 & 0.402 & 0.775 & 0.155 & ND \\
\hline Shiqingdong & China & 103.70 & 36.78 & 0.503 & 0.054 & 0.084 & 0.078 \\
\hline Shujigou & China & 124.62 & 42.13 & 2.980 & 0.033 & 0.092 & ND \\
\hline Sigequan & China & 104.25 & 36.68 & 0.503 & 0.120 & 0.157 & 0.062 \\
\hline Tiemurte & China & 88.10 & 47.90 & 0.408 & 0.140 & 0.203 & 0.087 \\
\hline Tongchanggou & China & 104.25 & 36.68 & 0.503 & ND & ND & ND \\
\hline Tongchangjie & China & 99.75 & 24.33 & 0.329 & 0.008 & ND & ND \\
\hline Tongkuangyu & China & 111.70 & 35.50 & 2.050 & 2.164 & 2.003 & ND \\
\hline Tongyu & China & 110.30 & 34.53 & 0.490 & 0.065 & ND & ND \\
\hline Wutai & China & 112.59 & 38.93 & 2.500 & $\mathrm{ND}$ & ND & $\mathrm{ND}$ \\
\hline Xiacun & China & 99.85 & 31.10 & 0.201 & 0.077 & 0.677 & 0.418 \\
\hline Xiaorequanzi & China & 89.52 & 42.28 & 0.320 & 0.005 & 0.002 & ND \\
\hline Xiaotieshan & China & 104.25 & 36.68 & 0.503 & 0.428 & 1.812 & 1.153 \\
\hline Xibeishan & China & 124.58 & 42.11 & 2.980 & 0.016 & 0.021 & ND \\
\hline Xiqiu & China & 120.63 & 29.92 & 1.300 & 0.319 & 0.567 & ND \\
\hline Xitieshan & China & 95.61 & 37.24 & 0.478 & ND & 0.486 & 0.416 \\
\hline Yargla & China & 99.17 & 29.33 & 0.263 & 0.006 & ND & ND \\
\hline Zhanghugou & China & 124.93 & 42.12 & 2.980 & 0.002 & 0.090 & ND \\
\hline Zheyaoshan & China & 104.25 & 36.68 & 0.503 & 0.500 & ND & ND \\
\hline El Alacran & Columbia & -76.32 & 7.40 & 0.083 & 0.067 & ND & ND \\
\hline El Roble & Columbia & -76.42 & 6.10 & 0.083 & 0.057 & ND & ND \\
\hline Guadalupe & Columbia & -75.54 & 7.74 & 0.110 & 0.526 & ND & ND \\
\hline Santa Anita & Columbia & -75.73 & 5.67 & 0.083 & 0.013 & ND & ND \\
\hline Antonio & Cuba & -79.83 & 22.11 & 0.123 & 0.027 & 0.060 & ND \\
\hline Cacarajicara & Cuba & -83.28 & 22.81 & 0.113 & 0.007 & ND & ND \\
\hline Carlota & Cuba & -80.15 & 22.03 & 0.150 & 0.027 & ND & ND \\
\hline Cuba Libre & Cuba & -77.92 & 21.42 & 0.113 & 0.010 & ND & ND \\
\hline El Cobre-Zona Barita & Cuba & -75.93 & 20.02 & 0.052 & 0.164 & ND & ND \\
\hline Guachinango & Cuba & -80.12 & 22.07 & 0.150 & 0.041 & ND & ND \\
\hline Hierro Mantua & Cuba & -84.13 & 22.47 & 0.132 & 0.199 & ND & ND \\
\hline Infierno-El Pino-El Roble & Cuba & -76.33 & 20.02 & 0.052 & 0.280 & 0.636 & 0.176 \\
\hline Jcaro & Cuba & -83.28 & 22.86 & 0.113 & 0.008 & ND & ND \\
\hline La Victoria & Cuba & -80.15 & 22.08 & 0.150 & 0.005 & $\mathrm{ND}$ & ND \\
\hline San Fernando-Los Mangos & Cuba & -80.08 & 22.20 & 0.123 & 0.037 & ND & ND \\
\hline Agrokipia A & Cyprus & 33.15 & 35.03 & 0.092 & 0.012 & 0.006 & $\mathrm{ND}$ \\
\hline Agrokipia B & Cyprus & 33.15 & 35.03 & 0.092 & 0.018 & 0.027 & ND \\
\hline Alestos & Cyprus & 33.02 & 35.04 & 0.092 & 0.012 & ND & ND \\
\hline Apliki & Cyprus & 32.85 & 35.07 & 0.092 & 0.030 & ND & ND \\
\hline East Lefka & Cyprus & 32.83 & 35.10 & 0.092 & 0.019 & ND & ND \\
\hline Kalavasos & Cyprus & 33.75 & 34.80 & 0.092 & 0.060 & 0.030 & 0.001 \\
\hline Kambia (Kokkinonero) & Cyprus & 33.28 & 35.00 & 0.092 & ND & ND & ND \\
\hline Kinousa (underground and open cut) & Cyprus & 32.52 & 35.03 & 0.092 & 0.012 & 0.012 & ND \\
\hline Kokkinopezoula & Cyprus & 33.12 & 35.03 & 0.092 & 0.007 & ND & ND \\
\hline Kokkinoyia & Cyprus & 33.04 & 35.07 & 0.092 & 0.019 & ND & ND \\
\hline Limni & Cyprus & 32.48 & 35.03 & 0.092 & 0.160 & 0.032 & ND \\
\hline Mangaleni & Cyprus & 33.75 & 34.80 & 0.092 & 0.001 & ND & ND \\
\hline Mathiatis & Cyprus & 33.35 & 34.97 & 0.092 & 0.006 & 0.028 & ND \\
\hline Mavrovouni & Cyprus & 32.83 & 35.10 & 0.092 & 0.675 & 0.075 & ND \\
\hline Memi & Cyprus & 33.04 & 35.04 & 0.092 & 0.002 & ND & ND \\
\hline Peristerka & Cyprus & 33.23 & 34.99 & 0.092 & 0.003 & 0.001 & ND \\
\hline Phoenix (Skouriotissa) & Cyprus & 32.88 & 35.08 & 0.092 & 0.160 & ND & ND \\
\hline Phoukasa (Skouriotissa) & Cyprus & 32.88 & 35.08 & 0.092 & 0.135 & 0.004 & ND \\
\hline Pitharochoma & Cyprus & 33.23 & 34.99 & 0.092 & 0.007 & 0.007 & ND \\
\hline Sha & Cyprus & 34.95 & 33.37 & 0.092 & 0.004 & ND & ND \\
\hline Three Hills & Cyprus & 32.90 & 35.09 & 0.092 & 0.023 & ND & ND \\
\hline West Apliki & Cyprus & 32.83 & 35.07 & 0.092 & 0.012 & ND & ND \\
\hline Tisovi & Czech Republic & 12.54 & 50.32 & 0.475 & 0.010 & ND & ND \\
\hline Zlate Hory & Czech Republic & 17.41 & 50.27 & 0.380 & 0.170 & 0.595 & 0.145 \\
\hline Cerro de Maimn & Dominican Republic & -70.23 & 18.97 & 0.123 & 0.152 & 0.107 & ND \\
\hline El Anon - Anomaly B & Dominican Republic & -70.96 & 19.48 & 0.113 & 0.005 & 0.005 & ND \\
\hline
\end{tabular}




\begin{tabular}{|c|c|c|c|c|c|c|c|}
\hline Deposit & Country & Lon. ${ }^{a}$ & Lat. $^{a}$ & $\begin{array}{l}\text { Age } \\
(\mathrm{Ga})\end{array}$ & $\begin{array}{c}\mathrm{Cu} \\
(\mathrm{Mt})\end{array}$ & $\begin{array}{c}\mathrm{Zn} \\
(\mathrm{Mt})\end{array}$ & $\begin{array}{c}\mathrm{Pb} \\
(\mathrm{Mt})\end{array}$ \\
\hline Loma Pesada & Dominican Republic & -70.36 & 19.09 & 0.123 & 0.024 & 0.008 & 0.000 \\
\hline San Antonio (Parcela) & Dominican Republic & -70.09 & 18.80 & 0.123 & ND & ND & ND \\
\hline La Plata & Ecuador & -78.90 & -1.50 & 0.043 & 0.034 & 0.035 & 0.006 \\
\hline Mercedes & Ecuador & -79.10 & -2.10 & 0.043 & 0.043 & ND & ND \\
\hline Um Samiuki & Egypt & 34.41 & 27.01 & 0.712 & 0.003 & 0.035 & 0.003 \\
\hline Adi Nefas & Eritrea & 39.03 & 15.33 & 0.750 & 0.038 & 0.229 & ND \\
\hline Bisha & Eritrea & 37.50 & 15.40 & 0.750 & 0.262 & 1.513 & 0.053 \\
\hline Debarwa & Eritrea & 39.00 & 15.12 & 0.750 & 0.020 & 0.038 & ND \\
\hline Emba Derho & Eritrea & 38.88 & 15.42 & 0.750 & 0.449 & 0.863 & ND \\
\hline Aijala & Finland & 23.36 & 60.19 & 1.895 & 0.013 & 0.006 & ND \\
\hline Attu & Finland & 22.31 & 60.19 & 1.895 & 0.007 & 0.076 & 0.045 \\
\hline Hallaper & Finland & 26.51 & 63.68 & 1.925 & 0.015 & 0.030 & ND \\
\hline Hllinmki & Finland & 27.55 & 62.06 & 1.900 & 0.033 & ND & ND \\
\hline Hammaslahti & Finland & 30.03 & 62.46 & 1.943 & 0.085 & 0.093 & ND \\
\hline Haveri & Finland & 23.24 & 61.71 & 1.904 & 0.131 & ND & ND \\
\hline Kylylahti & Finland & 29.35 & 62.86 & 1.926 & 0.051 & 0.015 & ND \\
\hline Luikonlahti & Finland & 28.70 & 62.94 & 1.943 & 0.074 & 0.038 & ND \\
\hline Metsmonttu & Finland & 23.34 & 60.19 & 1.895 & 0.004 & 0.050 & 0.011 \\
\hline Mullikkorme & Finland & 26.16 & 63.70 & 1.921 & 0.011 & 0.277 & 0.029 \\
\hline Orijrvi & Finland & 23.54 & 60.23 & 1.895 & 0.012 & 0.031 & 0.010 \\
\hline Outokumpu & Finland & 28.99 & 62.72 & 1.943 & 1.083 & 0.305 & 0.001 \\
\hline Pahtavuoma & Finland & 24.25 & 67.80 & 2.050 & 0.064 & 0.143 & 0.017 \\
\hline Perttilahti & Finland & 29.19 & 62.79 & 1.943 & 0.028 & 0.021 & ND \\
\hline Pyhsalmi & Finland & 26.05 & 63.66 & 1.932 & 0.518 & 1.424 & 0.039 \\
\hline Rauhala & Finland & 24.79 & 64.06 & 1.905 & 0.023 & 0.081 & 0.016 \\
\hline Riihilathi & Finland & 28.70 & 62.71 & 1.943 & 0.005 & 0.001 & ND \\
\hline Ruostesuo & Finland & 26.36 & 63.59 & 1.925 & 0.011 & 0.054 & ND \\
\hline Salo-Issakka & Finland & 28.78 & 61.10 & 1.895 & 0.006 & 0.030 & ND \\
\hline Saramki & Finland & 29.13 & 62.94 & 1.943 & 0.024 & 0.021 & ND \\
\hline Svi & Finland & 26.66 & 63.21 & 1.924 & 0.047 & 0.025 & ND \\
\hline Taivaljrvi & Finland & 29.05 & 63.94 & 2.790 & 0.001 & 0.033 & 0.017 \\
\hline Tupala & Finland & 23.55 & 60.61 & 1.881 & ND & 0.029 & 0.005 \\
\hline Vihanti & Finland & 25.14 & 64.41 & 1.925 & 0.178 & 1.484 & 0.134 \\
\hline Vuohtojoki & Finland & 25.93 & 63.99 & 1.925 & 0.002 & 0.018 & ND \\
\hline Vuonos & Finland & 29.09 & 62.76 & 1.943 & 0.144 & 0.063 & ND \\
\hline Bodennec & France & -3.58 & 48.52 & 0.350 & 0.024 & 0.061 & 0.015 \\
\hline Chessy & France & 4.61 & 45.90 & 0.360 & 0.137 & 0.479 & 0.021 \\
\hline Chizeuil & France & 4.12 & 46.22 & 0.366 & ND & ND & ND \\
\hline La Port-aux-moines & France & -2.93 & 48.30 & 0.350 & 0.014 & 0.146 & 0.031 \\
\hline Rouez & France & -0.08 & 48.13 & 0.609 & 0.544 & 1.361 & ND \\
\hline Sain Bel & France & 4.61 & 45.80 & 0.360 & 0.100 & 0.100 & ND \\
\hline Madneuli & Georgia & 44.46 & 41.36 & 0.077 & 1.324 & 1.847 & ND \\
\hline Oxec & Guatemala & -89.44 & 15.53 & 0.125 & 0.027 & ND & ND \\
\hline Ambaji & India & 72.85 & 24.33 & 0.987 & 0.236 & 0.626 & 0.451 \\
\hline Deri & India & 72.83 & 24.38 & 0.987 & ND & 0.102 & 0.080 \\
\hline Kalyadi & India & 76.50 & 11.50 & 3.352 & 0.007 & ND & ND \\
\hline Kali Kunning barite & Indonesia & 126.28 & -7.78 & 0.005 & 0.001 & 0.000 & 0.022 \\
\hline Lerokis and Kali Kunning pyrite & Indonesia & 126.28 & -7.78 & 0.005 & 0.281 & 0.022 & 0.026 \\
\hline Lerokis barite & Indonesia & 126.28 & -7.78 & 0.005 & 0.001 & 0.000 & 0.029 \\
\hline Barika & Iran & 36.19 & 45.66 & 0.105 & ND & ND & ND \\
\hline Bavanat & Iran & 30.46 & 53.59 & 0.191 & 0.180 & 0.030 & ND \\
\hline Chahgaz & Iran & 54.70 & 29.45 & 0.176 & 0.060 & 0.900 & 0.600 \\
\hline Koushk (Kushk; Koushke) & Iran & 55.76 & 31.75 & 0.528 & ND & 0.594 & 0.124 \\
\hline Sargaz & Iran & 57.36 & 28.72 & 0.218 & 0.040 & 0.011 & 0.002 \\
\hline Avoca & Ireland & -6.22 & 52.87 & 0.457 & 0.096 & ND & ND \\
\hline Abeshiro & Japan & 141.03 & 41.18 & 0.014 & 0.037 & 0.201 & 0.017 \\
\hline Ainai & Japan & 140.75 & 40.38 & 0.012 & 0.065 & 0.164 & 0.053 \\
\hline Besshi & Japan & 133.32 & 33.85 & 0.157 & 0.779 & 0.090 & ND \\
\hline Ezuri & Japan & 140.60 & 40.24 & 0.012 & 0.027 & 0.303 & 0.100 \\
\hline Fukazawa & Japan & 140.68 & 40.23 & 0.012 & 0.100 & 0.305 & 0.095 \\
\hline Furutobe & Japan & 140.42 & 40.21 & 0.014 & 0.084 & 0.092 & 0.032 \\
\hline Hanaoka - Doyashiki & Japan & 140.48 & 40.32 & 0.012 & 0.336 & 0.420 & 0.084 \\
\hline Hanaoka - Matsumine & Japan & 140.48 & 40.32 & 0.013 & 0.780 & 0.690 & 0.180 \\
\hline Hanawa & Japan & 140.87 & 40.13 & 0.012 & 0.053 & 0.116 & 0.032 \\
\hline Higashiyame & Japan & 134.31 & 33.93 & 0.157 & 0.013 & ND & ND \\
\hline Hitachi & Japan & 140.40 & 36.35 & 0.533 & 0.381 & 0.163 & ND \\
\hline Iimori & Japan & 135.43 & 34.41 & 0.157 & 0.033 & ND & ND \\
\hline Iwami (Iwame and Iwame West) & Japan & 132.44 & 35.18 & 0.012 & 0.023 & 0.332 & 0.068 \\
\hline Kamikita & Japan & 140.92 & 40.73 & 0.014 & 0.034 & 0.020 & ND \\
\hline Kosaka - Motoyama & Japan & 140.74 & 40.35 & 0.012 & 0.330 & 0.675 & 0.120 \\
\hline Kosaka - Uchinotai & Japan & 140.75 & 40.33 & 0.011 & 0.227 & 0.386 & 0.118 \\
\hline Kosaka - Uwamuki & Japan & 140.75 & 40.33 & 0.011 & 0.029 & 0.300 & 0.094 \\
\hline Kotsu & Japan & 134.26 & 34.02 & 0.157 & 0.025 & ND & ND \\
\hline Kune & Japan & 137.84 & 35.08 & 0.175 & 0.107 & $\mathrm{ND}$ & ND \\
\hline Kunitomi & Japan & 140.70 & 43.03 & 0.012 & 0.005 & 0.032 & 0.001 \\
\hline Kurosawa & Japan & 139.33 & 37.35 & 0.014 & 0.072 & 0.482 & 0.050 \\
\hline
\end{tabular}




\begin{tabular}{|c|c|c|c|c|c|c|c|}
\hline Deposit & Country & Lon. $^{a}$ & Lat. ${ }^{a}$ & $\begin{array}{l}\text { Age } \\
(\mathrm{Ga})\end{array}$ & $\begin{array}{c}\mathrm{Cu} \\
(\mathrm{Mt})\end{array}$ & $\begin{array}{c}\mathrm{Zn} \\
(\mathrm{Mt})\end{array}$ & $\begin{array}{c}\mathrm{Pb} \\
(\mathrm{Mt})\end{array}$ \\
\hline Makimine & Japan & 131.31 & 32.73 & 0.089 & 0.085 & ND & ND \\
\hline Matsuki & Japan & 140.53 & 40.23 & 0.012 & 0.057 & 0.102 & 0.032 \\
\hline Nurukawa & Japan & 140.79 & 40.50 & 0.012 & 0.007 & 0.079 & 0.039 \\
\hline Oshio & Japan & 139.48 & 37.40 & 0.014 & 0.040 & 0.105 & 0.026 \\
\hline Sazare & Japan & 133.57 & 33.90 & 0.158 & 0.065 & 0.015 & ND \\
\hline Shakanai & Japan & 140.32 & 40.18 & 0.016 & 0.147 & 0.427 & 0.127 \\
\hline Shimokawa & Japan & 142.98 & 43.90 & 0.048 & 0.182 & 0.107 & ND \\
\hline Shingu & Japan & 133.68 & 33.94 & 0.157 & 0.006 & ND & ND \\
\hline Shirataki & Japan & 133.47 & 33.82 & 0.157 & 0.031 & 0.008 & ND \\
\hline Taisho (including Nishimata) & Japan & 140.91 & 41.46 & 0.014 & 0.045 & 0.154 & 0.022 \\
\hline Takaura & Japan & 138.83 & 35.58 & 0.175 & 0.003 & ND & ND \\
\hline Tashiro & Japan & 139.45 & 37.42 & 0.014 & 0.033 & 0.045 & 0.012 \\
\hline Terano & Japan & 132.75 & 33.69 & 0.157 & 0.001 & ND & ND \\
\hline Yanahara & Japan & 132.50 & 35.20 & 0.265 & 0.272 & ND & ND \\
\hline Yoshino & Japan & 140.42 & 38.33 & 0.014 & 0.063 & 0.200 & ND \\
\hline 50 Let Oktyrbrya & Kazakhstan & 59.11 & 50.49 & 0.388 & 0.837 & 0.216 & ND \\
\hline Abyz & Kazakhstan & 76.24 & 49.33 & 0.375 & 0.124 & 0.325 & ND \\
\hline Akbastau & Kazakhstan & 77.79 & 48.61 & 0.475 & 0.343 & 0.211 & ND \\
\hline Anisimov Klyuch & Kazakhstan & 83.00 & 50.68 & 0.375 & 0.061 & 0.105 & 0.014 \\
\hline Artemievskoe & Kazakhstan & 82.81 & 50.60 & 0.375 & 0.964 & 3.278 & 1.011 \\
\hline Avangard & Kazakhstan & 59.03 & 50.61 & 0.388 & 0.195 & 0.180 & ND \\
\hline Belousovskoye & Kazakhstan & 82.50 & 50.13 & 0.395 & 0.330 & 1.422 & 0.345 \\
\hline Chekmar & Kazakhstan & 83.62 & 50.64 & 0.395 & 0.267 & 2.273 & 0.832 \\
\hline Dolinnoye-Obruchev & Kazakhstan & 83.60 & 50.33 & 0.395 & 0.095 & 0.220 & 0.110 \\
\hline Gabrielevskoe & Kazakhstan & 83.25 & 50.32 & 0.390 & 0.041 & 0.074 & 0.013 \\
\hline Grekhovskoe & Kazakhstan & 84.31 & 49.73 & 0.392 & 0.236 & 1.652 & 0.826 \\
\hline Irtyshskoe & Kazakhstan & 82.37 & 50.15 & 0.395 & 0.648 & 1.536 & 0.213 \\
\hline Kamyshinskoe & Kazakhstan & 81.78 & 50.60 & 0.375 & 0.396 & 0.416 & 0.158 \\
\hline Karchiga & Kazakhstan & 85.51 & 48.44 & 0.530 & 0.190 & 0.043 & ND \\
\hline Kosmurun & Kazakhstan & 77.79 & 48.60 & 0.475 & 0.745 & 0.192 & ND \\
\hline Krasnoyarskoe & Kazakhstan & 82.43 & 50.36 & 0.380 & 0.045 & 0.202 & 0.061 \\
\hline Kunduzdy & Kazakhstan & 58.61 & 49.16 & 0.388 & 0.329 & 0.350 & ND \\
\hline Limannoe & Kazakhstan & 58.78 & 49.81 & 0.388 & 0.591 & 0.643 & ND \\
\hline Maikain cluster & Kazakhstan & 75.80 & 51.48 & 0.490 & ND & ND & ND \\
\hline Maiskoe & Kazakhstan & 84.15 & 49.43 & 0.390 & 0.030 & 0.449 & 0.172 \\
\hline Maleevskoe & Kazakhstan & 84.29 & 49.89 & 0.390 & 1.150 & 3.750 & 0.650 \\
\hline Mizek & Kazakhstan & 77.42 & 48.95 & 0.451 & ND & ND & ND \\
\hline Nikolayevskoe & Kazakhstan & 81.88 & 50.53 & 0.376 & 0.967 & 1.306 & 0.173 \\
\hline Novo-Berezovskoe & Kazakhstan & 82.24 & 50.27 & 0.388 & 0.088 & 0.195 & 0.006 \\
\hline Novo-Leningorskoe & Kazakhstan & 83.57 & 50.36 & 0.395 & 0.085 & 2.157 & 0.764 \\
\hline Orlovskoe & Kazakhstan & 81.36 & 50.93 & 0.392 & 2.256 & 1.536 & 0.432 \\
\hline Priorskoye & Kazakhstan & 59.00 & 50.54 & 0.388 & 0.380 & 1.406 & ND \\
\hline Putintsevskoe & Kazakhstan & 84.26 & 49.88 & 0.388 & 0.016 & 0.027 & 0.018 \\
\hline Ridder-Sokolnoye & Kazakhstan & 83.54 & 50.35 & 0.400 & 0.876 & 3.727 & 1.751 \\
\hline Rulikha & Kazakhstan & 81.97 & 50.49 & 0.371 & ND & ND & ND \\
\hline Shemonaikha & Kazakhstan & 81.87 & 50.68 & 0.375 & 0.095 & 0.192 & 0.036 \\
\hline Shubinskoe & Kazakhstan & 83.68 & 50.39 & 0.388 & 0.057 & 0.113 & 0.017 \\
\hline Snegirikha & Kazakhstan & 82.98 & 50.68 & 0.375 & 0.203 & 0.197 & 0.030 \\
\hline Starkovskoe & Kazakhstan & 83.82 & 50.42 & 0.388 & 0.046 & 0.184 & 0.027 \\
\hline Strezhanskoe & Kazakhstan & 83.67 & 50.53 & 0.388 & 0.085 & 0.212 & 0.038 \\
\hline Suvenir & Kazakhstan & 75.18 & 50.89 & 0.490 & ND & ND & ND \\
\hline Tesiktas & Kazakhstan & 76.43 & 47.09 & 0.490 & $\mathrm{ND}$ & ND & ND \\
\hline Tishinskoye & Kazakhstan & 83.37 & 50.28 & 0.395 & 0.300 & 3.180 & 0.540 \\
\hline Vavilonskoe & Kazakhstan & 81.36 & 50.41 & 0.371 & 0.132 & 0.027 & ND \\
\hline Vesennee & Kazakhstan & 59.45 & 50.63 & 0.401 & 0.367 & 0.325 & ND \\
\hline Zyryanovskoe & Kazakhstan & 84.30 & 49.74 & 0.395 & 0.500 & 5.625 & 3.375 \\
\hline West Sualog & Malaysia & 117.31 & 5.87 & 0.067 & 0.079 & 0.005 & 0.000 \\
\hline Azulaquez & Mexico & -99.70 & 18.57 & 0.140 & 0.002 & 0.042 & 0.015 \\
\hline El Cuale-La Prieta & Mexico & -105.08 & 20.38 & 0.154 & 0.006 & 0.080 & 0.025 \\
\hline El Largo & Mexico & -100.13 & 18.19 & 0.145 & 0.025 & 0.093 & 0.017 \\
\hline El Rey & Mexico & -100.13 & 18.21 & 0.145 & 0.018 & 0.088 & 0.020 \\
\hline La Esmerelda & Mexico & -100.40 & 19.05 & 0.132 & $\mathrm{ND}$ & 0.009 & 0.005 \\
\hline La Minita & Mexico & -103.08 & 18.59 & 0.123 & ND & 0.180 & 0.018 \\
\hline La Suriana & Mexico & -100.12 & 18.22 & 0.145 & 0.002 & ND & 0.027 \\
\hline Los Gavilanes & Mexico & -116.17 & 32.17 & 0.146 & ND & ND & ND \\
\hline Naranjo & Mexico & -100.14 & 18.19 & 0.145 & 0.074 & 0.184 & 0.049 \\
\hline Reforma & Mexico & -100.13 & 18.21 & 0.145 & 0.084 & 0.245 & 0.089 \\
\hline Rey de Plata & Mexico & -99.90 & 18.33 & 0.145 & 0.015 & 0.261 & 0.063 \\
\hline San Nicolas & Mexico & -102.00 & 22.65 & 0.148 & 1.353 & 1.632 & 0.149 \\
\hline Tizapa & Mexico & -100.40 & 19.08 & 0.132 & 0.032 & 0.356 & 0.081 \\
\hline Tumurtii-Ovoo & Mongolia & 113.70 & 47.40 & 0.380 & ND & 0.886 & ND \\
\hline Ulaan & Mongolia & 115.20 & 49.50 & 0.380 & ND & 1.360 & 0.816 \\
\hline Bleida & Morocco & -6.44 & 30.38 & 0.788 & 0.160 & 0.060 & ND \\
\hline Douar Lahjar & Morocco & -8.20 & 31.55 & 0.332 & 0.144 & 1.520 & 0.448 \\
\hline Hajar & Morocco & -8.18 & 31.51 & 0.332 & 0.100 & 1.600 & 0.600 \\
\hline Kettara & Morocco & -8.18 & 31.87 & 0.332 & 0.210 & ND & ND \\
\hline
\end{tabular}




\begin{tabular}{|c|c|c|c|c|c|c|c|}
\hline Deposit & Country & Lon. ${ }^{a}$ & Lat. ${ }^{a}$ & $\begin{array}{l}\text { Age } \\
(\mathrm{Ga})\end{array}$ & $\begin{array}{c}\mathrm{Cu} \\
(\mathrm{Mt})\end{array}$ & $\begin{array}{c}\mathrm{Zn} \\
(\mathrm{Mt})\end{array}$ & $\begin{array}{c}\mathrm{Pb} \\
(\mathrm{Mt})\end{array}$ \\
\hline Koudiat Acha & Morocco & -8.21 & 31.89 & 0.332 & 0.027 & 0.122 & 0.054 \\
\hline Tazakourt (Draa Sfar) & Morocco & -8.14 & 31.71 & 0.332 & 0.033 & 0.590 & 0.225 \\
\hline Gorob & Namibia & 15.33 & -23.47 & 0.755 & 0.027 & ND & ND \\
\hline Matchless & Namibia & 16.75 & -22.83 & 0.755 & 0.056 & ND & ND \\
\hline Otjihase & Namibia & 17.25 & -22.50 & 0.755 & 0.355 & 0.046 & ND \\
\hline Rosh Pinah & Namibia & 16.76 & -27.95 & 0.752 & 0.026 & 1.964 & 0.510 \\
\hline Skorpion & Namibia & 16.66 & -27.82 & 0.752 & ND & 6.843 & 0.604 \\
\hline soren & Norway & 9.44 & 61.79 & 0.450 & 0.010 & 0.010 & ND \\
\hline Bjrksen & Norway & 16.78 & 68.33 & 0.595 & 0.027 & 0.060 & 0.007 \\
\hline Bleikvassli & Norway & 13.88 & 65.92 & 0.595 & 0.009 & 0.240 & 0.120 \\
\hline Bossmo & Norway & 14.27 & 66.38 & 0.470 & 0.008 & 0.008 & ND \\
\hline Bursi & Norway & 16.00 & 67.15 & 0.437 & 0.027 & 0.008 & 0.001 \\
\hline Charlotta & Norway & 16.06 & 67.14 & 0.437 & 0.060 & 0.017 & ND \\
\hline Fahlbands & Norway & 9.62 & 59.63 & 1.800 & 0.050 & 0.050 & ND \\
\hline Fjellsj & Norway & 11.27 & 62.69 & 0.488 & ND & ND & ND \\
\hline Folldal & Norway & 10.00 & 62.14 & 0.488 & 0.057 & 0.033 & ND \\
\hline Fosdalen & Norway & 11.21 & 64.08 & 0.465 & 0.021 & ND & ND \\
\hline Giken & Norway & 16.09 & 67.13 & 0.437 & 0.236 & 0.074 & ND \\
\hline Gjersvik & Norway & 13.43 & 64.86 & 0.488 & 0.034 & 0.010 & ND \\
\hline Grimeli & Norway & 5.08 & 61.44 & 0.443 & 0.030 & 0.015 & ND \\
\hline Grimsdallen & Norway & 9.83 & 62.11 & 0.488 & 0.041 & 0.191 & ND \\
\hline Hammarfjell stre & Norway & 17.16 & 68.36 & 0.595 & ND & ND & ND \\
\hline Hankabakken & Norway & 16.11 & 67.14 & 0.437 & 0.035 & 0.010 & ND \\
\hline Hersjgruva & Norway & 11.13 & 62.68 & 0.488 & 0.051 & 0.042 & ND \\
\hline Jacobsbakken & Norway & 15.70 & 67.07 & 0.437 & 0.072 & 0.108 & ND \\
\hline Joma & Norway & 13.88 & 64.85 & 0.488 & 0.335 & 0.326 & ND \\
\hline Killingdal & Norway & 11.47 & 62.80 & 0.488 & 0.060 & 0.193 & 0.014 \\
\hline Kisgruva & Norway & 9.61 & 59.60 & 1.320 & 0.006 & 0.007 & ND \\
\hline Kongens gruve & Norway & 11.30 & 62.67 & 0.488 & 0.066 & 0.207 & 0.015 \\
\hline Lergruvbakken & Norway & 11.34 & 62.65 & 0.488 & 0.009 & 0.088 & 0.004 \\
\hline Lillebo & Norway & 5.47 & 59.79 & 0.430 & 0.009 & 0.009 & 0.009 \\
\hline Lkken & Norway & 9.70 & 63.12 & 0.487 & 0.690 & 0.540 & 0.006 \\
\hline Mofjell & Norway & 14.16 & 66.30 & 0.475 & 0.017 & 0.193 & 0.038 \\
\hline Mons Petter & Norway & 16.03 & 67.14 & 0.437 & 0.044 & 0.012 & ND \\
\hline Mos & Norway & 14.20 & 66.32 & 0.510 & 0.006 & 0.014 & 0.000 \\
\hline Muggruva & Norway & 11.29 & 62.72 & 0.488 & 0.013 & 0.002 & ND \\
\hline Nordre Geitryggen & Norway & 10.09 & 62.15 & 0.488 & 0.033 & 0.080 & 0.005 \\
\hline Ny-Sulitjelma & Norway & 16.14 & 67.14 & 0.437 & 0.052 & 0.014 & ND \\
\hline Nye/Gamle Storwartz & Norway & 11.54 & 62.63 & 0.488 & 0.031 & 0.206 & 0.015 \\
\hline Olavsgruva & Norway & 11.56 & 62.63 & 0.488 & 0.041 & 0.033 & ND \\
\hline Quintus & Norway & 11.55 & 62.63 & 0.488 & 0.007 & ND & ND \\
\hline Rieppe & Norway & 21.59 & 69.74 & 0.439 & 0.015 & 0.060 & ND \\
\hline Rdhammeran & Norway & 11.42 & 62.95 & 0.488 & 0.003 & ND & ND \\
\hline Rdkleiv & Norway & 5.23 & 59.35 & 0.493 & 0.022 & 0.065 & ND \\
\hline Sagmo & Norway & 16.01 & 67.12 & 0.437 & 0.038 & 0.005 & ND \\
\hline Skiftesmyr & Norway & 12.61 & 64.48 & 0.488 & 0.034 & 0.051 & ND \\
\hline Skorovas & Norway & 13.10 & 64.63 & 0.488 & 0.079 & 0.187 & ND \\
\hline Stord & Norway & 5.42 & 59.79 & 0.430 & ND & 0.025 & ND \\
\hline Tverrfjellet & Norway & 9.51 & 62.23 & 0.475 & 0.190 & 0.228 & 0.038 \\
\hline Undal & Norway & 10.05 & 62.82 & 0.510 & 0.012 & 0.019 & ND \\
\hline Vaddas & Norway & 21.58 & 69.81 & 0.439 & 0.019 & 0.000 & ND \\
\hline Vigsnes & Norway & 5.22 & 59.35 & 0.493 & 0.057 & 0.072 & ND \\
\hline Visletten & Norway & 13.20 & 64.79 & 0.488 & 0.007 & 0.030 & ND \\
\hline Ytterya & Norway & 11.18 & 63.80 & 0.475 & 0.010 & 0.012 & 0.002 \\
\hline Aarja & Oman & 56.42 & 24.33 & 0.095 & 0.048 & 0.029 & 0.000 \\
\hline Al Ajal & Oman & 57.95 & 23.50 & 0.264 & 0.008 & 0.003 & 0.000 \\
\hline Al Bishara & Oman & 56.54 & 23.66 & 0.095 & 0.033 & ND & ND \\
\hline Aswad & Oman & 56.40 & 24.94 & 0.095 & 0.055 & ND & ND \\
\hline Bayda & Oman & 56.38 & 24.55 & 0.095 & 0.028 & 0.013 & 0.000 \\
\hline Daris East & Oman & 57.44 & 23.59 & 0.095 & 0.006 & ND & ND \\
\hline Ghuzayn & Oman & 57.04 & 23.82 & 0.095 & 0.175 & ND & ND \\
\hline Hatta & Oman & 56.44 & 25.00 & 0.095 & 0.028 & 0.008 & ND \\
\hline Hayl-As-Safil & Oman & 56.55 & 23.66 & 0.095 & 0.104 & 0.048 & 0.001 \\
\hline Khaznah & Oman & 56.45 & 24.99 & 0.095 & 0.004 & ND & ND \\
\hline Lasail & Oman & 56.44 & 24.45 & 0.095 & 0.252 & 0.005 & ND \\
\hline Mahab 4 & Oman & 56.71 & 24.05 & 0.095 & 0.031 & ND & ND \\
\hline Mandoos & Oman & 56.44 & 24.79 & 0.095 & 0.112 & ND & ND \\
\hline Maqail South & Oman & 56.56 & 24.12 & 0.095 & 0.006 & ND & ND \\
\hline Rakah & Oman & 56.62 & 23.65 & 0.095 & 0.031 & 0.005 & 0.000 \\
\hline Safwa & Oman & 56.42 & 24.60 & 0.095 & 0.037 & ND & ND \\
\hline Shinas & Oman & 56.38 & 24.76 & 0.095 & 0.055 & ND & ND \\
\hline Laloki & Papua-New Guinea & 147.33 & -9.43 & 0.041 & 0.015 & 0.009 & ND \\
\hline Cerro Lindo & Peru & -75.98 & -13.08 & 0.100 & 0.668 & 2.460 & 0.270 \\
\hline Perubar & Peru & -76.58 & -11.91 & 0.106 & ND & 0.552 & 0.078 \\
\hline Tambo Grande 1 & Peru & -80.42 & -4.92 & 0.104 & 0.899 & 0.562 & 0.169 \\
\hline Tambo Grande 3 & Peru & -80.42 & -4.93 & 0.104 & 0.820 & 1.148 & 0.246 \\
\hline
\end{tabular}




\begin{tabular}{|c|c|c|c|c|c|c|c|}
\hline Deposit & Country & Lon. ${ }^{a}$ & Lat. ${ }^{a}$ & $\begin{array}{l}\text { Age } \\
(\mathrm{Ga})\end{array}$ & $\begin{array}{l}\mathrm{Cu} \\
(\mathrm{Mt})\end{array}$ & $\begin{array}{c}\mathrm{Zn} \\
(\mathrm{Mt})\end{array}$ & $\begin{array}{c}\mathrm{Pb} \\
(\mathrm{Mt})\end{array}$ \\
\hline Ayala & Philippines & 122.13 & 7.28 & 0.020 & 0.029 & 0.259 & 0.162 \\
\hline Bagacay & Philippines & 125.27 & 11.80 & 0.020 & 0.168 & 0.129 & ND \\
\hline Canatuan & Philippines & 121.78 & 7.80 & 0.138 & 0.042 & 0.033 & ND \\
\hline $\mathrm{F}$ & Philippines & 119.96 & 15.99 & 0.044 & 0.044 & 0.051 & ND \\
\hline Hixbar & Philippines & 124.19 & 13.19 & 0.084 & 0.017 & 0.028 & ND \\
\hline Marcos & Philippines & 120.68 & 18.04 & 0.020 & 0.066 & ND & ND \\
\hline Ungay-Malobago & Philippines & 124.13 & 13.19 & 0.084 & 0.087 & 0.145 & ND \\
\hline Aljustrel & Portugal & -8.16 & 37.86 & 0.352 & 0.690 & 1.176 & 0.662 \\
\hline Lagoa Salgada & Portugal & -8.48 & 38.45 & 0.356 & 0.013 & 0.164 & 0.119 \\
\hline Lousal & Portugal & -8.45 & 38.05 & 0.352 & 0.350 & 0.700 & 0.400 \\
\hline Neves Corvo & Portugal & -7.97 & 37.60 & 0.354 & 4.167 & 6.798 & ND \\
\hline Sao Domingos & Portugal & -7.47 & 37.67 & 0.359 & 0.360 & 0.900 & ND \\
\hline Zambujal-Lombador & Portugal & -7.97 & 37.60 & 0.350 & 0.462 & 1.271 & ND \\
\hline Aidyrlinskoe & Russia & 59.85 & 52.07 & 0.386 & 0.110 & 0.140 & ND \\
\hline Aleksandrinskoe & Russia & 59.37 & 53.52 & 0.391 & 0.448 & 0.550 & 0.052 \\
\hline Amurskoe & Russia & 59.62 & 52.56 & 0.380 & 0.034 & 0.824 & 0.019 \\
\hline Bakr-Tau & Russia & 58.18 & 52.44 & 0.396 & 0.034 & 0.061 & 0.009 \\
\hline Bakr-Uzayk & Russia & 58.24 & 52.88 & 0.396 & 0.030 & 0.050 & ND \\
\hline Balta Tau & Russia & 58.36 & 52.36 & 0.396 & 0.105 & 0.179 & ND \\
\hline Barsuchy Log & Russia & 60.26 & 51.17 & 0.388 & 0.368 & 0.603 & ND \\
\hline Blyavinskoe & Russia & 57.67 & 51.45 & 0.438 & 0.300 & 0.500 & ND \\
\hline Burubaiskoe & Russia & 58.16 & 51.96 & 0.398 & 0.570 & 0.360 & 0.030 \\
\hline Chebach'e & Russia & 59.40 & 54.10 & 0.388 & 0.241 & 0.327 & ND \\
\hline Dal'nee & Russia & 95.60 & 52.02 & 0.531 & 0.008 & 0.150 & 0.015 \\
\hline Degtyarkskoe & Russia & 60.09 & 56.71 & 0.413 & 1.690 & 3.510 & 0.130 \\
\hline Dergamish & Russia & 58.09 & 51.76 & 0.420 & ND & ND & ND \\
\hline Dzerzhinskoe & Russia & 60.20 & 55.49 & 0.386 & 0.191 & 0.173 & ND \\
\hline Dzhusinskoe & Russia & 59.52 & 51.27 & 0.386 & 0.218 & 0.163 & ND \\
\hline Gaiskoe & Russia & 58.49 & 51.46 & 0.398 & 6.566 & 2.814 & 0.281 \\
\hline Ishkinino & Russia & 58.21 & 51.41 & 0.420 & 0.064 & 0.000 & 0.000 \\
\hline Ivonovskoe & Russia & 57.92 & 52.45 & 0.430 & 0.108 & 0.030 & ND \\
\hline Kainooja & Russia & 32.57 & 61.73 & 2.945 & ND & 0.018 & 0.022 \\
\hline Kaluginskoe & Russia & 60.20 & 58.63 & 0.431 & 0.036 & 0.026 & ND \\
\hline Kamenushinskoe & Russia & 85.81 & 54.38 & 0.431 & 0.109 & ND & ND \\
\hline Karabash & Russia & 60.22 & 55.52 & 0.365 & 0.153 & 0.162 & ND \\
\hline Kasarginskoe & Russia & 61.87 & 55.83 & 0.388 & 0.080 & 0.100 & ND \\
\hline Khotoidokh & Russia & 141.14 & 66.45 & 0.154 & 0.042 & 0.894 & 0.309 \\
\hline Komsomolskoe & Russia & 56.97 & 51.23 & 0.438 & 0.390 & 0.438 & 0.043 \\
\hline Korbalikhinskoe & Russia & 82.32 & 51.28 & 0.377 & 0.365 & 2.453 & 0.503 \\
\hline Krasnogvardeyskoe & Russia & 60.06 & 58.37 & 0.430 & 0.305 & 0.103 & ND \\
\hline Kyzyl-Tashtg & Russia & 95.59 & 52.02 & 0.531 & 0.085 & 1.339 & 0.371 \\
\hline Leschevskoe & Russia & 36.10 & 63.10 & 2.690 & ND & ND & ND \\
\hline Letnee & Russia & 59.48 & 50.93 & 0.431 & 0.218 & 0.102 & 0.003 \\
\hline Levikhinskoe & Russia & 59.92 & 57.58 & 0.431 & 0.227 & 0.227 & ND \\
\hline Lindolampi & Russia & 33.93 & 62.10 & 2.000 & 0.130 & ND & ND \\
\hline Maiskoe (Maysk) & Russia & 58.22 & 52.32 & 0.398 & 0.011 & 0.044 & ND \\
\hline Makanskoe & Russia & 58.30 & 52.00 & 0.397 & 0.085 & 0.025 & ND \\
\hline Maukskoe & Russia & 60.29 & 56.00 & 0.438 & 0.047 & 0.049 & ND \\
\hline Molodezhnoe & Russia & 59.42 & 54.09 & 0.388 & 0.352 & 0.560 & ND \\
\hline Novo-Shermuskoe (Shermskoye Novy) & Russia & 59.95 & 60.56 & 0.431 & 0.490 & 0.525 & ND \\
\hline Oktyabrskoe & Russia & 58.26 & 52.02 & 0.397 & 0.454 & 0.239 & ND \\
\hline Osennee & Russia & 59.54 & 50.92 & 0.431 & 0.342 & 0.018 & ND \\
\hline Ozernoe & Russia & 111.70 & 52.93 & 0.531 & ND & 11.160 & 2.160 \\
\hline Pervomaiskoe & Russia & 60.21 & 55.44 & 0.386 & 0.098 & 0.113 & ND \\
\hline Podolskoe & Russia & 58.45 & 52.05 & 0.396 & 2.145 & 1.699 & 0.114 \\
\hline Rubtsovskoe & Russia & 81.18 & 51.43 & 0.388 & ND & 0.560 & 0.326 \\
\hline Rybozero & Russia & 35.48 & 63.07 & 2.600 & ND & ND & ND \\
\hline Rybozerskoe & Russia & 35.47 & 63.08 & 2.690 & ND & ND & ND \\
\hline Safyanovka & Russia & 61.53 & 57.38 & 0.390 & 0.767 & 0.312 & ND \\
\hline Salairskoe & Russia & 85.78 & 54.24 & 0.530 & 0.150 & 2.100 & 0.435 \\
\hline Semenov East & Russia & 58.21 & 51.51 & 0.365 & 0.011 & 0.075 & ND \\
\hline Sibaiskoe (Sibay) & Russia & 58.64 & 52.70 & 0.391 & 1.150 & 1.794 & 0.046 \\
\hline Stepnoe & Russia & 81.95 & 51.42 & 0.388 & ND & 0.743 & 0.374 \\
\hline Sultanovskoe & Russia & 61.71 & 55.63 & 0.388 & 0.229 & 0.099 & ND \\
\hline Sumskoe & Russia & 34.13 & 64.03 & 3.000 & 0.050 & ND & ND \\
\hline Talganskoe & Russia & 59.37 & 54.14 & 0.388 & 0.113 & 0.084 & ND \\
\hline Talovskoe & Russia & 81.91 & 51.45 & 0.388 & ND & 1.100 & 0.535 \\
\hline Talpus- 1 & Russia & 33.72 & 62.82 & 2.690 & 0.080 & ND & ND \\
\hline Tarnyerskoe & Russia & 59.92 & 60.82 & 0.430 & 0.144 & 0.386 & 0.061 \\
\hline Tash Tau & Russia & 58.22 & 52.44 & 0.400 & 0.136 & 0.042 & ND \\
\hline $\begin{array}{c}\text { Uchalinskoe (incl. Uchaly, Uchaly } \\
\text { Novy) }\end{array}$ & Russia & 59.43 & 54.31 & 0.391 & 2.305 & 7.232 & ND \\
\hline Urskoe & Russia & 85.40 & 54.45 & 0.530 & 0.254 & 0.870 & 0.020 \\
\hline Uzelginskoe & Russia & 59.34 & 54.13 & 0.388 & 1.142 & 2.856 & ND \\
\hline Valentorskoe & Russia & 59.62 & 59.82 & 0.431 & 0.116 & 0.087 & ND \\
\hline Verhne-Vozhma & Russia & 36.25 & 63.27 & 2.875 & 0.065 & ND & ND \\
\hline Vostochno-Povenetz & Russia & 34.87 & 62.83 & 2.000 & 0.020 & ND & $\mathrm{ND}$ \\
\hline
\end{tabular}




\begin{tabular}{|c|c|c|c|c|c|c|c|}
\hline Deposit & Country & Lon. ${ }^{a}$ & Lat. $^{a}$ & $\begin{array}{l}\text { Age } \\
(\mathrm{Ga})\end{array}$ & $\begin{array}{c}\mathrm{Cu} \\
(\mathrm{Mt})\end{array}$ & $\begin{array}{c}\mathrm{Zn} \\
(\mathrm{Mt})\end{array}$ & $\begin{array}{l}\mathrm{Pb} \\
(\mathrm{Mt})\end{array}$ \\
\hline Vostochno-Semenovskoe & Russia & 58.33 & 52.51 & 0.400 & 0.011 & 0.075 & ND \\
\hline XIX Partsiezda & Russia & 59.37 & 54.15 & 0.388 & 0.745 & 0.508 & ND \\
\hline Yaman Kasey & Russia & 57.57 & 51.38 & 0.438 & 0.059 & 0.128 & ND \\
\hline Yubileinoe & Russia & 58.13 & 52.17 & 0.400 & 2.033 & 1.284 & 0.107 \\
\hline Yubileinoe & Russia & 81.57 & 50.87 & 0.377 & 0.070 & 0.387 & 0.103 \\
\hline Yulalinskoe & Russia & 58.31 & 52.42 & 0.400 & 0.031 & 0.009 & ND \\
\hline Zakharovskoe & Russia & 81.67 & 51.82 & 0.377 & 0.079 & 0.412 & 0.232 \\
\hline Zalomaevskoe & Russia & 35.15 & 63.31 & 2.913 & ND & ND & ND \\
\hline Zapadno-Ashchebutakskoe & Russia & 58.87 & 51.30 & 0.388 & 0.030 & 0.069 & ND \\
\hline Zapadno-Ozernoe (Ozernoe West) & Russia & 59.28 & 54.19 & 0.390 & 0.459 & 0.561 & ND \\
\hline Zapadno-Rybozero & Russia & 35.37 & 63.07 & 2.913 & $\mathrm{ND}$ & ND & ND \\
\hline Zarechenskoe & Russia & 82.12 & 51.18 & 0.390 & 0.013 & 0.059 & 0.043 \\
\hline Zimnee & Russia & 59.92 & 50.98 & 0.039 & 0.151 & 0.109 & ND \\
\hline Zmeinogorskoe & Russia & 82.18 & 51.15 & 0.390 & 0.040 & 0.280 & 0.200 \\
\hline Zolotoporozhskoe & Russia & 35.96 & 63.17 & 2.875 & ND & ND & ND \\
\hline Zolutushinskoe & Russia & 81.44 & 50.99 & 0.388 & 0.290 & 2.176 & 0.462 \\
\hline Al Gehab & Saudi Arabia & 41.40 & 20.68 & 0.700 & 0.020 & 0.012 & ND \\
\hline As Safra & Saudi Arabia & 41.88 & 24.18 & 0.680 & 0.058 & 0.036 & 0.018 \\
\hline Jabal ash Shizm & Saudi Arabia & 37.54 & 26.46 & 0.700 & 0.029 & 0.007 & 0.004 \\
\hline Jabal Sayid & Saudi Arabia & 40.85 & 22.92 & 0.720 & 0.534 & 0.020 & ND \\
\hline Khnaiguiyah & Saudi Arabia & 45.08 & 24.28 & 0.700 & 0.032 & 1.036 & ND \\
\hline Nuqrah & Saudi Arabia & 41.44 & 25.64 & 0.680 & 0.011 & 0.080 & 0.023 \\
\hline Annex & South Africa & 22.41 & -30.23 & 1.285 & 0.023 & 0.008 & ND \\
\hline Areachap & South Africa & 22.28 & -29.92 & 1.250 & 0.042 & 0.199 & ND \\
\hline Bien Venue & South Africa & 31.23 & -25.67 & 3.259 & 0.009 & 0.120 & 0.045 \\
\hline Kantienpan & South Africa & 21.54 & -29.09 & 1.250 & 0.025 & 0.205 & ND \\
\hline Kielder K3 & South Africa & 22.34 & -29.98 & 1.285 & 0.004 & 0.056 & ND \\
\hline Kielder K6 & South Africa & 22.34 & -29.98 & 1.285 & 0.004 & 0.089 & ND \\
\hline LCZ (Letaba) & South Africa & 30.81 & -23.87 & 2.975 & 0.011 & 0.066 & 0.000 \\
\hline Maranda $\mathrm{J}$ & South Africa & 30.52 & -23.99 & 2.964 & 0.033 & 0.253 & 0.000 \\
\hline Preiska & South Africa & 22.30 & -29.93 & 1.285 & 0.691 & 1.819 & ND \\
\hline Romotshidi & South Africa & 30.50 & -23.99 & 2.970 & 0.005 & 0.069 & 0.003 \\
\hline Aguas Teidas & Spain & -6.82 & 37.77 & 0.350 & 0.023 & ND & ND \\
\hline Aguas Teidas Este & Spain & -6.85 & 37.78 & 0.350 & 0.951 & 2.357 & 1.134 \\
\hline Arinteiro & Spain & -8.32 & 42.88 & 0.471 & 0.084 & ND & ND \\
\hline Aznalcollar-Los Frailes & Spain & -6.28 & 37.53 & 0.346 & 0.664 & 4.267 & 2.244 \\
\hline Bama & Spain & -8.35 & 42.88 & 0.471 & 0.100 & ND & ND \\
\hline Concepcin & Spain & -6.68 & 37.78 & 0.350 & 0.322 & 0.322 & 0.087 \\
\hline Cueva de la Mora & Spain & -6.83 & 37.78 & 0.350 & 0.063 & 0.029 & 0.013 \\
\hline Forns & Spain & -8.49 & 42.85 & 0.471 & 0.015 & ND & ND \\
\hline Herrerias & Spain & -7.29 & 37.62 & 0.350 & 0.045 & 0.020 & 0.025 \\
\hline La Romanera & Spain & -7.35 & 37.68 & 0.350 & 0.136 & 0.782 & 0.408 \\
\hline La Zarza & Spain & -6.88 & 37.72 & 0.350 & 2.059 & 4.118 & 1.716 \\
\hline Las Cruces & Spain & -5.97 & 37.51 & 0.354 & 1.266 & 1.266 & 0.518 \\
\hline Lomero-Poyatos & Spain & -6.93 & 37.81 & 0.350 & 0.025 & 0.143 & 0.086 \\
\hline Monte Romero & Spain & -6.81 & 37.78 & 0.350 & 0.016 & 0.040 & 0.022 \\
\hline Rio Tinto & Spain & -6.60 & 37.70 & 0.350 & 9.198 & 6.433 & 3.452 \\
\hline San Miguel & Spain & -6.75 & 37.76 & 0.350 & 0.039 & ND & ND \\
\hline San Platn & Spain & -6.67 & 37.76 & 0.350 & 0.037 & 0.037 & 0.006 \\
\hline San Telmo & Spain & -6.96 & 37.80 & 0.350 & 0.048 & 0.480 & 0.016 \\
\hline Sierracilla & Spain & -7.29 & 37.67 & 0.350 & 0.015 & 0.120 & 0.050 \\
\hline Sotiel-Migollas & Spain & -6.85 & 37.61 & 0.350 & 0.970 & 3.674 & 1.611 \\
\hline $\begin{array}{c}\text { Tharsis (Filon Norte and San } \\
\text { Guillermo) }\end{array}$ & Spain & -7.10 & 37.58 & 0.350 & 0.575 & 3.105 & 0.690 \\
\hline Valverde & Spain & -6.83 & 37.54 & 0.350 & 0.400 & 1.188 & 0.584 \\
\hline Vuelta Falsa & Spain & -7.44 & 37.69 & 0.350 & 0.013 & 0.207 & 0.088 \\
\hline Adak-Lindskld & Sweden & 18.63 & 65.37 & 1.889 & 0.114 & ND & ND \\
\hline kulla Vastra & Sweden & 20.25 & 64.91 & 1.889 & 0.010 & ND & ND \\
\hline Alfrida-Hllefors & Sweden & 14.48 & 59.85 & 1.889 & $\mathrm{ND}$ & ND & ND \\
\hline mmeberg-Zinkgruvan & Sweden & 15.10 & 58.81 & 1.891 & 0.101 & 4.459 & 2.027 \\
\hline sen & Sweden & 19.88 & 64.93 & 1.889 & 0.008 & 0.011 & 0.001 \\
\hline Bjurtrsk Norra & Sweden & 19.73 & 64.99 & 1.889 & 0.002 & 0.009 & 0.000 \\
\hline Boliden & Sweden & 20.37 & 64.87 & 1.894 & 0.118 & 0.075 & 0.025 \\
\hline Falun & Sweden & 15.50 & 60.60 & 1.891 & 0.100 & 0.900 & 0.500 \\
\hline Garpenberg & Sweden & 16.21 & 60.32 & 1.891 & 0.088 & 4.422 & 2.034 \\
\hline Holmtjrn nya & Sweden & 19.57 & 65.11 & 1.889 & 0.002 & 0.018 & 0.002 \\
\hline Horntrskviken & Sweden & 18.52 & 65.09 & 1.889 & 0.006 & 0.031 & 0.004 \\
\hline Kankberg & Sweden & 20.27 & 64.92 & 1.889 & 0.016 & 0.021 & 0.003 \\
\hline Kedtrsk & Sweden & 19.89 & 64.95 & 1.889 & 0.002 & 0.017 & 0.002 \\
\hline Kimheden & Sweden & 18.60 & 65.09 & 1.889 & 0.001 & 0.000 & ND \\
\hline Kristineberg & Sweden & 18.57 & 65.06 & 1.889 & 0.380 & 2.102 & 0.090 \\
\hline Lngdal & Sweden & 20.23 & 64.83 & 1.889 & 0.008 & 0.241 & 0.063 \\
\hline Lngsele & Sweden & 20.27 & 64.83 & 1.889 & 0.058 & 0.435 & 0.019 \\
\hline Maurliden Norra & Sweden & 19.56 & 65.05 & 1.889 & 0.001 & 0.009 & 0.001 \\
\hline Maurliden stra & Sweden & 19.55 & 65.05 & 1.889 & 0.021 & 0.018 & ND \\
\hline Maurliden Vstra & Sweden & 19.52 & 65.06 & 1.889 & 0.010 & 0.172 & 0.020 \\
\hline Nsliden & Sweden & 19.10 & 65.10 & 1.889 & 0.048 & 0.116 & 0.011 \\
\hline
\end{tabular}




\begin{tabular}{|c|c|c|c|c|c|c|c|}
\hline Deposit & Country & Lon. $^{a}$ & Lat. ${ }^{a}$ & $\begin{array}{l}\text { Age } \\
(\mathrm{Ga})\end{array}$ & $\begin{array}{c}\mathrm{Cu} \\
(\mathrm{Mt})\end{array}$ & $\begin{array}{c}\mathrm{Zn} \\
(\mathrm{Mt})\end{array}$ & $\begin{array}{c}\mathrm{Pb} \\
(\mathrm{Mt})\end{array}$ \\
\hline Norrliden Norra & Sweden & 19.59 & 65.02 & 1.889 & 0.019 & 0.183 & 0.016 \\
\hline Petikns Norra & Sweden & 20.05 & 64.94 & 1.889 & 0.016 & 0.055 & 0.006 \\
\hline Petikns Sdra & Sweden & 20.04 & 64.93 & 1.889 & 0.049 & 0.265 & 0.049 \\
\hline Rakkejaur & Sweden & 19.12 & 65.13 & 1.889 & 0.002 & 0.009 & 0.002 \\
\hline Rvliden & Sweden & 18.47 & 65.07 & 1.889 & 0.016 & 0.066 & 0.012 \\
\hline Rvlidmyran & Sweden & 18.50 & 65.08 & 1.889 & 0.068 & 0.284 & 0.039 \\
\hline Renstrm & Sweden & 20.09 & 64.92 & 1.889 & 0.124 & 1.111 & 0.220 \\
\hline Rudtjebcken & Sweden & 18.50 & 65.37 & 1.889 & 0.045 & 0.135 & 0.001 \\
\hline Saxberget & Sweden & 14.94 & 60.14 & 1.891 & 0.058 & 0.457 & 0.142 \\
\hline Stekenjokk-Levi & Sweden & 14.46 & 65.10 & 0.488 & 0.376 & 0.778 & 0.081 \\
\hline Svansele & Sweden & 19.82 & 64.98 & 1.889 & 0.009 & 0.009 & 0.003 \\
\hline Tjokkola & Sweden & 14.40 & 65.10 & 0.488 & 0.020 & 0.112 & 0.016 \\
\hline Udden & Sweden & 19.84 & 64.96 & 1.889 & 0.024 & 0.272 & 0.018 \\
\hline A karsen & Turkey & 29.68 & 41.48 & 0.077 & 0.115 & ND & ND \\
\hline Akkoy & Turkey & 38.98 & 40.93 & 0.091 & 0.008 & 0.051 & ND \\
\hline Asikoy (Kre) & Turkey & 33.70 & 41.80 & 0.169 & 0.175 & ND & ND \\
\hline Cayeli (Madenky) & Turkey & 42.12 & 41.38 & 0.091 & 0.579 & 0.831 & 0.021 \\
\hline Cerateppe & Turkey & 41.90 & 41.40 & 0.077 & 0.141 & 0.018 & ND \\
\hline Ergani (Anatatak; Mihrapdag) & Turkey & 39.73 & 38.28 & 0.045 & 0.211 & ND & ND \\
\hline Harky & Turkey & 40.93 & 38.88 & 0.091 & 0.022 & 0.037 & 0.010 \\
\hline Irsahan & Turkey & 41.81 & 41.29 & 0.077 & 0.004 & 0.031 & 0.013 \\
\hline Kayabasi (Kankoy) & Turkey & 39.00 & 40.97 & 0.091 & 0.037 & ND & ND \\
\hline Killik & Turkey & 38.68 & 40.82 & 0.091 & 0.009 & 0.002 & ND \\
\hline Kizilkaya & Turkey & 38.75 & 40.90 & 0.091 & 0.041 & 0.051 & 0.001 \\
\hline Kprbai (Tirebolu) & Turkey & 38.72 & 41.00 & 0.083 & 0.039 & 0.277 & 0.188 \\
\hline Kotarak Dere & Turkey & 40.11 & 40.87 & 0.091 & 0.013 & 0.026 & ND \\
\hline Kutlular & Turkey & 40.88 & 40.07 & 0.091 & 0.030 & 0.018 & 0.000 \\
\hline Kuvarshan & Turkey & 40.68 & 41.80 & 0.077 & 0.018 & 0.036 & 0.007 \\
\hline Lahanos & Turkey & 38.70 & 40.75 & 0.091 & 0.154 & 0.174 & 0.012 \\
\hline Madenkoy-Siirt & Turkey & 42.14 & 38.05 & 0.045 & 0.531 & 0.240 & ND \\
\hline Murgul (Anayatak; Cakmakkaya) & Turkey & 41.57 & 41.22 & 0.091 & 0.920 & 0.078 & 0.039 \\
\hline Seyitler & Turkey & 41.86 & 41.22 & 0.077 & 0.024 & 0.035 & ND \\
\hline Sinkot & Turkey & 41.84 & 41.22 & 0.077 & 0.020 & ND & ND \\
\hline Tunca & Turkey & 41.15 & 41.17 & 0.091 & 0.005 & 0.003 & 0.000 \\
\hline Yenipazar & Turkey & 35.02 & 39.43 & 0.298 & 0.074 & 0.367 & 0.241 \\
\hline Kerry Road & United Kindom & -5.71 & 57.73 & 1.950 & ND & ND & ND \\
\hline Parys Mountain & United Kindom & -4.42 & 53.38 & 0.436 & 0.151 & 0.345 & 0.168 \\
\hline Afterthought & USA & -122.07 & 40.77 & 0.248 & 0.005 & 0.024 & 0.003 \\
\hline Alder Pond & USA & -70.21 & 45.36 & 0.484 & 0.011 & 0.046 & 0.003 \\
\hline Andersonville No Zone 18 & USA & -78.56 & 37.44 & 0.471 & 0.004 & 0.034 & 0.004 \\
\hline Andersonville No Zone 24 & USA & -78.51 & 37.44 & 0.471 & 0.005 & 0.024 & 0.003 \\
\hline Arctic & USA & -156.37 & 67.19 & 0.376 & 1.174 & 1.667 & 0.278 \\
\hline Balaklala & USA & -122.50 & 40.73 & 0.400 & 0.031 & 0.014 & ND \\
\hline Bald Mountain & USA & -68.73 & 46.74 & 0.467 & 0.309 & 0.336 & 0.015 \\
\hline Barite Hill & UsA & -82.29 & 33.88 & 0.566 & ND & ND & ND \\
\hline Barrett & USA & -67.23 & 44.97 & 0.430 & 0.007 & 0.008 & ND \\
\hline Beatson & USA & -147.85 & 60.03 & 0.059 & 0.090 & ND & ND \\
\hline Bend & USA & -90.60 & 45.29 & 1.870 & 0.066 & ND & ND \\
\hline Big Hill & USA & -67.22 & 44.97 & 0.430 & 0.001 & 0.023 & 0.008 \\
\hline Binghampton-Copper Queen & USA & -112.19 & 34.46 & 1.745 & 0.011 & ND & ND \\
\hline Black Hawk & USA & -68.77 & 44.43 & 0.504 & 0.024 & 0.200 & 0.081 \\
\hline Blue Hill & USA & -68.48 & 44.39 & 0.504 & 0.009 & 0.069 & ND \\
\hline Blue Moon & USA & -120.20 & 37.60 & 0.154 & 0.025 & 0.289 & 0.016 \\
\hline Bruce-Old Dick & USA & -113.23 & 34.55 & 1.740 & 0.048 & 0.160 & ND \\
\hline B T & USA & -155.76 & 67.15 & 0.382 & 0.060 & 0.091 & 0.032 \\
\hline Catwillow & USA & -88.55 & 45.63 & 1.870 & 0.040 & 0.069 & ND \\
\hline Chestatee & USA & -83.88 & 34.55 & 0.850 & 0.011 & 0.008 & ND \\
\hline CL Zone & USA & -68.74 & 46.74 & 0.467 & 0.018 & 0.117 & ND \\
\hline Copper Chief & USA & -112.09 & 34.70 & 1.739 & 0.001 & ND & ND \\
\hline Crandon & USA & -88.92 & 45.48 & 1.875 & 0.685 & 3.665 & 0.316 \\
\hline Davis & USA & -72.87 & 42.70 & 0.464 & 0.006 & 0.050 & 0.000 \\
\hline $\mathrm{DD}$ & USA & -144.24 & 63.27 & 0.359 & 0.038 & 0.172 & 0.083 \\
\hline Dry Creek & USA & -147.37 & 63.92 & 0.357 & 0.006 & 0.128 & 0.055 \\
\hline Duchess & USA & -147.92 & 60.02 & 0.059 & 0.019 & 0.006 & ND \\
\hline Ducktown & USA & -84.37 & 35.01 & 0.758 & 1.633 & 1.470 & ND \\
\hline DW-LP & USA & -144.09 & 63.25 & 0.372 & 0.035 & 0.393 & 0.148 \\
\hline Eisenbrey (Thornapple) & USA & -91.12 & 45.44 & 1.870 & 0.021 & 0.027 & ND \\
\hline Elizabeth & USA & -72.33 & 43.82 & 0.405 & 0.052 & 0.015 & ND \\
\hline Ellamar & USA & -146.70 & 60.89 & 0.059 & 0.009 & ND & ND \\
\hline Flambeau & USA & -91.14 & 45.51 & 1.870 & 0.267 & 0.065 & ND \\
\hline Gossan Lead & USA & -80.75 & 36.82 & 0.750 & 0.050 & 0.200 & 0.010 \\
\hline Gray Eagle & USA & -123.37 & 41.86 & 0.153 & 0.041 & ND & ND \\
\hline Greens Creek & USA & -134.63 & 58.08 & 0.221 & 0.070 & 3.057 & 1.121 \\
\hline Harborside & USA & -68.81 & 44.35 & 0.504 & 0.010 & 0.044 & 0.004 \\
\hline Hawk & USA & -89.76 & 45.45 & 1.870 & 0.011 & 0.037 & ND \\
\hline Horse Shoe & USA & -89.62 & 45.44 & 1.870 & 0.016 & 0.036 & 0.006 \\
\hline
\end{tabular}




\begin{tabular}{|c|c|c|c|c|c|c|c|}
\hline Deposit & Country & Lon. $^{a}$ & Lat. $^{a}$ & $\begin{array}{l}\text { Age } \\
\text { (Ga) }\end{array}$ & $\begin{array}{c}\mathrm{Cu} \\
(\mathrm{Mt}) \\
\end{array}$ & $\begin{array}{c}\mathrm{Zn} \\
(\mathrm{Mt}) \\
\end{array}$ & $\begin{array}{c}\mathrm{Pb} \\
(\mathrm{Mt})\end{array}$ \\
\hline Iron Dyke & USA & -116.86 & 45.03 & 0.285 & 0.014 & ND & ND \\
\hline Iron King & USA & -111.74 & 34.50 & 1.745 & 0.009 & 0.360 & 0.123 \\
\hline Iron Mountain & USA & -122.53 & 40.68 & 0.400 & 0.156 & 0.063 & ND \\
\hline Jenny Stone & USA & -84.92 & 33.78 & 0.850 & 0.006 & 0.004 & ND \\
\hline Jones Hill & USA & -81.40 & 36.29 & 1.720 & 0.434 & 0.497 & ND \\
\hline Keystone-Union & USA & -122.51 & 40.72 & 0.400 & 0.007 & 0.009 & ND \\
\hline Ledge Ridge & USA & -70.96 & 45.19 & 0.440 & 0.035 & 0.085 & 0.031 \\
\hline Lookout & USA & -132.14 & 55.05 & 0.565 & 0.071 & 0.125 & ND \\
\hline Lynne & USA & -89.97 & 45.69 & 1.870 & 0.024 & 0.473 & 0.087 \\
\hline Mammoth & USA & -122.46 & 40.76 & 0.400 & 0.122 & 0.142 & ND \\
\hline Midas & USA & -146.39 & 61.01 & 0.083 & 0.002 & ND & ND \\
\hline Milan & USA & -71.25 & 44.57 & 0.465 & 0.011 & 0.036 & 0.008 \\
\hline Mount Chase & USA & -68.46 & 46.14 & 0.467 & 0.042 & 0.326 & 0.140 \\
\hline Orange Point & USA & -137.00 & 58.55 & 0.270 & 0.052 & 0.190 & 0.002 \\
\hline Ore Knob & USA & -81.33 & 36.38 & 0.750 & 0.034 & 0.007 & ND \\
\hline Pecos & USA & -105.67 & 35.77 & 1.720 & 0.002 & 0.259 & 0.080 \\
\hline Pelican River & USA & -89.29 & 45.60 & 1.870 & 0.020 & 0.090 & ND \\
\hline Penn & USA & -120.87 & 38.23 & 0.154 & 0.018 & 0.069 & 0.049 \\
\hline PP2 2 & USA & -144.08 & 63.24 & 0.372 & 0.021 & 0.247 & 0.113 \\
\hline Pyriton & USA & -85.55 & 33.36 & 0.470 & 0.033 & 0.014 & 0.001 \\
\hline Red Ledge & USA & -116.67 & 45.23 & 0.285 & 0.152 & 0.371 & ND \\
\hline Rising Star-Bully Hill & USA & -122.20 & 40.80 & 0.248 & 0.024 & 0.019 & ND \\
\hline Ritchie Creek & USA & -90.06 & 45.49 & 1.870 & 0.017 & 0.003 & ND \\
\hline Rua Cove & USA & -147.63 & 60.35 & 0.059 & 0.012 & ND & ND \\
\hline Shasta King & USA & -122.50 & 40.73 & 0.400 & 0.002 & 0.006 & ND \\
\hline Smucker & USA & -157.19 & 67.29 & 0.382 & 0.064 & 0.544 & 0.184 \\
\hline Standard Copper & USA & -146.54 & 60.85 & 0.059 & 0.000 & $\mathrm{ND}$ & ND \\
\hline Stone Hill & USA & -85.55 & 33.49 & 0.900 & 0.008 & 0.013 & ND \\
\hline Sumdum & USA & -133.45 & 57.78 & 0.360 & 0.138 & 0.090 & ND \\
\hline Sun & USA & -155.04 & 67.08 & 0.386 & 0.351 & 0.820 & 0.217 \\
\hline Threeman & USA & -146.54 & 60.85 & 0.059 & 0.018 & ND & ND \\
\hline Trio & USA & -132.13 & 55.05 & 0.565 & 0.025 & 0.039 & ND \\
\hline TRIO & USA & -144.03 & 63.26 & 0.372 & 0.001 & 0.012 & 0.002 \\
\hline Turner Albright & USA & -123.77 & 42.00 & 0.164 & 0.044 & 0.103 & ND \\
\hline United Verde & USA & -112.13 & 34.76 & 1.739 & 1.425 & 1.284 & 0.245 \\
\hline United Verde Extended & USA & -112.11 & 34.58 & 1.739 & 0.361 & ND & ND \\
\hline Verde Central & USA & -112.12 & 34.74 & 1.739 & 0.005 & ND & ND \\
\hline WTF & USA & -147.33 & 63.92 & 0.363 & 0.003 & 0.168 & 0.070 \\
\hline Bailadores & Venezuela & -71.85 & 8.20 & 0.340 & 0.022 & 0.377 & 0.102 \\
\hline Sunyati & Zimbabwe & 29.15 & -17.83 & 2.000 & 0.235 & 0.519 & 0.139 \\
\hline
\end{tabular}

${ }^{a}$ In decimal degrees

Table 7: Global compilation of 691 porphyry copper deposits shown in Figure S33, drawn primarily from Sillitoe (2010). Ga = billion years; $\mathrm{Mt}=$ million tonnes; $\mathrm{ND}=$ no data.

\begin{tabular}{|c|c|c|c|c|c|}
\hline Deposit & Country & Lon. ${ }^{a}$ & Lat. $^{a}$ & $\begin{array}{l}\text { Age } \\
(\mathrm{Ga})\end{array}$ & $\begin{array}{c}\mathrm{Cu} \\
(\mathrm{Mt})\end{array}$ \\
\hline Agua Rica & Argentina & -66.28 & -27.37 & 0.006 & 7.40 \\
\hline Alcaparrosa & Argentina & -69.37 & -31.30 & 0.267 & ND \\
\hline Arroyo Chita & Argentina & -69.75 & -30.50 & 0.012 & ND \\
\hline Bajo de Agua Tapado & Argentina & -66.65 & -27.27 & 0.009 & ND \\
\hline Bajo de la Alumbrera & Argentina & -66.61 & -27.33 & 0.008 & 4.27 \\
\hline Bajo de la Leona & Argentina & -67.31 & -48.08 & 0.200 & ND \\
\hline Bajo de San Lucas & Argentina & -66.55 & -27.40 & 0.007 & ND \\
\hline Bajo El Durazno & Argentina & -66.57 & -27.28 & 0.008 & 0.64 \\
\hline Betito & Argentina & -67.90 & -26.30 & 0.014 & ND \\
\hline Campana Mahuida & Argentina & -70.58 & -38.25 & 0.074 & 0.95 \\
\hline Carrizal & Argentina & -69.17 & -30.00 & 0.261 & ND \\
\hline Cerro Mercedario & Argentina & -70.05 & -31.95 & 0.013 & ND \\
\hline El Oculto & Argentina & -66.60 & -24.13 & ND & ND \\
\hline El Salado & Argentina & -69.63 & -30.93 & ND & ND \\
\hline Filo Colorado & Argentina & -66.22 & -27.38 & ND & ND \\
\hline Inca Viejo & Argentina & -66.76 & -25.14 & 0.015 & ND \\
\hline La Voluntad & Argentina & -70.63 & -39.18 & 0.281 & 0.38 \\
\hline Los Azules & Argentina & -70.18 & -31.24 & ND & ND \\
\hline Nevados de Famatina & Argentina & -67.75 & -29.00 & 0.004 & 1.11 \\
\hline Pancho Arias & Argentina & -65.87 & -24.20 & 0.015 & ND \\
\hline Paramillos Norte & Argentina & -69.08 & -32.42 & 0.014 & 1.08 \\
\hline Paramillos Sur & Argentina & -69.10 & -32.48 & 0.014 & 0.99 \\
\hline Quebrada del Bronce & Argentina & -70.47 & -37.43 & 0.045 & ND \\
\hline San Jorge & Argentina & -69.43 & -32.25 & 0.260 & 1.49 \\
\hline Taca Taca Alto & Argentina & -67.78 & -24.57 & 0.029 & ND \\
\hline Taca Taca Bajo & Argentina & -67.73 & -24.58 & 0.031 & 2.99 \\
\hline
\end{tabular}




\begin{tabular}{|c|c|c|c|c|c|}
\hline Deposit & Country & Lon. ${ }^{a}$ & Lat. ${ }^{a}$ & $\begin{array}{l}\text { Age } \\
(\mathrm{Ga})\end{array}$ & $\begin{array}{c}\mathrm{Cu} \\
(\mathrm{Mt}) \\
\end{array}$ \\
\hline Yalguaraz & Argentina & -69.44 & -32.14 & 0.264 & $\mathrm{ND}$ \\
\hline Agarak & Armenia & 46.19 & 38.92 & 0.040 & 0.70 \\
\hline Ankavan & Armenia & 44.52 & 40.63 & 0.033 & ND \\
\hline Dastakert & Armenia & 46.02 & 39.38 & 0.022 & ND \\
\hline Kadjaran & Armenia & 46.14 & 39.14 & 0.022 & 4.59 \\
\hline Shikahoh & Armenia & 46.47 & 39.10 & 0.144 & $\mathrm{ND}$ \\
\hline Teghout & Armenia & 44.86 & 41.10 & 0.121 & 1.62 \\
\hline Anabama Hill & Australia & 140.24 & -32.77 & 0.440 & ND \\
\hline Andromache River & Australia & 148.26 & -20.57 & 0.265 & ND \\
\hline Boddington & Australia & 116.36 & -32.74 & 2.620 & 0.80 \\
\hline Cadia Hill/Ridgeway & Australia & 149.00 & -33.47 & 0.449 & 3.87 \\
\hline Cargo & Australia & 148.85 & -33.62 & 0.416 & ND \\
\hline Chinaman Creek & Australia & 151.62 & -25.24 & 0.250 & ND \\
\hline Coalstoun & Australia & 151.92 & -25.68 & 0.235 & 0.25 \\
\hline Copper Hill & Australia & 148.87 & -33.05 & 0.447 & 0.45 \\
\hline Copper Hills & Australia & 119.96 & -21.66 & 0.470 & 0.28 \\
\hline Coppin Gap & Australia & 120.11 & -20.89 & 3.234 & 0.79 \\
\hline Dogwood & Australia & 148.01 & -37.57 & 0.410 & ND \\
\hline Endeavour & Australia & 148.03 & -32.92 & 0.442 & 1.44 \\
\hline Frogmore & Australia & 148.84 & -34.27 & 0.430 & ND \\
\hline Kelly & Australia & 119.87 & -21.79 & 2.630 & ND \\
\hline Kiwi Carpet & Australia & 150.88 & -24.67 & 0.235 & ND \\
\hline Limonite Hill & Australia & 150.63 & -23.69 & 0.246 & ND \\
\hline Mandamah & Australia & 147.42 & -33.97 & 0.445 & $\mathrm{ND}$ \\
\hline Marsden & Australia & 147.53 & -33.72 & 0.470 & 0.58 \\
\hline Moonmera & Australia & 150.40 & -23.60 & 0.245 & ND \\
\hline Mount Cannindah & Australia & 151.37 & -24.82 & 0.235 & $\mathrm{ND}$ \\
\hline Mt. Abbot & Australia & 147.95 & -20.20 & ND & ND \\
\hline Mt. Leslie & Australia & 140.17 & -20.34 & ND & ND \\
\hline Mt. Poole & Australia & 152.37 & -29.84 & ND & ND \\
\hline Mt. Robin & Australia & 146.98 & -20.58 & 0.285 & ND \\
\hline Mt. Turner & Australia & 143.42 & -18.25 & 0.310 & ND \\
\hline Peak Hill & Australia & 148.22 & -32.75 & ND & ND \\
\hline Struck Oil & Australia & 150.46 & -23.61 & 0.250 & ND \\
\hline Thursdays Gossan & Australia & 142.61 & -37.61 & 0.505 & 0.06 \\
\hline Town Creek & Australia & 146.78 & -20.42 & 0.285 & $\mathrm{ND}$ \\
\hline Whitewash & Australia & 150.87 & -24.81 & 0.235 & ND \\
\hline Yeoval & Australia & 148.67 & -32.77 & 0.390 & ND \\
\hline Yeppoon & Australia & 150.69 & -23.00 & 0.220 & ND \\
\hline Damirli & Azerbaijan & 46.75 & 40.02 & 0.135 & ND \\
\hline Garadag & Azerbaijan & 45.85 & 40.63 & 0.135 & $\mathrm{ND}$ \\
\hline Goshgarchai & Azerbaijan & 46.15 & 40.53 & 0.135 & ND \\
\hline Kedabek & Azerbaijan & 45.79 & 40.56 & 1.141 & ND \\
\hline Misdag & Azerbaijan & 46.05 & 39.05 & 0.040 & ND \\
\hline Herzogenhugel & Belgium & 5.92 & 50.28 & 0.419 & 0.03 \\
\hline Bom Jardim & Brazil & -51.60 & -17.53 & 0.840 & $\mathrm{ND}$ \\
\hline Chapada & Brazil & -49.37 & -14.25 & 0.840 & 0.59 \\
\hline Estrela & Brazil & -49.62 & -6.40 & 1.880 & 0.15 \\
\hline Assarel & Bulgaria & 23.98 & 42.58 & 0.090 & 1.56 \\
\hline Byrdtseto & Bulgaria & 27.53 & 41.97 & 0.081 & $\mathrm{ND}$ \\
\hline Elatsite & Bulgaria & 24.03 & 42.75 & 0.092 & 1.37 \\
\hline Medet & Bulgaria & 24.09 & 42.72 & 0.090 & 0.90 \\
\hline Plana & Bulgaria & 23.42 & 42.48 & 0.076 & ND \\
\hline Prohorovo & Bulgaria & 26.30 & 42.34 & 0.081 & ND \\
\hline Spahievo & Bulgaria & 25.25 & 42.12 & 0.033 & $\mathrm{ND}$ \\
\hline Tsar Assen & Bulgaria & 24.34 & 42.36 & 0.090 & 0.03 \\
\hline Vlaykov Vruh & Bulgaria & 24.23 & 42.35 & 0.086 & 0.05 \\
\hline Afton & Canada & -120.52 & 50.66 & 0.206 & 1.11 \\
\hline Ajax & Canada & -120.53 & 50.61 & 0.206 & 0.65 \\
\hline Axe & Canada & -120.53 & 49.65 & 0.179 & 0.50 \\
\hline Beidelman Bay & Canada & -91.00 & 49.83 & 2.500 & ND \\
\hline Bell Copper & Canada & -126.23 & 55.00 & 0.053 & 1.78 \\
\hline Berg & Canada & -127.44 & 53.80 & 0.050 & 0.95 \\
\hline Bethlehem & Canada & -121.00 & 50.49 & 0.200 & 3.05 \\
\hline Big Onion & Canada & -126.89 & 54.81 & 0.053 & 0.40 \\
\hline Brenda & Canada & -120.01 & 49.88 & 0.143 & 0.36 \\
\hline Bronson & Canada & -131.09 & 56.67 & 0.195 & 0.15 \\
\hline Cash & Canada & -137.62 & 62.42 & ND & 0.10 \\
\hline Casino & Canada & -138.83 & 62.74 & 0.073 & 2.12 \\
\hline Catface & Canada & -125.98 & 49.26 & 0.036 & 1.14 \\
\hline Chibougamau & Canada & -74.23 & 49.87 & 2.715 & ND \\
\hline Chuchi & Canada & -124.54 & 55.26 & 0.188 & ND \\
\hline Coles Creek & Canada & -127.23 & 53.53 & 0.086 & ND \\
\hline Copper Canyon & Canada & -131.35 & 57.12 & 0.212 & 0.58 \\
\hline Copper Mountain & Canada & -120.56 & 49.34 & 0.199 & 1.53 \\
\hline Coxheath & Canada & -60.37 & 46.08 & 0.621 & ND \\
\hline
\end{tabular}




\begin{tabular}{|c|c|c|c|c|c|}
\hline Deposit & Country & Lon. $^{a}$ & Lat. ${ }^{a}$ & $\begin{array}{l}\text { Age } \\
(\mathrm{Ga})\end{array}$ & $\begin{array}{c}\mathrm{Cu} \\
(\mathrm{Mt})\end{array}$ \\
\hline Don Rouyn & Canada & -79.00 & 48.27 & 2.700 & 0.05 \\
\hline Dorothy & Canada & -126.17 & 55.25 & 0.050 & 0.12 \\
\hline Eaglehead & Canada & -129.11 & 58.48 & 0.186 & 0.12 \\
\hline Fish Lake & Canada & -123.63 & 51.46 & 0.079 & 2.53 \\
\hline Galaxy & Canada & -120.42 & 50.64 & ND & 0.03 \\
\hline Galore Creek & Canada & -131.45 & 57.13 & 0.208 & 3.00 \\
\hline Gambier Island & Canada & -123.42 & 49.50 & ND & 0.33 \\
\hline Gaspe & Canada & -65.52 & 48.97 & 0.348 & 1.86 \\
\hline Giant Copper & Canada & -121.03 & 49.17 & ND & 0.66 \\
\hline Gibraltar & Canada & -122.29 & 52.52 & 0.210 & 3.69 \\
\hline Gnat Lake & Canada & -129.83 & 58.25 & ND & 0.12 \\
\hline Granisle & Canada & -126.16 & 54.95 & 0.051 & 0.37 \\
\hline Highmont & Canada & -120.92 & 50.43 & ND & 0.70 \\
\hline Huckleberry & Canada & -127.18 & 53.68 & 0.082 & 0.77 \\
\hline Hushamu & Canada & -127.86 & 50.68 & 0.170 & 1.46 \\
\hline Island Copper & Canada & -127.48 & 50.60 & 0.171 & 1.55 \\
\hline Jogran & Canada & -84.62 & 47.04 & 1.070 & 0.04 \\
\hline Katie & Canada & -117.33 & 49.13 & ND & ND \\
\hline Kemess North & Canada & -126.76 & 57.06 & 0.203 & 1.24 \\
\hline Kemess South & Canada & -126.75 & 57.01 & 0.200 & 0.55 \\
\hline Kerr & Canada & -130.27 & 56.47 & 0.194 & 1.06 \\
\hline Kinaskan & Canada & -130.24 & 57.65 & 0.205 & 0.59 \\
\hline Krain & Canada & -120.97 & 50.58 & ND & 0.22 \\
\hline Kwanika & Canada & -125.30 & 55.50 & 0.121 & 0.07 \\
\hline Lennac Lake & Canada & -126.33 & 54.75 & 0.078 & ND \\
\hline Lornex & Canada & -121.04 & 50.45 & 0.197 & 2.19 \\
\hline Lorraine & Canada & -125.43 & 55.93 & 0.184 & 0.21 \\
\hline Louise Lake & Canada & -127.68 & 54.78 & ND & 0.15 \\
\hline Maggie & Canada & -121.42 & 50.92 & 0.061 & 0.51 \\
\hline McIntyre & Canada & -81.25 & 48.50 & 2.575 & ND \\
\hline Misty & Canada & -125.51 & 55.92 & 0.172 & ND \\
\hline Morrison & Canada & -126.32 & 55.19 & 0.050 & 1.03 \\
\hline Mt. Milligan & Canada & -124.03 & 55.12 & 0.186 & 0.96 \\
\hline Mt. Polly & Canada & -121.64 & 52.55 & 0.202 & 0.67 \\
\hline O.K. & Canada & -124.65 & 50.05 & 0.036 & 0.34 \\
\hline Ox Lake & Canada & -127.06 & 53.67 & 0.084 & 0.07 \\
\hline Pine & Canada & -126.73 & 57.23 & 0.197 & 0.06 \\
\hline Poison Mountain & Canada & -122.61 & 51.13 & 0.057 & 1.94 \\
\hline Poplar & Canada & -126.99 & 54.02 & 0.074 & 0.87 \\
\hline Primer & Canada & -120.46 & 49.76 & ND & 0.05 \\
\hline Rayfield & Canada & -121.09 & 51.31 & ND & ND \\
\hline Red Bluff & Canada & -131.10 & 56.67 & 0.195 & 0.09 \\
\hline Red Chris & Canada & -129.81 & 57.70 & 0.203 & 1.83 \\
\hline Red Dog & Canada & -127.97 & 50.71 & ND & 0.14 \\
\hline Schaft Creek & Canada & -130.99 & 57.36 & 0.220 & 3.59 \\
\hline Stancop & Canada & -80.75 & 47.97 & 2.633 & ND \\
\hline Sulphurets & Canada & -130.26 & 56.50 & 0.194 & 1.55 \\
\hline Taseko & Canada & -123.40 & 51.10 & 0.085 & 0.08 \\
\hline Tribag & Canada & -84.48 & 47.09 & 1.055 & 0.25 \\
\hline Trojan & Canada & -121.00 & 50.57 & ND & ND \\
\hline Valley & Canada & -121.05 & 50.49 & 0.196 & 3.60 \\
\hline Whipsaw & Canada & -120.76 & 49.29 & ND & ND \\
\hline Whiting Creek/Rusty Zone & Canada & -127.22 & 53.76 & 0.083 & ND \\
\hline Willa & Canada & -117.37 & 49.88 & 0.183 & ND \\
\hline Williams Creek & Canada & -136.69 & 62.34 & ND & ND \\
\hline Andacollo & Chile & -71.42 & -30.25 & 0.112 & 2.43 \\
\hline Angelina & Chile & -69.61 & -24.40 & ND & ND \\
\hline Antucoya & Chile & -69.92 & -22.53 & 0.142 & 2.13 \\
\hline Centinela & Chile & -69.17 & -23.16 & 0.044 & ND \\
\hline Cerro Casale & Chile & -69.23 & -27.78 & 0.014 & 4.50 \\
\hline Cerro Colorado & Chile & -69.26 & -20.04 & 0.052 & 4.92 \\
\hline Chimborazo & Chile & -69.08 & -24.13 & 0.037 & 1.42 \\
\hline Chuquicamata & Chile & -68.90 & -22.28 & 0.033 & 125.96 \\
\hline Collahuasi & Chile & -68.71 & -20.96 & 0.032 & 26.66 \\
\hline Conchi & Chile & -68.74 & -21.95 & 0.036 & 2.49 \\
\hline Copaquire & Chile & -68.89 & -20.90 & 0.035 & ND \\
\hline Dos Hermanos & Chile & -69.72 & -18.29 & 0.013 & ND \\
\hline El Abra & Chile & -68.83 & -21.92 & 0.036 & 8.79 \\
\hline El Loa & Chile & -68.73 & -21.12 & 0.252 & ND \\
\hline El Salvador & Chile & -69.55 & -26.25 & 0.042 & 17.15 \\
\hline El Telagrafo & Chile & -69.08 & -22.99 & 0.029 & 4.04 \\
\hline El Teniente & Chile & -70.46 & -34.09 & 0.005 & 128.53 \\
\hline Escondida & Chile & -69.07 & -24.27 & 0.037 & 85.81 \\
\hline Esperanza & Chile & -69.06 & -22.97 & 0.041 & 7.32 \\
\hline Gaby & Chile & -68.82 & -23.41 & 0.042 & 11.97 \\
\hline Inca de Oro & Chile & -69.87 & -26.77 & 0.063 & ND \\
\hline
\end{tabular}




\begin{tabular}{|c|c|c|c|c|c|}
\hline Deposit & Country & Lon. $^{a}$ & Lat. $^{a}$ & $\begin{array}{l}\text { Age } \\
(\mathrm{Ga})\end{array}$ & $\begin{array}{c}\mathrm{Cu} \\
(\mathrm{Mt}) \\
\end{array}$ \\
\hline La Fortuna & Chile & -69.88 & -28.63 & 0.034 & 5.10 \\
\hline La Planada & Chile & -69.08 & -20.18 & 0.031 & ND \\
\hline Lilian & Chile & -68.75 & -22.67 & 0.275 & ND \\
\hline Lomas Bayas & Chile & -69.51 & -23.45 & 0.058 & 3.43 \\
\hline Los Bronces/Rio Blanco & Chile & -70.27 & -33.13 & 0.005 & 101.06 \\
\hline Los Pelambres - El Pachon, AGTN & Chile & -70.50 & -31.71 & 0.010 & 46.02 \\
\hline Mana & Chile & -69.24 & -22.56 & 0.064 & ND \\
\hline Mansa Mina & Chile & -68.91 & -22.38 & 0.034 & 13.00 \\
\hline Mocha & Chile & -69.28 & -19.81 & 0.058 & ND \\
\hline Opache & Chile & -68.97 & -22.47 & 0.036 & 1.81 \\
\hline Polo Sur & Chile & -69.23 & -23.30 & ND & ND \\
\hline Potrerillos & Chile & -69.42 & -26.49 & 0.037 & 10.05 \\
\hline Puntillas & Chile & -69.83 & -21.92 & 0.132 & ND \\
\hline Quebrada Blanca & Chile & -68.80 & -21.00 & 0.036 & 7.85 \\
\hline Queen Elizabeth & Chile & -68.97 & -19.87 & 0.036 & ND \\
\hline Regalito & Chile & -69.60 & -28.22 & ND & 3.68 \\
\hline Relincho & Chile & -70.30 & -28.50 & 0.064 & 2.50 \\
\hline Rio Frio & Chile & -69.23 & -25.22 & 0.292 & ND \\
\hline Sierra Gorda & Chile & -69.34 & -22.88 & 0.064 & 0.66 \\
\hline Spence & Chile & -69.30 & -22.84 & 0.057 & 4.57 \\
\hline Ticnamar & Chile & -69.45 & -18.59 & ND & 1.00 \\
\hline Toki & Chile & -68.95 & -22.42 & 0.038 & 11.99 \\
\hline Turbio & Chile & -72.15 & -46.03 & ND & ND \\
\hline Ujina & Chile & -68.64 & -20.99 & 0.035 & 9.22 \\
\hline Vizcachitas & Chile & -70.23 & -32.88 & 0.011 & 4.42 \\
\hline Anjishan & China & 119.10 & 32.07 & 0.115 & ND \\
\hline Bainamiao & China & 112.55 & 41.72 & 0.450 & 0.51 \\
\hline Beiya & China & 100.20 & 26.15 & 0.037 & ND \\
\hline Changaan & China & 103.00 & 22.80 & 0.036 & ND \\
\hline Chengmenshan & China & 115.83 & 29.68 & 0.142 & 3.07 \\
\hline Chihu & China & 92.97 & 42.20 & 0.350 & ND \\
\hline Chonjiang & China & 90.00 & 29.58 & 0.014 & 0.50 \\
\hline Dexing & China & 117.73 & 29.02 & 0.173 & 8.38 \\
\hline Dongga & China & 88.38 & 29.38 & 0.014 & 2.73 \\
\hline Duobaoshan & China & 125.69 & 50.17 & 0.260 & 4.37 \\
\hline Duoxiasongduo & China & 97.87 & 31.08 & 0.036 & 0.90 \\
\hline Fengshandong & China & 115.45 & 29.81 & 0.144 & 0.40 \\
\hline Gegongnong & China & 98.50 & 30.47 & 0.044 & 0.51 \\
\hline Habo & China & 102.58 & 22.88 & 0.037 & ND \\
\hline Hengxingcuo & China & 97.35 & 31.48 & 0.042 & ND \\
\hline Jiama & China & 91.75 & 29.69 & 0.015 & ND \\
\hline Jicuo & China & 98.58 & 29.92 & 0.041 & ND \\
\hline Jiru & China & 88.93 & 29.68 & ND & ND \\
\hline Kalatage & China & 91.92 & 42.53 & 0.348 & ND \\
\hline Lakangae & China & 91.48 & 29.58 & 0.014 & ND \\
\hline Linglong & China & 92.85 & 42.17 & 0.350 & ND \\
\hline Machangqing & China & 100.50 & 25.67 & 0.036 & 0.31 \\
\hline Malasongduo & China & 97.95 & 31.00 & 0.037 & 1.03 \\
\hline Mamupu & China & 98.53 & 29.83 & 0.038 & ND \\
\hline Mangzhong & China & 97.80 & 31.20 & 0.038 & 0.25 \\
\hline Nanmu & China & 90.82 & 29.47 & 0.015 & ND \\
\hline Pulang & China & 99.83 & 28.03 & 0.213 & 0.29 \\
\hline Qulong & China & 91.58 & 29.60 & 0.016 & 7.89 \\
\hline Ridanguo & China & 96.77 & 32.15 & 0.042 & ND \\
\hline Saishitang & China & 99.82 & 35.29 & ND & 0.57 \\
\hline Sanchakou & China & 94.83 & 42.35 & 0.350 & ND \\
\hline Seli & China & 98.52 & 30.03 & 0.036 & ND \\
\hline Shaxi & China & 117.27 & 31.18 & 0.148 & ND \\
\hline Tinggong & China & 90.05 & 29.55 & 0.016 & ND \\
\hline Tongchankou & China & 114.80 & 30.17 & 0.136 & 0.42 \\
\hline Tongkuangyu & China & 111.70 & 35.50 & 2.150 & 3.04 \\
\hline Tuwu & China & 92.62 & 42.12 & 0.333 & 2.10 \\
\hline Wunugetushan & China & 117.43 & 49.39 & 0.183 & 2.23 \\
\hline Xiariduo & China & 97.13 & 31.68 & 0.046 & ND \\
\hline Xietongmen & China & 88.57 & 29.52 & 0.162 & 0.95 \\
\hline Xifanping & China & 101.13 & 27.40 & 0.032 & 0.18 \\
\hline Yandong & China & 92.52 & 42.08 & 0.333 & 2.16 \\
\hline Yulong & China & 97.73 & 31.40 & 0.041 & 7.14 \\
\hline Zhanaga & China & 97.73 & 31.25 & 0.039 & 0.30 \\
\hline Zhunuo & China & 87.53 & 29.43 & ND & 1.00 \\
\hline Zijinshan & China & 116.40 & 25.05 & 0.105 & 1.74 \\
\hline Acandi & Colombia & -77.32 & 8.49 & 0.048 & ND \\
\hline California & Colombia & -72.87 & 7.32 & 0.144 & ND \\
\hline Dolores & Colombia & -75.03 & 3.52 & 0.166 & ND \\
\hline Infierno-Chile & Colombia & -75.30 & 4.18 & 0.131 & ND \\
\hline Mocoa & Colombia & -76.67 & 1.24 & 0.166 & 1.05 \\
\hline
\end{tabular}




\begin{tabular}{|c|c|c|c|c|c|}
\hline Deposit & Country & Lon. $^{a}$ & Lat. ${ }^{a}$ & $\begin{array}{l}\text { Age } \\
(\mathrm{Ga})\end{array}$ & $\begin{array}{c}\mathrm{Cu} \\
(\mathrm{Mt}) \\
\end{array}$ \\
\hline Murindo & Colombia & -76.75 & 7.05 & 0.055 & $\mathrm{ND}$ \\
\hline Pantanos-Pegadorcito & Colombia & -76.50 & 6.70 & 0.043 & ND \\
\hline Piedrasentada & Colombia & -76.88 & 2.10 & 0.017 & $\mathrm{ND}$ \\
\hline Nari & Costa Rica & -83.36 & 9.70 & ND & $\mathrm{ND}$ \\
\hline Sukut & Costa Rica & -82.98 & 9.37 & ND & ND \\
\hline Arimao & Cuba & -80.03 & 22.12 & ND & 0.22 \\
\hline El Cobre & Cuba & -75.95 & 20.05 & 0.052 & ND \\
\hline Eureca & Cuba & -76.87 & 20.25 & ND & ND \\
\hline Majagual & Dominican Republic & -70.25 & 18.52 & ND & $\mathrm{ND}$ \\
\hline Balzapamba-Las Guardias & Ecuador & -79.15 & -1.67 & 0.020 & ND \\
\hline Chaso Juan & Ecuador & -79.12 & -1.38 & 0.020 & ND \\
\hline Chaucha & Ecuador & -79.42 & -2.93 & 0.011 & 1.45 \\
\hline Cumay & Ecuador & -78.88 & -4.02 & 0.141 & ND \\
\hline El Hito & Ecuador & -78.95 & -4.25 & 0.154 & $\mathrm{ND}$ \\
\hline Fierro Urcu & Ecuador & -79.33 & -3.58 & 0.010 & 0.11 \\
\hline Gaby-Papa Grande & Ecuador & -79.68 & -3.05 & 0.019 & 0.20 \\
\hline Junin & Ecuador & -78.58 & 0.33 & 0.007 & 2.26 \\
\hline Los Linderos & Ecuador & -80.00 & -4.33 & 0.013 & ND \\
\hline Mirador & Ecuador & -78.90 & -4.65 & 0.154 & 4.98 \\
\hline Panantza & Ecuador & -78.50 & -3.60 & 0.154 & 3.06 \\
\hline Rio Playas & Ecuador & -79.58 & -4.20 & 0.014 & ND \\
\hline San Carlos & Ecuador & -78.42 & -3.65 & 0.154 & 4.25 \\
\hline Telimbela & Ecuador & -79.13 & -1.57 & 0.015 & ND \\
\hline Tumi & Ecuador & -79.25 & -4.25 & 0.154 & $\mathrm{ND}$ \\
\hline Warintza & Ecuador & -78.60 & -3.78 & 0.154 & 0.76 \\
\hline Namosi & Fiji & 178.18 & -18.04 & 0.006 & 4.19 \\
\hline Waivaka & Fiji & 178.18 & -18.11 & 0.006 & 0.17 \\
\hline Kopsa & Finland & 25.23 & 63.77 & 1.850 & ND \\
\hline Fakos & Greece & 25.19 & 39.81 & 0.021 & ND \\
\hline Kassiteres & Greece & 25.79 & 41.02 & 0.024 & ND \\
\hline Maronia & Greece & 25.56 & 40.87 & 0.029 & ND \\
\hline Pontokerassia & Greece & 23.19 & 41.06 & ND & ND \\
\hline Skouries/Fisoka & Greece & 23.70 & 40.47 & 0.019 & 1.99 \\
\hline Douvray & Haiti & -71.78 & 19.55 & ND & 1.44 \\
\hline Terre-Neuve & Haiti & -72.70 & 19.52 & 0.066 & ND \\
\hline Barzsany Mountains & Hungary & 19.05 & 47.91 & 0.014 & ND \\
\hline Recsk & Hungary & 20.10 & 47.93 & 0.036 & 4.62 \\
\hline Malanjkhand & India & 80.72 & 22.02 & 2.490 & 6.62 \\
\hline Baroi & Indonesia & 113.18 & -0.50 & ND & ND \\
\hline Batu Hijau & Indonesia & 116.87 & -8.97 & 0.004 & 7.22 \\
\hline Bulagidun & Indonesia & 121.77 & 0.95 & 0.009 & $\mathrm{ND}$ \\
\hline Ciemas & Indonesia & 106.56 & -7.22 & 0.003 & ND \\
\hline Grasberg & Indonesia & 137.23 & -3.82 & 0.003 & 24.00 \\
\hline Hila & Indonesia & 128.09 & -3.61 & 0.004 & ND \\
\hline Ibu & Indonesia & 109.25 & 0.83 & 0.105 & $\mathrm{ND}$ \\
\hline Kaputusan & Indonesia & 127.58 & -0.52 & ND & 0.25 \\
\hline Mudik & Indonesia & 101.25 & -1.70 & ND & ND \\
\hline Sassak & Indonesia & 119.48 & -3.16 & 0.011 & ND \\
\hline Tangse & Indonesia & 95.95 & 5.03 & 0.011 & 0.90 \\
\hline Tapadaa & Indonesia & 123.22 & 0.52 & 0.004 & 0.23 \\
\hline Tombulilato & Indonesia & 123.40 & 0.35 & 0.003 & 1.81 \\
\hline Ali-Abad & Iran & 53.85 & 31.66 & 0.016 & 0.29 \\
\hline Dallil & Iran & 49.27 & 34.55 & 0.015 & ND \\
\hline Darreh-Zerreshk & Iran & 53.82 & 31.58 & 0.016 & 0.21 \\
\hline Darrehzar & Iran & 55.90 & 29.88 & 0.015 & 0.23 \\
\hline Kale Kafi & Iran & 54.54 & 33.54 & ND & 0.64 \\
\hline Meiduk & Iran & 55.17 & 30.42 & 0.011 & 1.49 \\
\hline Raigan & Iran & 57.23 & 28.90 & 0.012 & $\mathrm{ND}$ \\
\hline Sar Cheshmeh & Iran & 55.86 & 29.95 & 0.013 & 14.40 \\
\hline Sungun & Iran & 46.37 & 38.81 & 0.015 & 4.89 \\
\hline Calabona & Italy & 8.37 & 40.53 & 0.031 & 0.13 \\
\hline Carbonia & Italy & 8.50 & 39.17 & 0.030 & ND \\
\hline Ogliastra & Italy & 9.52 & 39.82 & 0.285 & $\mathrm{ND}$ \\
\hline Aktogai & Kazakhstan & 79.97 & 46.93 & 0.333 & 10.28 \\
\hline Almaly & Kazakhstan & 73.70 & 48.68 & 0.310 & ND \\
\hline Baiskoe & Kazakhstan & 75.60 & 49.16 & 0.310 & ND \\
\hline Bataly & Kazakhstan & 61.42 & 52.88 & 0.301 & ND \\
\hline Benkala & Kazakhstan & 61.75 & 51.77 & 0.312 & 1.30 \\
\hline Besshoky & Kazakhstan & 76.27 & 48.23 & 0.310 & $\mathrm{ND}$ \\
\hline Borly & Kazakhstan & 74.08 & 47.50 & 0.329 & 0.32 \\
\hline Boshchekul & Kazakhstan & 74.18 & 51.82 & 0.479 & 6.70 \\
\hline Chatyrkul & Kazakhstan & 74.26 & 43.62 & 0.401 & 0.54 \\
\hline Karatas & Kazakhstan & 73.63 & 46.65 & 0.310 & 0.13 \\
\hline Kazkyrmyskoye & Kazakhstan & 74.28 & 45.48 & 0.375 & 1.54 \\
\hline Kenkuduk & Kazakhstan & 75.23 & 47.38 & 0.294 & 0.08 \\
\hline Kepcham & Kazakhstan & 75.10 & 47.50 & ND & 0.12 \\
\hline
\end{tabular}




\begin{tabular}{|c|c|c|c|c|c|}
\hline Deposit & Country & Lon. $^{a}$ & Lat. ${ }^{a}$ & $\begin{array}{l}\text { Age } \\
(\mathrm{Ga})\end{array}$ & $\begin{array}{c}\mathrm{Cu} \\
(\mathrm{Mt}) \\
\end{array}$ \\
\hline Koksai & Kazakhstan & 78.43 & 44.45 & 0.422 & 1.76 \\
\hline Koktasdzhal & Kazakhstan & 76.16 & 50.16 & 0.292 & 0.35 \\
\hline Kounrad & Kazakhstan & 74.99 & 46.99 & 0.330 & 3.75 \\
\hline Kyzylkain & Kazakhstan & 84.42 & 47.53 & 0.325 & 1.63 \\
\hline Kyzyltu & Kazakhstan & 72.33 & 51.95 & 0.445 & 0.32 \\
\hline Nurbay & Kazakhstan & 79.33 & 47.92 & 0.300 & ND \\
\hline Nurkazgan & Kazakhstan & 76.73 & 50.03 & 0.410 & 1.73 \\
\hline Ozernoe & Kazakhstan & 75.98 & 49.33 & 0.315 & 0.70 \\
\hline Saryshagan & Kazakhstan & 73.20 & 46.26 & 0.310 & 0.87 \\
\hline Sokurkoiy & Kazakhstan & 74.42 & 46.60 & 0.310 & ND \\
\hline Spiridonovskoe & Kazakhstan & 62.18 & 52.33 & ND & ND \\
\hline Varvarinskoye & Kazakhstan & 62.57 & 53.02 & 0.310 & 0.78 \\
\hline Yubileinoe & Kazakhstan & 58.68 & 48.93 & 0.355 & ND \\
\hline Taldy-Bulak & Kyrgyzstan & 75.65 & 42.70 & 0.420 & 1.46 \\
\hline Phu Kham & Laos & 102.93 & 18.92 & 0.250 & 1.41 \\
\hline Buchim & Macedonia & 22.60 & 41.51 & 0.023 & 0.45 \\
\hline Ilovitza & Macedonia & 22.82 & 41.37 & 0.033 & ND \\
\hline Kadiica & Macedonia & 22.88 & 41.62 & 0.034 & ND \\
\hline Osogovo & Macedonia & 22.87 & 41.80 & 0.023 & ND \\
\hline Bongkud & Malaysia & 116.75 & 6.03 & ND & ND \\
\hline Mamut & Malaysia & 116.47 & 6.03 & 0.007 & 0.94 \\
\hline Mengpur & Malaysia & 102.87 & 3.85 & 0.245 & 0.81 \\
\hline Nungkok & Malaysia & 116.47 & 6.10 & 0.008 & ND \\
\hline Bahuerachi & Mexico & -108.34 & 27.05 & 0.066 & 2.40 \\
\hline Batopilas & Mexico & -107.70 & 27.03 & 0.052 & ND \\
\hline Caballo Blanco & Mexico & -96.45 & 19.68 & 0.004 & ND \\
\hline Cananea & Mexico & -110.32 & 30.95 & 0.059 & 23.13 \\
\hline Cerro Colorado & Mexico & -107.33 & 26.25 & 0.046 & ND \\
\hline Cuatro Hermanos & Mexico & -109.66 & 28.39 & 0.056 & 1.00 \\
\hline Cumobabi & Mexico & -109.96 & 29.87 & 0.059 & 0.18 \\
\hline El Arco & Mexico & -113.57 & 28.03 & 0.164 & 5.26 \\
\hline El Batamote & Mexico & -109.75 & 30.48 & 0.057 & 0.02 \\
\hline Inguaran & Mexico & -101.64 & 18.88 & 0.036 & 0.09 \\
\hline La Caridad & Mexico & -109.56 & 30.32 & 0.054 & 8.14 \\
\hline La Florida & Mexico & -109.73 & 30.38 & 0.052 & 0.45 \\
\hline La Reyna & Mexico & -106.07 & 23.33 & 0.075 & 0.17 \\
\hline La Verde & Mexico & -102.03 & 19.08 & 0.033 & 0.77 \\
\hline Luz del Cobre & Mexico & -109.38 & 28.43 & 0.075 & 0.11 \\
\hline Mariquita & Mexico & -110.42 & 31.06 & 0.063 & 0.48 \\
\hline Milpillas & Mexico & -110.45 & 31.12 & 0.063 & 1.96 \\
\hline Piedras Verdes & Mexico & -109.02 & 27.17 & 0.060 & 1.07 \\
\hline Pilares & Mexico & -109.63 & 30.33 & 0.053 & 1.53 \\
\hline Rodeo & Mexico & -100.85 & 18.62 & 0.075 & ND \\
\hline San Isidro & Mexico & -101.98 & 18.94 & 0.033 & 0.05 \\
\hline Santo Tomas & Mexico & -108.23 & 26.72 & 0.057 & 1.36 \\
\hline Suaqui Verde & Mexico & -109.80 & 28.41 & 0.057 & 0.37 \\
\hline Tameapa & Mexico & -107.35 & 25.67 & 0.054 & 0.13 \\
\hline Tepal & Mexico & -102.92 & 19.12 & 0.075 & 0.20 \\
\hline Tiamaro & Mexico & -100.68 & 19.38 & 0.135 & ND \\
\hline Toliman & Mexico & -92.33 & 15.32 & 0.006 & ND \\
\hline Tuligtic & Mexico & -97.85 & 19.70 & 0.018 & ND \\
\hline Avdartolgoi & Mongolia & 114.84 & 49.67 & 0.154 & ND \\
\hline Bayan-Uul & Mongolia & 104.88 & 46.68 & 0.222 & ND \\
\hline Erdenet & Mongolia & 104.13 & 49.00 & 0.230 & 9.01 \\
\hline Kharmagtai & Mongolia & 106.17 & 44.00 & 0.330 & 0.80 \\
\hline Khongoot & Mongolia & 103.65 & 49.13 & 0.300 & ND \\
\hline Khongor & Mongolia & 102.80 & 43.17 & ND & ND \\
\hline Naran Bulag & Mongolia & 97.78 & 48.58 & 0.260 & ND \\
\hline Nariin Khudag & Mongolia & 108.03 & 44.23 & 0.300 & ND \\
\hline Oyu Tolgoi & Mongolia & 106.87 & 43.00 & 0.367 & 21.00 \\
\hline Oyuut Ulaar Ovoo & Mongolia & 109.44 & 44.57 & ND & ND \\
\hline Saran Uul & Mongolia & 100.60 & 45.78 & 0.327 & ND \\
\hline Shand & Mongolia & 104.22 & 48.78 & ND & ND \\
\hline Shuteen & Mongolia & 107.50 & 44.17 & 0.295 & ND \\
\hline Tsagaan-Suvarga & Mongolia & 108.33 & 43.87 & 0.370 & 1.27 \\
\hline Zos Uul & Mongolia & 98.34 & 48.71 & 0.250 & ND \\
\hline Zost Tolgoi & Mongolia & 98.34 & 48.72 & 0.260 & ND \\
\hline Monywa & Myanmar & 95.08 & 22.25 & 0.016 & 6.29 \\
\hline Shangalon & Myanmar & 95.52 & 23.71 & ND & ND \\
\hline Haib & Namibia & 17.85 & -28.68 & 1.800 & 1.32 \\
\hline Lorelei & Namibia & 16.90 & -28.07 & 1.930 & ND \\
\hline Thames & New Zealand & 175.56 & -37.10 & 0.011 & ND \\
\hline Dasht-e-Kain & Pakistan & 64.50 & 29.55 & 0.021 & 1.05 \\
\hline Koh-i-Dalil & Pakistan & 62.19 & 29.12 & 0.015 & ND \\
\hline Reko Diq & Pakistan & 62.08 & 29.12 & 0.012 & 12.34 \\
\hline Saindak & Pakistan & 61.58 & 29.27 & 0.021 & 1.80 \\
\hline
\end{tabular}




\begin{tabular}{|c|c|c|c|c|c|}
\hline Deposit & Country & Lon. $^{a}$ & Lat. ${ }^{a}$ & $\begin{array}{l}\text { Age } \\
(\mathrm{Ga})\end{array}$ & $\begin{array}{c}\mathrm{Cu} \\
(\mathrm{Mt})\end{array}$ \\
\hline Ziarat Pir Sultan & Pakistan & 64.14 & 29.40 & ND & ND \\
\hline Cerro Azul & Panama & -79.38 & 9.28 & 0.057 & ND \\
\hline Cerro Chorcha & Panama & -82.20 & 8.63 & 0.003 & 0.65 \\
\hline Cerro Colorado & Panama & -81.78 & 8.50 & 0.005 & 14.55 \\
\hline Cerro Quema & Panama & -80.60 & 7.63 & 0.059 & ND \\
\hline Cobre Panama & Panama & -81.50 & 8.43 & 0.034 & 1.77 \\
\hline Petaquilla-Botija & Panama & -80.67 & 8.83 & 0.033 & 6.09 \\
\hline Rio Pito & Panama & -77.57 & 8.63 & 0.049 & ND \\
\hline Arie & Papua New Guinea & 146.88 & -2.02 & 0.015 & 0.53 \\
\hline Esis & Papua New Guinea & 151.72 & -5.17 & 0.025 & ND \\
\hline Frieda River & Papua New Guinea & 141.78 & -4.70 & 0.013 & 5.52 \\
\hline Legusulum & Papua New Guinea & 151.65 & -3.20 & 0.024 & ND \\
\hline Mount Bini & Papua New Guinea & 147.58 & -9.30 & 0.004 & 0.34 \\
\hline Mount Kren & Papua New Guinea & 146.95 & -2.12 & 0.014 & ND \\
\hline Mt. Nakru & Papua New Guinea & 150.47 & -5.98 & 0.024 & ND \\
\hline Ok Tedi & Papua New Guinea & 141.13 & -5.20 & 0.001 & 5.47 \\
\hline Panguna & Papua New Guinea & 155.50 & -6.32 & 0.003 & 6.60 \\
\hline Plesyumi & Papua New Guinea & 150.38 & -5.97 & 0.024 & ND \\
\hline Simuku & Papua New Guinea & 150.02 & -5.72 & 0.024 & ND \\
\hline Star Mt. Futik & Papua New Guinea & 141.33 & -5.07 & 0.004 & 0.35 \\
\hline Star Mt. Nong River & Papua New Guinea & 141.22 & -5.02 & 0.004 & 0.30 \\
\hline Wafi River & Papua New Guinea & 146.45 & -6.88 & 0.009 & 1.76 \\
\hline Wamum & Papua New Guinea & 146.28 & -6.75 & ND & ND \\
\hline Yandera & Papua New Guinea & 145.17 & -5.75 & 0.007 & 1.42 \\
\hline$A \cos$ & Peru & -74.45 & -14.20 & ND & ND \\
\hline Aguila & Peru & -77.90 & -8.56 & 0.005 & 0.29 \\
\hline Almacen & Peru & -75.92 & -13.23 & ND & $\mathrm{ND}$ \\
\hline Alondra & Peru & -73.58 & -15.82 & ND & ND \\
\hline Alto Dorado & Peru & -78.18 & -8.17 & ND & ND \\
\hline Anita de Tibilos & Peru & -75.15 & -14.18 & ND & ND \\
\hline Antapaccay & Peru & -71.35 & -14.96 & 0.036 & 3.49 \\
\hline Canariaco & Peru & -79.28 & -6.08 & 0.015 & 3.69 \\
\hline Cerro Colorado & Peru & -69.90 & -17.68 & 0.059 & 2.22 \\
\hline Cerro Corona & Peru & -78.61 & -6.76 & 0.011 & 0.90 \\
\hline Cerro Negro & Peru & -71.55 & -16.55 & 0.057 & 0.37 \\
\hline Cerro Verde/Santa Rosa & Peru & -71.59 & -16.54 & 0.062 & 12.51 \\
\hline Chalcobamba & Peru & -72.33 & -14.03 & 0.036 & ND \\
\hline Chapi & Peru & -71.36 & -16.77 & ND & ND \\
\hline Chavez N2, Concesion & Peru & -75.42 & -14.23 & ND & ND \\
\hline Constancia & Peru & -71.77 & -14.46 & 0.033 & 1.65 \\
\hline Coroccohuayco & Peru & -71.26 & -14.95 & 0.031 & 2.43 \\
\hline Cotabambas & Peru & -72.35 & -14.18 & 0.036 & 0.78 \\
\hline Cuajone & Peru & -70.71 & -17.05 & 0.051 & 11.25 \\
\hline El Galeno & Peru & -78.32 & -7.02 & 0.017 & 4.09 \\
\hline Eliana & Peru & -75.72 & -13.77 & ND & ND \\
\hline La Granja & Peru & -79.12 & -6.36 & 0.012 & 16.80 \\
\hline La Vega & Peru & -79.28 & -5.70 & ND & ND \\
\hline Laguna Chamis & Peru & -78.58 & -7.12 & ND & ND \\
\hline Lahuani & Peru & -72.99 & -14.46 & 0.036 & ND \\
\hline Los Chancas & Peru & -73.13 & -14.16 & 0.032 & 2.00 \\
\hline Los Pinos & Peru & -76.14 & -12.98 & ND & 0.15 \\
\hline Magistral & Peru & -77.77 & -8.22 & 0.015 & 1.38 \\
\hline Michiquillay & Peru & -78.32 & -7.30 & 0.020 & 4.55 \\
\hline Minas Conga & Peru & -78.36 & -6.92 & 0.016 & 1.92 \\
\hline Paramo & Peru & -79.21 & -5.72 & ND & ND \\
\hline Pashpap & Peru & -78.00 & -8.79 & 0.015 & 0.64 \\
\hline Puquio & Peru & -75.35 & -13.93 & ND & ND \\
\hline Puy-Puy & Peru & -76.08 & -11.48 & 0.007 & ND \\
\hline Quechua & Peru & -71.31 & -14.98 & 0.038 & 2.04 \\
\hline Quellaveco & Peru & -70.62 & -17.11 & 0.054 & 6.33 \\
\hline Rio Blanco & Peru & -79.31 & -4.94 & 0.016 & 7.16 \\
\hline San Salvador de Patillani & Peru & -70.99 & -15.63 & 0.005 & ND \\
\hline Tantahuatay & Peru & -78.67 & -6.73 & 0.013 & 2.96 \\
\hline Tingo & Peru & -75.09 & -13.69 & ND & ND \\
\hline Tintaya & Peru & -71.31 & -14.91 & 0.033 & $\mathrm{ND}$ \\
\hline Toquepala & Peru & -70.61 & -17.25 & 0.057 & 12.76 \\
\hline Toromocho & Peru & -76.13 & -11.60 & 0.008 & 9.92 \\
\hline Amacan & Philippines & 126.15 & 7.33 & 0.010 & 0.33 \\
\hline Atlas & Philippines & 123.83 & 10.37 & 0.108 & 6.36 \\
\hline Aya Aya & Philippines & 122.70 & 9.43 & 0.020 & 0.12 \\
\hline Balak-5 & Philippines & 124.25 & 10.13 & ND & 0.04 \\
\hline Basay & Philippines & 122.68 & 9.49 & 0.030 & 1.15 \\
\hline Batong Buhay & Philippines & 121.06 & 17.34 & 0.007 & 0.52 \\
\hline Boneng Lobo & Philippines & 120.82 & 17.47 & 0.011 & 0.64 \\
\hline Botilao & Philippines & 121.01 & 17.30 & ND & 0.43 \\
\hline Boyongan & Philippines & 125.49 & 9.55 & 0.004 & 1.80 \\
\hline
\end{tabular}




\begin{tabular}{|c|c|c|c|c|c|}
\hline Deposit & Country & Lon. ${ }^{a}$ & Lat. $^{a}$ & $\begin{array}{l}\text { Age } \\
(\mathrm{Ga})\end{array}$ & $\begin{array}{c}\mathrm{Cu} \\
(\mathrm{Mt}) \\
\end{array}$ \\
\hline Cadan & Philippines & 126.17 & 7.55 & 0.010 & $\mathrm{ND}$ \\
\hline Dinkidi & Philippines & 121.29 & 16.32 & 0.023 & 0.47 \\
\hline Dizon & Philippines & 120.20 & 14.97 & 0.003 & 0.67 \\
\hline Far Southeast-Bato Tabio & Philippines & 120.78 & 16.86 & 0.001 & 4.23 \\
\hline Guinaoang-Tirad & Philippines & 120.80 & 16.79 & 0.004 & 1.40 \\
\hline Hale-Mayabo & Philippines & 120.73 & 17.17 & ND & 0.18 \\
\hline Hinobaan & Philippines & 122.57 & 9.75 & 0.018 & 1.59 \\
\hline Ino-Capayang & Philippines & 121.88 & 13.50 & ND & 0.25 \\
\hline Kalamatan & Philippines & 126.07 & 7.59 & ND & 0.09 \\
\hline Kennon SE/Black Mountain & Philippines & 120.60 & 16.37 & 0.002 & 0.23 \\
\hline Kilongolao & Philippines & 120.87 & 17.40 & ND & 0.18 \\
\hline Kingking & Philippines & 125.99 & 7.17 & 0.010 & 2.90 \\
\hline Labangan & Philippines & 123.30 & 7.93 & ND & ND \\
\hline Lingig & Philippines & 126.38 & 8.05 & ND & $\mathrm{ND}$ \\
\hline Lumbay & Philippines & 121.32 & 14.77 & ND & 0.31 \\
\hline Luna-Asiga & Philippines & 125.52 & 9.26 & 0.004 & 0.09 \\
\hline Manag & Philippines & 121.23 & 17.77 & ND & 0.10 \\
\hline Mapula & Philippines & 126.02 & 7.35 & 0.010 & 0.31 \\
\hline Marcopper & Philippines & 122.08 & 13.45 & 0.021 & 2.05 \\
\hline Marian & Philippines & 121.35 & 16.75 & 0.025 & 0.23 \\
\hline Matanlang & Philippines & 122.73 & 14.23 & 0.021 & 0.23 \\
\hline Pisumpan & Philippines & 120.37 & 15.01 & 0.002 & 0.08 \\
\hline Salatan & Philippines & 124.40 & 6.57 & 0.020 & $\mathrm{ND}$ \\
\hline San AntonioPhilex & Philippines & 120.70 & 16.75 & ND & 0.75 \\
\hline San Fabian & Philippines & 120.98 & 16.38 & 0.021 & 0.85 \\
\hline Santo Nirio & Philippines & 120.66 & 16.49 & 0.010 & 0.99 \\
\hline Santo Tomas II & Philippines & 120.62 & 16.26 & 0.002 & 1.68 \\
\hline Sinipsip & Philippines & 120.77 & 16.73 & ND & $\mathrm{ND}$ \\
\hline Sipalay & Philippines & 122.45 & 9.82 & 0.030 & 3.82 \\
\hline Suguibon & Philippines & 122.63 & 9.57 & ND & 0.09 \\
\hline Sulat & Philippines & 125.25 & 11.82 & 0.010 & 0.20 \\
\hline Tagpura-Maangob & Philippines & 126.10 & 7.54 & ND & 0.33 \\
\hline Tampakan & Philippines & 125.05 & 6.48 & 0.004 & 12.00 \\
\hline Tawi-Tawi & Philippines & 120.87 & 16.45 & 0.005 & 0.62 \\
\hline Taysan & Philippines & 121.13 & 13.80 & 0.007 & 1.86 \\
\hline Dolina Bedkowska & Poland & 19.95 & 50.12 & 0.343 & $\mathrm{ND}$ \\
\hline Myszkow & Poland & 19.37 & 50.62 & 0.298 & 0.70 \\
\hline Pilica & Poland & 19.62 & 50.47 & 0.343 & ND \\
\hline Rio Vivi & Puerto Rico & -66.42 & 18.25 & 0.041 & 1.59 \\
\hline Tanama & Puerto Rico & -66.82 & 18.25 & 0.042 & 0.81 \\
\hline Bolcana & Romania & 23.03 & 45.98 & 0.010 & 0.27 \\
\hline Bozovici & Romania & 22.00 & 44.75 & 0.065 & $\mathrm{ND}$ \\
\hline Bucium Tarnita & Romania & 23.20 & 46.23 & 0.015 & 1.68 \\
\hline Ciclova & Romania & 21.78 & 44.98 & 0.065 & ND \\
\hline Cofu & Romania & 22.35 & 45.55 & 0.065 & ND \\
\hline Deva & Romania & 22.89 & 45.88 & 0.013 & ND \\
\hline Moldova Noua & Romania & 21.70 & 44.74 & 0.065 & 1.75 \\
\hline Musariu & Romania & 22.80 & 46.15 & 0.013 & 0.02 \\
\hline Oravita & Romania & 21.82 & 45.10 & 0.065 & ND \\
\hline Rosia Poieni & Romania & 23.17 & 46.33 & 0.009 & 2.37 \\
\hline Rovina & Romania & 22.90 & 46.17 & 0.015 & 0.47 \\
\hline Sasca & Romania & 21.72 & 44.87 & 0.065 & $\mathrm{ND}$ \\
\hline Sopot & Romania & 21.95 & 44.75 & 0.065 & ND \\
\hline Talagiu & Romania & 22.15 & 46.27 & 0.008 & 0.53 \\
\hline Tincova & Romania & 22.23 & 45.57 & 0.065 & $\mathrm{ND}$ \\
\hline Valea Morii & Romania & 22.85 & 46.15 & 0.011 & 0.25 \\
\hline Voia & Romania & 22.97 & 46.06 & 0.011 & ND \\
\hline Aksug & Russia & 96.67 & 53.43 & 0.515 & 2.48 \\
\hline Birgildinskoe & Russia & 61.09 & 55.00 & 0.347 & ND \\
\hline Borgulikan & Russia & 126.62 & 53.75 & 0.123 & $\mathrm{ND}$ \\
\hline Kiyalykh-uzen & Russia & 89.57 & 54.05 & 0.347 & 0.30 \\
\hline Krasnogorskoe & Russia & 157.38 & 53.92 & 0.015 & $\mathrm{ND}$ \\
\hline Kyzyk-Chadr & Russia & 96.78 & 52.93 & ND & ND \\
\hline Lekyntelbei & Russia & 66.33 & 67.87 & 0.315 & ND \\
\hline Lora & Russia & 153.77 & 59.25 & 0.095 & 0.89 \\
\hline Miheevskoye & Russia & 60.82 & 53.23 & 0.345 & 1.58 \\
\hline Nakhodka & Russia & 164.73 & 66.48 & 0.142 & ND \\
\hline Novonikolaevsk & Russia & 60.57 & 53.23 & 0.340 & ND \\
\hline Osennee & Russia & 150.32 & 59.72 & 0.095 & $\mathrm{ND}$ \\
\hline Peschanka & Russia & 164.57 & 66.60 & 0.142 & 4.79 \\
\hline Salavat & Russia & 57.47 & 53.09 & 0.347 & $\mathrm{ND}$ \\
\hline Tominskoe & Russia & 61.27 & 54.93 & 0.347 & 1.40 \\
\hline Tumannoe & Russia & 157.67 & 54.28 & 0.015 & ND \\
\hline Viking & Russia & 152.68 & 58.97 & 0.095 & ND \\
\hline Voznesenskoe & Russia & 59.80 & 54.63 & 0.367 & ND \\
\hline Yaguzak & Russia & 61.13 & 54.96 & 0.347 & ND \\
\hline
\end{tabular}




\begin{tabular}{|c|c|c|c|c|c|}
\hline Deposit & Country & Lon. $^{a}$ & Lat. ${ }^{a}$ & $\begin{array}{l}\text { Age } \\
(\mathrm{Ga}) \\
\end{array}$ & $\begin{array}{c}\mathrm{Cu} \\
(\mathrm{Mt})\end{array}$ \\
\hline Zelenodolskoe & Russia & 61.07 & 54.72 & 0.340 & ND \\
\hline Bor & Serbia & 22.09 & 44.10 & 0.085 & 6.72 \\
\hline Majdanpek & Serbia & 21.95 & 44.38 & 0.084 & 6.00 \\
\hline Rudnitsa & Serbia & 20.72 & 43.23 & 0.014 & ND \\
\hline Veliki Krivelj & Serbia & 22.10 & 44.13 & 0.084 & 3.30 \\
\hline Zlatno & Slovakia & 18.86 & 48.44 & 0.015 & 0.22 \\
\hline Hidden Valley & Solomon Islands & 159.73 & -9.37 & 0.003 & ND \\
\hline Koloula & Solomon Islands & 160.03 & -9.78 & 0.002 & 0.09 \\
\hline Mase & Solomon Islands & 157.52 & -8.08 & 0.004 & ND \\
\hline Mbetilonga & Solomon Islands & 159.91 & -9.53 & 0.031 & ND \\
\hline Poha & Solomon Islands & 159.83 & -9.43 & 0.024 & ND \\
\hline Aitik & Sweden & 20.96 & 67.07 & 1.890 & 5.36 \\
\hline Tallberg & Sweden & 19.77 & 64.99 & 1.886 & 0.12 \\
\hline Vaikijaur & Sweden & 19.81 & 66.53 & 1.880 & ND \\
\hline Chimei & Taiwan & 121.45 & 23.43 & 0.022 & ND \\
\hline Phu Hin Lek Fai & Thailand & 101.67 & 17.50 & 0.230 & ND \\
\hline Phu Lon & Thailand & 102.08 & 18.12 & 0.231 & 1.02 \\
\hline Phu Thong Daeng & Thailand & 101.50 & 17.33 & 0.230 & ND \\
\hline Bakircay & Turkey & 35.44 & 40.93 & 0.038 & 0.40 \\
\hline Berta & Turkey & 41.90 & 41.20 & 0.040 & ND \\
\hline Cevizlidere & Turkey & 39.60 & 39.27 & ND & ND \\
\hline Derekoy & Turkey & 27.32 & 41.91 & 0.071 & 0.53 \\
\hline Gamahane & Turkey & 41.85 & 41.18 & 0.053 & 0.40 \\
\hline Gazelyayla & Turkey & 39.65 & 40.86 & 0.059 & 0.56 \\
\hline Ikiztepe & Turkey & 27.68 & 41.83 & 0.075 & 0.05 \\
\hline Sukrupasa & Turkey & 27.45 & 41.93 & 0.082 & ND \\
\hline Tereoba & Turkey & 27.15 & 39.60 & 0.025 & $\mathrm{ND}$ \\
\hline Uluta & Turkey & 40.88 & 40.45 & 0.059 & 0.38 \\
\hline Ajo & USA & -112.87 & 32.36 & 0.063 & 4.27 \\
\hline Allard & USA & -108.09 & 37.41 & 0.068 & 0.80 \\
\hline Ann Mason & USA & -119.27 & 38.96 & 0.169 & 1.98 \\
\hline Bagdad & USA & -113.21 & 34.59 & 0.072 & 6.40 \\
\hline Baultoff & USA & -141.21 & 62.11 & 0.111 & 0.28 \\
\hline Bear-Lagomarsino & USA & -119.18 & 39.03 & ND & 1.82 \\
\hline Beavertown & USA & -112.08 & 46.34 & 0.100 & 0.25 \\
\hline Bee Creek & USA & -158.40 & 56.52 & 0.004 & ND \\
\hline Bingham & USA & -112.15 & 40.53 & 0.037 & 28.49 \\
\hline Bisbee & USA & -109.90 & 31.43 & 0.180 & 2.27 \\
\hline Bobcat Gulch & USA & -113.99 & 45.36 & ND & 0.27 \\
\hline Bond Creek & USA & -142.73 & 62.22 & ND & 1.50 \\
\hline Butte Valley & USA & -115.15 & 39.80 & ND & ND \\
\hline Caribou Mountain & USA & -111.32 & 43.09 & 0.050 & $\mathrm{ND}$ \\
\hline Carl Creek & USA & -141.58 & 62.03 & ND & 0.02 \\
\hline Casa Grande West & USA & -111.95 & 32.87 & 0.068 & 8.53 \\
\hline Castle Dome & USA & -110.95 & 33.40 & 0.059 & 4.75 \\
\hline Catheart Mt. & USA & -70.22 & 45.54 & 0.443 & 0.10 \\
\hline Chilito & USA & -110.80 & 33.07 & ND & 0.60 \\
\hline Christmas & USA & -110.75 & 33.06 & 0.064 & 0.53 \\
\hline Contact & USA & -114.77 & 41.77 & 0.150 & 0.43 \\
\hline Continental/Butte & USA & -112.51 & 46.02 & 0.061 & 35.13 \\
\hline Copper Basin & USA & -117.04 & 40.61 & 0.086 & 0.15 \\
\hline Copper Basin & USA & -112.58 & 34.50 & 0.064 & 0.91 \\
\hline Copper Canyon & USA & -117.13 & 40.55 & 0.038 & 0.27 \\
\hline Copper Creek & USA & -110.48 & 32.75 & 0.058 & 0.56 \\
\hline Copper Flat & USA & -108.12 & 32.81 & 0.075 & 0.22 \\
\hline Copper King & USA & -105.19 & 41.15 & ND & 0.07 \\
\hline Crescent Peak & USA & -115.13 & 35.48 & 0.073 & ND \\
\hline Elder Creek & USA & -117.08 & 40.69 & 0.038 & ND \\
\hline Ely & USA & -115.00 & 39.26 & 0.110 & 4.62 \\
\hline Esperanza-Sierrita & USA & -111.12 & 31.87 & 0.055 & 6.65 \\
\hline Fish Creek & USA & -117.22 & 40.42 & 0.089 & ND \\
\hline Gibson & USA & -110.94 & 33.33 & 0.061 & 0.08 \\
\hline Glacier Peak & USA & -120.98 & 48.20 & 0.021 & 5.71 \\
\hline Gold Mountain & USA & -121.33 & 48.22 & ND & 0.20 \\
\hline Hannover Mountains & USA & -108.09 & 32.85 & 0.064 & 4.78 \\
\hline Heddleston & USA & -112.36 & 47.03 & 0.046 & 1.09 \\
\hline Helvetia & USA & -110.76 & 31.83 & 0.059 & 5.26 \\
\hline Horsfield & USA & -141.22 & 62.05 & ND & 0.09 \\
\hline Ithaca Peak & USA & -114.15 & 35.37 & 0.073 & 1.25 \\
\hline Johnson Camp & USA & -110.07 & 32.10 & 0.053 & 1.22 \\
\hline Kelsey & USA & -119.48 & 49.00 & 0.179 & 0.80 \\
\hline Kennedy & USA & -117.75 & 40.27 & 0.029 & ND \\
\hline Kijik River & USA & -154.32 & 60.35 & 0.060 & ND \\
\hline Kirwin & USA & -109.31 & 43.88 & 0.040 & 0.90 \\
\hline Lakeshore & USA & -111.90 & 32.52 & 0.066 & 4.71 \\
\hline Lights Creek & USA & -120.85 & 40.20 & 0.100 & 1.08 \\
\hline
\end{tabular}




\begin{tabular}{|c|c|c|c|c|c|}
\hline Deposit & Country & Lon. $^{a}$ & Lat. $^{a}$ & $\begin{array}{l}\text { Age } \\
(\mathrm{Ga})\end{array}$ & $\begin{array}{c}\mathrm{Cu} \\
(\mathrm{Mt}) \\
\end{array}$ \\
\hline Lonesome Pine & USA & -110.90 & 33.34 & 0.061 & 0.07 \\
\hline MacArthur & USA & -119.24 & 39.05 & 0.161 & 0.18 \\
\hline Margaret & USA & -122.08 & 46.36 & 0.017 & 1.88 \\
\hline Margerie Glacier & USA & -137.08 & 59.02 & 0.034 & 0.29 \\
\hline Mazama & USA & -120.38 & 48.61 & 0.089 & 0.49 \\
\hline Miami-Inspiration & USA & -110.74 & 33.42 & 0.064 & 10.02 \\
\hline Middle Fork & USA & -121.37 & 47.50 & 0.025 & 0.38 \\
\hline Mineral Butte & USA & -111.58 & 33.11 & 0.070 & 0.05 \\
\hline Mission-Pima & USA & -111.07 & 31.98 & 0.058 & 4.68 \\
\hline Morenci-Metcalf & USA & -109.36 & 33.10 & 0.056 & 33.90 \\
\hline North Fork Snoqualmie River & USA & -121.64 & 47.68 & 0.018 & 0.87 \\
\hline Nunatak & USA & -136.10 & 58.99 & ND & 0.22 \\
\hline OK & USA & -113.30 & 38.48 & 0.028 & 0.05 \\
\hline Orange Hill & USA & -142.84 & 62.21 & 0.105 & 1.12 \\
\hline Park Premier & USA & -111.38 & 40.63 & 0.033 & ND \\
\hline Pebble Copper & USA & -155.30 & 59.90 & 0.090 & 31.24 \\
\hline Pine Flat & USA & -112.35 & 34.37 & ND & 0.09 \\
\hline Poston Butte & USA & -111.42 & 33.12 & 0.062 & 2.76 \\
\hline Pyramid & USA & -160.67 & 55.63 & 0.006 & 0.59 \\
\hline Ray & USA & -110.98 & 33.16 & 0.069 & 10.76 \\
\hline Red Hills & USA & -111.22 & 33.04 & 0.065 & 0.45 \\
\hline Red Hills & USA & -104.40 & 29.81 & 0.060 & ND \\
\hline Red Hills & USA & -118.43 & 38.62 & 0.105 & ND \\
\hline Red Mountain & USA & -110.72 & 31.49 & 0.060 & 3.59 \\
\hline Resolution & USA & -111.08 & 33.30 & 0.064 & ND \\
\hline Round Top & USA & -157.05 & 64.13 & 0.075 & 0.11 \\
\hline Royston & USA & -117.50 & 38.33 & 0.207 & ND \\
\hline Sacaton & USA & -111.82 & 32.95 & 0.063 & 0.35 \\
\hline Safford & USA & -109.60 & 32.93 & 0.053 & 32.02 \\
\hline Sally Mountain & USA & -70.33 & 45.60 & 0.443 & ND \\
\hline San Manuel-Kalamazoo & USA & -110.68 & 32.70 & 0.068 & 8.34 \\
\hline San Xavier North & USA & -111.02 & 31.97 & 0.056 & 1.12 \\
\hline Sanchez & USA & -109.53 & 32.88 & ND & 0.55 \\
\hline Santa Rita & USA & -108.07 & 32.79 & 0.056 & 14.18 \\
\hline SFS & USA & -118.08 & 38.49 & 0.105 & 0.73 \\
\hline Sheep Mountain & USA & -112.46 & 34.08 & ND & 3.15 \\
\hline Silver Bell & USA & -111.50 & 32.40 & 0.068 & 1.77 \\
\hline Silver Creek & USA & -109.68 & 44.03 & 0.040 & 0.17 \\
\hline Southwest Tintic & USA & -112.13 & 39.86 & 0.036 & 1.57 \\
\hline Squaw Peak & USA & -111.87 & 34.48 & ND & 0.07 \\
\hline Stinkingwater & USA & -109.60 & 44.03 & 0.029 & 0.21 \\
\hline Sullivan & USA & -117.95 & 38.78 & 0.081 & 0.08 \\
\hline Sunnyside & USA & -110.75 & 31.45 & ND & 1.10 \\
\hline Sunrise & USA & -121.50 & 48.01 & 0.028 & 0.22 \\
\hline Superior East & USA & -111.00 & 33.38 & 0.060 & 4.96 \\
\hline Taurus & USA & -141.32 & 63.52 & 0.069 & 2.25 \\
\hline Twin Buttes & USA & -111.04 & 31.89 & 0.058 & 4.72 \\
\hline Two Peaks & USA & -110.46 & 31.77 & 0.074 & 0.09 \\
\hline Tyrone & USA & -108.37 & 32.63 & 0.056 & 5.15 \\
\hline Vekol Hills & USA & -112.09 & 32.58 & ND & 0.53 \\
\hline Venus & USA & -149.33 & 67.63 & 0.390 & ND \\
\hline Yerington & USA & -119.20 & 38.98 & 0.167 & 4.77 \\
\hline Almalyk & Uzbekistan & 69.65 & 40.81 & 0.290 & 23.71 \\
\hline Kyzata & Uzbekistan & 69.71 & 40.80 & 0.290 & 5.95 \\
\hline Sarycheku & Uzbekistan & 69.78 & 40.78 & 0.290 & 1.00 \\
\hline Tekeli & Uzbekistan & 70.13 & 41.10 & 0.295 & ND \\
\hline Samba & Zambia & 27.88 & -12.61 & 1.964 & 0.25 \\
\hline
\end{tabular}

${ }^{a}$ In decimal degrees 
Table 8: Compilation of 25 Australian IOCG deposits drawn from the authors' own knowledge and other disparate sources, building on the Geoscience Australia OZMin database (Sexton, 2011). Ga = billion years; Mt = million tonnes; ND = no data.

\begin{tabular}{|c|c|c|c|c|c|c|c|}
\hline Deposit & State & Lon. ${ }^{a}$ & Lat. $^{a}$ & $\begin{array}{l}\text { Age } \\
(\mathrm{Ga})\end{array}$ & Ore $(\mathrm{Mt})$ & $\begin{array}{l}\mathrm{Cu} \\
(\%)\end{array}$ & $\begin{array}{l}\mathrm{Cu} \\
(\mathrm{Mt})\end{array}$ \\
\hline Warrego & Northern Territory & 133.82 & -19.44 & 1.848 & 4.8 & 2.0 & 0.10 \\
\hline Peko & Northern Territory & 134.28 & -19.68 & 1.848 & 3.2 & 4.0 & 0.13 \\
\hline Ernest Henry & Queensland & 140.70 & -20.44 & 1.525 & 166.0 & 1.1 & 1.83 \\
\hline E1 & Queensland & 140.78 & -20.44 & ND & 38.5 & 0.8 & 0.31 \\
\hline Roseby & Queensland & 140.15 & -20.31 & ND & 128.5 & 0.7 & 0.90 \\
\hline Rocklands & Queensland & 140.36 & -20.68 & ND & 25.0 & 2.0 & 0.50 \\
\hline Kuridala & Queensland & 140.51 & -21.28 & ND & 3.5 & 1.3 & 0.05 \\
\hline Starra (Selwyn) & Queensland & 140.48 & -21.68 & 1.568 & 37.4 & 1.1 & 0.41 \\
\hline Osborne & Queensland & 140.57 & -22.09 & 1.595 & 11.2 & 3.5 & 0.39 \\
\hline Monakoff & Queensland & 140.69 & -20.63 & ND & 1.9 & 1.6 & 0.03 \\
\hline Great Australia & Queensland & 140.69 & -20.63 & ND & 2.1 & 1.5 & 0.03 \\
\hline Eloise & Queensland & 140.98 & -20.95 & 1.522 & 3.5 & 3.1 & 0.11 \\
\hline Mount Elliott & Queensland & 140.98 & -20.95 & 1.513 & 478.3 & 0.5 & 2.39 \\
\hline Greenmount & Queensland & 140.53 & -21.03 & ND & 8.0 & 1.0 & 0.08 \\
\hline Mount Dore & Queensland & 140.53 & -21.03 & 1.508 & 80.0 & 0.6 & 0.48 \\
\hline Merlin & Queensland & 140.49 & -21.66 & ND & 13.0 & 0.2 & 0.03 \\
\hline Kalman & Queensland & 139.97 & -21.05 & 1.475 & 61.0 & 0.3 & 0.18 \\
\hline Mount Cuthbert & Queensland & 139.91 & -19.99 & ND & 8.3 & 1.0 & 0.08 \\
\hline Kaiser Bill & Queensland & 144.04 & -18.53 & ND & 15.6 & 0.9 & 0.14 \\
\hline Olympic Dam & South Australia & 136.89 & -30.44 & 1.598 & 10400.0 & 0.8 & 83.20 \\
\hline Prominent Hill & South Australia & 135.57 & -29.72 & 1.595 & 278.8 & 1.0 & 2.79 \\
\hline Carapeteena & South Australia & 137.50 & -31.21 & 1.595 & 134.0 & 1.5 & 2.01 \\
\hline Hillside & South Australia & 137.87 & -34.54 & 1.595 & 337.0 & 0.6 & 2.02 \\
\hline Kalkaroo & South Australia & 140.53 & -31.73 & 1.592 & 232.5 & 0.5 & 1.16 \\
\hline North Portia & South Australia & 140.46 & -31.43 & 1.595 & 11.4 & 0.9 & 0.10 \\
\hline
\end{tabular}

\section{References}

Abdulin, A. A., H. A. Bespaev, C. Z. Daukeev, L. A. Miroshnichenko, \& E. S. Votsalevskiy (1998). Copper deposits of Kazakhstan. Ministry of Ecology and Natural Resources of the Republic of Kazakhstan, Almaty, Kazakhstan.

Abdullah S., V. M., Chmyriov, K. F. Stazhilo-Alekseev, V. I. Dronov, P. Gannon, B. K. Lubemov, A. K. Kafarskiy, \& E. P. Malyarov (1977). Mineral resources of Afghanistan. Afghan Geological and Mines Survey, Ministry of Mines and Industries, Republic of Afghanistan, Kabul, Afghanistan, 2 edn.

Adenis, A., E. Debayle, \& Y. Ricard (2017). Attenuation tomography of the upper mantle. Geophysical Research Letters, 44, $7715-7724$.

Afonso, J. C., F. Salajegheh, W. Szwillus, J. Ebbing, \& C. Gaina (2019). A global reference model of the lithosphere and upper mantle from joint inversion and analysis of multiple data sets. Geophysical Journal International, 217, 1602-1628.

Ahlness, J. K. \& M. G. Pojar (1983). In situ copper leaching in the United States: Case histories of operations. Tech. rep., U. S. Bureau of Mines, Washington DC, USA.

Ahsan, S. H. \& K. A. Mallick (1999). Geology and genesis of barite deposits of Lasbela and Khuzdar districts, Balochistan, Pakistan. Resource Geology, 49, 105-111.

Ahsan, S. H. \& I. H. Quraishi (1997). Mineral/rock resources of Lasbela and Khuzdar districts, Balochistan, Pakistan. Geological Bulletin of the University of Peshawar, 30, 41-51.

Akande, S. \& M. Zentilli (1984). Geologic, fluid inclusion, and stable isotope studies of the Gays River lead-zinc deposit, Nova Scotia. Economic Geology, 79, 1187-1211.

Amelin, Y., C. Li, \& A. J. Naldrett (1999). Geochronology of the Voisey's Bay intrusion, Labrador, Canada, by precise U-Pb dating of coexisting baddeleyite, zircon, and apatite. Lithos, 47 (1-2), 33-51.

Ameta, S. S. \& B. B. Sharma (2008). Geology metallogeny and exploration of concealed lead-zinc deposit in Sindesar KhurdLathiyakheri area, Rajsamand district, Rajasthan,. Journal of the Geological Society of India, 72, 381-399.

Anderson, B. R., J. B. Gemmell, \& R. F. Berry (2001). The geology of the Nifty copper deposit, Throssell Group, Western Australia: Implications for ore genesis. Economic Geology, 96 (7), 1535-1565.

Anderson, H. E. \& R. R. Parrish (2000). U-Pb geochronological evidence for the geological history of the Belt-Purcell Supergroup, southeastern British Columbia. Geological Association of Canada, Mineral Deposits Division Special Publication, 1, $113-126$. 
Anger, G., H. Nielson, H. Puchelt, \& W. Ricke (1966). Sulfur isotopes in the Rammelsberg ore deposit (Germany). Economic Geology, 61, 511-536.

Anglo American Corp. (1989). Tech. rep., London, UK.

Anonymous (1985). Geological report on exploration for lead-zinc ore, Gorubathan (Mal Khola) block, District - Darjeeling, West Bengal. Unpublished Mineral Exploration Corporation Limited Report. URL mecl.gov. in/Reports/Gorubathan\_F.pdf.

Anvil Mining NL (2003). Tech. rep., Montréal, Canada.

Artemieva, I. M. (2006). Global 1 x 1 thermal model TC1 for the continental lithosphere: Implications for lithosphere secular evolution. Tectonophysics, 416, 245-277.

Ayer, J., Y. Amelin, F. Corfu, S. Kamo, J. Ketchum, K. Kwok, \& N. Trowell (2002). Evolution of the southern Abitibi greenstone belt based on U-Pb geochronology: Autochthonous volcanic construction followed by plutonism, regional deformation and sedimentation. Precambrian Research, 115 (1-4), 63-95.

Ayuso, R. A., K. D. Kelley, D. L. Leach, L. E. Young, J. F. Slack, J. F. Wandless, A. M. Lyon, \& J. L. Dillingham (2004). Origin of the Red Dog Zn-Pb-Ag deposits, Brooks Range, Alaska: Evidence from regional Pb and Sr isotope sources. Economic Geology, 99, 1533-1553.

Bailes, R. J., J. E. Christoffersen, V. F. Escandon, \& G. Peatfield (2001). Sediment-hosted deposits of the Boléo copper-cobalt-zinc district, Baja California Sur, Mexico. Society of Economic Geologists Special Publication, 8, 291-306.

Balla, J. C. (1982). Geology of the Troy deposit, Northwestern Montana. In: Proceedings of the Denver Regional Exploration Geologists Society Symposium, The genesis of Rocky Mountain ore deposits: Changes with time and tectonics, p. 29. Denver, USA.

Barley, M. E. \& D. I. Groves (1990). Deciphering the tectonic evolution of Archaean greenstone belts: The importance of contrasting histories to the distribution of mineralization in the Yilgarn Craton, Western Australia. Precambrian Research, 46 (1-2), 3-20.

Barnes, S.-J., J.-F. Couture, E. W. Sawyer, \& C. Bouchaib (1993). Nickel-copper occurrences in the Belleterre-Angliers Belt of the Pontiac Subprovince and the use of $\mathrm{Cu}-\mathrm{Pd}$ ratios in interpreting platinum-group element distributions. Economic Geology, 88 (6), 1402-1418.

Barrie, C. T., F. Corfu, P. Davis, A. C. Coutts, \& D. MacEachern (1999). Geochemistry of the Dundonald komatiite-basalt suite and genesis of Dundeal Ni deposit, Abitibi subprovince, Canada. Economic Geology, 94 (6), 845-866.

Barrie, C. T. \& A. J. Naldrett (1989). Geology and tectonic setting of the Montcalm gabbroic complex and Ni-Cu deposit, Western Abitibi subprovince, Ontario, Canada. In: Proceedings of the 5th Magmatic Sulphides Conference, pp. 151-163.

Basuki, N. I., B. E. Taylor, \& E. T. C. Spooner (2008). Sulfur isotope evidence for thermochemical reduction of dissolved sulfate in Mississippi Valley-type zinc-lead mineralization, Bongara area, northern Peru. Economic Geology, 103 (4), 783-799.

Behn, M. D., G. Hirth, \& J. R. Elsenbeck (2009). Implications of grain size evolution on the seismic structure of the oceanic upper mantle. Earth and Planetary Science Letters, 282, 178-189.

Belperio, A., W. Priss, M. Fairclough, C. Gatehouse, J. Gum, J. Hough, \& A. Burtt (1998). Tectonic and metallogenic framework of the Cambrian Stansbury Basin - Kanmantoo Trough, South Australia. Australian Geological Survey Organisation Journal of Australian Geology and Geophysics, 17, 183-200.

Bhattacharya, H. N. (2004). Analysis of the sedimentary succession hosting the Paleoproterozoic Zawar zinc-lead sulphide ore deposit, Rajasthan, India. In: Sediment-hosted lead-zinc sulphide deposits - attributes and models of some major deposits in India, Australia and Canada (edited by M. Deb \& W. D. Goodfellow), pp. 350-361. New Delhi, Narosa Publishing House.

Bhawan, B. A. (2006). Geological report on exploration for lead-zinc, Bajta (Central) block phase-I, District Ajmer, Rajasthan. Unpublished Mineral Exploration Corporation Limited Report. URL mecl.gov. in/Reports/BajtaCentralPh1 \_F.pdf.

Bird, P., Z. Liu, \& W. K. Rucker (2008). Stresses that drive the plates from below: Definitions, computational path, model optimization, and error analysis. Journal of Geophysical Research: Solid Earth, 113 (B11406).

Bjørlykke, A., S. Olerud, \& J. S. Sandstad (1985). Metallogeny of Finnmark, North Norway. Norges Geologiske Undersøkelse Bulletin, 403, 183-196.

Blakeman, R. J., J. H. Ashton, A. J. Boyce, A. E. Fallick, \& M. J. Russell (2002). Timing of interplay between hydrothermal and surface fluids in the Navan $\mathrm{Zn}-\mathrm{Pb}$ orebody, Ireland: Evidence from metal distribution trends, mineral textures, and $\delta 34 \mathrm{~S}$ analyses. Economic Geology, 97 (1), 73-91.

Bodon, S. B. (1998). Paragenetic relationships and their implications for ore genesis at the Cannington Ag-Pb-Zn deposit Mount Isa Inlier, Queensland, Australia. Economic Geology, 93, 1463-1488.

Borodaev, Y. S., N. N. Mozgova, S. V. Ezhov, S. M. Gandhi, \& S. Mookherjee (2002). Textural and mineralogical features of metamorphosed ores from the Rangpo polymetallic deposit (Sikkim, India). Moscow University Geology Bulletin, 57 (3), 3953. 
Both, R. A. (1990). Kanmantoo Trough - Geology and mineral deposits. Australasian Institute of Mining and Metallurgy Monograph, 14, 1195-1203.

Both, R. A. \& J. W. Smith (1975). A sulfur isotope study of base metal mineralization in the Willyama Complex, western New South Wales, Australia. Economic Geology, 70, 308-318.

Bouabdellah, M., L. Fontboté, Y. Haeberlin, L. Llinares, D. Leach, \& J. Spangenberg (1999). Zoned sulphur isotope signatures at the Mississippi Valley-type Touissit Bou Becker, El Abed district, Morocco, Algeria - Evidence for thermochemical sulphate reduction and mixing of sulphur sources. In: Mineral deposits: Processes to processing, pp. 821-824. Balkema, Amsterdam.

Bouabdellah, M., D. F. Sangster, D. L. Leach, A. C. Brown, C. A. Johnson, \& P. Emsbo (2012). Genesis of the Touissit-Bou Beker Mississippi valley-type district (Morocco-Algeria) and its relationship to the Africa-Europe collision. Economic Geology, 107, $117-146$.

Bouhifd, M. A., D. Andrault, G. Fiquet, \& P. Richet (1996). Thermal expansion of forsterite up to the melting point. Geophysical Research Letters, 23 (10), 1143-1146.

Brannon, J. C., F. A. Podosek, \& S. C. Cole (1996). Radiometric dating of Mississippi Valley-type ore deposits. Society of Economic Geologists Special Publication, 4, 536-545.

Brannon, J. C., F. A. Podosek, \& R. K. McLimans (1992). Alleghenian age of the Upper Mississippi Valley zinc-lead deposit determined by Rb-Sr dating of sphalerite. Nature, 356 (6369), 509-511.

Brenner, T. L., N. A. Teixeira, J. A. L. Oliveira, N. D. Franke, \& J. F. H. Thompson (1990). The O'Toole nickel deposit, Morro do Ferro greenstone belt, Brazil. Economic Geology, 85 (5), 904-920.

British Columbia Geological Survey (2020a). URL minfile.gov.bc.ca/Summary.aspx?minfilno=082LSE012.

British Columbia Geological Survey (2020b). URL minfile.gov.bc.ca/Summary.aspx?minfilno=094F $\% 20 \% 20008$.

British Columbia Geological Survey (2020c). URL minfile.gov.bc.ca/Summary.aspx?minfilno=082M $\% 20 \backslash \% 20086$.

British Columbia Geological Survey (2020d). URL minfile.gov.bc .ca/Summary . aspx?minfilno=094K++066.

British Columbia Geological Survey (2020e). URL minfile.gov .bc.ca/Summary .aspx?minfilno=082LNE007.

British Columbia Geological Survey (2020f). URL minfile.gov.bc.ca/Summary .aspx?minfilno=082GNW009.

British Columbia Geological Survey (2020g). URL minfile.gov.bc.ca/Summary .aspx?minfilno=082M++001.

British Columbia Geological Survey (2020h). URL minfile.gov.bc.ca/Summary.aspx?minfilno=082M $\% 20 \% 20084$.

British Columbia Geological Survey (2020i). URL minfile.gov.bc.ca/Summary .aspx?minfilno=082FNE052.

Brizzi, A. S. \& F. A. C. Roberto (1988). Jazida de cobre de Pedra Verde - Viçosa do Ceará, Ceará. In: Principais Depósitos Minerais do Brasil - Metais Básicos Não Ferrosos, Ouro e Aluminio (edited by C. Schobbenhaus \& C. Coelho), vol. 3, pp. 71-80. DNPM and Companhia Vale do Rio Doce, Brasilia, Brazil.

Broadbent, G. C., R. E. Myers, \& J. V. Wright (1998). Geology and origin of shale-hosted Zn-Pb-Ag mineralization at the Century deposit northwest Queensland, Australia. Economic Geology, 93, 1264-1294.

Buschendorf, F., H. Nielsen, H. Puchelt, \& W. Ricke (1963). Schwefel-Isotopen-Untersuchungen am Pyrit-Sphalerit-Baryt-Lager Meggen/Lenne (Deutschland) und an verschiedenen Devon-Evaporiten. Geochimica et Cosmochimica Acta, 27, 501-523.

Campbell, F. A., V. G. Ethier, H. R. Krouse, \& R. A. Both (1978). Isotopic composition of sulfur in the Sullivan orebody, British Columbia. Economic Geology, 73, 246-268.

Camus, F. (1986). Los yacimientos estratoligados de Cu, Zn-Pb y Ag de Chile. In: Geologia y recursos minerales de Chile (edited by J. Frutos, R. Oyarzun, \& M. Pincheira), vol. 2, pp. 547-635. Editorial de la Universidad de Concepción, Concepción, Chile.

Canerpa-Amax (1974). Project Report 536. Tech. rep.

Carr, G. R. (1984). Primary geochemical and mineralogical dispersion in the vicinity of the Lady Loretta Zn-Pb-Ag deposit northwest Queensland. Journal of Geochemical Exploration, 22, 217-238.

Carr, G. R., G. J. Denton, M. J. Korsch, J. M. Parr, A. S. Andrew, D. Whitford, L. A. I. Wyborn, \& S. S. Sun (2001). User friendly isotope technologies in mineral exploration: Northern Australian Proterozoic basins. Australian Mineral Industry Research Association Final Report P480, 313.

Carr, G. R. \& J. W. Smith (1977). A comparative isotopic study of the Lady Loretta zinc-lead-silver deposit. Mineralium Deposita, $12,105-110$.

Celli, N. L., S. Lebedev, A. J. Schaeffer, \& C. Gaina (2020a). African cratonic lithosphere carved by mantle plumes. Nature Communications, 11 (92). 
Celli, N. L., S. Lebedev, A. J. Schaeffer, M. Ravenna, \& C. Gaina (2020b). The upper mantle beneath the South Atlantic Ocean, South America and Africa from waveform tomography with massive data sets. Geophysical Journal International, 221, 178-204.

Chapman, L. H. (2004). Geology and mineralization styles of the George Fisher Zn-Pb-Ag deposit, Mt Isa. Economic Geology, 99, $233-255$.

Charef, A., A. Guedes, F. Noronha, \& M. Sousa (2009). Fossil and present-day hydrothermal fluids from North Tunisia: An example of a dynamic fluid evolution. Cadernos Laboratorio Xeoloóxico de Laxe Corunña, 34, 43-58.

Charef, A. \& S. M. F. Sheppard (1987). Pb-Zn mineralization associated with diapirism: Fluid inclusion and stable isotope (H, C, O) evidence for the origin and evolution of the fluids at Fedj-el-Adoum, Tunisia. Chemical Geology, 61, 113-134.

Christensen, J. N., A. N. Halliday, J. R. Vearncombe, \& S. E. Kesler (1995). Testing models of large-scale crustal fluid flow using direct dating of sulfides: Rb-Sr evidence for early dewatering and formation of Mississippi Valley-type deposits, Canning Basin, Australia. Economic Geology, 90, 877-884.

Christensen, N. I. \& W. D. Mooney (1995). Seismic velocity structure and composition of the continental crust: A global view. Journal of Geophysical Research, 100 (B7), 9761-9788.

Clark, D. J. (2001). Geology and genesis of the Mammoth Cu deposit Mount Isa inlier, Australia. Ph.D. thesis, University of Tasmania.

Connor, J. I. R. M. M. D., A. G. (1990). Dugald River zinc-lead deposit. Australasian Institute of Mining and Metallurgy Monograph, $14,949-953$.

Cook, F. A., A. J. Van Der Velden, K. W. Hall, \& B. J. Roberts (1999). Frozen subduction in Canada's Northwest Territories: Lithoprobe deep lithospheric reflection profiling of the western Canadian Shield. Tectonics, 18 (1), 1-24.

Cooke, D. R., S. W. Bull, S. Donovan, \& J. R. Rogers (1998). K-metasomatism and base metal depletion in volcanic rocks from the McArthur Basin, Northern Territory — Implications for base metal mineralization. Economic Geology, 93, 1237-1263.

Coomer, P. G. \& B. W. Robinson (1976). Sulphur and sulphate-oxygen isotopes and the origin of the Silvermines deposits, Ireland. Mineralium Deposita, 11 (2), 155-169.

Cornell, D., Å. Pettersson, M. Whitehouse, \& A. Scherstén (2009). A new chronostratigraphic paradigm for the age and tectonic history of the Mesoproterozoic Bushmanland ore district, South Africa. Economic Geology, 104, 385-404.

Cox, D. P., R. Carrasco, O. Andre-Ramos, A. Hinojosa-Velasco, \& K. R. Long (1992). Copper in sedimentary rocks. U.S. Geological Survey Bulletin, 1975, 95-108.

Cox, D. P., D. A. Lindsey, D. A. Singer, B. C. Moring, \& M. F. Diggles (2007). Sediment-hosted copper deposits of the world: Deposit models and database. U.S. Geological Survey Open-File Report, 03-107.

Crew Development Corp. (1998). Annual Report. Tech. rep., Vancouver, Canada.

Cumming, G. L. \& D. Krstic (1991). Geochronology at the Namew Lake Ni-Cu deposit, Flin Flon area, Manitoba, Canada: A $\mathrm{Pb} / \mathrm{Pb}$ study of whole rocks and ore minerals. Canadian Journal of Earth Sciences, 28 (9), 1328-1339.

Czarnota, K., G. G. Roberts, N. J. White, \& S. Fishwick (2014). Spatial and temporal patterns of Australian dynamic topography from river profile modeling. Journal of Geophysical Research: Solid Earth, 119, 1384-1424.

Daitx, E. C. (1996). Origem e evolução dos depósitos sulfetados tipo-Perau (Pb-Zn-Ag), com base nas jazidas Canoas e Perau (Vale do Ribeira, Paraná). Ph.D. thesis, Universidade Estadual Paulista, Instituto de Geociências e Ciências Exatas. 453.

Dalton, C. A., G. Ekström, \& A. M. Dziewonski (2009). Global seismological shear velocity and attenuation: A comparison with experimental observations. Earth and Planetary Science Letters, 284, 65-75.

Dannberg, J., Z. Eilon, U. Faul, R. Gassmöller, P. Moulik, \& R. Myhill (2017). The importance of grain size to mantle dynamics and seismological observations. Geochemistry, Geophysics, Geosystems, 18, 3034-3061.

Davidson, G. J. \& G. H. Dixon (1992). Two sulphur isotope provinces deduced from ores in the Mount Isa Eastern Succession, Australia. Mineralium Deposita, 27, 30-41.

Davies, D. R., N. Rawlinson, G. Iaffaldano, \& I. H. Campbell (2015). Lithospheric controls on magma composition along Earth's longest continental hotspot track. Nature, 525, 511-514.

Davis, D. \& R. Sutcliffe (1985). U-Pb ages from the Nipigon Plate and northern Lake Superior. Geological Society of America Bulletin, 96 (12), 1572-1579.

Dayton, S. H. \& M. P. Sassos (1985). Carajás: A new district, new mines and a big future. Engineering and Mining Journal, $186(11), 24-46$. 
Deb, M. (1986). Sulfur and carbon isotope compositions in the stratiform Zn-Pb-Cu sulfide deposits of the Rajpura-Dariba belt, Rajasthan, NW India: A model of ore genesis. Mineralium Deposita, 21, 313-321.

Deb, M. \& T. Pal (2004). Geology and genesis of the base metal sulphide deposits of the Dariba-Rajpura-Bethumni belt, Rajasthan, India, in light of basin evolution. In: Sediment-hosted lead-zinc sulphide deposits - Attributes and models of some major deposits in India, Australia and Canada (edited by M. Deb \& W. Goodfellow), pp. 304-327. Narosa Publishing House, New Delhi.

Deb, M. \& S. C. Sarkar (1990). Proterozoic tectonic evolution and metallogenesis in the Aravalli-Delhi orogenic complex, northwestern India. Precambrian Research, 46, 115-137.

Deb, M. \& R. I. Thorpe (2004). Geochronological constraints in the Precambrian geology of Rajasthan and their metallogenic implications. In: Sediment-hosted lead-zinc sulphide deposits - Attributes and models of some major deposits in India, Australia and Canada (edited by M. Deb \& W. Goodfellow), pp. 246-263. Narosa Publishing House, New Delhi.

Deb, M., R. I. Thorpe, G. L. Cumming, \& A. Wagner (1989). Age, source and stratigraphic implications of Pb isotope data for conformable, sediment-hosted, base-metal deposits in the Proterozoic Aravalli-Delhi orogenic belt, northwestern India. Precambrian Research, 43, 1-22.

Debayle, E., F. Dubuffet, \& S. Durand (2016). An automatically updated S-wave model of the upper mantle and the depth extent of azimuthal anisotropy. Geophysical Research Letters, 43, 674-682.

Deblond, A. \& L. Tack (1999). Main characteristics and review of mineral resources of the Kabanga-Musongati mafic-ultramafic alignment in Burundi. Journal of African Earth Sciences, 29 (2), 313-328.

Delta Gold (2000). Technical review of Ngamiland JV Botswana. Tech. rep., Delta Gold NL, Sydney, Australia.

Denaro, T. J., I. W. Withnall, J. H. C. Bain, \& D. E. Mackenzie (1997). Mineral resource assessment, Georgetown-Croydon area. Queensland Minerals and Energy Review Series, p. 228.

Dewing, K., R. J. Sharp, \& E. Turner (2007). Synopsis of the Polaris Zn-Pb district, Canadian Arctic Islands, Nunavut. In: Mineral deposits of Canada: A synthesis of major deposit types, district metallogeny, the evolution of geological provinces, and exploration methods (edited by W. D. Goodfellow), pp. 655-672. Geological Association of Canada, Mineral Deposits Division, Special Publication No. 5.

Ding, T. \& S. Y. Jiang (2000). Stable isotope study of the Langshan polymetallic mineral district, Inner Mongolia, China. Resource Geology, 50, 25-38.

Disnar, J. R. (1996). A comparison of mineralization histories for two MVT deposits, Trèves and Les Malines (Causses Basin, France), based on the geochemistry of associated organic matter. Ore Geology Reviews, 11, 133-156.

Dixon, G. \& G. J. Davidson (1996). Stable isotope evidence for thermochemical sulfate reduction in the Dugald River (Australia) strata-bound shale-hosted zinc-lead deposit. Chemical Geology, 129, 227-246.

Dodin, D. A., N. M. Chernyshov, \& B. A. Yatskevich (2000). Platinum Metal Deposits of Russia. Ministry of Natural Resources of the Russian Federation and Nauka, Moscow, Russia.

Dora, O. O. (1977). The strata-bound lead-zinc deposits from Menderes Massif in Bayindir (West-Anatolia). In: Time- and strata-bound ore deposits (edited by D. Klemm \& H. Schneider), pp. 220-231. Springer, Berlin.

Drummond, A. D. (1996). Corocoro oxide copper deposit. Tech. rep., Reward Mining Corporation and George Resource Company Ltd., Vancouver, Canada.

Duan, S. G., C. J. Xue, C. H. Yan, G. Y. Liu, Y. W. Song, \& D. H. Zhang (2008). Comparison of Pb-Zn metallogenic characteristics between northern and southern margins of North China landmass. Mineral Deposits, 27, 383-398.

Durieux, C. G. \& A. C. Brown (2001). Diagenetic stratiform copper-silver mineralization, Salta district, northwestern Argentina. In: Mineral Deposits at the Beginning of the 21 ${ }^{\text {st }}$ Century, Proceedings of the Joint Sixth Biennial SGA-SEG Meeting, Kraków, Poland, 26-29 August 2001 (edited by A. Piestrzynski), pp. 227-230. A. A. Balkema, Lisse, Netherlands.

Eckstrand, O. (1995). Magmatic nickel-copper-platinum group elements. In: Geology of Canadian Mineral Deposit Types, vol. 8, pp. 583-605. Geological Society of America, Boulder, CO, USA.

Eckstrand, O. R. \& L. J. Hulbert (2007). Magmatic nickel-copper-platinium group element deposits. Geological Association of Canada Special Publication, 5, 205-222.

Ehya, F., M. Lotfi, \& I. Rasa (2010). Emarat carbonate-hosted Zn-Pb deposit, Markazi Province, Iran: A geological, mineralogical and isotopic (S, Pb) study. Journal of Asian Earth Sciences, 37 (2), 186-194.

Eldridge, C. S., N. William, \& J. L. Walshe (1993). Sulfur isotope variability in sediment-hosted massive sulfide deposits as determined using the ion microprobe SHRIMP II: A study of the HYC deposit at McArthur River, Northern Territory, Australia. Economic Geology, 88, 1-26. 
Escande, B. \& C. Majesté-Menjoulas (1985). Age dévonien moyen à supeérieur de la succession calcaréo-détritique à minéralisations stratiformes de la région d'Arrens (Hautes-Pyrénées). Bulletin de la Société Géologique de France, 1, 277-279.

Evins, M., A. R. Wilde, D. R. W. Foster, S. W. McKnight, \& T. G. Blenkinsop (2007). Significance of monazite EPMA ages from the Quamby Conglomerate, Queensland. Australian Journal of Earth Sciences, 54, 19-26.

Fallara, F., M. M. Savard, \& S. Paradis (1998). A structural, petrographic, and geochemical study of the Jubilee Zn-Pb deposit, Nova Scotia, Canada and a new metallogenic model. Economic Geology, 93, 757-778.

Fernández, F. G., R. A. Both, J. Mangas, \& A. Arribas (2000). Metallogenesis of Zn-Pb carbonate-hosted mineralization in the southeastern region of the Picos de Europa (central northern Spain) province: Geologic, fluid inclusion, and stable isotope studies. Economic Geology, 95, 19-40.

Fichtner, A., H. Igel, H.-P. Bunge, \& B. L. N. Kennett (2009a). Simulation and inversion of seismic wave propagation on continental scales based on a spectral-element method. Journal of Numerical Analysis, Industrial and Applied Mathematics, 4 (1-2), 11-22.

Fichtner, A., B. L. N. Kennett, H. Igel, \& H.-P. Bunge (2009b). Full seismic waveform tomography for upper-mantle structure in the Australasian region using adjoint methods. Geophysical Journal International, 179, 1703-1725.

Fichtner, A., B. L. N. Kennett, H. Igel, \& H.-P. Bunge (2010). Full waveform tomography for radially anisotropic structure: New insights into present and past states of the Australasian upper mantle. Earth and Planetary Science Letters, 290, 270-280.

Fishwick, S., M. Heintz, B. L. N. Kennett, A. M. Reading, \& K. Yoshizawa (2008). Steps in lithospheric thickness within eastern Australia, evidence from surface wave tomography. Tectonics, 27 (4009).

Fishwick, S. \& N. Rawlinson (2012). 3-D structure of the Australian lithosphere from evolving seismic datasets. Australian Journal of Earth Sciences, 59, 809-826.

Fletcher, I. R. \& R. M. Farquhar (1977). Lead isotopes in the Grenville and adjacent Palaeozoic formations. Canadian Journal of Earth Sciences, 14, 56-66.

Fletcher, I. R. \& R. M. Farquhar (1982). Lead isotopic compositions of Balmat ores and their genetic implications. Economic Geology, 77, 464-473.

Fontbote, L. \& H. Gorzawski (1990). Genesis of the Mississippi Valley-type Zn-Pb deposit of San Vicente, central Peru: Geologic and isotopic (Sr, O, C, S, Pb) evidence. Economic Geology, 85 (7), 1402-1437.

Forrestal, J. (1990). Mount Isa and Hilton silver-lead-zinc deposits. Australasian Institute of Mining and Metallurgy Monograph, 14, 927-934.

Forsyth, D. W. (1992). Geophysical constraints on mantle flow and melt generation beneath mid-ocean ridges. Geophysical Monograph, 71, 1-65.

Franklin, J. M., H. L. Gibson, I. R. Jonasson, \& A. G. Galley (2005). Volcanogenic massive sulfide deposits. Economic Geology 100th Anniversary Volume.

Frick, L. R., D. D. Lambert, \& D. M. Hoatson (2001). Re-Os dating of the Radio Hill Ni-Cu deposit, west Pilbara Craton, Western Australia. Australian Journal of Earth Sciences, 48 (1), 43-47.

Fu, C., J. Wang, R. M. Peng, J. J. Liu, Z. J. Liu, \& Z. M. Liu (2010). Features of sulfur isotope of the Jiashengpan lead-zinc-sulfur deposit in inner Mongolia and its genesis significance. Geoscience, 24, 34-41.

Gardner, H. D. \& I. Hutcheon (1985). Geochemistry, mineralogy, and geology of the Jason Pb-Zn deposits, Macmillan Pass, Yukon, Canada. Economic Geology, 80, 1257-1276.

Gauert, C. D. (2005). Stratiform coticule-barite-sulphide horizons in the sediment-hosted Tsongoari-Omupokko Pb-Cu-Ba-Zn-Ag prospects, Kaokoland, Namibia. South African Journal of Geology, 108, 87-118.

Gemmell, J. B., H. Zantop, \& L. D. Meinert (1992). Genesis of the Aguilar zinc-lead-silver deposit, Argentina: Contact metasomatic vs. sedimentary exhalative. Economic Geology, 87, 2085-2112.

Gencor (1995). Technical review of Ngamiland JV Botswana, Geological Memorandum No. 22, Vol. 1. Tech. rep., Gencor Mineral Resources Target Generation Unit, Johannesburg, South Africa.

Geological Survey of India (1994). Detailed information on copper-lead-zinc ores in Rajasthan-Gujarat (India). Geological Survey of India, p. 168.

Geological Survey of Queensland (2020). URL qdexdata.dnrme.qld.gov.au.

Geological Survey of South Australia (2020). South Australian Resources Information Gateway Selected Publications. URL sarigbasis.pir.sa.gov.au/WebtopEw/ws/samref/sarig1. 
Ghazban, F., R. H. McNutt, \& H. P. Schwarcz (1994). Genesis of sediment-hosted Zn-Pb-Ba deposits in the Irankuh district, Esfahan area, west-central Iran. Economic Geology, 89 (6), 1262-1278.

Ghosh, A. K., R. I. Thorpe, \& C. K. Chakrabarti (2005). Interpretation of Pb and S isotope data for the Ganesh Himal metamorphosed stratiform Zn-Pb deposit, central Nepal Himalaya. Journal of the Geological Society of India, 65, 725-737.

Gilg, H. A., M. Boni, G. Balassone, C. R. Allen, D. Banks, \& F. Moore (2006). Marble-hosted sulfide ores in the Angouran $\mathrm{Zn}-(\mathrm{Pb}-\mathrm{Ag})$ deposit, NW Iran: Interaction of sedimentary brines with a metamorphic core complex. Mineralium Deposita, $41(1)$.

Glencore (2020). URL www.glencore.com.au/en/who-we-are/metals-and-minerals/Pages/zinc.aspx.

Goodfellow, W. D. (2007). Base metal metallogeny of the Selwyn Basin, Canada. Geological Association of Canada, Mineral Deposits Division Special Publication, 5, 553-579.

Gourlay, A. W. (2003). Independent technical review of the Coates Lake copper deposit, Nahanni mining district, western Northwest Territories. Tech. rep., CRS Copper Resources Corp. and First Trimark Ventures Inc., Vancouver, Canada.

Groenewald, P. B., M. G. M. Painter, I. R. Roberts, M. McCabe, \& A. Fox (2009). East Yilgarn geoscience database, 1:100,000 geology Menzies to Norseman — An explanatory note. Tech. Rep. 78, Geological Survey of Western Australia.

Grose, C. J. \& J. C. Afonso (2013). Comprehensive plate models for the thermal evolution of oceanic lithosphere. Geochemistry, Geophysics, Geosystems, 14 (9).

Groves, I. M., D. I. Groves, F. Bierlein, J. Broome, \& J. Penhall (2008). Recognition of the hydrothermal feeder to the structurally inverted, giant Broken Hill deposit, New South Wales, Australia. Economic Geology, 103, 1389-1394.

Gu, L., K. Zaw, W. Hu, K. Zhang, et al. (2007). Distinctive features of Late Palaeozoic massive sulphide deposits in South China. Ore Geology Reviews, 31 (1), 107-138.

Gunnesch, K. A., A. Baumann, \& M. Gunnesch (1990). Lead isotope variations across the central Peruvian Andes. Economic Geology, 85 (7), 1384-1401.

Gwatkin, C. \& P. Muccilli (2002). Pillara mine - December 2001 resources and reserves report. Tech. rep., Western Metals Ltd.

Haines, W., S. Turner, J. D. Foden, \& J. B. Jago (2009). Isotopic and geochemical characterisation of the Cambrian Kanmantoo Group, South Australia: Implications for stratigraphy and provenance. Australian Journal of Earth Sciences, 56, $1095-1110$.

Hall, C., D. York, C. Aunders, \& D. Strong (1989). Laser ${ }^{40} \mathrm{Ar} /{ }^{39}$ Ar dating of Mississippi Valley-type mineralization from western Newfoundland. In: International Geological Congress, vol. 28, pp. 2.10-2.11.

Hall, W. E. (1985). Stratigraphy of and mineral deposits in Middle and Upper Paleozoic rocks of the black-shale mineral belt, central Idaho. United States Geological Survey Bulletin, 1658AS, 118-131.

Hancock, M. C. \& A. H. Purvis (1990). Lady Loretta silver-lead-zinc deposit. Australasian Institute of Mining and Metallurgy Monograph, 14, 943-948.

Hannigan, P. (2007). Metallogeny of the Pine Point Mississippi Valley-type zinc-lead district, southern Northwest Territories. Mineral Deposits of Canada, Geological Association of Canada, Mineral Deposits Division, Special Publication, 5, 609-632.

Hanski, E., H. Huhma, V. F. Smolkin, \& M. Vaasjoki (1990). The age of the ferropicritic volcanics and comagmatic Ni-bearing intrusions at Pechenga, Kola Peninsula, USSR. Bulletin of the Geological Society of Finland, 62 (2), $123-133$.

Harper, D. D. \& D. M. Borrok (2007). Dolomie fronts and associated zinc-lead mineralization, USA. Economic Geology, 102, $1345-1352$.

Hayes, G. P., G. L. Moore, D. E. Portner, M. Hearne, H. Flamme, M. Furtney, \& G. M. Smoczyk (2018). Slab2, a comprehensive subduction zone geometry model. Science, 362, 58-61.

Heinrich, C. A., J. H. C. Bain, T. P. Mernagh, L. A. I. Wyborn, A. S. Andrew, \& C. L. Waring (1995). Fluid and mass transfer during metabasalt alteration and copper mineralization at Mount Isa, Australia. Economic Geology, 90 (4), 705-730.

Henry, B., H. Rouvier, M. le Goff, D. Leach, J.-C. Macquar, J. Thibieroz, \& M. Lewchuk (2001). Paleomagnetic dating of widespread remagnetization on the southeastern border of the French Massif Central and implications for fluid-flow and Mississippi Valleytype mineralization. Geophysical Journal International, 145, 368-380.

Hewton, R. S. (1982). Gayna River: A Proterozoic Mississipppi Valley-type zinc-lead deposit, Precambrian sulphide. Geological Association of Canada Special Paper, 25, 668-700.

Hirschmann, M. M. (2000). Mantle solidus: Experimental constraints and the effects of peridotite composition. Geochemistry Geophysics Geosystems, 1 (10). 
Hitzman, M. W., R. Kirkham, D. Broughton, J. Thorson, \& D. Selley (2005). The sediment-hosted stratiform copper ore system. Economic Geology 100th Anniversary Volume.

Hitzman, M. W., C. H. Thorman, G. Romagna, T. F. Oliviera, M. A. Dardennes, \& L. Drew (1995). The Morro Agudo Zn-Pb deposit, Minais Gerais, Brazil: A Proterozoic Irish-type carbonate-hosted Sedex-replacement (Irish-type) deposit. In: Geological Society of America, Annual Meeting, New Orleans, Abstracts with Program, Vol. 27, 6.

Hnatyshin, D., R. Morden, E. Turner, D. Kontak, \& R. A. Creaser (2005). Re-Os and fluid inclusion constraints on the timing and nature of sulfide mineralization at Nanisivik and Hawker Creek, Baffin Island, Nunavut. Geological Society of America, Abstracts with Programs, 43, 633.

Hoatson, D. M., S. Jaireth, \& A. L. Jaques (2006). Nickel sulfide deposits in Australia: Characteristics, resources, and potential. Ore Geology Reviews, 29, 177-241.

Hoatson, D. M. \& S.-S. Sun (2002). Archean layered mafic-ultramafic intrusions in the West Pilbara Craton, Western Australia: A synthesis of some of the oldest orthomagmatic mineralizing systems in the world. Economic Geology, 97 (4), 847-872.

Hoffman, F., D. Hawkins, C. E. Isachsen, \& S. A. Bowring (1996). Precise U-Pb zircon ages for early Damaran magmatism in the Summas and Welwitschia inlier, northern Damara Belt, Namibia. Communications of the Geological Survey of Namibia, 11, $47-52$.

Hofmeister, A. M. (2005). Dependence of diffusive radiative transfer on grain-size, temperature, and Fe-content: Implications for mantle processes. Journal of Geodynamics, 40, 51-72.

Hofmeister, A. M. (2007). Pressure dependence of thermal transport properties. Proceedings of the National Academy of Sciences of the United States of America, 104 (22), 9192-9197.

Howe, S. S. \& W. E. Hall (1985). Light stable isotope characteristics of ore systems in central Idaho. United States Geological Survey Bulletin, 1658AS, 183-192.

Höy, T. (1975). Big Ledge (82L/8E). Geology in British Columbia, pp. G12-G18.

Huizenga, J.-M., J. Gutzmer, D. Banks, \& L. Greyling (2006). The Paleoproterozoic carbonate-hosted Pering Zn-Pb deposit, South Africa. II: Fluid inclusion, fluid chemistry and stable isotope constraints. Mineralium Deposita, 40 (686).

Hulbert, L. J. (1997). Geology and metallogeny of the Kluane mafic-ultramafic belt, Yukon Territory, Canada: Eastern Wrangellia, a new Ni-Cu-PGE metallogenic terrane, vol. 506. Geological Survey of Canada.

Hulbert, L. J., M. A. Hamilton, M. F. Horan, \& R. F. J. Scoates (2005). U-Pb zircon and Re-Os isotope geochronology of mineralized ultramafic intrusions and associated nickel ores from the Thompson Nickel Belt, Manitoba, Canada. Economic Geology, 100 (1), 29-41.

Husain, V., H. Khan, K. Germann, \& K. Zak (2002). Geological investigations of stratbound Ganga barite deposits of Khuzday (Balochistan), Pakistan. Resource Geology, 52, 49-58.

Huston, D. L., P. Morant, F. Pirajno, B. Cummins, D. Baker, \& T. P. Mernagh (2007). Paleoarchean mineral deposits of the Pilbara Craton: Genesis, tectonic environment and comparisons with younger deposits. Developments in Precambrian Geology, $15,411-450$.

Huston, D. L., B. Stevens, N. Southgate, P. Muhling, \& L. Wyborn (2006). Australian Zn-Pb-Ag ore-forming systems: A review and analysis. Economic Geology, 101, 1117-1158.

Ireland, T., R. R. Large, P. McGoldrick, \& M. Blake (2004). Spatial distribution patterns of sulfur isotopes, nodular carbonate, and ore textures in the McArthur (HYC) Zn-Pb-Ag deposit, Northern Territory, Australia. Economic Geology, 99, 1687-1710.

Ironbark (2020). URL www.ironbark.gl.

Irwin, S. E. B. \& M. J. Orchard (1989). Conodont biostratigrapahy and constraints on Upper Devonian mineral deposits in the Earn Group, northern British Columbia and Yukon, Canada. Geological Survey of Canada Paper, 89-1E, 13-20.

Jain, C., J. Korenaga, \& S. I. Karato (2018). On the grain size sensitivity of olivine rheology. Journal of Geophysical Research: Solid Earth, 123, 674-688.

James, L. P. \& E. W. Newman (1986). Subsurface character of mineralization at Silver Reef, Utah, and a possible model for ore genesis. Utah Geological Association Publication, 15, 149-158.

Jemmali, N., F. Souissi, E. J. M. Carranza, \& T. W. Vennemann (2013). Sulfur and lead isotopes of Guern Halfaya and Bou Grine deposits (Domes zone, northern Tunisia): Implications for sources of metals and timing of mineralization. Ore Geology Reviews, $54,17-28$.

Jiang, S. Y., M. R. Palmer, Y. H. Li, \& C. J. Xue (1995). Chemical compositions of tourmaline in the Yindongzi-Tongmugou $\mathrm{Pb}-\mathrm{Zn}$ deposits, Qinling, China: Implications for hydrothermal ore-forming processes. Mineralium Deposita, 30, 225-234. 
Johnson, C. A., K. D. Kelley, \& D. L. Leach (2004). Sulfur and oxygen isotopes in barite deposits of the western Brooks Range, Alaska, and implications for the origin of the Red Dog massive sulfide deposits. Economic Geology, 99, 1435-1448.

Jones, D., S. Bull, \& P. McGoldrick (1999). The Kamarga Deposit: A large, low grade, stratabound zinc resource in the Proterozoic 'Carpentaria Zinc Belt' of northern Australia. In: Mineral deposits: Processes to processing (edited by C. J. Stanley, A. H. Rankin, R. J. Bodnar, J. Naden, B. W. D. Yardley, A. J. Criddle, R. D. Hagni, A. P. Gize, J. Pasava, A. J. Fleet, R. Seltmann, C. Halls, M. Stemprok, B. Williamson, R. J. Herrington, R. E. T. Hill, H. M. Prichard, F. Wall, C. T. Williams, I. McDonald, J. J. Wilkinson, D. Cooke, N. J. Cook, B. J. Marshall, P. Spry, Z. Khin, L. Meinert, K. Sundblad, P. Scott, S. H. B. Clark, E. Valsami-Jones, N. J. Beukes, H. J. Stein, J. L. Hannah, F. Neubauer, D. J. Blundell, D. H. M. Alderton, M. P. Smith, S. Mulshaw, \& R. A. Ixer), pp. 873-876. A.A. Balkema, Rotterdam.

Jones, H. D., S. E. Kesler, F. C. Furman, \& J. R. Kyle (1996). Sulfur isotope geochemistry of southern Appalachian Mississippi Valley-type deposits. Economic Geology, 91 (2), 355-367.

Kagara Ltd. (2008). Drilling update - Victoria Project near Chillagoe. Tech. rep. URL www.kagara.com.au.

Kamo, S. L., G. K. Czamanske, Y. Amelin, V. A. Fedorenko, D. Davis, \& V. Trofimov (2003). Rapid eruption of Siberian floodvolcanic rocks and evidence for coincidence with the Permian-Triassic boundary and mass extinction at 251 Ma. Earth and Planetary Science Letters, 214, 75-91.

Karpenko, S., M. H. Delevaux, \& B. R. Doe (1981). Lead isotope analyses of galenas from selected ore deposits of the USSR. Economic Geology, 76, 716-742.

KBL Mining Ltd. (2017). URL www.kblmining.com.au.

Kelley, K. D., J. A. Dumoulin, \& S. Jennings (2004a). The Anarraaq Zn-Pb-Ag and barite deposit, northern Alaska: Evidence for replacement of carbonate by barite and sulfides. Economic Geology, 99, 1577-1591.

Kelley, K. D., D. L. Leach, C. A. Johnson, J. L. Clark, et al. (2004b). Textural, compositional, and sulfur isotope variations of sulfide minerals in the Red Dog Zn-Pb-Ag deposits, Brooks Range, Alaska: Implications for ore formation. Economic Geology, 99, 1509-1532.

Kennett, B. L. N., A. Fichtner, S. Fishwick, \& K. Yoshizawa (2013). Australian seismological reference model (AuSREM): Mantle component. Geophysical Journal International, 192, 871-887.

Kennett, B. L. N., M. Salmon, E. Saygin, \& A. W. Group (2011). AusMoho: The variation of Moho depth in Australia. Geophysical Journal International, 187 (2), 946-958.

Kesler, S. E., M. S. Appold, G. L. Cumming, \& D. Krstic (1994). Lead isotope geochemistry of Mississippi Valley-type mineralization in the central Appalachians. Economic Geology, 89 (7), 1492-1500.

Kesler, S. E. \& M. H. Reich (2006). Precambrian Mississippi Valley-type deposits: Relation to changes in composition of the hydrosphere and atmosphere. In: Evolution of Early Earth's Atmosphere, Hydrosphere, and Biosphere - Constraints from Ore Deposits (edited by S. E. Kesler \& H. Ohmoto), Geological Society of America Memoirs, vol. 198, pp. 185-204. Geological Society of America, Boulder, USA.

Khiltova, V. Y. \& G. P. Pleskach (1997). Yenisei fold belt. In: Precambrian ore deposits of the East European and Siberian Cratons (edited by D. V. Rundkvist \& C. Gillen), pp. 289-316. Elsevier, Amsterdam.

Kirkham, R. V., J. J. Carrière, R. M. Laramée, \& D. F. Garson (1994). Global distribution of sediment-hosted stratiform copper deposits and occurrences. Tech. Rep. Open File Report 2915b, Geological Survey of Canada. URL geoscan.nrcan.gc.ca/ starweb/geoscan/servlet. starweb?path=geoscan/fulle. web\\&search1=R=207806.

Kobe, H. W. (1960). Cu-Ag deposits of the red-bed type at Negra Huanusha in central Peru. Schweizerische Mineralogische und Petrogrographische Mitteilungen, 40, 163-176.

Kontak, D. J. (1992). A preliminary report on geological, geochemical, fluid inclusion and isotopic studies of the Gays River Zn- $\mathrm{Pb}$ deposit, Nova Scotia. Tech. rep., Nova Scotia Department of Natural Resources.

Kontak, D. J., E. Farrar, \& S. L. McBride (1994). ${ }^{40} \mathrm{Ar} /{ }^{39} \mathrm{Ar}$ dating of fluid migration in a Mississippi Valley-type deposit: The Gays River Zn-Pb deposit, Nova Scotia, Canada. Economic Geology, 89, 1501-1517.

Koptagel, O., U. Ulusoy, \& A. E. Fallick (2007). Sulfur and lead isotope investigations of the carbonate-hosted Pb-Zn deposits in the Yahyali region, Kayseri, southern Turkey. Turkish Journal of Earth Sciences, 16, 57-76.

Korenaga, T. \& J. Korenaga (2016). Evolution of young oceanic lithosphere and the meaning of seafloor subsidence rate. Journal of Geophysical Research: Solid Earth, 121, 6315-6332.

Kositcin, N., S. J. Brown, M. E. Barley, B. Krapež, K. F. Cassidy, \& D. C. Champion (2008). SHRIMP U-Pb zircon age constraints on the Late Archaean tectonostratigraphic architecture of the Eastern Goldfields superterrane, Yilgarn craton, Western Australia. Precambrian Research, 161, 5-33. 
Kositcin, N., D. C. Champion, \& D. L. Huston (2009). Geodynamic synthesis of the north Queensland region and implications for metallogeny. Geoscience Australia Record, 2009/30, 196.

Kragh, K., S. M. Jensen, \& H. Fougt (1997). Ore geological studies of the Citronen Fjord zinc deposit, North Greenland: Project 'Resources of the sedimentary basins of North and East Greenland'. Geology of Greenland Survey Bulletin, 176, 44-49.

Kruger, F. J., R. G. Cawthorn, P. S. Meyer, \& K. L. Walsh (1986). Sr-isotopic, chemical and mineralogical variations across the pyroxenite marker and in the upper zone of the western Bushveld Complex. In: Proceedings of Geo-Congress 1986, 21st Congress, pp. 609-612.

Kuiper, Y. D., C. Shields, \& M. N. Turbrett (2011). Detrital age constraints on the and of deposition and provenance of the metasedimentary cover sequence of the Thor-Odin Dome, British Columbia. Geological Society of America Abstracts with Programs, 43 (5), 101.

Large, D. \& E. Walcher (1999). The Rammelsberg massive sulphide Cu-Zn-Pb-Ba-Deposit, Germany, an example of sedimenthosted, massive sulphide mineralisation. Mineralium Deposita, 34, 522-538.

Large, D. E. (1980). On the geology, geochemistry and genesis of the Tom Pb-Zn-barite deposit, Yukon Territory, Canada. Ph.D. thesis, Institute of Geology and Palaeontology, Braunschweig, West Germany.

Lau, H. C., J. X. Mitrovica, J. Austermann, O. Crawford, D. Al-Attar, \& K. Latychev (2016). Inferences of mantle viscosity based on ice age data sets: Radial structure. Journal of Geophysical Research: Solid Earth, 121 (10), 6991-7012.

Lawrence, L. J. \& T. A. Rafter (1962). Sulfur isotope distribution in sulfides and sulfates from Broken Hill South, New South Wales. Economic Geology, 57, 217-225.

Lea, E. R. \& D. B. Dill Jr. (1968). Zinc deposits of the Balmat-Edwards district, New York. In: Ore deposits of the United States, 1933-1967 (Graton-Sales Volume) (edited by J. D. Ridge), vol. 1, pp. 20-48. American Institute of Mining, Metallurgical and Petroleum Engineers, New York.

Leach, D., J. Viets, A. Kozlowski, \& S. Kibitlewski (1996). Geology, geochemistry, and genesis of the Silesia-Cracow zinc-lead district, Southern Poland. Society of Economic Geologists Special Publication, 4, 144-170.

Leach, D. L., D. Bradley, M. T. Lewchuk, D. T. Symons, G. de Marsily, \& J. Brannon (2001a). Mississippi Valley-type leadzinc deposits through geological time: Implications from recent age-dating research. Mineralium Deposita, 36, 711-740.

Leach, D. L., J. C. Macquar, V. Lagneau, J. Leventhal, P. Emsbo, \& W. Premo (2006). Precipitation of lead-zinc ores in the Mississippi Valley-type deposit at Trèves, Cévennes region of southern France. Geofluids, 6, 24-44.

Leach, D. L., W. Premo, M. Lewchuk, B. Henry, M. le Goff, H. Rouvier, J. C. Macquar, \& J. Thibieroz (2001b). Evidence for Mississippi Valley-type lead-zinc mineralization in the Cévennes region, southern France, during Pyrenees orogeny. In: Mineral Deposits at the Beginning of the 21st Century (edited by A. Piestrzynski), pp. 157-160. Balkema, Rotterdam.

Lee, J. E. \& D. A. Glenister (1976). Stratiform sulfide mineralization at Oamites copper mine, South West Africa. Economic Geology, 71 (1), 369-383.

Lees, T. \& P. Buckle (2009). Base metal deposits in the Einasleigh area. Australian Institute of Geoscientists Bulletin, 49, 75-78.

Li, F. S., W. Wang, \& J. M. Yang (2005). Geological and geochemical characteristics and genesis of the Wulagen lead and zinc deposit in Wuqia County, Xinjiang. Mineral Resources and Geology, 17, 10-16.

Li, H. M., Y. C. Chen, D. H. Wang, \& H. Q. Li (2007a). Geochemistry and mineralisation age of the Mayuan zinc deposit, Nanzheng, southern Shanxi, China. Bulletin of China, 26, 546-552.

Li, J. \& T. M. Kusky (2007). World's largest known Precambrian fossil black smoker chimneys and associated microbial vent communities, north China, implications for early life. Gondwana Research, 12, 84-100.

Li, W., Z. Huang, \& M. Yin (2007b). Dating of the giant Huize ZnPb ore field of Yunnan Province, southwest China: Constraints from the SmNd system in hydrothermal calcite. Resource Geology, 57, 90-97.

Li, W., Z. Huang, \& M. Yin (2007c). Isotope geochemistry of the Huize Zn-Pb ore field, Yunnan Province, Southwestern China: Implication for the sources of ore fluid and metals. Geochemical Journal, 47, 65-81.

Li, X., L. Su, B. Song, \& D. Liu (2004). SHRIMP U-Pb zircon age of the Jinchuan ultramafic intrusion and its geological significance. Chinese Science Bulletin, 49 (4), 420-422.

Li, X. N. (2002). Deposit genesis and geological characteristics of Houjiangqiao Pb-Zn deposit in Hunan. Contributions to Geology and Mineral Resources Research, 17, 41-46.

Li, Z. D., C. J. Xue, X. F. Dong, Z. R. Liu, T. Z. Zhong, \& S. J. Qi (2013). Ore geology, S- and Pb-isotopic compositions of the Wulagen $\mathrm{Zn}-\mathrm{Pb}$ deposit, Wuqia county, Xinjiang. Earch Science Frontiers, 20, 40-54. 
Liu, J. S., Z. Q. Gao, G. Q. Deng, M. Liu, \& Q. D. Liu (2002). One potential super-large Pb-Zn ore occurrence with Himalayan thermal brine genesis, Wuqia region, Xinjiang, China. Journal of Central South University of Technology, 9, 41-46.

Logan, R. G., W. J. Murray, \& N. Williams (1990). HYC silver-lead-zinc deposit, McArthur River. Australasian Institute of Mining and Metallurgy Monograph, 14, 907-911.

Long, K. R. (1992). Mines, prospects and mineral occurrences, Altiplano and Cordillera Occidental, Bolivia. U.S. Geological Survey Bulletin, 1975, 243-272.

Long, S., N. McQuarrie, T. Tobgay, C. Rose, G. Gehrels, \& D. Grujic (2011). Tectonostratigraphy of the Lesser Himalaya of Bhutan: Implications for the along-strike stratigraphic continuity of the northern Indian margin. Geological Society of America Bulletin, 123, 1406-1426.

Lori, J. (2014). Trend mining and production. Society of Economic Geologists Guidebook Series, 45, 11-16.

Ltd., M. M. (2009). Quarterly report - 1 January to 31 March. ASX Release, p. 16. URL www.asx.com.au/asxpdf/20090430/ pdf/31hcg6505p5qcy.pdf.

Lungu, C. V. (1998). Zambian mining in transition. Mining Magazine, September, 116-117.

Lydon, J. W. (2007). Geology and metallogeny of the Belt-Purcell Basin. Geological Association of Canada Mineral Deposits Division Special Publication, 5, 581-607.

Ma, G., G. Beaudoin, S. Qi, \& Y. Li (2004). Geology and geochemistry of the Changba SEDEX Pb-Zn deposit, Qinling orogenic belt, China. Mineralium Deposita, 39, 380-395.

Ma, G., G. Beaudoin, S. Zhong, Y. Li, \& Z. Zeng (2007). Geology and geochemistry of the Dengjiashan SEDEX Zn-Pb deposit, Qinling Belt, China. Canadian Journal of Earth Sciences, 44, 479-492.

Maiden, K. J., A. H. Innes, M. J. King, S. Master, \& I. Pettitt (1984). Regional controls on the localisation of stratabound copper deposits: Proterozoic examples from southern Africa and South Australia. Precambrian Research, 25, 99-118.

Mather, K. A., D. G. Pearson, D. P. McKenzie, B. A. Kjarsgaard, \& K. Priestley (2011). Constraints on the depth and thermal history of cratonic lithosphere from peridotite xenoliths, xenocrysts and seismology. Lithos, 125, 729-742.

Matthäi, S. K., C. A. Heinrich, \& T. Driesner (2004). Is the Mount Isa copper deposit the product of forced brine convection in the footwall of a major reverse fault? Geology, 32 (4), 357-360.

McClung, C. R., J. Gutzmer, N. J. Beukes, K. Mezger, H. Strauss, \& E. Gertloff (2007). Geochemistry of bedded barite of the Mesoproterozoic Aggeneys-Gamsberg Broken Hill-type district, South Africa. Mineralium Deposita, 42, 537-549.

McCracken, S. R., H. Etiman, A. G. Connor, \& V. A. Williams (1996). Geology of the Admiral Bay carbonate-hosted zinc-lead deposit, Canning Basin, Western Australia. Society of Economic Geologists Special Publication, 4, 330-349.

McGregor, I. A. (1991). Assessment of mineral exploration opportunities in Zambia. Tech. rep., Vans, Griffis and McOuat.

McKenzie, D. (2000). Constraints on melt generation and transport from U-series activity ratios. Chemical Geology, 162, 81-94.

McKenzie, D. P. (1978). Some remarks on the development of sedimentary basins. Earth and Planetary Science Letters, 40, 25-32.

MDIO (2020). URL www.geologyontario.mndm.gov.on.ca/mndmfiles/mdi/data/records/MDI31F07NE00063.html.

Meisel, T., J. Moser, \& W. Wegscheider (2001). Recognizing heterogeneous distribution of platinum group elements (PGE) in geological materials by means of the Re-Os isotope system. Fresenius' Journal of Analytical Chemistry, 370, 566-572.

Middleton, T. (2004). The Dairi zinc-lead project, north Sumatra, Indonesia - Discovery to feasibility. URL www.smedg.org.au/ Tiger/DairiZinc.htm.

Middleton, T. W. (2020). URL smedg.org.au/Tiger/DairiZinc.htm.

Minčeva-Stefanova, J. (1972). Mineral composition and origin of the stratiform polymetallic ore deposits in the Balkanides compared with the stratiform lead-zinc deposits of the Alps. In: Proceedings of second internation symposium on the mineral deposits of the Alps, pp. 301-313. Ljubljana, Slovenia.

Mining Journal of London (1989). Fleck agreement on Dunka. 312 (8006), 104.

Mining Magazine (1998a). May, RSA 5.

Mining Magazine (1998b). May, RSA 6.

Misi, A., S. S. Iyer, C. E. S. Coelho, C. C. Tassinari, et al. (2005). Sediment hosted leadzinc deposits of the Neoproterozoic Bambuí Group and correlative sequences, São Francisco Craton, Brazil: A review and a possible metallogenic evolution model. Ore Geology Reviews, 26 (3), 263-304. 
Misi, A., S. S. Iyer, C. C. Tassinari, J. R. Kyle, et al. (1999). Geological and isotopic constraints on the metallogenic evolution of the Proterozoic sediment-hosted Pb-Zn (Ag) deposits of Brazil. Gondwana Research, 2, 47-65.

MMG (2020). URL www.mmg.com/our-business/dugald-river.

Morelli, R. M., R. A. Creaser, D. Selby, K. D. Kelley, D. L. Leach, \& A. R. King (2004). Re-Os sulfide geochronology of the Red Dog sediment-hosted Zn-Pb-Ag deposit, Brooks Range, Alaska. Economic Geology, 99, 1569-1576.

Moroskat, M., S. A. Gleeson, R. J. Sharp, A. Simonetti, \& C. J. Gallagher (2015). The geology of the carbonate-hosted Blende $\mathrm{Ag}-\mathrm{Pb}-\mathrm{Zn}$ deposit, Wernecke Mountains, Yukon, Canada. Mineralium Deposita, 50 (1), 83-104.

Mosier, D., V. Berger, \& D. A. Singer (2009). Volcanogenic massive sulfide deposits of the world - Database and grade and tonnage models. Tech. rep., US Geological Survey. URL pubs.usgs.gov/of/2009/1034.

Mueller, A. G. (2005). The sedimentary-exhalative Meggen, Zn-Pb sulfide and barite deposit, Germany: Geology and plate-tectonic setting. SGA Web mineral deposit archive. URL e-sga.org/publications/mineral-deposit-archive/the-meggen-deposit.

Mueller, A. G. (2008). The Rammelsberg shale-hosted Cu-Zn-Pb sulfide and barite deposit, Germany: Linking SEDEX and Kurokotype massive sulfides. SGA Web mineral deposit archive. URL e-sga.org/publications/mineral-deposit-archive/therammelsberg-deposit.

Mukasa, S. B., A. H. Wilson, \& R. W. Carlson (1998). A multi-element geochronologic study of the Great Dyke, Zimbabwe: Significance of the robust and reset ages. Earth and Planetary Science Letters, 164, 353-369.

Nakai, S. I., A. N. Halliday, S. E. Kesler, H. D. Jones, J. R. Kyle, \& T. E. Lane (1993). Rb-Sr dating of sphalerites from Mississippi Valley-type (MVT) ore deposits. Geochimica et Cosmochimica Acta, 57, 417-427.

Naldrett, A. J. (1989). Magmatic sulfide deposits. Oxford Monographs on Geology and Geophysics, 14, 186.

Narkelyun, L. F., A. M. Filin, Y. P. Bezrodnykh, \& A. I. Trubachev (1971). Cupriferous shales in Poland and their analogues in eastern parts of the USSR. International Geology Review, 13 (11), 1600-1610.

Nelson, D. R. (1997a). Evolution of the Archaean granite-greenstone terranes of the Eastern Goldfields, Western Australia: SHRIMP U-Pb constraints. Precambrian Research, 83, 57-81.

Nelson, D. R. (1997b). SHRIMP U-Pb zircon chronological constraints on the evolution of the Eastern Goldfields granite-greenstone terranes. Australian Geological Survey Organisation Record, 41, 11-14.

Nelson, J., S. Paradis, J. Christensen, \& J. Gabites (2002). Canadian Cordilleran Mississippi Valley-type deposits: A case for Devonian-Mississippian back-arc hydrothermal origin. Economic Geology, 97, 1013-1036.

Neradovsky, Y. N., V. V. Borisova, \& V. V. Sholokhnev (1997). The Monchegorsk layered complex and related mineralization. In: Ore Deposits of the Kola Peninsula, Northwestern Russia (edited by T.-F. I. M. Mitrofanov, F.), vol. 45, pp. 13-17.

Newham, W. D. N. (1986). The Lomagund and Sabi metallogenic provinces of Zimbabwe. In: Mineral deposits of Southern Africa (edited by C. R. Anhaeusser \& S. Maske), vol. 1-2, pp. 1351-1393. Johannesburg, South Africa.

Newnham, L. (2003). Development of Avebury nickel sulphide deposit. In: Australian Nickel Conference, p. 6.

Nickel, K. G. \& D. H. Green (1985). Empirical geothermobarometry for garnet peridotites and implications for the nature of the lithosphere, kimberlites and diamonds. Earth and Planetary Science Letters, 73, 158-170.

Nimis, P. \& W. R. Taylor (2000). Single clinopyroxene thermobarometry for garnet peridotites. Part I. Calibration and testing of a Cr-in-Cpx barometer and an enstatite-in-Cpx thermometer. Contributions to Mineralogy and Petrology, 139, 541-554.

Nockleberg, W. J., T. K. Bundtzen, K. M. Dawson, R. A. Eremin, et al. (1997). Significant metalliferous and selected nonmetalliferous lode deposits and placer districts for the Russian Far East, Alaska, and the Canadian Cordillera. Tech. Rep. 96-513-B, U.S. Geological Survey.

Nokleberg, W. J., T. V. Bounaeva, R. J. Miller, Z. V. Seminskiy, \& M. F. Diggles (2003). Significant metalliferous and selected non-metalliferous lode deposits and selected placer districts for northeast Asia. Tech. Rep. 03-220, U.S. Geological Survey.

Nokleberg, W. J., T. K. Bundtzen, R. A. Eremin, V. V. Ratkin, et al. (2005). Metallogenesis and tectonics of the Russian Far East Alaska, and the Canadian Cordillera, vol. 1697. U.S. Geological Survey, Menlo Park, USA.

Northern Miner (1995). Neuquen project in Argentina: Yamana, MIM explore 'red bed deposits. The Northern Miner. URL www.northernminer. com/news/neuquen-project-in-argentina-yamana-mim-explore-red-bed-deposits/1000094461.

Northern Miner (1996a). Latin American special: Bolivias mineral wealth attracts companies. The Northern Miner. URL www.northernminer.com/news/latin-american-special-bolivia-s-mineral-wealth-attracts-companies/1000096396.

Northern Miner (1996b). Optimism inflates Western indices. The Northern Miner. URL www.northernminer.com/news/optimisminflates-western-indices/1000096924. 
Northern Miner (1996c). South Atlantic submits proposals for African copper-cobalt projects. The Northern Miner. URL www . northernminer. com/news/south-atlantic-submits-proposals-for-african-copper-cobalt-projects/1000142539.

Northern Miner (1996d). Summo hits copper at Champion. The Northern Miner. URL www.northernminer.com/news/summohits-copper-at-champion/1000160510.

Northern Miner (1997). Yuma completes feasibility study: Delays caused by efforts to gain approvals for process water. The Northern Miner. URL www.northernminer.com/news/literature-review-yuma-completes-feasibility-study-delayscaused-by-efforts-to-gain-approvals-for/1000183032.

Northern Miner (1998). Zambia nears end of ZCCM privatization: Kafue Consortium snaps up Nchanga-Nkana copper-cobalt complex. The Northern Miner. URL www.northernminer.com/news/africa-zambia-nears-end-of-zccm-privatizationkafue-consortium-snaps-up-nchanga-nkana-copper-cobal/1000148084.

Northern Miner (2000a). Crew builds new Zambian mine. The Northern Miner. URL www.northernminer.com/news/crewbuilds-new-zambian-mine/1000104001.

Northern Miner (2000b). First Quantum, Glencore close ZCCM deal. The Northern Miner. URL www.northernminer.com/news/ first-quantum-glencore-close-zccm-deal/1000164063.

Northern Miner (2000c). Glencore bankrolls Zambian copper deal. The Northern Miner. URL www.northernminer.com/news/ glencore-bankrolls-zambian-copper-deal/1000103556.

Northern Miner (2002a). Anglo American bids farewell to Kolwezi. The Northern Miner. URL www.northernminer.com/news/ anglo-american-bids-farewell-to-kolwezi/1000115613.

Northern Miner (2002b). Noranda nixes Montana silver project. The Northern Miner. URL www.northernminer.com/news/ noranda-nixes-montana-silver-project/1000169505.

Northern Miner (2004a). Anvil expands Dikulushi copper-silver mine. The Northern Miner. URL www.northernminer.com/news/ anvil-expands-dikulushi-copper-silver-mine/1000191429.

Northern Miner (2004b). Bwana Mkubwa copper output soars. The Northern Miner. URL www.northernminer.com/news/bwanamkubwa-copper-output-soars/1000159472.

Northern Miner (2004c). First Quantum proves up resource at Lufua. The Northern Miner. URL www.northernminer.com/news/ first-quantum-proves-up-resource-at-Lufua/1000156355.

Northern Miner (2004d). Rubicon gains stake in African company. The Northern Miner. URL www.northernminer.com/news/ rubicon-gains-stake-in-african-company/1000158730.

Northern Miner (2004e). Southern Cross to explore Ethiudna. The Northern Miner. URL www.northernminer.com/news/ southern-cross-to-explore-ethiudna/1000157572.

Olson, R. (1984). Genesis of paleokarst and strata-bound zinc-lead sulfide deposits in a Proterozoic dolostone, northern Baffin Island, Canada. Economic Geology, 79, 1056-1103.

Orgeval, J. J. (1995). Peridiapiric metal concentration at Bou Grine (Tunisian Atlas): Some geochemical characteristics. In: Mineral deposits: From their origin to the environmental impacts (edited by J. Pasava, B. Kribek, \& K. Zak), pp. 299-302. Balkema, Rotterdam.

Oszczepalski, S. \& A. Rydzewski (1997). Metallogenic atlas of Zechstein copper-bearing series in Poland. Wydawnictwo Kartograficzne Polskiej Agencji Ekologicznej.

Paces, J. B. \& J. D. Miller Jr. (1993). Precise U-Pb ages of Duluth complex and related mafic intrusions, northeastern Minnesota: Geochronological insights to physical, petrogenetic, paleomagnetic, and tectonomagmatic processes associated with the $1.1 \mathrm{Ga}$ midcontinent rift system. Journal of Geophysical Research: Solid Earth, 98 (B8), 13,997-14,013.

Page, R. W., C. H. H. Conor, B. P. J. Stevens, G. M. Gibson, W. V. Preiss, \& P. N. Southgate (2005). Correlation of Olary and Broken Hill Domains, Curnamona Province: Possible relationship to Mount Isa and other north Australian Pb-Zn-Ag-bearing successions. Economic Geology, 100, 663-676.

Page, R. W. \& D. M. Hoatson (2000). Geochronology of the mafic-ultramafic intrusions. In: Geology and Economic Potential of the Palaeoproterozoic Layered Maficultramafic Intrusions in the East Kimberley, Western Australia (edited by D. M. Hoatson \& D. H. Blake), vol. 246, pp. 163-172. Australian Geological Survey Organisation Bulletin, Canberra, Australia.

Page, R. W., M. J. Jackson, \& A. A. Krassay (2000). Constraining sequence stratigraphy in north Australiam basins: SHRIMP U-Pb zircon geochronology between Mt Isa and McArthur River. Australian Journal of Earth Sciences, 47, 431-460.

Painter, M. G. M., S. G. Golding, K. W. Hanan, \& M. K. Neudert (1999). Sedimentologic, petrographic, and sulfur isotope constraints on fine-grained pyrite formation at Mount Isa mine and environments, northwest Queensland, Australia. Economic Geology, 94, 883-912. 
Paktunc, A. D. (1987). Nickel, copper, platinum and palladium relations in Ni-Cu deposits of the St. Stephen intrusion, New Brunswick. Geological Survey of Canada, 87-1A, 543-553.

Pan, H. \& D. T. A. Symons (1993). Paleomagnetism of the Mississippi Valley-type Newfoundland zinc deposit: Evidence for Devonian mineralization in the northern Appalachians. Journal of Geophysical Research, 98, 22,415-22,427.

Pan, H., D. T. A. Symons, \& D. F. Sangster (1993). Paleomagnetism of the Gays River zinc-lead deposit, Nova Scotia: Pennsylvanian ore genesis. Geophysical Research Letters, 20, 1159-1162.

Papunen, H. \& G. I. Gorbunov (1985). Nickel-copper deposits of the Baltic Shield and Scandinavian Caledonides. Bulletin-Geological survey of Finland, 333.

Paradis, S., P. Hannigan, \& K. Dewing (2007). Mississippi Valley-type lead-zinc deposits. Mineral deposits of Canada, Geological Association of Canada, Mineral Deposits Division, Special Publication, 5, 185-203.

Paradis, S., J. L. Nelson, \& S. E. Irwin (1998). Age constraints on the Devonian shale-hosted Zn-Pb-Ba deposits, Gataga District, northeastern British Columbia, Canada. Economic Geology, 93, 184-200.

Parr, J. (1994). The preservation of pre-metamorphic colloform banding in pyrite from the Broken Hill-type Pinnacles deposit, New South Wales, Australia. Mineralogical Magazine, 58, 461-472.

Parr, J. M., B. P. J. Stevens, G. R. Carr, \& R. W. Page (2004). Subseafloor origin for Broken Hill Pb-Zn-Ag mineralization, New South Wales, Australia. Geology, 32, 589-592.

Parrish, R. R. (1989). U-Pb geochronology of the Cape Smith Belt and Sugluk block, northern Quebec. Geoscience Canada, 16, $126-130$.

Pasyanos, M. E., T. G. Masters, G. Laske, \& Z. Ma (2014). LITHO1.0: An updated crust and lithospheric model of the Earth. Journal of Geophysical Research: Solid Earth, 119, 2153-2173.

Pedersen, F. (1980). Remobilization of the massive sulfide ore of the Black Angel Mine, central West Greenland. Economic Geology, 75 (7), 1022-1041.

Pegmont (2020). URL www. pegmont.com.au.

Peng, R. M. \& Y. S. Zhai (2004). The characteristics of hydrothermal exhalative mineralization of the Langshan-Zhaertai belt, Inner Mongolia, China. Earth Science Frontiers, 11, 257-268.

Perkins, W. (1984). Mount Isa silica dolomite and copper orebodies: The result of a syntectonic hydrothermal alteration system. Economic Geology, 79 (4), 601-637.

Pertermann, M. \& A. M. Hofmeister (2006). Thermal diffusivity of olivine-group minerals at high temperature. American Mineralogist, 91, 1747-1760.

Piestrzyński, A. \& A. Wodzicki (2000). Origin of the gold deposit in the Polkowice-West mine, Lubin-Sieroszowice mining district, Poland. Mineralium Deposita, 35 (1), 37-47.

Plimer, I. R. (1977). The origin of albite-rich rocks enclosing the cobaltian pyrite deposit at Thackaringa, N.S.W., Australia. Mineralium Deposita, 12, 175-187.

Plimer, I. R. (1986). Sediment-hosted exhalative Pb-Zn deposits — products of contrasting ensialic rifting. Transactions of the Geological Society of South Africa, 89, 57-73.

PorterGeo (2020a). URL www.portergeo.com.au/database/mineinfo.asp?mineid=mn252.

PorterGeo (2020b). URL www.portergeo.com.au/database/mineinfo.asp?mineid=mn1464.

PorterGeo (2020c). URL www.portergeo.com.au/database/mineinfo.asp?mineid=mn260.

PorterGeo (2020d). URL www. portergeo.com.au/database/mineinfo.asp?mineid=mn1574.

Pouit, G. \& J. P. Bois (1986). Arrens Zn (Pb), Ba Devonian deposit, Pyrénées, France: An exhalative-sedimentary-type deposit similar to Meggen. Mineralium Deposita, 21, 181-189.

Prendergast, M. D. (2003). The nickeliferous Late Archean Reliance komatiitic event in the Zimbabwe Craton - Magmatic architecture, physical volcanology, and ore genesis. Economic Geology, 98 (5), 865-891.

Press, W. H., S. A. Teukolsky, W. T. Vetterling, \& B. P. Flannery (1992). Numerical recipes in Fortran. Cambridge University Press, 2 edn.

Priestley, K., D. McKenzie, \& T. Ho (2018). A lithosphere-asthenosphere boundary - A global model derived from multimode surface-wave tomography and petrology. In: Geophysical Monograph 239, Lithospheric Discontinuities (edited by H. Yuan \& B. Romanowicz), chap. 6, pp. 111-123. John Wiley and Sons, Washington D.C. 
Priestley, K. \& D. P. McKenzie (2013). The relationship between shear wave velocity, temperature, attenuation and viscosity in the shallow part of the mantle. Earth and Planetary Science Letters, 381, 78-91.

Przeniosło, S. (2000). Mineral resources of Poland. Polish Geological Institute, Warsaw, Poland.

Raghu Nundan, K. R., B. K. Dhruva Rao, \& M. L. Sinhal (1981). Exploration for copper, lead and zinc ores in India. Bulletin of the Geological Survey of India, Series A Economic Geology, 47, 222.

Ramakrishnan, M. \& R. Vaidyanathan (2008). Geology of India. Geological Society of India, 1, 556.

Randell, R. \& G. Anderson (1996). Geology of the Polaris Zn-Pb deposit and surrounding area, Canadian Arctic Archipelago. Society of Economic Geologists Special Publication, 4, 307-319.

Redtail Metals (2020). URL www.redtailmetals.com.

Reichert, J. (2007). A metallogenetic model for carbonate-hosted non-sulphide zinc deposits based on observations of Mehdi Abad and Irankuh, central and southwestern Iran. Ph.D. thesis, Martin-Luther-Universitt Halle-Wittenberg.

Reid, D. L., H. J. Welke, C. B. Smith, \& J. M. Moore (1997). Lead isotope patterns in Proterozoic stratiform mineralization in the Bushmanland Group, Namaqualand Province, South Africa. Economic Geology, 92, 248-258.

Ren, Z. (1994). Geology of Dongchuan copper mine, Yunnan, China. Tech. rep., Southwest Geological Exploration Bureau of China National Nonferrous Metals Industry Corporation.

Reynolds, N. E. \& P. M. Geerdts (2012). Structural controls and modification of the Sopokomil SHMS Zn-Pb deposits, Dairi, Sumatra. AIG Bulletin, 56, 149.

Rhodes, D., E. A. Lantos, J. A. Lantos, R. J. Webb, \& D. C. Owens (1984). Pine Point orebodies and their relationship to the stratigraphy, structure, dolomitization, and karstification of the Middle Devonian barrier complex. Economic Geology, 79, 991-1055.

Richards, F. D., M. J. Hoggard, L. R. Cowton, \& N. J. White (2018). Reassessing the thermal structure of oceanic lithosphere with revised global inventories of basement depths and heat flow measurements. Journal of Geophysical Research: Solid Earth, 123, 9136-9161.

Richards, F. D., M. J. Hoggard, N. J. White, \& S. Ghelichkhan (2020). Quantifying the relationship between short-wavelength dynamic topography and thermomechanical structure of the upper mantle using calibrated parameterization of anelasticity. Journal of Geophysical Research: Solid Earth.

Ringrose, C. R. (1984). The geology and genesis of the Narlarla lead-zinc deposits, Napier Range, W. A. In: The Canning Basin (edited by P. G. Purcell), pp. 455-462. Geological Society of Australia, Perth.

Robinson, M. \& C. I. Godwin (1995). Genesis of the Blende carbonate-hosted Zn-Pb-Ag deposit, north-central Yukon Territory: Geological, fluid inclusion and isotopic constraints. Economic Geology, 90, 369-384.

Rodriguez, S. E. (1990). Mineral deposits in the Venezuelan Andes. In: Geology of the Andes and its relation to hydrocarbon and mineral resources (edited by G. E. Ericksen, M. T. Pinochet, \& J. A. Reinemund), pp. 237-244. Circum-Pacific Council for Energy and Mineral Resources, Houston, USA.

Rox Resources (2020). URL roxresources.com.au/wp-content/uploads/2012/09/RRL1158D-IM.pdf.

Roy, A. B., S. Kumar, L. Vivek, \& N. K. Chauhan (2004). Tectonostratigraphy of the lead-zinc-bearing metasedimentary rocks of the Rampucha-Agucha Mine and its neighbourhood, district Bhilwara, Rajasthan: Implications on metallogeny. In: Sedimenthosted lead-zinc sulphide deposits - Attributes and models of some major deposits in India, Australia and Canada (edited by M. Deb \& W. D. Goodfellow), pp. 273-289. Narosa Publishing House, New Delhi.

Rozendaal, A. (1986). The Gamsberg zinc deposit, Namaqualand district. In: Mineral deposits of Southern Africa (edited by C. Anhaeusser \& S. Maske), pp. 1477-1488. Geological Society of South Africa, Johannesburg.

Ruelle, J. C. L. (1982). Depositional environments and genesis of stratiform copper deposits of the Redstone copper belt, Mackenzie Mountains, N.W.T. Geological Association of Canada Special Paper, 25, 701-738.

Rui, Z. Y., N. Li, \& L. S. Wang (1991). The Guanmenshan lead-zinc deposit: Its basin brine. In: Ore-forming Process and Lead Isotopic Targeting, pp. 28-79. Geological Publishing House.

Ryan, P. J., A. L. Lawrence, R. D. Lipson, J. M. Moore, A. Paterson, D. P. Stedman, \& D. Van Zyl (1986). The Aggeneys base metal sulphide deposits, Namaqualand, South Africa. In: Mineral deposits of Southern Africa (edited by C. Anhaeusser \& S. Maske), pp. 1447-1474. Geological Society of South Africa, Johannesburg.

Rye, D. \& N. Williams (1981). Studies of the base metal sulfide deposits at McArthur River, Northern Territory, Australia: III. The stable isotope geochemistry of the H.Y.C., Ridge and Cooley deposits. Economic Geology, 76, 826-842. 
Rzhevskii, V. F., I. F. Gablina, L. V. Vasilovskaya, \& A. M. Luré (1988). Genetic features of the Graviisk copper deposit. Lithology and Mineral Resources, 23 (2), 174-183.

Saha, A. B. (1985). On the nature of lead-zinc-magnetite ore bodies in Daling Group of rocks in Gorubathan area, Darjeeling district, West Bengal. Indian Minerals, 39 (4), 37-40.

Sainfeld, P. (1956). The lead-zinc-bearing deposits of Tunisia. Economic Geology, 51, 150-177.

Sarkar, S. C. \& S. Banerjee (2004). Carbonate-hosted lead-zinc deposits of Zawar, Rajasthan, in the context of the world scenario. In: Sediment-hosted lead-zinc sulphide deposits - Attributes and models of some major deposits in India, Australia and Canada (edited by M. Deb \& W. Goodfellow), pp. 328-349. Narosa Publishing House, New Delhi.

Sarkar, S. C., I. V. Chernyshev, \& H. Banerjee (2000). Mid-Proterozoic Pb-Pb ages for some Himalayan base-metal deposits and comparison to deposits in Rajasthan, NW India. Precambrian Research, 99, 171-178.

Sasaki, A. \& H. R. Krouse (1969). Sulfur isotopes and the Pine Point lead-zinc mineralization. Economic Geology, 64, 718-730.

Schaeffer, A. J. \& S. Lebedev (2013). Global shear speed structure of the upper mantle and transition zone. Geophysical Journal International, 194, 417-449.

Schaeffer, A. J. \& S. Lebedev (2014). Imaging the North American continent using waveform inversion of global and USArray data. Earth and Planetary Science Letters, 402, 26-41.

Schneider, W., A. Geng, F. Lapponi, \& T. Bechstadt (2002). Carbonate-hosted zinc-lead deposits in the lower Cambrian of Huayuan, South China, a radiogenic (Pb, Sr) isotope study. Economic Geology, 97, 1815-1827.

Schroll, E., V. Koppel, \& I. Cerny (2006). Pb and Sr isotope and geochemical data from the Pb-Zn deposit Bleiberg (Austria): Constraints on the age of mineralization. Mineralogy and Petrology, 86, 129-156.

Schroll, E. \& G. Rantitsch (2005). Sulphur isotope patterns from the Bleiberg deposit (Eastern Alps) and their implications for genetically affiliated leadzinc deposits. Mineralogy and Petrology, 84, 1-18.

Schütfort, E. G. (2001). The genesis of the San Vicente lead zinc rhythmite deposit, Peru: A petrologic, geochemical, and sulfur isotope study. Ph.D. thesis, Oregon State University.

Schwartz, M. O., P. Akanyang, K. Trippler, \& T. H. Ngwisanyi (1995). The sediment-hosted Ngwako Pan copper deposit, Botswana. Economic Geology, 90 (5), 1118-1147.

Scott, K. M. \& G. F. Taylor (1977). Geochemistry of the Mammoth copper deposit, northwest Queensland, Australia. Journal of Geochemical Exploration, 8, 153-168.

Scott, K. M. \& G. F. Taylor (1982). Eastern Creek Volcanics as the source of copper at the Mammoth Mine, northwest Queensland. BMR Journal of Australian Geology \& Geophysics, 7 (2), 93-98.

Seasor, R. W. \& A. C. Brown (1989). Syngenetic and diagenetic concepts at the White Pine copper deposit, Michigan. Geological Association of Canada Special Paper, 36, 257-267.

Seccombe, P. K., P. G. Spry, R. A. Both, M. T. Jones, \& J. C. Schiller (1985). Base metal mineralization in the Kanmantoo Group, South Australia: A regional sulfur isotope study. Economic Geology, 80, 1824-1841.

Seltmann, R., S. Soloviev, V. Shatov, F. Pirajno, E. Naumov, \& S. Cherasov (2010). Metallogeny of Siberia: Tectonic, geologic and metallogenic settings of selected significant deposits. Australian Journal of Earth Sciences, 57, 655-706.

Sexton, J. (2011). Australian mineral occurrences collection. Geoscience Australia Dataset, eCat Id 73. URL ecat.ga.gov.au/ geonetwork.

Shah, N. (2004). Rampura-Agucha: A remobilised SEDEX deposit, southeastern Rajasthan, India. In: Sediment-hosted leadzinc sulphide deposits - Attributes and models of some major deposits in India, Australia and Canada (edited by M. Deb \& W. Goodfellow), pp. 290-303. Narosa Publishing House, New Delhi.

Sherlock, R., J. Lee, \& B. Cousens (2004). Geological and geochronological constraints on the timing of mineralization at the Nanisivik zinc-lead Mississippi Valley-type deposit, northern Baffin Island, Nunavut, Canada. Economic Geology, 99, $279-293$.

Shpikerman, V. I. (1990). Stratiform and stratabound ore mineralization of central parts of northeastern Russia. Tech. rep.

Sillitoe, R. H. (1980). Strata-bound ore deposits related to Infra-Cambrian rifting along northern Gondwanaland. In: Proceedings of the $5^{\text {th }}$ Quadrennial IAGOD Symposium, vol. 1, pp. 163-171. Snowbird, USA.

Sillitoe, R. H. (2010). Porphyry copper systems. Economic Geology, 105, 3-41.

Singer, D. A., V. I. Berger, \& B. C. Moring (2009). Sediment-hosted zinc-lead deposits of the world — Database and grade and tonnage models. Tech. rep., U.S. Geological Survey. 
Skwarnecki, M. S. \& R. W. Fitzpatrick (2003). Regional geochemical dispersion in acid sulfate soils in relation to base-metal mineralisation of the Kanmantoo Group, Mt Torrens-Strathalbyn region, eastern Mt Lofty Ranges, South Australia. Tech. rep., CRC LEME.

Slack, J. F., K. D. Kelley, V. M. Anderson, J. L. Clark, \& R. A. Ayuso (2004). Multistage hydrothermal silicification and Fe-Tl-AsSb-Ge-REE enrichment in the Red Dog Zn-Pb-Ag district, northern Alaska: Geochemistry, origin, and exploration applications. Economic Geology, 99, 1481-1508.

Smethurst, M., D. Symons, D. Sangster, \& M. Lewchuk (1999). Paleomagnetic age for Zn-Pb mineralization at Robb Lake, northeastern British Columbia. Bulletin of Canadian Petroleum Geology, 47, 548-555.

Smirnov, V. I. \& D. I. Gorzhevsk (1977). Deposits of lead and zinc. In: Ore Deposits of the U.S.S.R. (edited by V. I. Smirnov), vol. 2, pp. 182-256. Pitman, London.

Smith, J. W., M. S. Burns, \& N. J. W. Croxford (1978). Stable isotope studies of the origins of mineralization at Mount Isa. Mineralium Deposita, 13, 369-381.

Smith, J. W. \& N. J. W. Croxford (1973). Sulfur isotope ratios in the McArthur zinc-lead-silver deposit. Nature, 245, 10-12.

St Marie, J. \& S. E. Kesler (2000). Iron-rich and iron-poor Mississippi Valley-type mineralization, Metaline district, Washington. Economic Geology, 95 (5), 1091-1106.

Stalder, M. \& A. Rozendaal (2005). Distribution and geochemical characteristics of barite and barium-rich rocks associated with the Broken Hill-type Gamsberg Zn-Pb deposit, Namaqua Province, South Africa. South African Journal of Geology, 108, 35-50.

Steers, J. E. (2003). Resource and reserve audit, Balmat no. 4 mine, Balmat-Edwards mining district, Balmat, N.Y., USA. URL instruct .uwo.ca/earth-sci/fieldlog/Grenville/balmat.htm.

Steinberger, B. \& T. W. Becker (2018). A comparison of lithospheric thickness models. Tectonophysics, 746, 325-338.

Steven, N. \& R. Armstrong (2003). A metamorphosed Proterozoic carbonaceous shale-hosted Co-Ni-Cu deposit at Kalumbila, Kabompo Dome: The Copperbelt ore shale in northwestern Zambia. Economic Geology, 98 (5), 893-909.

StratDB (2020). URL thera2.usask.ca:8091八\$.

Stribrny, B. (1985). The conglomerate-hosted Repparfjord copper ore deposit, Finnmark, Norway. Monograph Series on Mineral Deposits, 24, 1-75.

Summo Minerals Corp. (2001). Annual Report. Tech. rep.

Sureda, R. J. \& J. L. Martin (1990). El Aguilar Mine: An Ordovician sediment-hosted stratiform lead-zinc deposit in the central Andes. In: Stratabound Ore Deposits in the Andes (edited by F. L., G. C. Amstutz, M. Cardozo, E. Cedillo, \& J. Frutos), pp. 161-174. Springer-Verlag, Berlin.

Sverjensky, D. A. (1981). The origin of a Mississippi Valley-type deposit in the Viburnum Trend, southeast Missouri. Economic Geology, 76 (7), 1848-1872.

Symons, D., M. Lewchuk, \& D. Sangster (1998a). Laramide orogenic fluid flow into the Western Canada Sedimentary Basin: Evidence from paleomagnetic dating of the Kicking Horse Mississippi Valley-type ore deposit. Economic Geology, 93, 68-83.

Symons, D., T. Symons, \& D. Sangster (2000). Paleomagnetism of the Society Cliffs dolostone and the age of the Nanisivik zinc deposits, Baffin Island, Canada. Mineralium Deposita, 35, 672-682.

Symons, D. T., M. T. Lewchuk, K. Kawasaki, F. Velasco, \& D. L. Leach (2009). The Reocín zinc-lead deposit, Spain: Paleomagnetic dating of a late Tertiary ore body. Mineralium Deposita, 44, 867-880.

Symons, D. T. A. (2007). Paleomagnetism of the HYC Zn-Pb SEDEX deposit, Australia: Evidence of an epigenetic origin. Economic Geology, 102, 1295-1310.

Symons, D. T. A. \& D. C. Arne (2003). Paleomagnetic dating of mineralization in the Kapok MVT deposit, Lennard Shelf, Western Australia. Journal of Geochemical Exploration, 78, 267-272.

Symons, D. T. A. \& D. C. Arne (2005). Paleomagnetic constraints on Zn-Pb ore genesis of the Pillara Mine, Lennard Shelf, Western Australia. Mineralium Deposita, 39, 944-959.

Symons, D. T. A., H. Pan, D. F. Sangster, \& E. C. Jowett (1993). Paleomagnetism of the Pine Point Zn-Pb deposits. Canadian Journal of Earth Sciences, 30, 1028-1036.

Symons, D. T. A., D. Sangster, \& D. Leach (1995). A Tertiary age from paleomagnetism for the Mississippi Valley-type zinc-lead mineralization in Upper Silesia. Economic Geology, 90, 782-794.

Symons, D. T. A., D. Sangster, \& D. Leach (1998b). Age and duration of the Mississippi Valley-type mineralizing fluid flow event in the Viburnum Trend, southeast Missouri, USA, determined from palaeomagnetism. Geological Society of London Special Publications, 144, 27-39. 
Symons, D. T. A. \& D. F. Sangster (1992). Late Devonian paleomagnetic age for the Polaris Mississippi Valley-type Zn-Pb deposit, Canadian Arctic Archipelago. Canadian Journal of Earth Sciences, 29, 15-25.

Takei, Y. (2017). Effects of partial melting on seismic velocity and attenuation: A new insight from experiments. Annual Review of Earth and Planetary Sciences, 45, 447-470.

Tanaka, W. (2004). The Cashin Copper Deposit, Colorado, USA. Tech. rep., Summo USA Corp., Lakewood, USA.

Taylor, R. D., D. L. Leach, D. C. Bradley, \& S. A. Pisarevsky (2009). Compilation of mineral resource data for Mississippi Valley-type and clastic-dominated sediment-hosted lead-zinc deposits. Tech. Rep. 1297, U.S. Geological Survey.

Taylor, W. R. (1998). An experimental test of some geothermometer and geobarometer formulations for upper mantle peridotites with application to the thermobarometry of fertile lherzolite and garnet websterite. Neues Jahrbuch für Mineralogie - Abhandlungen, 172 (2-3), 381-408.

Teixeira, G. \& M. Gonzalez (1988). Minas do Camaqua, Municipio de Cacapava do Sul, RS. In: Principais Depósitos Minerais do Brasil - Metais Básicos Não Ferrosos, Ouro e Alumínio (edited by C. Schobbenhaus \& C. Coelho), vol. 3, pp. 71-80. DNPM and Companhia Vale do Rio Doce, Brasilia, Brazil.

Tenke Mining Corp. (2003). Tech. rep., Vancouver, Canada.

Terramin Australia Ltd. (2018). ISR copper resource at Kapunda. Tech. Rep. ASX Announcement, Fullarton, South Australia. URL www.envirocopper.com.au/sites/envirocopper/media/banners/terramintzn-resource-feb-2018.pdf.

Thomassen, B. (2006). The Black Angel lead-zinc mine at Maarmorilik in West Greenland. Geology and Ore, 2 (2), 1-12.

Thorpe, R. I. (2008). Release of lead isotope data in 4 databases: Canadian, Western Superior, Foreign, and Whole rock and feldspar. Geological Survey of Canada, Open File 5664, 42.

Todorov, T. (1997). Geochemistry of gold in 'Venesta' sandstone-hosted stratiform copper deposit in Bulgaria. In: Mineral deposits: Research and exploration - Where do they meet? (edited by H. Papunen), Proceedings of the 4th Biennial SGA Meeting, pp. 327-334. A.A. Balkema, Rotterdam.

Tompkins, L. A., B. Eisenlohr, D. I. Groves, \& M. Raetz (1997). Temporal changes in mineralization style at the Cadjebut Mississippi Valley-type deposit, Lennard Shelf, W.A. Economic Geology, 92, 843-862.

Tompkins, L. A., V. A. Pedone, M. T. Roche, \& D. I. Groves (1994). The Cadjebut deposit as an example of Mississippi Valley-type mineralization on the Lennard Shelf, Western Australia - single episode or multiple events? Economic Geology, 89, 450-466.

Turner, R. J. W. \& B. R. Otto (1995). Structural and stratigraphic setting of the Triumph stratiform zinc-lead-silver deposit, Devonian Milligen Formation, central Idaho. United States Geological Survey Bulletin, 2064E, 27.

U.S. Bureau of Mines (1974). The Mineral Industry of Zaire. Tech. rep.

U.S. Bureau of Mines (1980). The Mineral Industry of Zimbabwe (Southern Rhodesia). Tech. rep.

U.S. Bureau of Mines (1984). The Mineral Industry of Jordan. Tech. rep., U.S. Bureau of Mines.

U.S. Bureau of Mines (1998). The Mineral Industry of New Mexico. Tech. rep., U.S. Bureau of Mines.

USGS (2020a). URL mrdata.usgs .gov/sedznpb/show-sedznpb.php?rec $\% 20 i d=189$.

USGS (2020b). URL mrdata.usgs.gov.

Valdés-Nodarse, E. L. (1998). Pb-Zn "SEDEX" deposits and their copper stockwork roots, western Cuba. Mineralium Deposita, $33,560-567$.

Valdés-Nodarse, E. L., A. Díaz-Carmona, J. F. Davies, R. E. Whitehead, \& L. Fonseca (1993). Cogenetic SEDEX Zn-Pb and stockwork $\mathrm{Cu}$ ores, western Cuba. Exploration and Mining Geology, 2, 297-305.

Van Eden, J. G. (1978). Stratiform copper and zinc mineralization in the Cretaceous of Angola. Economic Geology, 73 (6), $1154-1161$.

Vaughan, J. P. \& R. L. Stanton (1986). Sedimentary and metamorphic factors in the development of the Pegmont stratiform Pb-Zn deposit, Queensland, Australia. Institute of Mining and Metallurgy Transactions, 95 (B), B94-B121.

Vearncombe, J. R., J. N. Christensen, S. L. Dorling, N. J. McNaughton, \& A. R. Reed (1995a). The Blendevale orebody: Zinc-lead mineralization on the southeast Lennard Shelf, Canning Basin, Western Australia. Society of Economic Geologists Guidebook Series, 23, 103-135.

Vearncombe, J. R., S. L. Dorling, \& M. J. Rayner (1995b). The Cadjebut orebody: Zinc-lead mineralization on the southeast Lennard Shelf, Canning Basin, Western Australia. Society of Economic Geologists Guidebook Series, 23, 81-102. 
Velasco, F., J. M. Herrero, I. Yusta, J. A. Alonso, I. Seebold, \& D. Leach (2003). Geology and geochemistry of the Reocín zinc-lead deposit, Basque-Cantabrian Basin, northern Spain. Economic Geology, 98, 1371-1396.

Velasco, F., A. Pesquera, \& J. M. Herrero (1996). Lead isotope study of Zn-Pb ore deposits associated with the Basque-Cantabrian Basin and Paleozoic basement, northern Spain. Mineralium Deposita, 31, 84-92.

Vered-Weiss, J., E. A. Graber, \& J. Good (1971). How Timna copper mines increased output and raised worker efficiency. World Mining, 24, 36-41.

Volodin, R. N., V. S. Chechetkin, Y. V. Bogdanov, L. F. Narkelyun, \& A. I. Trubachev (1994). The Udokan cupriferous sandstone deposit (eastern Siberia). Geology of Ore Deposits, 36 (1), 1-25.

Walters, S. \& A. Bailey (1998). Geology and mineralization of the Cannington Ag-Pb-Zn deposit: An example of Broken Hill-Type mineralization in the Eastern Succession, Mount Isa Inlier, Australia. Economic Geology, 93, 1307-1329.

Walther, H. W. (1986). Federal Republic of Germany. In: Mineral Deposits of Europe (edited by F. W. Dunning \& A. M. Evans), pp. 175-301. Institution of Mining and Metallurgy and the Mineralogical Society, London.

Wang, C., J. Deng, E. J. M. Carranza, \& X. Lai (2014). Nature, diversity and temporal-spatial distributions of sediment-hosted Pb-Zn deposits in China. Ore Geology Reviews, 56, 327-351.

Wang, M. L., W. X. Xu, H. Li, \& S. L. Peng (2005). Isotope geochemical evidence of the Fankou lead and zinc deposit. Acta Geologica Sinica, 26, 164-167.

Wang, Q., L. Schiøtte, \& I. H. Campbell (1996). Geochronological constraints on the age of komatiites and nickel mineralisation in the Lake Johnston greenstone belt, Yilgarn Craton, Western Australia. Australian Journal of Earth Sciences, 43 (4), 381-385.

Wang, X. C., Z. R. Zhang, M. H. Zheng, \& X. H. Xu (2000). Metallogenic mechanism of the Tianbaoshan Pb-Zn deposit, Sichuan. Chinese Journal of Geochemistry, 19, 121-133.

Wang, X. H., C. J. Xue, Z. M. Li, Q. Li, \& R. J. Yang (2008). Geological and geochemical characteristics of Mayuan Pb-Zn ore deposit on northern margin of Yangtze landmass. Mineralium Deposita, 27, 37-48.

Waring, C. L., C. A. Heinrich, \& V. J. Wall (1998). Proterozoic metamorphic copper deposits. AGSO Journal of Australian Geology E Geophysics, 17 (4).

Whelan, J. F., R. O. Rye, \& W. DeLorraine (1984). The Balmat-Edwards zinc-lead deposits — Synsedimentary ore from Mississippi Valley-type fluids. Economic Geology, 79, 239-265.

Whitehead, R. E., J. F. Davies, E. L. Valdés-Nodarse, \& A. Díaz-Carmona (1996). Mineralogical and chemical variations, Castellanos shale-hosted Zn-Pb-Ba deposit, northwestern Cuba. Economic Geology, 91, 713-722.

Wilband, J. T. (1978). The copper resources of northern Michigan. Tech. Rep. Contract No. J0366067, U.S. Bureau of Mines.

Williams, N. (1978a). Studies of base metal sulfide deposits at McArthur River, Northern Territory, Australia: I. The Cooley and Ridge deposits. Economic Geology, 73, 1005-1035.

Williams, N. (1978b). Studies of base metal sulfide deposits at McArthur River, Northern Territory, Australia: II. The sulfide-S and organic-C relationships of the concordant deposits and their significance. Economic Geology, 73, 1036-1056.

Williams, P. J. \& M. Heinemann (1993). Maramungee: A Proterozoic Zn skarn in the Cloncurry District, Mount Isa Inlier, Queensland, Australia. Economic Geology, 88, 1114-1134.

Williams, P. J., W. J. Pendergast, \& G. Dong (1998). Late orogenic alteration in the wall rocks of the Pegmont Pb-Zn deposit, Cloncurry District, Queensland, Australia. Economic Geology, 93, 1180-1189.

Wodzicki, A. \& A. Piestrzyński (1994). An ore genetic model for the LubinSieroszowice mining district, Poland. Mineralium Deposita, 29 (1), 30-43.

World Mineral Deposits (2020). URL freegisdata.org/record/urn: uuid: ee97878f-cfce-40d0-bf80-781c3bbb15cd-GSC: WORLD\_SedexDeposits.

Yamana Resources Inc. (1996). Annual Report. Tech. rep., Toronto, Canada.

Yamauchi, H. \& Y. Takei (2016). Polycrystal anelasticity at near-solidus temperatures. Journal of Geophysical Research: Solid Earth, 121 (11), 7790-7820.

Ye, L., N. J. Cook, T. Liu, C. L. Ciobanu, W. Gao, \& Y. Yang (2012). The Niujiaotang Cd-rich zinc deposit, Duyun, Guizhou province, southwest China: Ore genesis and mechanisms of cadmium concentration. Mineralium Deposita, 47, 683-700.

Yin, M., W. Li, \& X. Sun (2009). Rb-Sr isotopic dating of sphalerite from the giant Huize Zn-Pb ore field, Yunnan Province, Southwestern China. Chinese Journal of Geochemistry, 28, 70-75. 
Yoshizawa, K. (2014). Radially anisotropic 3-D shear wave structure of the Australian lithosphere and asthenosphere from multimode surface waves. Physics of the Earth and Planetary Interiors, 235, 33-48.

Yoshizawa, K. \& B. L. N. Kennett (2004). Multimode surface wave tomography for the Australian region using a three-stage approach incorporating finite frequency effects. Journal of Geophysical Research: Solid Earth, 109 (B2), 1-19.

Young, L. E. (2004). A geologic framework for mineralization in the western Brooks Range, Alaska. Economic Geology, 99, $1281-1306$.

Yukon Geological Survey (2008). Yukon mineral deposits summary,. Yukon Geological Survey, Yukon, Canada.

Zappettini, E. O. (1999). Clasificación de depósitos minerales de Argentina. In: Recursos Minerales de la República Argentina (edited by E. O. Zappettini), vol. Anales 35, pp. 75-103. Instituto de Geología y Recursos Minerales, Servicio Geológico Minero Argentino, Subsecretaría de Minería de la Nación, Buenos Aires, Argentina.

Zeng, Y. \& C. J. Li (2007). Discussion on the geological characteristics and sources of ore-forming materials of Dongjiahe Pb-Zn deposit in western Hunan Province. Geology and Mineral Resources of South China, 3, 24-30.

Zhang, F. (1991). Exhalites associated with Pb-Zn mineralization in Devonian system and their prospecting implications, Qinling, China. Chinese Journal of Geochemistry, 10, 348-356.

Zheng, M. H. \& X. C. Wang (1991). Genesis of the Daliangzi Pb-Zn deposit in Sichuan, China. Economic Geology, 86, 831-846.

Zhou, J., Z. Huang, \& Z. Yan (2013a). The origin of the Maozu carbonate-hosted Pb-Zn deposit, southwest China: Constrained by C-O-S-Pb isotopic compositions and Sm-Nd isotopic age. Journal of Asian Earth Sciences, 73, 39-47.

Zhou, J. X., J. G. Gao, D. Chen, \& X. K. Liu (2013b). Ore genesis of the Tianbaoshan carbonate-hosted Pb-Zn deposit, Southwest China: Geologic and isotopic (C-H-O-S-Pb) evidence. International Geology Review, 55, 1300-1310.

Zhu, X., Q. Zhang, Y. He, \& C. Zhu (2006). Lead isotopic composition and lead source of the Huogeqi Cu-Pb-Zn deposit, Inner Mongolia, China. Acta Geologica Sinica (English Edition), 80, 528-539. 